\title{
Synthesis of Methacrylates from Coal-derived Syngas
}

\section{Final Report}

Reporting Period: October 1, 1994 to November 30, 1999

B. W.-L. Jang

J.J. Spivey

M.R. Gogate
J.R. Zoeller

R.D. Colberg

G.N. Choi

October 18, 1999

Work Performed Under Contract No. DE-AC22-94PC94065--20

for

U.S. Department of Energy Federal Energy Technology Center

P.O. Box 10940

Pittsburgh, PA 15236-0940

Research Triangle Institute

P.O. Box 12194

Research Triangle Park, NC 27709-2194

Eastman Chemical Company

P.O. Box 1972

Kingsport, TN 37662-5150

Bechtel

P.O. Box 193965

San Francisco, CA 94119-3965 


\section{DISCLAIMER}

This report was prepared as an account of work sponsored by an agency of the United States Government. Neither the United States Government nor any agency thereof, nor any of their employees, makes any warranty, express or implied, or assumes any legal liability or responsibility for the accuracy, completeness, or usefulness of any information, apparatus, product, or process disclosed, or represents that its use would not infringe privately owned rights. Reference herein to any specific commercial product, process, or service by trade name, trademark, manufacturer, or otherwise does not necessarily constitute or imply its endorsement, recommendation, or favoring by the United States Government or any agency thereof. The views and opinions of authors expressed herein do not necessarily state or reflect those of the United States Government or any agency thereof. 


\section{ABSTRACT}

Research Triangle Institute (RTI), Eastman Chemical Company, and Bechtel have developed a novel process for synthesis of methyl methacrylate (MMA) from coal-derived syngas, under a contract from the U.S. Department of Energy/Fossil Energy Technology Center (DOE/FETC). This project has resulted in five U.S. patents (four already published and one pending publication). It has served as the basis for the technical and economic assessment of the production of this high-volume intermediate from coal-derived synthesis gas. The three-step process consists of the synthesis of a propionate from ethylene carbonylation using coal-derived $\mathrm{CO}$, condensation of the propionate with formaldehyde to form methacrylic acid (MAA); and esterification of MAA with methanol to yield MMA. The first two steps, propionate synthesis and condensation catalysis, are the key technical challenges and the focus of the research presented here.

Propionate Synthesis. Propionate synthesis is the first step in the process to generate MMA from coal-derived syngas. Eastman has developed novel homogeneous Mo-based catalysts for the synthesis of propionic acid/anhydride from ethylene, coal-derived carbon monoxide, and, optionally, water. These catalysts, which work at substantially lower pressures than Ni-based conventional industrial catalysts (30 to 70 atm versus more than $200 \mathrm{~atm}$ ), significantly reduce the cost of this step.

Condensation Catalysis. A series of niobium supported on silica catalysts have been developed for the condensation of propionates and formaldehyde. These $\mathrm{Nb}_{2} \mathrm{O}_{5}$-based catalysts had MAA yields up to 40 percent. Although they deactivate steadily due to carbon deposition with time on stream, they can be completely regenerated under a mild oxidative regeneration using a 2 percent oxygen/nitrogen gas stream, at $400{ }^{\circ} \mathrm{C}$. A 400-h) continuous run, consisting of six activity and five regeneration cycles, shows that the selectivity to $\mathrm{CO}_{2}$ and diethyl ketone gradually increases.

Economic Analysis. Two detailed process conceptual design and economic analysis were carried out by Bechtel and Eastman based on a plant capacity to produce 250 million lb/yr of MMA. The first analysis deals with the propionate synthesis via ethylene carbonylation, and the second analysis focuses on the overall MMA economics based on the RTI-Eastman-Bechtel three-step process with specific emphasis placed on the propionic acid/formaldehye condensation reaction process design.

For the RTI-Eastman-Bechtel three-step MMA process to be economically competitive, the carbonylation step for propionic acid synthesis has to be included as an integral part of the overall process. MMA can be produced at a cost of $\$ 0.64 / \mathrm{lb}$, with a propionic acid cost of $\$ 0.20 / \mathrm{lb}$ and a 25 percent rate of return of investment. Current market price for MMA varies between $\$ 0.65$ and $\$ 0.70 / \mathrm{lb}$. Total plant investment is estimated at about $\$ 98.8$ million of which the propionate synthesis step accounts for about 44 percent of the total cost. A 35 percent contingency is included in the cost estimate to account for the first-of-kind nature of the plant. The MMA economics is dominated by raw material costs. Significant improvement in cost benefits can be realized by improving the $\mathrm{Nb}_{2} \mathrm{O}_{5} / \mathrm{SiO}_{2}$ condensation reaction conversion and selectivity to MAA. 
Dimethyl Ether (DME) Studies. The first in-situ formaldehyde generation from DME and subsequent condensation with methyl propionate to make MMA in one reactor was successfully demonstrated. The yields and selectivities of experiments indicate that the process has great economic potential to significantly lower the process cost. 


\section{TABLE OF CONTENTS}

Section

Page

EXECUTIVE SUMMARY $\ldots \ldots \ldots \ldots \ldots \ldots \ldots \ldots \ldots \ldots \ldots \ldots \ldots$

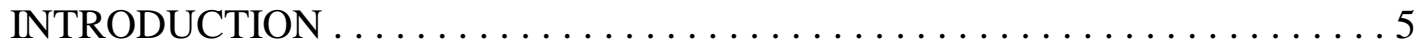

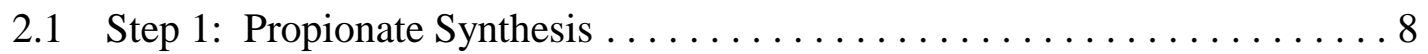

2.2 Step 2: HCHO_Propionate Condensation $\ldots \ldots \ldots \ldots \ldots \ldots \ldots$

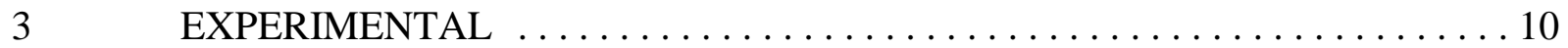

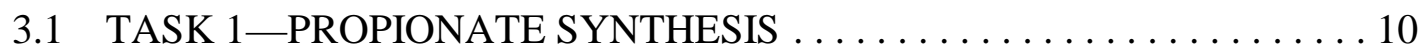

3.1.1 Generation of Propionic Anhydride $\left[\left(\mathrm{CH}_{3} \mathrm{CH}_{2} \mathrm{CO}\right)_{2} \mathrm{O}\right] \ldots \ldots \ldots$

3.1.2 Generation of Propionic Acid $\left[\mathrm{CH}_{3} \mathrm{CH}_{2} \mathrm{COOH}\right] \ldots \ldots \ldots \ldots \ldots 12$

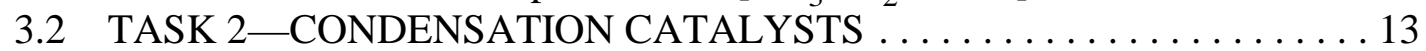

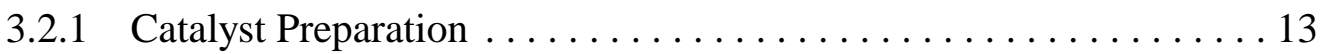

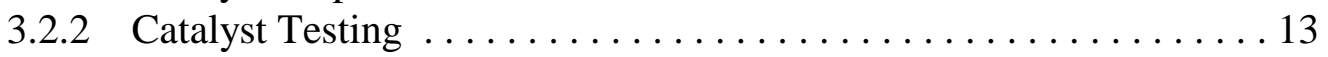

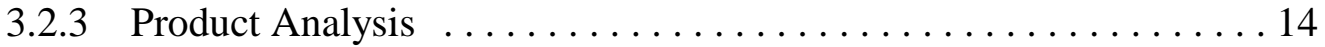

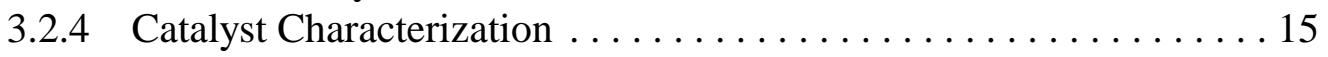

3.3 TASK $3-$ SLURRY REACTOR STUDIES $\ldots \ldots \ldots \ldots \ldots \ldots \ldots \ldots \ldots$

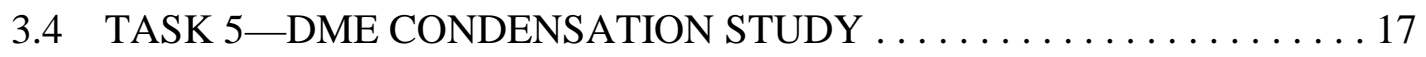

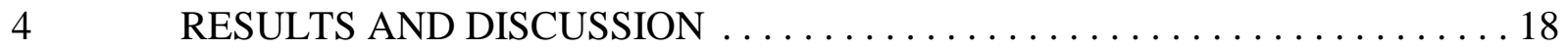

4.1 TASK 1 -PROPIONATE SYNTHESIS $\ldots \ldots \ldots \ldots \ldots \ldots \ldots \ldots \ldots$

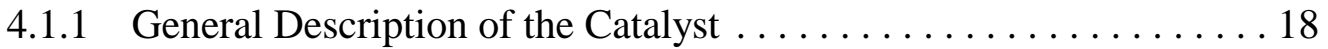

4.1.2 Mo Catalyzed Carbonylation of Ethylene to Propionic Anhydride . . 19

4.1.3 Mechanistic Interpretation . . . . . . . . . . . . . . 31

4.1.4 Conceptual Design and Economic Analysis of Propionate

Synthesis ............................. 34

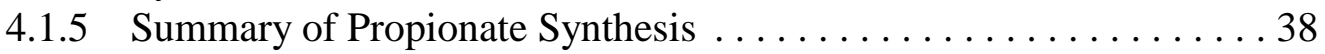

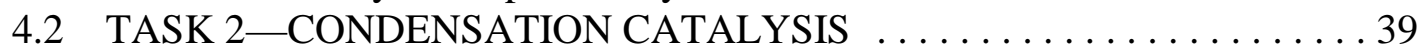

4.2.1 Catalyst Characterization of V-Si-P Catalysts . . . . . . . . . . . 39

4.2.2 Formalin as an Alternative Feedstock . . . . . . . . . . . . . 45

4.2.3 Characterization with TGA, XRD, and ESCA . . . . . . . . . 47

4.2.4 Long-Term Tests on $\mathrm{V}-\mathrm{Si}-\mathrm{P}(1: 10: 2.8)$ and $\mathrm{Ta} / \mathrm{SiO}_{2}$ Catalysts . . . . 56

4.2.5 Acid-Base Properties of V-Si-P Catalysts . . . . . . . . . . . . 58

4.2.6 Extended Activity and Stability Tests of Niobium Catalysts . . . . . . 62

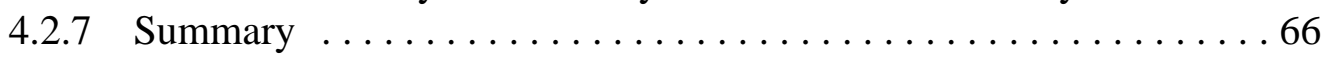

4.3 TASK $3-$ SLURRY REACTOR STUDIES . . . . . . . . . . 67 


\section{TABLE OF CONTENTS (continued)}

4.4 TASK 4-CONCEPTUAL DESIGN AND ECONOMIC ANALYSIS: "EXTERNAL" FORMALDEHYDE - PROPIONIC ACID CONDENSATION ROUTE $\ldots \ldots \ldots \ldots \ldots \ldots \ldots \ldots \ldots$

4.4.1 Process Description/Design Basis . ................. 68

4.4.2 Formaldehyde and Propionic Acid Condensation-Design and ASPEN Simulation ... . . . . . . . . . . . . . . . . 72

4.4.3 Simplified Overall Process Flow Diagram and Material Balance . . 80

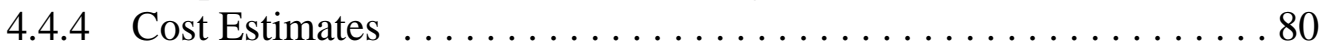

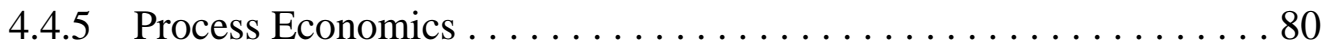

4.5 TASK 5-DME CONDENSATION STUDY (RTI AND EASTMAN) . . . 83

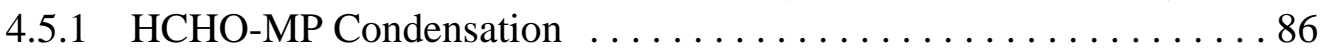

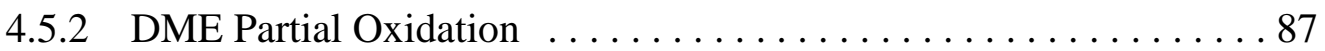

4.5.3 In-situ DME Oxidation and Condensation with MP . . . . . . . 88

CONCLUSIONS . . . . . . . . . . . . . . . . . . . . . . 91

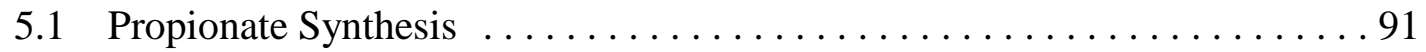

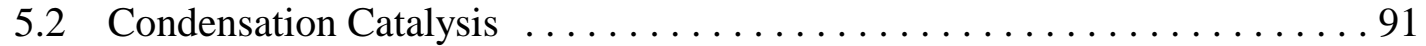

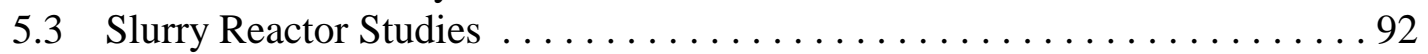

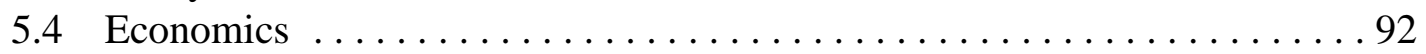

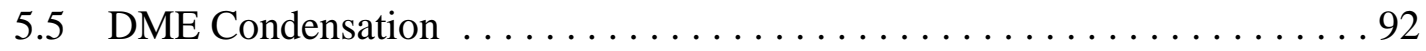

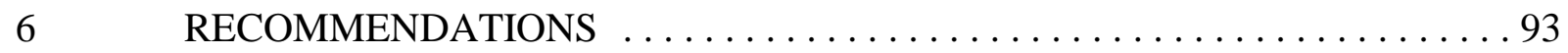

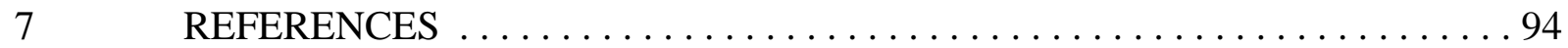




\section{LIST OF FIGURES}

Number

Page

The RTI-Eastman-Bechtel three-step MMA process (with external

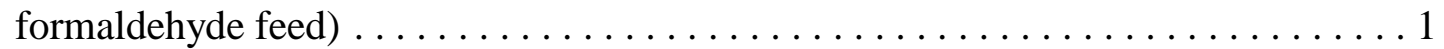

Schematic of in-situ DME partial oxidation and condensation with methyl

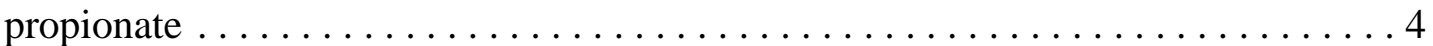

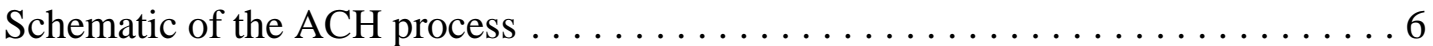

$\mathrm{C}_{2}$-carbonylation technologies for MMA manufacture $\ldots \ldots \ldots \ldots \ldots \ldots$

Autoclave system at Eastman . . . . . . . . . . . . . . . . . . 10

Fixed-bed reactor system for formalin as the source of formaldehyde $\ldots \ldots \ldots 14$

RTI-Eastmen slurry reactor system - feed section instrumentation . . . . . . . 16

RTI-Eastman slurry reactor system - product section instrumentation . . . . . . 16

RTI-Eastman slurry reactor system-flow diagram $\ldots \ldots \ldots \ldots \ldots \ldots \ldots$

Comparison of Mo catalyzed processes for propionic acid and propionic

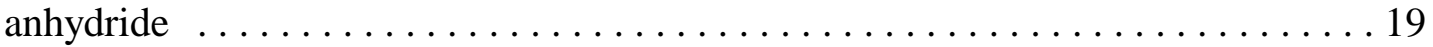

11 Reaction profile for the carbonylation of ethylene to propionic anhydride . . . . 20

12 Schematic of the $\mathrm{Bu}_{4} \mathrm{PI}-\mathrm{Mo}(\mathrm{CO})_{6}$-EtI catalyzed system $\ldots \ldots \ldots \ldots \ldots \ldots \ldots 21$

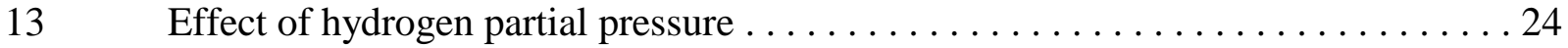

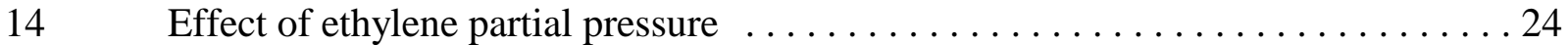

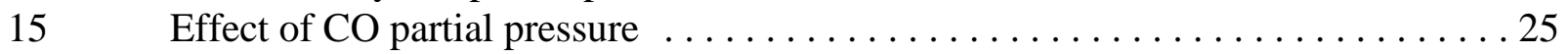

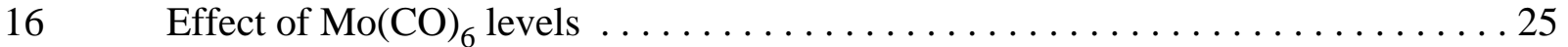

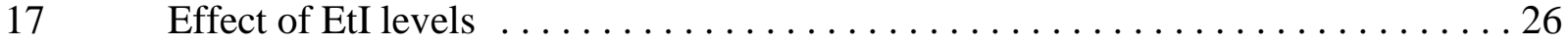

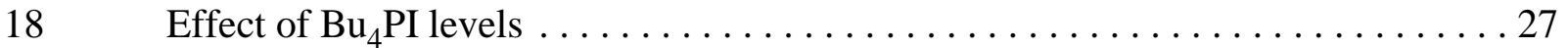

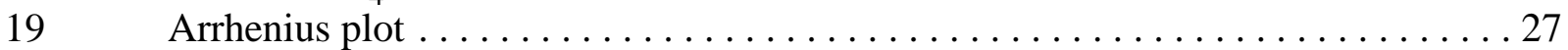

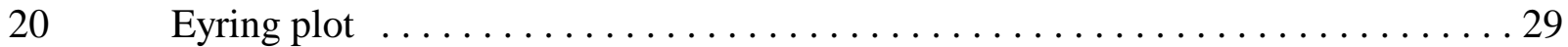

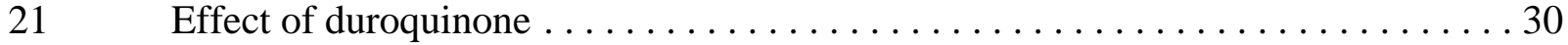

22 Proposed mechanism for the generation of propionic anhydride from

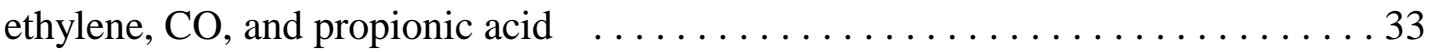

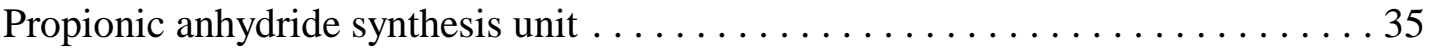

$\mathrm{NH}_{3}$-TPD spectra of $\mathrm{V}$-Si-P and tantalum catalysts $\ldots \ldots \ldots \ldots \ldots \ldots \ldots \ldots$

$\mathrm{CO}_{2}$-TPD spectra of $\mathrm{V}-\mathrm{Si}$-P and tantalum condensation catalysts $\ldots \ldots \ldots \ldots . .41$

$\mathrm{NH}_{3}$-TPD pattern for $\mathrm{V}$-Si-P 1:12:2.8 catalyst, TPD heating rate $1{ }^{\circ} \mathrm{C} / \mathrm{min} \ldots \ldots 43$

$\mathrm{NH}_{3}$-TPD pattern for $\mathrm{V}$-Si-P 1:12:2.8 catalyst, TPD heating rate $5{ }^{\circ} \mathrm{C} / \mathrm{min} \ldots \ldots 43$

$\mathrm{NH}_{3}$-TPD pattern for $\mathrm{V}$-Si-P 1:12:2.8 catalyst, TPD heating rate $10{ }^{\circ} \mathrm{C} / \mathrm{min} \ldots .44$

$\mathrm{NH}_{3}$-TPD pattern for $\mathrm{V}$-Si-P 1:12:2.8 catalyst, TPD heating rate $20{ }^{\circ} \mathrm{C} / \mathrm{min} \ldots .44$

$\mathrm{NH}_{3}$-TPD pattern for $\mathrm{V}$-Si-P 1:12:2.8 catalyst, TPD heating rate $30{ }^{\circ} \mathrm{C} / \mathrm{min} \ldots .45$

Results of long-term activity test with $10 \% \mathrm{Nb} / \mathrm{SiO}_{2}$ catalyst-MAA yields . . . . 46

Results of long-term activity test with $10 \% \mathrm{Nb} / \mathrm{SiO}_{2}$ catalyst-MAA and

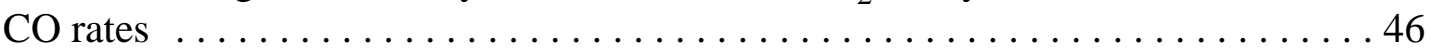

TGA test on deactivated $10 \% \mathrm{Nb} / \mathrm{SiO}_{2}$ catalyst ................... 48

XRD pattern for a fresh $20 \% \mathrm{Nb} / \mathrm{SiO}_{2}$ catalyst $\ldots \ldots \ldots \ldots \ldots \ldots \ldots \ldots$

XRD pattern for deactivated $20 \% \mathrm{Nb} / \mathrm{SiO}_{2}$ catalyst . . . . . . . . . . . . 49

Comparative XRD patterns for fresh and deactivated $20 \% \mathrm{Nb} / \mathrm{SiO}_{2}$ catalyst . . . 50 


\section{LIST OF FIGURES (continued)}

Number

Page

37 XPS pattern for a deactivated $20 \% \mathrm{Nb}_{2} \mathrm{O}_{5} / \mathrm{SiO}_{2}$ catalyst $\ldots \ldots \ldots \ldots \ldots \ldots \ldots$

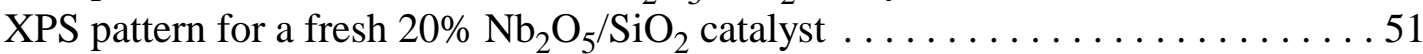

Comparative XPS patterns for fresh and deactivated $20 \% \mathrm{Nb}_{2} \mathrm{O}_{5} / \mathrm{SiO}_{2}$

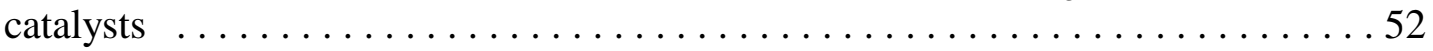

Comparative TGA plots of fresh, deactivated, and reactivated $10 \% \mathrm{Nb}_{2} \mathrm{O}_{5} / \mathrm{SiO} 2$

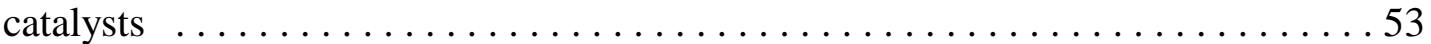

Pore size distribution for a fresh $10 \% \mathrm{Nb}_{2} \mathrm{O}_{5} / \mathrm{SiO}_{2}$ catalyst $\ldots \ldots \ldots \ldots \ldots \ldots 4$

Pore size distribution for a reactivated $10 \% \mathrm{Nb}_{2} \mathrm{O}_{5} / \mathrm{SiO}_{2}$ catalyst (regenerated using a $2 \% \mathrm{O}_{2} / \mathrm{N}_{2}$ mixture at $120 \mathrm{~mL} / \mathrm{min}$ at $400{ }^{\circ} \mathrm{C}$ for $\left.24 \mathrm{~h}\right) \ldots \ldots \ldots . \ldots 54$

Pore size distribution for a reactivated $10 \% \mathrm{Nb}_{2} \mathrm{O}_{5} / \mathrm{SiO}_{2}$ catalyst (reactivated catalyst in Figure 33 subjected to two experimental runs under formalin

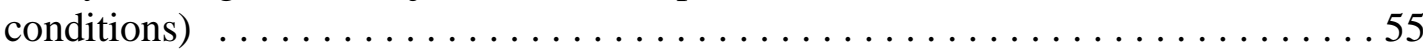

Pore size distribution for a deactivated $10 \% \mathrm{Nb}_{2} \mathrm{O}_{5} / \mathrm{SiO}_{2}$ catalyst (subjected to long-term run for $70 \mathrm{~h}$ under formalin conditions) $\ldots \ldots \ldots \ldots \ldots \ldots 5$ Comparative XRD patterns for pure $\mathrm{Nb}_{2} \mathrm{O}_{5}$ (labeled as calcined $\mathrm{Nb}$ ) and

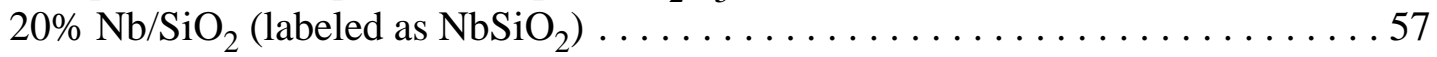

Long-term activity check on V-Si-P 1:10:2.8, 10\% Ta-Si, and 10\% Nb-Si

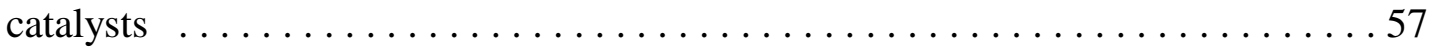

$\mathrm{NH}_{3}$-TPD pattern (surface acidity) of a $\mathrm{V}-\mathrm{Si}-\mathrm{P}$ 1:10:2.8catalyst as a function of pretreatment temperature . . . . . . . . . . . . . . . . 59

$\mathrm{NH}_{3}$-TPD pattern (surface acidity) of a V-Si-P 1:10:2.8 catalystas a function of pretreatment time . . . . . . . . . . . . . . . . . . 60

$\mathrm{NH}_{3}$-TPD pattern (surface acidity) of fresh and deactivated V-Si-P 1:10:2.8

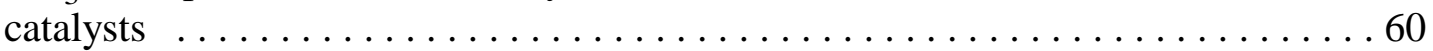

Comparative $\mathrm{NH}_{3}$-TPD patterns (surface acidity) of fresh and deactivated

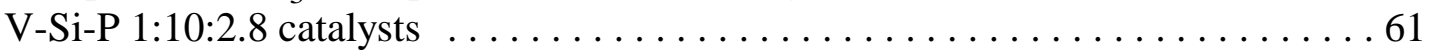

Reaction-regeneration cycle study on a10\% $\mathrm{Nb}_{2} \mathrm{O}_{5} / \mathrm{SiO}_{2}$ catalyst . . . . . . . 62

Long-term reaction-regeneration cycle study on a $10 \% \mathrm{Nb}_{2} \mathrm{O}_{5} / \mathrm{SiO}_{2}$ catalyst . . . 63

Rate formation of MAA, DEK, and $\mathrm{CO}_{2}$ during the long-term run over

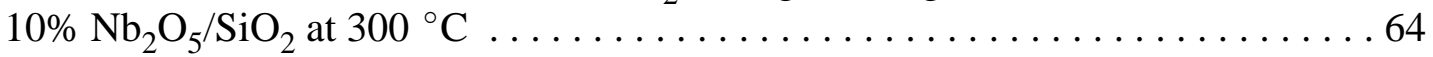

54 Long-term reaction-regeneration cycle study of $\mathrm{HOPr}: \mathrm{HCHO}$ condensation

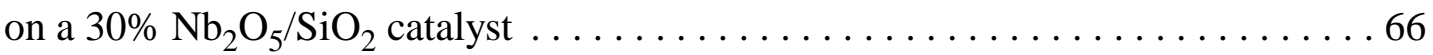

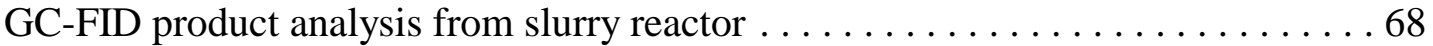

Simplified process flow diagram (formalin dehydration section) $\ldots \ldots \ldots \ldots \ldots 70$

Simplified process flow diagram (formaldehyde/propionic acid condensation

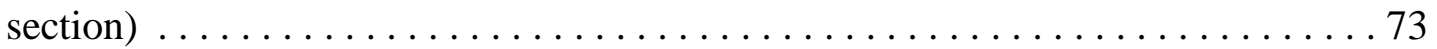




\section{LIST OF TABLES}

Number

Page

1 Representative Prices for Premium Chemicals Potentially

Available from Syngas . . . . . . . . . . . . . . . . . . . 6

2 Comparison of Different Halides and Group 6 Metal Hexacarbonyl Catalysts

for the Carbonylation of Ethylene to Propionic Anhydride . . . . . . . . . 18

3 Reaction Rates of Mo Species with Different Salts . . . . . . . . . . . . . . . 22

4 Rate as a Function of Temperature . . . . . . . . . . . . . . . . . . . . . . . . 29

5 Inhibition of Ethylene Carbonylation of Propionic Anhydride by Various

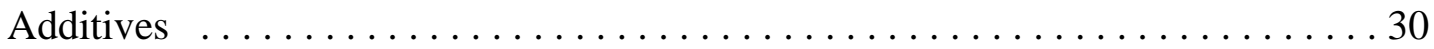

6(a) Propionic Anhydride Synthesis-Cost Estimates $\ldots \ldots \ldots \ldots \ldots \ldots \ldots \ldots \ldots$

6(b) Propionic Anhydride Synthesis Production Cost Estimates . . . . . . . . . . . . . 37

6(c) Propionic Acid Synthesis Production Cost Estimate . . . . . . . . . . . . . 38

7 Effect of Catalyst Acid-Base Properties on Methacrylic Acid Yield . . . . . . . . . 40

8 Comparison of Formaldehyde Feedstocks $\ldots \ldots \ldots \ldots \ldots \ldots \ldots \ldots \ldots \ldots$

9 Peak Listing for a XRD of a Fresh $20 \% \mathrm{Nb} / \mathrm{SiO}_{2}$ Catalyst . . . . . . . . . . . 49

10 Peak Listing for XRD of a Deactivated $20 \% \mathrm{Nb} / \mathrm{SiO}_{2}$ Catalyst . . . . . . . . . 50

11 Surface Area and Pore Structure Properties of $10 \% \mathrm{Nb}_{2} / \mathrm{O}_{5} / \mathrm{SiO}_{2} \ldots \ldots \ldots$

12 Comparison of Pure $\mathrm{Nb}_{2} \mathrm{O}_{5}$ and $10 \% \mathrm{Nb}_{2} \mathrm{O}_{5} / \mathrm{SiO}_{2}$ for Condensation Reactions . . . 56

13 Regeneration of Vanadia and Tantalum Catalysts . . . . . . . . . . . . . 59

14 Regeneration Effect on MAA Yield and Product Selectivity over

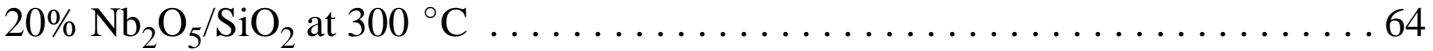

15 Effect of HOPr:HCHO Ratio on MAA Yield and Product Selectivity over

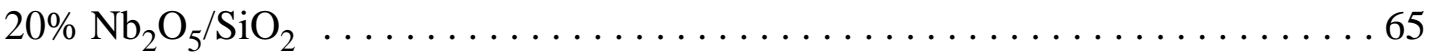

16 Carbon and Hydrogen Content of Unknown Solid and HCHO Polymer

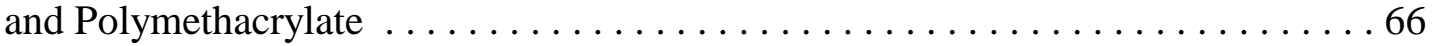

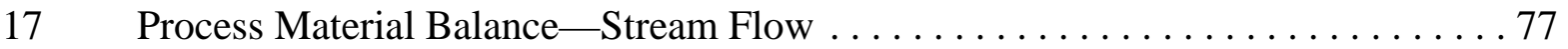

18 "External" Formaldehyde/ Propionic Acid Condensation Route to MMA . . . . . 81

19 "External" Formaldehyde/Propionic Acid Condensation MMA Synthesis . . . . . 82

20 "External" Formaldehyde/Propionic Acid Condensation MMA Synthesis . . . . . 84

21 Summary of methyl propionate condensation with formaldehyde (trioxane)

over $5 \%, 10 \%$, and $20 \% \mathrm{Nb}_{2} \mathrm{O}_{5} / \mathrm{SiO}_{2}$. Feed makeup:

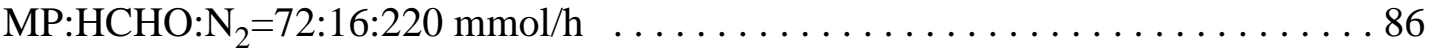

22 Deactivation of $10 \% \mathrm{Nb}_{2} \mathrm{O}_{5} / \mathrm{SiO}_{2}$ for Condensation of MP with

Formaldehyde at Temperatures from $300^{\circ} \mathrm{C}$ to $360{ }^{\circ} \mathrm{C} \ldots \ldots \ldots \ldots$. . . . . . . . . . .

23 Partial Oxidation of Dimethyl Ether to Formaldehyde . . . . . . . . . . . 87

24 DME Partial Oxidation and In-Situ Condensation with Methyl Propionate . . . . 89 


\section{LIST OF ACRONYMS}

$\begin{array}{ll}\text { ACH } & \text { Acetone cyanohydrin } \\ \text { ASPEN } & \text { Advanced system for process engineering } \\ \text { DEK } & \text { Diethyl ketone } \\ \text { DME } & \text { Dimethyl ether } \\ \text { DOE } & \text { Department of Energy } \\ \text { FETC } & \text { Federal Energy Technology Center } \\ \text { GC } & \text { Gas chromatograph } \\ \text { GC/MS } & \text { Gas chromatography/mass spectrometry } \\ \text { HCHO } & \text { Formaldehyde } \\ \text { HOPr } & \text { Propionic acid } \\ \text { HTHP } & \text { High-temperature, high-pressure } \\ \text { MAA } & \text { Methacrylic acid } \\ \text { MMA } & \text { Methyl methacrylate } \\ \text { MAAm } & \text { Methacrylamide } \\ \text { MP } & \text { Methyl propionate } \\ \text { NCSU } & \text { North Carolina State University } \\ \text { ROI } & \text { Return on investment } \\ \text { RTI } & \text { Research Triangle Institute } \\ \text { SRI } & \text { Stanford Research Institute } \\ \text { SS } & \text { Stainless steel } \\ \text { STP } & \text { Standard temperature and pressure } \\ \text { TCD } & \text { Thermal conductivity detector } \\ \text { TGA } & \text { Thermogravimetric analysis } \\ \text { TPD } & \text { temperature-programmed desorption } \\ \text { XPS } & \text { X-ray photoelectron spectroscopy } \\ \text { XRD } & \text { X-ray diffraction } \\ & \end{array}$




\section{ACKNOWLEDGMENTS}

The authors gratefully acknowledge the support of this research, by the U.S. Department of Energy/Federal Energy Technology Center (DOE/FETC), through contract No. DE-AC2294PC94065. The authors also are indebted to DOE Project Officer, Dr. Brad Tomer, for his support and guidance. 


\section{EXECUTIVE SUMMARY}

Research Triangle Institute (RTI), Eastman Chemical Company, and Bechtel have developed a novel process for synthesis of a high-value chemical, methyl methacrylate (MMA), from coalderived syngas, under a contract from the U.S. Department of Energy/Fossil Energy Technology Center (DOE/FETC). Although this project has focused on the synthesis of MMA, the catalysts and chemistry have much broader applicability and can serve as the basis for the synthesis of other industrially important syngas-based premium chemicals, particularly the wide range of polyols and hydroxy acids used in the production of polyesters, plastics, synthetic lubricants, and latex compounds.

This project has resulted in five U.S. patents (four approved, 5,710,328 5,744,026, 5,760,284, and 5,808,148, and one pending publication) and is based on a three-step process shown in Figure 1. First, a propionate is formed from ethylene carbonylation with coal-derived $\mathrm{CO}$. This propionate is condensed with formaldehyde to form methacrylic acid (MAA), which is then esterified with methanol to yield methyl methacrylate (MMA). Figure 1 shows a simplified MMA synthesis process scheme using propionic acid as the propionate. The first two steps, propionate synthesis and condensation catalysis, are the key technical challenges and the focus of the research presented here. Esterification of MAA to MMA is a proven technology. This final report summarizes the technical accomplishments throughout the project period of October 1, 1994, to November 30, 1999. These accomplishments are divided into five different tasks.

\section{Figure 1. The RTI-Eastman-Bechtel three-step MMA process (with external formaldehyde feed).}

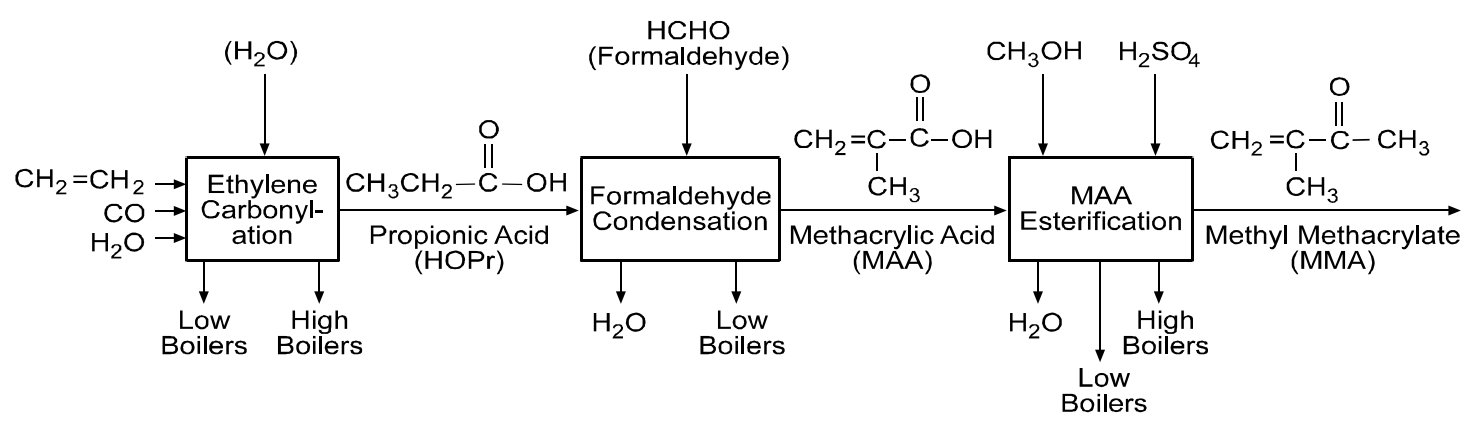

\section{Task 1: Propionate Synthesis (Eastman Chemical Company)}

Task 1 (propionate synthesis) is the first step in the process to generate MMA from coal-derived syngas. Eastman has focused on the development of novel homogeneous Cr-group catalysts for the synthesis of propionic acid/anhydride from ethylene, coal-derived carbon monoxide, and, optionally, water. The development of these catalysts, which work at substantially lower pressures than Ni-based conventional industrial catalysts (30 to 70 atm versus more than 200 atm), significantly reduces the cost of this step. 
This discovery represents the first case of an efficient carbonylation process based on the Cr-group metals and a unique method for initiating carbonylation catalysis. This also provides a new process for the use of coal-derived CO. Eastman has obtained two patents on this improved catalyst system for olefin carbonylation.

\section{Task 2: Condensation Catalysis (RTI)}

The development of an active, selective, and stable catalyst for the vapor phase condensation of the propionate with formaldehyde to MAA is the second step in the process (Figure 1). As a result of screening over 81 catalysts, Group $\mathrm{V}$ catalysts $(\mathrm{V}, \mathrm{Nb}$, and $\mathrm{Ta}$ ) have been discovered to be active and selective for this reaction. A series of $\mathrm{Nb}_{2} \mathrm{O}_{5} / \mathrm{SiO}_{2}$ catalysts gave the optimum conversion and selectivity. Although these $\mathrm{Nb}_{2} \mathrm{O}_{5}$-based catalysts gave MAA yields up to 40 percent, they deactivate steadily, likely due to carbon deposition. The catalysts can, however, be completely regenerated under a mild oxidative regeneration, using a 2 percent oxygen/nitrogen gas stream, at $400{ }^{\circ} \mathrm{C}$. For example, an approximately 400 -h continuous run studying the condensation of formaldehyde with propionic acid (PA) over 10 percent $\mathrm{Nb}_{2} \mathrm{O}_{5} / \mathrm{SiO}_{2}$ at $300{ }^{\circ} \mathrm{C}$ was carried out in which six activity and five regeneration cycles were completed. Although the activity of the catalyst could be restored by regeneration, the selectivity to MAA decreased slightly after each regeneration leading to a higher selectivity to diethyl ketone (DEK) and $\mathrm{CO}_{2}$ formation.

\section{Task 3: Slurry Reactor Studies (RTI)}

The third task focuses on the in-situ condensation catalysis in a slurry reactor. Methanol, oxygen, and propionic acid (HOPr) are fed under high pressures and temperatures over a physical mixture of two catalysts suspended in an inert fluid, and MMA is produced in one single step:

$$
\mathrm{CH}_{3} \mathrm{OH}+1 / 2 \mathrm{O}_{2}+\mathrm{CH}_{3} \mathrm{CH}_{2} \mathrm{COOH} \rightarrow \mathrm{CH}_{2}=\mathrm{C}\left(\mathrm{CH}_{3}\right) \mathrm{COOH}+2 \mathrm{H}_{2} \mathrm{O}
$$

The advantage of this one-step slurry reactor approach is that it obviates the need to generate and handle formaldehyde. One key to the operation of such a reactor is the slurry fluid, which must be chemically inert and stable for long periods of time in the presence of oxygen. The slurry fluid must also have the low vapor pressure and adequate transport properties to allow the reactions to proceed. A series of runs designed to test decalin as the slurry fluid were made at North Carolina State University (NCSU). Subsequent runs in the slurry reactor designed to produce MMA/MAA from HOPr, methanol, and oxygen were unsuccessful, with the product consisting of more than 40 compounds. Because a preliminary economic analysis by Eastman and Bechtel showed that the three-step process, with a fixed-bed vapor phase condensation reactor as the second step, can be potentially competitive with emerging and commercial technologies to make MMA, no further slurry reactor studies were carried out, and the remaining effort focused on the fixed-bed vapor phase condensation catalysis. 


\section{Task 4: Economic Analysis (Bechtel and Eastman)}

Two detailed process conceptual design and economic analysis were carried out for the project. These analyses were based on a plant capacity to produce 250 million lb/yr of MMA. The first analysis specifically deals with the propionate synthesis via ethylene carbonylation, based on a conceptual design for propionic anhydride. The second analysis focuses on the overall MMA economics based on the RTI-Eastman-Bechtel three-step process with specific emphasis placed on the propionic acid/formaldehye condensation reaction process design.

A conceptual design and economic analysis was developed for propionic anhydride synthesis via ethylene carbonylation $\left[\mathrm{C}_{2} \mathrm{H}_{4}+\mathrm{CO}+\mathrm{C}_{2} \mathrm{H}_{5} \mathrm{COOH} \rightarrow\left(\mathrm{CH}_{3} \mathrm{CH}_{2} \mathrm{CO}\right)_{2} \mathrm{O}\right]$ based on Eastman's experimental result of Mo hexacarbonyl catalyst at conditions of $180{ }^{\circ} \mathrm{C} / 750 \mathrm{psig}$. The design is identical to that for propionic acid synthesis $\left[\mathrm{C}_{2} \mathrm{H}_{4}+\mathrm{CO}+\mathrm{H}_{2} \mathrm{O} \rightarrow \mathrm{CH}_{3} \mathrm{CH}_{2} \mathrm{COOH}\right]$. The only significant difference is the use of water instead of propionic acid as a feed. The propionate synthesis step for the overall MMA plant is estimated to cost about $\$ 40.1$ million, and propionic anhydride production is estimated at $\$ 0.43 / \mathrm{lb}$. Propionic acid feedstock cost dominates the overall propionic anhydride production economics, accounting for about 57 percent of the total production cost.

Based on the same cost analysis, economics of propionic acid synthesis via ethylene carbonylation was analyzed, based on using water as a feed in addition to $\mathrm{C}_{2}=$ and $\mathrm{CO}$. Propionic acid production cost is estimated at about $\$ 0.20 / 1 b$.

The formaldehyde/propionic acid condensation plant for MAA synthesis and the subsequent MAA esterification plant adds an additional \$55.1 million to the overall cost of a 250 million lb/yr MMA plant. The formaldehyde/propionic acid condensation conceptual plant design was

developed based on RTI's experimental data of $\mathrm{Nb}_{2} \mathrm{O}_{5} / \mathrm{SiO}_{2}$ catalyst, and the MAA esterification plant is a standard commercial design.

For the RTI-Eastman-Bechtel three-step MMA process to be economically competitive, the carbonylation step for propionic acid synthesis has to be included as an integral part of the overall process. Under this scenario, MMA can be produced at a cost of $\$ 0.64 / \mathrm{lb}$, with a 25 percent rate of return of investment and 35 percent contingency for capital cost. Current market price for MMA varies between $\$ 0.65$ to $\$ 0.70 / \mathrm{lb}$. The MMA economics is dominated by raw material costs. Significant improvement in cost benefits can be realized if 1) the formaldehyde/propionic acid condensation reaction conversion and selectivity to MAA can be further increased, 2) better MAA effluent product separation and waste recovery schemes to minimize raw material loss, and 3) incorporation of an advanced MAA esterification process design into the final cost estimate.

\section{Task 5: DME Condensation Study (RTI)}

Because of the kinetic inhibition and deactivation effects of water, and the possibility of lower costs, a series of tests using dimethyl ether (DME), rather than formaldehyde with methyl propionate (MP), was undertaken. The overall reaction to MMA is as follows: 
$\mathrm{CH}_{3} \mathrm{OCH}_{3}+\mathrm{O}_{2} \rightarrow 2 \mathrm{HCHO}+\mathrm{H}_{2} \mathrm{O}$

$2 \mathrm{HCHO}+2 \mathrm{CH}_{3} \mathrm{CH}_{2} \mathrm{COOCH}_{3} \rightarrow 2 \mathrm{CH}_{3} \mathrm{C}\left(\mathrm{CH}_{2}\right) \mathrm{COOCH}_{3}+2 \mathrm{H}_{2} \mathrm{O}$

overall $\overline{\mathrm{CH}}_{3} \mathrm{OCH}_{3}+\mathrm{O}_{2}+2 \mathrm{CH}_{3} \mathrm{CH}_{2} \mathrm{COOCH}_{3} \rightarrow 2 \mathrm{CH}_{3} \mathrm{C}\left(\mathrm{CH}_{2}\right) \mathrm{COOCH}_{3}+3 \mathrm{H}_{2} \mathrm{O}$

To study these reactions, partial oxidation of DME and direct condensation between MP and formaldehyde have been investigated. The results suggest that silica supported niobium catalysts are active and selective for condensation of MP with formaldehyde (HCHO), but deactivation needs to be minimized for commercial application. Silica-supported niobium catalysts are also active for the partial oxidation of DME to HCHO [reaction (2)]. Best temperatures for partial oxidation are between 300 and $400{ }^{\circ} \mathrm{C}$.

In one unique reaction that has not been previously reported, the first in-situ generation of formaldehyde from DME and the subsequent condensation of formaldehyde with methyl propionate to make MMA in one reactor was successfully demonstrated [reaction (4)]. The conversion and selectivities are shown in Figure 2. The potential of this process to significantly lower the cost has not been explored.

Figure 2. Schematic of in-situ DME partial oxidation and condensation with methyl propionate.

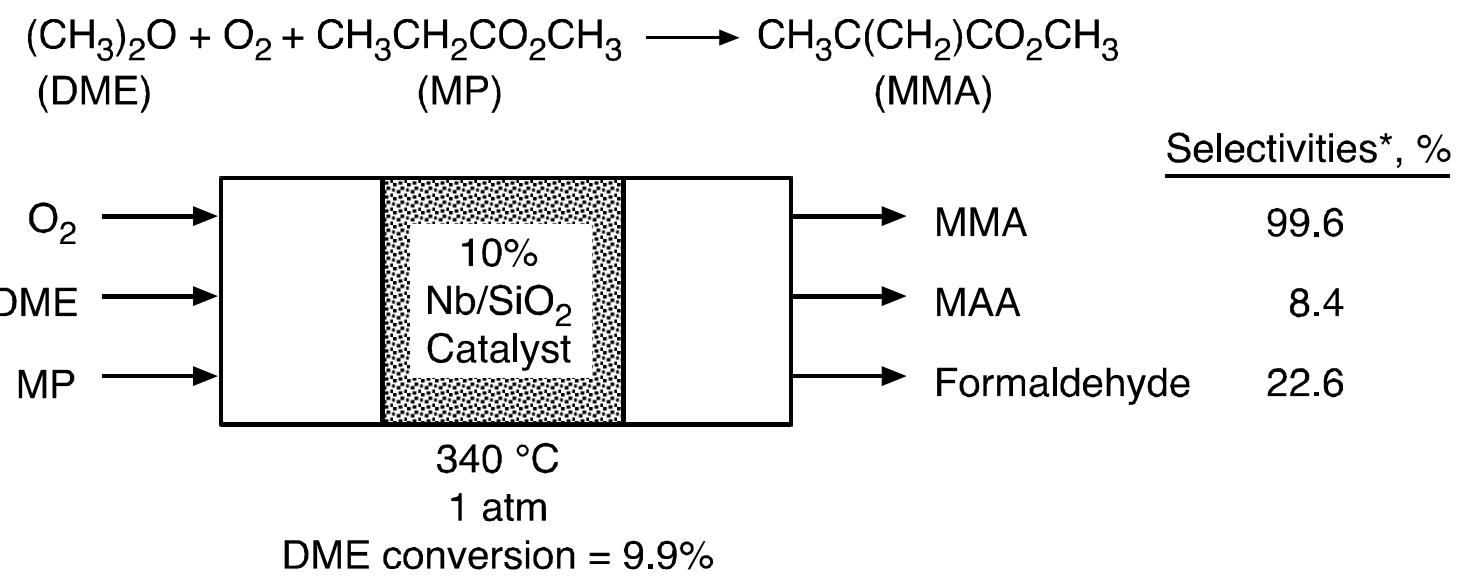

* Based on DME consumed. Selectivities add to more than $100 \%$ because some formaldehyde is likely formed from methanol, a product from of hydrolysis. 


\section{INTRODUCTION}

Because a wide range of premium and commodity chemicals can be produced from syngas, there is a continuing interest to develop cost-effective processes to synthesize industrial feedstocks and intermediates to replace conventional petroleum-derived chemicals. New catalysts, chemistry, and reactor design concepts must be carefully developed and tested for syngas-based chemicals to be cost-competitive with existing processes. At present, few large-scale commercial chemicals are manufactured entirely from synthesis gas. These include methanol, formaldehyde, acetic acid, methyl acetate, and acetic anhydride. One purpose of the work performed here is to develop a process for the generation of polyfunctional oxygenate derivatives (necessary for the production of industrial polyesters, plastics, latexes, and synthetic lubricants) using the sequential conversion of coal-derived $\mathrm{CO}$ to high molecular weight propionates, and the subsequent condensation and esterification of these compounds to high-value oxygenates.

Syngas-based chemicals could compete directly with their petroleum-based counterparts. Review of the production volumes and prices for various chemicals and intermediates indicates clearly that the acrylates and methacrylates represent the largest net financial opportunity for syngasbased products. In addition, these chemicals present key opportunities for coal-based technologies to penetrate the market. This is based both on the large volume of these chemicals and the expected strong growth in demand, creating a market-driven need for additional capacity and technologies.

Table 1 shows prices for the premium chemicals that could be made from syngas. The wide range of these chemicals suggests a correspondingly wide range of opportunities for syngasbased chemical synthesis routes. Note, however, that these chemicals are closely related and all could, in principle, be synthesized by using the chemistry described here or slight variations of it. Of specific interest is the methyl methacrylate, which is representative of the high-volume compounds that can be produced from syngas, and results in a near-term opportunity for commercialization.

The most widely practiced commercial technology for the synthesis of MAA and MMA is the acetone-cyanohydrin $(\mathrm{ACH})$ process (Figure 3). The $\mathrm{ACH}$ process accounts for 85 percent of the global production of MMA and is currently the only process practiced in the United States [1]. This process begins with the hydrocyanation of acetone and requires handling large quantities of extremely toxic and hazardous hydrogen cyanide and generates stoichiometric amounts of ammonium sulfate wastes, which are either discarded or reclaimed at substantial cost. The ACH technology is currently environmentally and economically untenable for any new expansions, primarily because of the cost of disposing or regenerating the bisulfate waste.

A strong drive exists within the chemical industry for a replacement process [2,3]. There is particular interest in the United States in a process that is not petroleum-based, but rather based on domestically produced coal-based syngas. The processes based on $\mathrm{C}_{2}=$ carbonylation shown in Figure 4 are commercially attractive technologies for MMA manufacture [2,3]. Each of these processes goes through a propionate intermediate, which can be condensed with formaldehyde to produce either MAA (Processes [I] and [II]) or a mixture of MAA and MMA (Processes [III] and 


\begin{tabular}{lc}
\multicolumn{2}{c}{$\begin{array}{c}\text { Table 1. Representative Prices for } \\
\text { Premium Chemicals Potentially } \\
\text { Available from Syngas }\end{array}$} \\
\hline \multicolumn{1}{c}{ Chemical Name } & $\begin{array}{c}\text { Representative Price } \\
\text { (\$/lb) }\end{array}$ \\
\hline Acrylic acid & 0.75 \\
Methyl acrylate & 0.83 \\
Ethyl acrylate & 0.74 \\
Butyl acrylate & 0.76 \\
2-ethylhexyl acrylate & 0.84 \\
Methacrylic acid & 1.04 \\
Methyl methacrylate & 0.71 \\
Ethyl methacrylate & 2.15 \\
Butyl methacrylate & 0.96 \\
Neopentyl glycol & 0.70 \\
Trimethylolpropane & 0.92 \\
Trimethylolpropane triacrylate & 1.85 \\
Pentaerythritol & 0.78 \\
Pentaerythritol triacrylate & 1.50 \\
Propionic acid & 0.41 \\
\hline
\end{tabular}

Chem. Marketing Reporter, April 25, 1994.

Figure 3. Schematic of the $\mathrm{ACH}$ process.

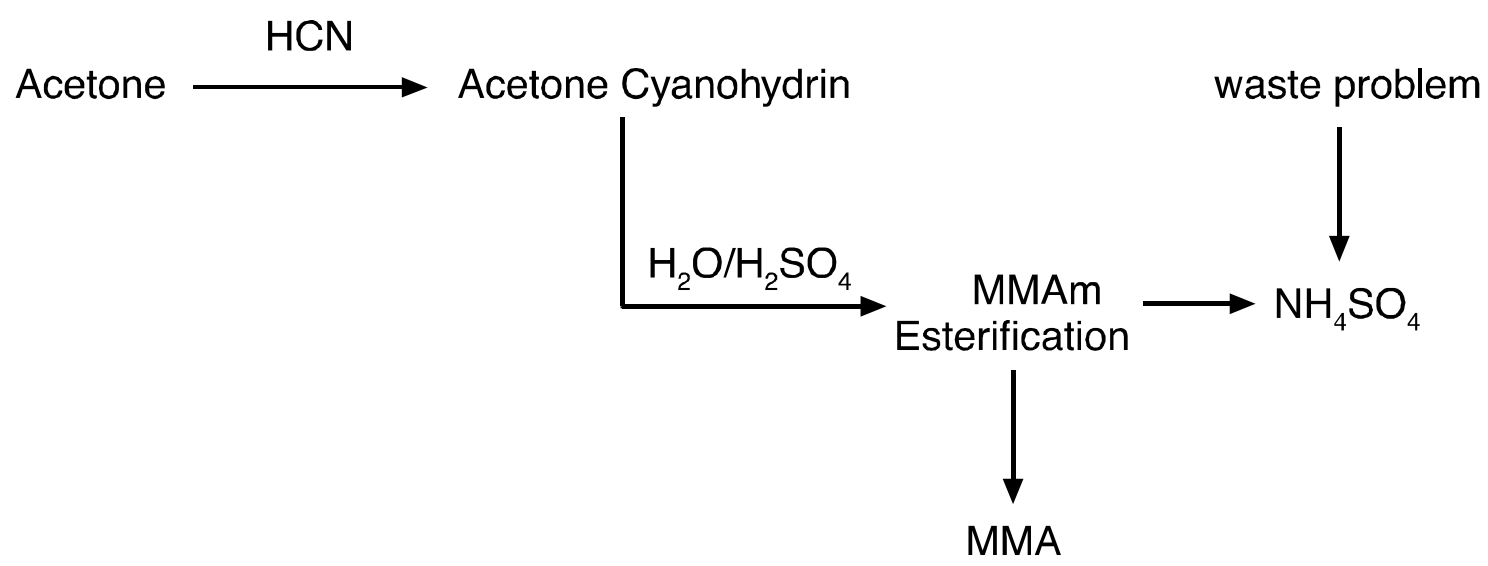


Figure 4. $\mathrm{C}_{2}$-carbonylation technologies for MMA manufacture.

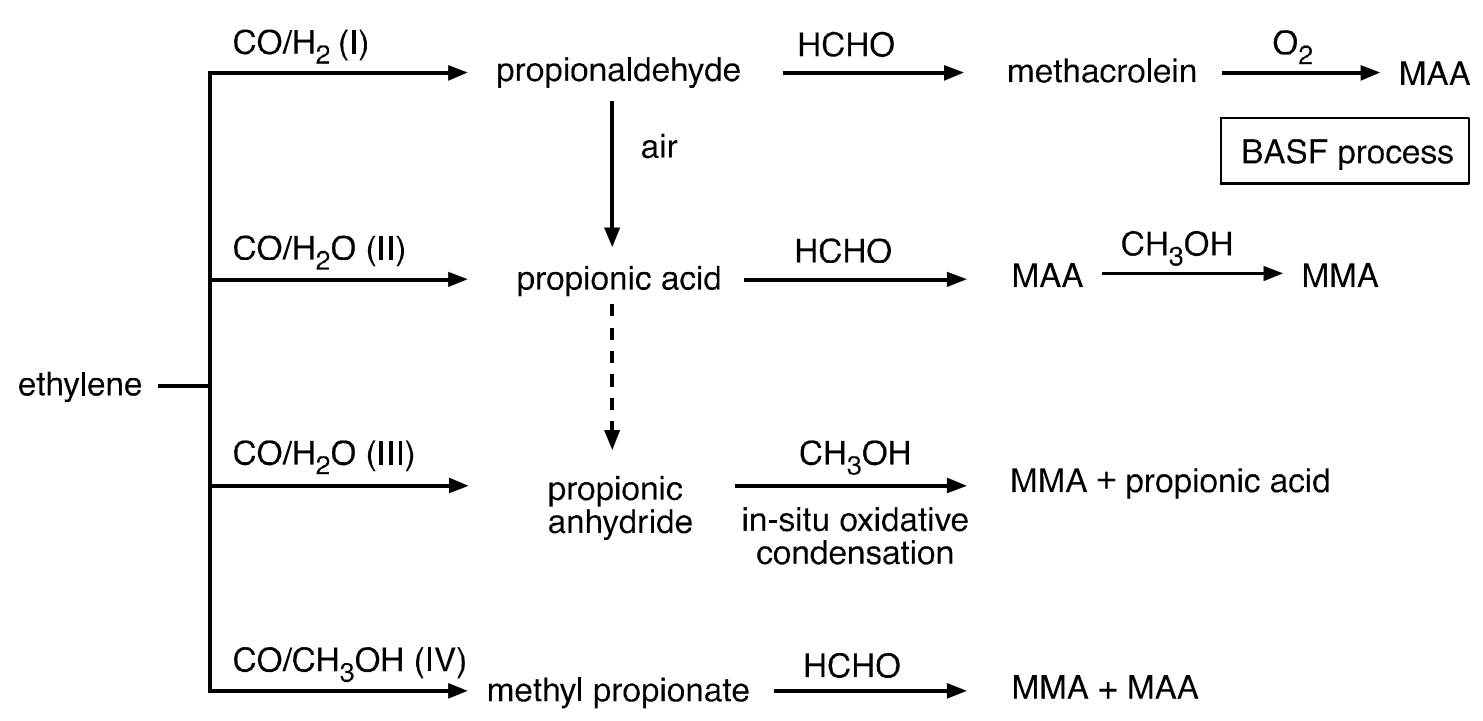

[IV]). (Note that in Process [III], formaldehyde is produced by partial oxidation of methanol, which also esterifies the resulting MAA to MMA. The water produced in the partial oxidation reaction hydrolyzes a portion of the propionic anhydride (PAN), to form propionic acid, which is recycled.) In each of the four processes shown in Figure 4, MMA and MAA are formed by the condensation of formaldehyde with three propionates: propionic acid (Process [II]), propionic anhydride (Process [III]), and methyl propionate (Process [IV]). In Process (I), MAA is produced by condensation of formaldehyde with propionaldehyde. Process [III] has a potential for a total lower cost, primarily because one less mole of water is produced. The MAA synthesis is composed of the following steps:

Step 1: Propionate synthesis from ethylene (5) and ethylene plus propionic acid (6)

$$
\begin{gathered}
\mathrm{H}_{2} \mathrm{C}=\mathrm{CH}_{2}+\mathrm{CO}+\mathrm{H}_{2} \mathrm{O} \rightarrow \mathrm{CH}_{3} \mathrm{CH}_{2} \mathrm{COOH} \\
\mathrm{CH}_{3} \mathrm{CH}_{2} \mathrm{COOH}+\mathrm{CO}+\mathrm{H}_{2} \mathrm{C}=\mathrm{CH}_{2} \rightarrow\left(\mathrm{CH}_{3} \mathrm{CH}_{2} \mathrm{CO}\right)_{2} \mathrm{O}
\end{gathered}
$$

Step 2: Condensation of propionic anhydride (7) or propionic acid (8) with formaldehyde

$$
\begin{gathered}
\left(\mathrm{CH}_{3} \mathrm{CH}_{2} \mathrm{CO}\right)_{2} \mathrm{O}+\mathrm{HCHO} \rightarrow \mathrm{CH}_{2}=\mathrm{C}\left(\mathrm{CH}_{3}\right) \mathrm{COOH}+\mathrm{CH}_{3} \mathrm{CH}_{2} \mathrm{COOH} \\
\mathrm{CH}_{3} \mathrm{CH}_{2} \mathrm{COOH}+\mathrm{HCHO} \rightarrow \mathrm{CH}_{2}=\mathrm{C}\left(\mathrm{CH}_{3}\right) \mathrm{COOH}+\mathrm{H}_{2} \mathrm{O} \\
\left(\mathrm{CH}_{3} \mathrm{CH}_{2} \mathrm{CO}\right)_{2} \mathrm{O}+2 \mathrm{HCHO} \rightarrow 2 \mathrm{CH}_{2}=\mathrm{C}\left(\mathrm{CH}_{3}\right) \mathrm{COOH}+\mathrm{H}_{2} \mathrm{O}
\end{gathered}
$$

Step 3: Esterification of methacrylic acid with methanol

$$
\mathrm{CH}_{2}=\mathrm{C}\left(\mathrm{CH}_{3}\right) \mathrm{COOH}+\mathrm{CH}_{3} \mathrm{OH} \rightarrow \mathrm{CH}_{2}=\mathrm{C}\left(\mathrm{CH}_{3}\right) \mathrm{COOCH}_{3}+\mathrm{H}_{2} \mathrm{O}
$$


In this proposed process for MMA manufacture, Step 1 was developed by Eastman Chemical Company [2], and Step 3 is a known art. Further improvement of Step 1 and the development of Step 2, however, present a challenge for successful commercial demonstration of the process.

\subsection{Step 1: Propionate Synthesis}

Propionic acid and its derivatives represent an important and rapidly growing class of chemical intermediates, with applications ranging from food and grain preservatives to the generation of propionate esters, such as cellulose propionate-based plastics. As the chemical industry seeks a combination of safer, more environmentally benign processes and products, along with better product performance, the potential of propionate derivatives as a feedstock, particularly for the generation of MAA derivatives and high-performance ester derivatives, continues to rise rapidly. To realize this potential, improved processes for the generation of these materials are required.

In principle, hydrocarboxylation (or hydroesterification in the case of esters), which is depicted in Reaction (11), represents the most direct process for the generation of these intermediates and is capable of generating any of the usual derivatives in a single step.

$$
\begin{aligned}
& \mathrm{H}_{2} \mathrm{C}=\mathrm{CH}_{2}+\mathrm{CO}+\mathrm{ROH} \rightarrow \mathrm{EtCO}_{2} \mathrm{R} \\
& \mathrm{R}=\mathrm{H}, \mathrm{EtC}(=\mathrm{O}), \text { alkyl }(\mathrm{Me}, \mathrm{Et} \text {, etc. }) .
\end{aligned}
$$

Although these processes are well-known [1], commercial application has been limited to a single unit at BASF, which uses a highly toxic (and volatile) $\mathrm{Ni}(\mathrm{CO})_{4}$ catalyst operating at high pressures $(>180 \mathrm{~atm})$ and high temperatures $\left(>270{ }^{\circ} \mathrm{C}\right)$ to produce propionic acid $[1,4]$. Alternative catalysts for the generation of propionic acid, which may operate at substantially lower pressures and temperatures, generally require expensive metals, such as $\mathrm{Rh}$, Ir, or Pd, and none have been commercially employed [4-8]. Use of these metals for the generation of esters or anhydrides suffer poor selectivity and conversion, respectively, and are therefore unsuitable. Given the harsh conditions and the expense associated with the catalysts alternative, most current producers of propionate derivatives still proceed through the more circuitous hydroformylationoxidation sequence to generate propionic acid, which subsequently is converted to its derivatives in a separate step.

While seeking improved processes for the propionates, Eastman discovered that halide-promoted Cr-group (Group 6) metals, preferably in the form of iodide-promoted Mo catalysts, allow the carbonylation of olefins to carboxylic acid derivatives to proceed at low to moderate pressures ( 25 to $70 \mathrm{~atm}$ ) and moderate temperatures ( 150 to $200{ }^{\circ} \mathrm{C}$ ) with high rates. The carbonylation of ethylene to propionate derivatives can be operated up to the limits imposed by mass transfer of the reactant gases, and Mo turnovers of $>250 / \mathrm{h}$ are readily achievable.

Cr-group metals have never shown (or been believed) to have significant catalytic activity in isolation. Prior to this study, the only known examples where Cr-group metals have been demonstrated to induce carbonylation of any substrate were limited to a stoichiometric carbonylation of alkyl iodides to esters using a $\mathrm{Mo}(\mathrm{CO})_{6} / \mathrm{F}^{-}$catalyst and a marginally catalytic ( $\sim 0.6$ turnovers/h) carbonylation of $\alpha$-difluorinated iodides using $\operatorname{Mo}(\mathrm{CO})_{6}[9,10]$. Therefore, the process described 
in this report represents the first demonstration of an efficient carbonylation catalyst using a Cr-group metal as the catalytically active metal component.

\subsection{Step 2: HCHO_Propionate Condensation}

The condensation of propionate derivatives with formaldehyde provides a novel synthetic route to production of $\alpha$-, $\beta$-unsaturated acids. The general condensation reaction can be written as

$$
\begin{gathered}
\mathrm{HCHO}+\mathrm{R}_{1}-\mathrm{CH}_{2}-\mathrm{COOR}_{2} \rightarrow \mathrm{H}_{2} \mathrm{C}=\mathrm{C}\left(\mathrm{R}_{1}\right) \mathrm{COOR}_{2}+\mathrm{H}_{2} \mathrm{O} \\
\mathrm{R}_{1}=\mathrm{H}, \mathrm{CH}_{3}, \mathrm{C}_{2} \mathrm{H}_{5 \ldots . .} \mathrm{R}_{2}=\mathrm{H}, \mathrm{CH}_{3}, \mathrm{C}_{2} \mathrm{H}_{5} \ldots \ldots
\end{gathered}
$$

These $\alpha$-, $\beta$-unsaturated acids and their ester derivatives are among the most widely used industrial intermediates. They are polymerized to form plastic sheeting for signs, coatings, adhesives, fibers, and paints. Although the work reported here is directed toward the system of MMA, other high-value products can be generated with the same chemistry.

Three propionates - propionic anhydride (PAN), propionic acid (HOPr), and methyl propionate (MP) - are considered in this study. While the condensation of HOPr or MP with formaldehyde to form MAA is a known art and has been widely studied [11-13], the condensation of propionic anhydride with formaldehyde using a heterogeneous catalyst has been reported in only one reference [14]. The condensation of propionic anhydride (rather than propionic acid or methyl propionate) has the advantage of producing one less mole of water, which can kinetically inhibit the reaction, hydrolyze the product, and make separation of the product more costly.

When propionic anhydride is the starting material, this condensation step (reaction [9]) is composed of two separate condensation reactions ([7] and [8]), which give the overall stoichiometry shown in reaction (9). Condensation of propionic acid with formaldehyde (reaction [8]) has been studied recently [11-13] using a V-Si-P catalyst, which has both acid and base properties. However, these catalysts have not been previously tested for the condensation of propionic anhydride and formaldehyde. There are some obvious advantages to using the anhydride for the condensation reaction, however. For example, both the condensation of formaldehyde with propionic acid (reaction [8]) and the condensation of methyl propionate with formaldehyde (reaction [13]),

$$
\mathrm{CH}_{3} \mathrm{CH}_{2} \mathrm{COOCH}_{3}+\mathrm{HCHO} \rightarrow \mathrm{CH}_{2}=\mathrm{C}\left(\mathrm{CH}_{3}\right) \mathrm{COOCH}_{3}+\mathrm{H}_{2} \mathrm{O}
$$

produce 1 mol of water per mole MAA or MMA produced. This water inhibits the reaction and, in the case of methyl propionate, also leads to hydrolysis of the ester (methyl propionate) itself. Water also complicates the downstream product separation. When the condensation reaction is carried out using propionic anhydride (reaction [9]), however, one less mole of water is produced ( 1 mol of water per $2 \mathrm{~mol}$ of MAA). In a stoichiometric excess of propionic anhydride, this water is consumed in a further reaction to produce propionic acid:

$$
\left(\mathrm{CH}_{3} \mathrm{CH}_{2} \mathrm{CO}\right)_{2} \mathrm{O}+\mathrm{H}_{2} \mathrm{O} \rightarrow 2 \mathrm{CH}_{3} \mathrm{CH}_{2} \mathrm{COOH}
$$


This means that the overall condensation (Step 2) can be carried out essentially anhydrously. There has been little reported on the gas phase condensation of formaldehyde and HOPr, with only one reference available [14], in which a 10 percent $\mathrm{Ta} / \mathrm{SiO}_{2}$ was used for the condensation reaction. The work presented here compares the experimental results on the condensation of formaldehyde with each of the three propionates in Figure 4 (propionic acid, propionic anhydride, and methyl propionate).

\section{EXPERIMENTAL}

\subsection{TASK 1-PROPIONATE SYNTHESIS}

\subsubsection{Generation of Propionic Anhydride $\left[\left(\mathrm{CH}_{3} \mathrm{CH}_{2} \mathrm{CO}\right)_{2} \mathrm{O}\right]$}

The experimental studies of the reaction of ethylene, propionic acid, and coal-derived $\mathrm{CO}$ were carried out in a 2-L Hastelloy $\mathrm{C}$ overhead stirred autoclave fitted with a high-pressure condenser and a dip tube for removing samples during the course of the reaction (Figure 5). Gas mixtures were prepared in a stirred gas mix tank heated to 45 to $50{ }^{\circ} \mathrm{C}$, and feed lines were heat traced and maintained at 40 to $50{ }^{\circ} \mathrm{C}$. Failure to keep the mix tank and lines heated often leads to ethylene liquefaction and separation, particularly when cooling begins (due to expansion) as ethylene is either added to the tank during preparation of the gas mixture or removed from the tank during the reaction. The following procedure is exemplary of a typical operation:

Figure 5. Autoclave system at Eastman.

\section{Reactor for Kinetics with Stable Gas Composition}

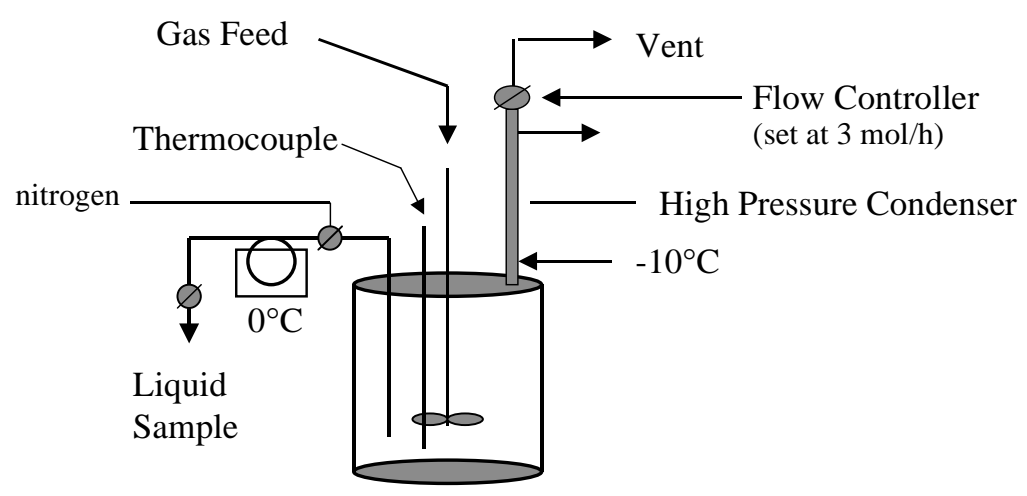


To the autoclave was added $5.81 \mathrm{~g}(0.022 \mathrm{~mol})$ of $\mathrm{Mo}(\mathrm{CO})_{6}, 15.5 \mathrm{~g}(0.040 \mathrm{~mol})$ of tetrabutylphosphonium iodide, $109.2 \mathrm{~g}(0.700 \mathrm{~mol})$ of ethyl iodide and $555 \mathrm{~g}(7.5 \mathrm{~mol})$ of propionic acid. The condenser temperature was set at $-10{ }^{\circ} \mathrm{C}$ using a cooled ethylene glycol/water mixture. The autoclave was then pressure tested with nitrogen at $68.0 \mathrm{~atm}$, and a gas purge of $3 \mathrm{~mol} / \mathrm{h}$ of gas was established through the high-pressure condenser. (During the reaction this gas purge permitted control of the gas composition over the reaction mixture, and it is necessary for kinetic measurements.) The nitrogen was vented, and the autoclave was then pressurized to $23.8 \mathrm{~atm}$ with 5 percent hydrogen in carbon monoxide and subsequently heated to $160{ }^{\circ} \mathrm{C}$. (The $3 \mathrm{~mol} / \mathrm{h}$ of gas purge was maintained throughout heating and the subsequent reaction.) Upon reaching temperature, the pressure was raised to 51.0 atm using a gas mixture consisting of 6 percent $\mathrm{H}_{2}$, 47 percent $\mathrm{CO}$, and 47 percent ethylene while using the $3 \mathrm{~mol} / \mathrm{h}$ purge to maintain the gas mixture. Liquid samples were removed every $20 \mathrm{~min}$ for $5 \mathrm{~h}$ and analyzed for ethyl iodide, ethyl propionate, propionic anhydride, and propionic acid content by gas chromatography (GC) using a Hewlett Packard 5890 GC containing a 25-m (0.25-mm ID, 0.25- $\mu \mathrm{m}$ film) Quadrex 007 FFAP capillary column with $p$-xylene as an internal standard. (A split injection was used to introduce the sample, and sample detection was accomplished with a thermal conductivity detector [TCD].) These components represented the only significant products present, and all other materials detectable by a gas chromatograph/mass spectrometer (GC/MS) were at trace levels. Gas samples were also removed hourly and analyzed by GC to ensure that the gas mixture was consistent. The molar quantities of propionic anhydride $\left(\mathrm{n}_{\mathrm{pan}}\right)$ formed were determined from the $\mathrm{GC}$ data using the following equation:

$$
\mathrm{n}_{\mathrm{pan}}=\frac{\mathrm{X}_{\mathrm{pan}}}{130} \cdot \frac{\mathrm{n}_{\mathrm{pa}}^{\mathrm{o}}+\mathrm{n}_{\mathrm{ei}}^{\mathrm{o}}}{\left[\left(\mathrm{X}_{\mathrm{ei}} / 156\right)+\left(\mathrm{X}_{\mathrm{pa}} / 74\right)+\left(\mathrm{X}_{\mathrm{pan}} / 130\right)+\left(\mathrm{X}_{\mathrm{ep}} / 102\right)\right]}
$$

where

$$
\begin{aligned}
\mathrm{n}_{\mathrm{pan}} & =\text { moles of the component } \\
\mathrm{X}_{\mathrm{i}} & =\text { weight fraction of the component (obtained from GC analysis) } \\
\mathrm{n}_{\mathrm{p}} & =\text { moles of propionyl initially present propionic acid added at start } \\
\mathrm{n}_{\mathrm{ei}}{ }^{\mathrm{o}} & =\text { ethyl iodide initially added }
\end{aligned}
$$

with subscript designations being

$$
\begin{aligned}
\text { ep } & =\text { ethyl propionate } \\
\text { pa } & =\text { propionic acid } \\
\text { pan } & =\text { propionic anhydride } \\
\text { ei } & =\text { ethyl iodide }
\end{aligned}
$$

The molar quantities were plotted against time, and the reaction displayed an essentially linear behavior from about 20 min into the reaction until the conversion of propionic acid approached $\sim 65$ to 70 percent, where the effects of dilution start to become apparent. (The 20-min "lag" is not due to an "initiation" period but represents the time it takes to replace the $\mathrm{H}_{2} / \mathrm{CO}$ gas mix within the autoclave with the reaction mixture of ethylene $/ \mathrm{CO} / \mathrm{H}_{2}$.) Therefore, the rate of the reaction (expressed as moles of propionic anhydride formed/kilogram of initial reaction solution/h) was easily determined by using a best fit slope of this plot until either the 5-h reaction 
period had expired or the conversion reached 65 percent. Experimental reaction orders for different components were determined from plots of rate as a function of each gas and catalyst component at varying levels using standard regression methods.

This apparatus and procedure allow access to studies of the effect of different gas components by changes in the gas composition. A purged system allows consistent gas compositions to be maintained above the reactor regardless of stoichiometry or a bias in the gas absorbed. Using conditions that displayed very high rates, the reactor system was tested for mass transfer limitations by adjusting the stirring rate of the autoclave. It was found that, with this equipment, mass transfer limitations typically were observed when rates exceeded $4 \mathrm{~mol} / \mathrm{kg} / \mathrm{h}$, representing $8 \mathrm{~mol}$ of gas absorbed/kg solution/h. Therefore, kinetic measurements within this report have been limited to reactions not exceeding $3.5 \mathrm{~mol} / \mathrm{kg} \cdot \mathrm{h}$ to avoid introducing mass transfer limitations.

\subsubsection{Generation of Propionic Acid $\left[\mathrm{CH}_{3} \mathrm{CH}_{2} \mathrm{COOH}\right]$}

The same apparatus and general procedure were used for the generation of propionic acid as were used for the generation of propionic anhydride, except that the process was run at $190{ }^{\circ} \mathrm{C}$ and the propionic acid was replaced with a mixture of $81 \mathrm{~g}(4.5 \mathrm{~mol}) \mathrm{H}_{2} \mathrm{O}$ and $450 \mathrm{~g}(7.5 \mathrm{~mol})$ acetic acid $(\mathrm{AcOH})$. (The $\mathrm{AcOH}$ is present as both solvent and internal standard.) The liquid samples obtained were analyzed for ethyl acetate, ethyl propionate, acetic acid, and propionic acid by GC. (The analysis uses the same GC, GC column, and internal standard as the propionic anhydride process.) Molar quantities of propionyl units generated were calculated by the following equation:

$$
\mathrm{n}_{\mathrm{p}}=\frac{\left[\left(\mathrm{X}_{\mathrm{pa}} / 74\right)+\left(\mathrm{X}_{\mathrm{ep}} / 102\right)\right] \cdot \mathrm{n}_{\mathrm{a}}^{\mathrm{o}}}{\left[\left(\mathrm{X}_{\mathrm{ea}} / 88\right)+\left(\mathrm{X}_{\mathrm{aa}} / 60\right)\right]}
$$

where

$$
\begin{aligned}
\mathrm{n} & =\text { moles } \\
\mathrm{X} & =\text { weight fraction (obtained from } \mathrm{GC} \text { analysis) } \\
\mathrm{n}_{\mathrm{p}} & =\text { total moles of propionyl products }=\Sigma \text { propionic acid }+ \text { ethyl propionate } \\
\mathrm{n}_{\mathrm{a}} & =\text { moles of acetyl initially present }=\text { acetic acid added at start }
\end{aligned}
$$

with subscript designations being

$$
\begin{aligned}
& \text { ep }=\text { ethyl propionate } \\
& \text { pa }=\text { propionic acid } \\
& \text { ea }=\text { ethyl acetate } \\
& \text { aa }=\text { acetic acid }
\end{aligned}
$$




\subsection{TASK 2-CONDENSATION CATALYSTS}

\subsubsection{Catalyst Preparation}

3.2.1.1 V-Si-P Catalysts. The V-Si-P ternary catalysts were prepared with different ratios of the constituent atoms, following the procedure of $\mathrm{Ai}$ [11-13]. For example, V-Si-P catalyst with an atomic ratio of 1:12:2.8 was prepared as follows: $23.4 \mathrm{~g} \mathrm{NH}_{4} \mathrm{VO}_{3}$ was dissolved in $100 \mathrm{~mL}$ of hot water containing $20 \mathrm{~mL}$ of lactic acid, and $64.4 \mathrm{~g}$ of 85 percent $\mathrm{H}_{3} \mathrm{PO}_{4}$ was dissolved in $100 \mathrm{~mL}$ of hot water. The two solutions were added to $480 \mathrm{~g}$ of DuPont Ludox colloidal silica (Ludox SM-30), containing $30 \mathrm{wt} \%$ silica in water. Excess water was evaporated by stirring. The cake obtained was dried in an oven gradually heating from 50 to $200{ }^{\circ} \mathrm{C}$, at the rate of $1{ }^{\circ} \mathrm{C} / \mathrm{min}$. The resulting solid was crushed to an 8- to 20 -mesh size portion and further calcined in air at $350{ }^{\circ} \mathrm{C}$ for $4 \mathrm{~h}$ and then again at $450{ }^{\circ} \mathrm{C}$ for $6 \mathrm{~h}$.

3.2.1.2 Ta Catalysts. The Ta catalysts were prepared using two silica supports, a Davison G-59 silica support and a NALCO-1034A colloidal silica support, using conventional metal salt impregnation.

3.2.1.3 Nb-Si Catalysts. Nb-Si catalysts with a metal-to-silicon atomic ratio of 1:99, 2:98, $5: 95,10: 90$, and 20:80 were prepared as follows: calculated amounts of metal precursor $\left(\mathrm{NbF}_{5}\right)$ were slowly added to preweighed silica solution $\left(36 \mathrm{wt} \%\right.$ in $\mathrm{H}_{2} \mathrm{O}$, NALCO colloidal silica 1034-A). The resulting solution was then heated gradually, with stirring, to drive off water. The mixtures were calcined at $300{ }^{\circ} \mathrm{C}$ for $4 \mathrm{~h}$ and then at $450{ }^{\circ} \mathrm{C}$ for $6 \mathrm{~h}$. Catalysts thus obtained were crushed and screened to a 16- to 25 -mesh size $(0.707$ to $1.19 \mathrm{~mm}$ for testing) and a $<25$-mesh size $(<0.707 \mathrm{~mm})$ for characterization.

\subsubsection{Catalyst Testing}

The V-Si-P and Ta catalysts were tested in a continuous-flow-type reaction apparatus (Figure 6). A charge of 15, 10, and $5 \mathrm{~g}$ catalyst was used for comparative experiments. This corresponded to the space velocities of 290,600, and $900 \mathrm{cc} / \mathrm{g}$ cat $\cdot \mathrm{h}$. The nominal flow rates of propionic anhydride, formaldehyde, and nitrogen were kept at 40, 20, and $220 \mathrm{mmol} / \mathrm{h}$. The actual flow rates varied slightly, and exact values are reported in Results and Discussion. For propionic acid and methyl propionate feeds, the mole ratio of the propionyl to formaldehyde was approximately $4: 1$, if not otherwise specified. The feed was prepared by dissolving 1,1,1-trioxane (a trimmer of formaldehyde, solid at room temperature) into the propionyl, which was then fed to a preheater using a syringe pump (ATI Orion SAGE M361). The vaporized feed was passed over the catalyst charge, located centrally in a $6-\mathrm{mm} \mathrm{ID} \times 356-\mathrm{mm}$ L SS 316 reactor tube. The catalyst charge was held in place by glass wool and beads. Both the preheater and the reactor were mounted horizontally in a Lindberg furnace (Blue M, Model \#TF55035A). A thermocouple mounted directly at the charge center provided temperature control and readout. The product vapors were cooled in an impinger with isopropanol controlled at $-5{ }^{\circ} \mathrm{C}$ with a circulating chiller. Permanent gases were collected in a Tedlar bag. Both liquid and gaseous products were analyzed off-line. 
Figure 6. Fixed-bed reactor system for formalin as the source of formaldehyde.

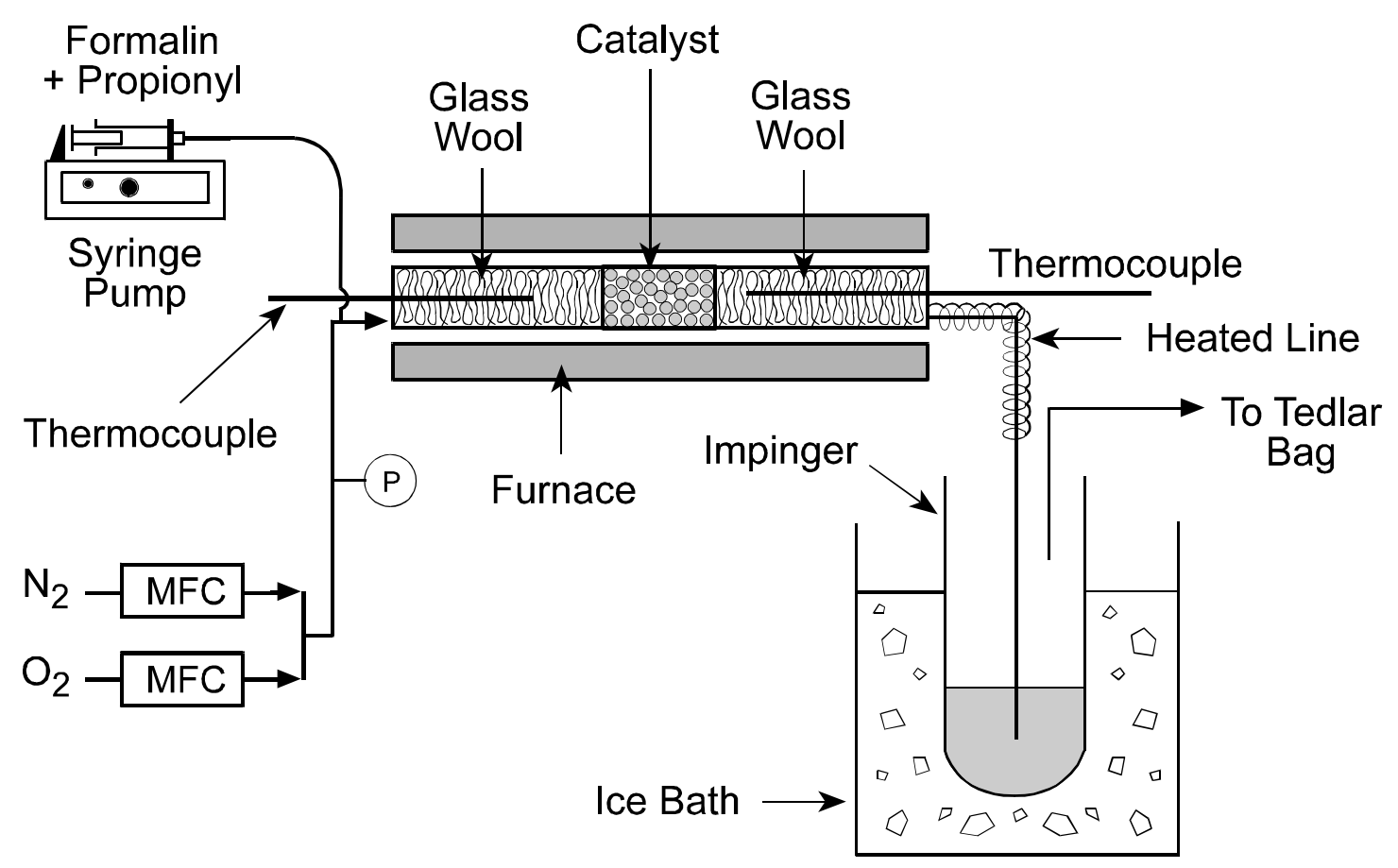

The fixed-bed microreactor system was modified extensively for use with formalin, with the addition of an ice bath and impinger. Isopropanol was used as a the impinger fluid for at least seven reaction species, including formaldehyde, water, methanol, propionic acid, diethyl ketone, methacrylic acid, and methyl propionate. A Tedlar bag was used for fixed-gas analysis, including $\mathrm{CO}, \mathrm{CO}_{2}$, and $\mathrm{N}_{2}$.

The nominal molar flow rates of propionic acid, formaldehyde, and nitrogen were identical for comparison between trioxane and formalin. Thus, while the nominal molar flow rates for HOPr:HCHO: $\mathrm{N}_{2}$ were at 72:16:220 $\mathrm{mmol} / \mathrm{h}$ for trioxane feed, the reactant feeds for the formalin case were $\mathrm{HOPr}: \mathrm{HCHO}: \mathrm{H}_{2} \mathrm{O}: \mathrm{CH}_{3} \mathrm{OH}: \mathrm{N}_{2}=72: 16: 38: 4: 220 \mathrm{mmol} / \mathrm{h}$. The experiments were carried out with a 10 percent $\mathrm{Nb} / \mathrm{SiO}_{2}$ catalyst (0.7- to $1.1-\mathrm{mm}$ size fraction), at $300{ }^{\circ} \mathrm{C}, 2 \mathrm{~atm}$, and in a fixed-bed microreactor system (Figure 6). For continuous long-term activity studies, a HPLC pump was used to deliver continuous feed to the reactor.

\subsubsection{Product Analysis}

For gas analysis, a Poropak $\mathrm{Q} /$ molecular sieve $5 \mathrm{~A}$ and a column isolation sequence in conjunction with a TCD were used for $\mathrm{CO}_{2}, \mathrm{O}_{2}, \mathrm{~N}_{2}, \mathrm{CH}_{4}$, and $\mathrm{CO}$ separation. For liquid analysis, a fused silica capillary column with a 1-mm film thickness of DB-wax was used, in conjunction 
with a flame ionization detector (FID). For additional separation of $\mathrm{HCHO}, \mathrm{H}_{2} \mathrm{O}$, methanol, and methyl propionate, a Poropak T column (80/100, 6-in. x 1/8-in. x 0.085- in.) with a TCD was used.

\subsubsection{Catalyst Characterization}

The surface area, pore volume, and acid-base properties of the catalysts were measured. The surface area and pore volume determinations were made on a Quantchrome NOVA 1000 BET-N ${ }_{2}$ surface area analyzer. The acid-base properties were determined using an ALTAMIRA AMI-100 catalyst characterization instrument. For measurement of acid sites and strength, $\mathrm{NH}_{3}$-temperature-programmed desorption (TPD) was used. A 10 percent $\mathrm{NH}_{3}-\mathrm{N}_{2}$ gas mixture was used as the treatment for adsorbing gas. A nominally identical charge of $150 \mathrm{mg}$ of catalyst sample was used for all measurements. $\mathrm{NH}_{3}$ adsorption was carried out with 10 percent $\mathrm{NH}_{3}-\mathrm{N}_{2}$ gas mixture $(25 \mathrm{~mL} / \mathrm{min})$ for $30 \mathrm{~min}$ at $50{ }^{\circ} \mathrm{C}$. The desorption was carried out from 50 to $500{ }^{\circ} \mathrm{C}$ at $10^{\circ} / \mathrm{min}$. The TCD response was continuously monitored. For basicity measurements, an identical temperature, time, and flow profile was followed, except a 10 percent $\mathrm{CO}_{2}-\mathrm{N}_{2}$ gas mixture was used as the treatment gas.

X-ray diffraction (XRD) and X-ray photoelectron spectroscopy (XPS) were used to examine fresh and used niobium catalysts to determine possible deactivation causes. XRD measurements were made using a Philips X'pert System X-ray diffractometer with mino-chromatized radiation. The XRD instrument spectra were scanned between $10^{\circ}$ and $80^{\circ}$ [20] at the rate of $2.4^{\circ} / \mathrm{min}$. XPS measurements were made on a Physical Electronics Model 5400 ESCA spectrometer using a monochromated AI Ka source. Survey spectra were measured at a pass energy of $89 \mathrm{eV}$ while higher resolution spectra of specific regions were measured at $35 \mathrm{eV}$. Samples were mounted on AI adhesive tape.

\subsection{TASK 3-SLURRY REACTOR STUDIES}

The third task focuses on the in-situ condensation catalysis of methanol, oxygen, and propionic acid in a slurry reactor. RTI has designed, assembled, and constructed a high-temperature, highpressure( HTHP) slurry reactor system for Task 3. A 50-mL stirred autoclave from Autoclave Engineers (Erie, PA) was used. The feed and product section instrumentation of the system are sketched in Figures 7 and 8. The entire unit is sketched in Figure 9. The condition for the tests were $20 \mathrm{~mL}$ decalin, $1 \mathrm{~g}$ catalyst charge $(\mathrm{Fe} / \mathrm{Mo}+\mathrm{V} / \mathrm{Si} / \mathrm{P}), 300{ }^{\circ} \mathrm{C}, 20 \mathrm{~atm}, 500 \mathrm{rpm}$, and 150:150:200:200 $\mathrm{mmol} / \mathrm{h}$ propionic acid:methanol:nitrogen:oxygen. 
Figure 7. RTI-Eastmen slurry reactor system-feed section instrumentation.

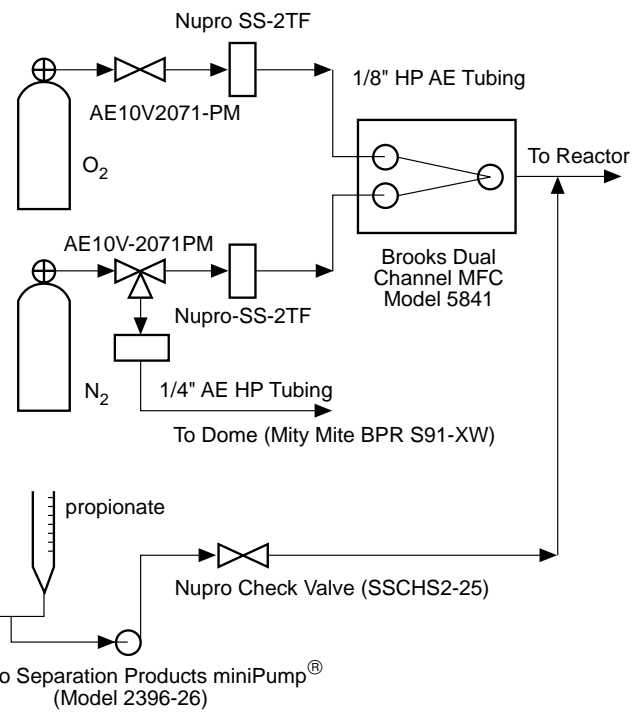

Figure 8. RTI-Eastman slurry reactor system-product section instrumentation.

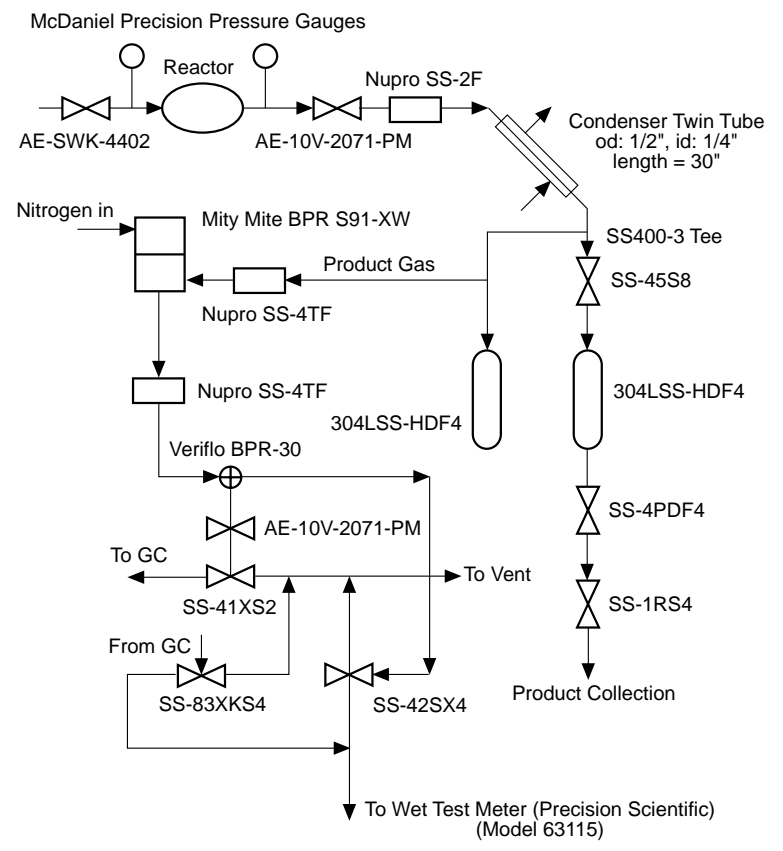


Figure 9. RTI-Eastman slurry reactor system-flow diagram.

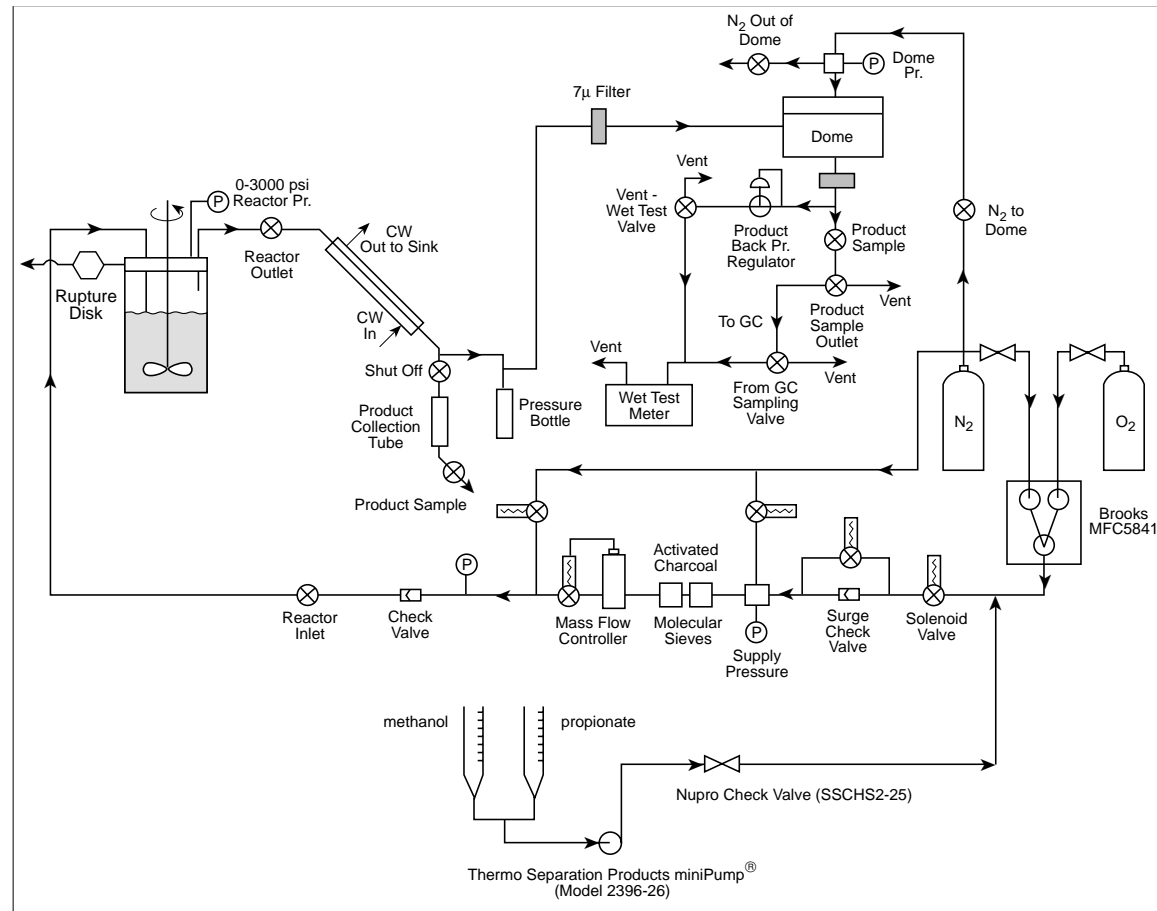

\subsection{TASK 5-DME CONDENSATION STUDY}

The experimental system of the DME condensation study is similar to the system described in Section 3.2.2. A certified gas mixture, containing 2 percent DME and 2 percent $\mathrm{O}_{2}$ in $\mathrm{N}_{2}$, and propionic acid or methyl propionate were used for in-situ partial oxidation and condensation. Both gas and liquid products were collected and analyzed according to the procedures in Sections 3.2.2 and 3.2.3.

For DME partial oxidation study, 0.1 percent DME, 0.1 percent $\mathrm{O}_{2}$, and balance nitrogen purchased from National Welders is used. Total flow of $100 \mathrm{cc} / \mathrm{min}$ of reactant mixture is passed over $5 \mathrm{~g}$ of 5 percent $\mathrm{Nb}_{2} \mathrm{O}_{5} / \mathrm{SiO}_{2}$ catalysts with reaction temperature ranging from 200 to $500{ }^{\circ} \mathrm{C}$. The products are collected with $15 \mathrm{ml}$ of isopropanol at $-5{ }^{\circ} \mathrm{C}$ and a Tedlar bag. Because the concentration of DME is low with 0.1 percent, the product collection periods were extended to 3 to $5 \mathrm{~h}$ to collect detectable formaldehyde. Both liquid and gaseous products are analyzed with GC-FID and GC-TCD. 


\section{RESULTS AND DISCUSSION}

\subsection{TASK 1-PROPIONATE SYNTHESIS}

\subsubsection{General Description of the Catalyst}

The homogeneous catalyst system for the reaction $\mathrm{CO}+\mathrm{C}_{2} \mathrm{H}_{4}+\mathrm{H}_{2} \mathrm{O} \rightarrow \mathrm{CH}_{3} \mathrm{CH}_{2} \mathrm{COOH}$ requires a Group 6 metal, a halide salt, and an organic halide. (Obviously, materials that generate the organic halide or the halide salt in-situ may be used as well.) Ratios of the components are not critical, although each component enters the rate equation. Table 2 shows that the observed order of reactivity for the Group 6 metal component is $\mathrm{Mo}>>\mathrm{W} \approx \mathrm{Cr}$. The halide may be either $\mathrm{Br}$ or I. (Presumably the chloride would also be useful, but the volatility and toxicity of $\mathrm{EtCl}$ precluded it from our investigation.) The metal catalyst is $\mathrm{Mo}(\mathrm{CO})_{6}$, which is a readily available, inexpensive, and easily handled (albeit highly toxic) solid. (The Mo oxides, the only other low-cost source of Mo, do not readily generate active catalysts.)

Table 2. Comparison of Different Halides and Group 6 Metal Hexacarbonyl Catalysts for the Carbonylation of Ethylene to Propionic Anhydride

\begin{tabular}{ccccc}
\hline Metal carbonyl & Halide & $\begin{array}{c}\mathrm{Bu}_{4} \mathrm{P}^{+} \text {Salt } \\
(\mathbf{m m o l})\end{array}$ & Rate & $\begin{array}{c}\text { Turnover } \\
\text { number }\end{array}$ \\
\hline $\mathrm{Mo}(\mathrm{CO})_{6}$ & $\mathrm{I}$ & 40 & 1.39 & 41 \\
$\mathrm{Mo}(\mathrm{CO})_{6}$ & $\mathrm{Br}$ & 40 & 1.04 & 31 \\
$\mathrm{Mo}(\mathrm{CO})_{6}$ & $\mathrm{I}$ & 72 & 2.22 & 71 \\
$\mathrm{Cr}(\mathrm{CO})_{6}$ & $\mathrm{I}$ & 72 & 0.18 & 6 \\
$\mathrm{~W}(\mathrm{CO})_{6}$ & $\mathrm{I}$ & 72 & 0.14 & 5 \\
\hline
\end{tabular}

Conditions: Metal hexacarbonyl, $22 \mathrm{mmol}$; EtX (X-halide), $0.7 \mathrm{~mol}$; EtCOOH, 7.5 mol; $\mathrm{Bu}_{4} \mathrm{PX}$ (quantity as indicated), $160{ }^{\circ} \mathrm{C}, 55 \mathrm{~atm}$. Gas composition: $5 \% \mathrm{H}_{2}$, $45 \% \mathrm{C}_{2} \mathrm{H}_{4}, 50 \% \mathrm{CO}$. Rate $=\mathrm{mol}(\mathrm{EtCO})_{2} \mathrm{O} / \mathrm{kg}$ initial solution $/ \mathrm{h}$; turnover number $=\mathrm{mol}(\mathrm{EtCO})_{2} \mathrm{O} / \mathrm{mol}$ metal carbonyl $/ \mathrm{h}$.

The CO partial pressure and temperature are critical parameters. As described in Section 2.1, the reaction rate is most rapid at the lowest pressures consistent with catalyst stability and adequate mass transfer of the gas components. At $160{ }^{\circ} \mathrm{C}$, the apparent minimum $\mathrm{CO}$ partial pressure is around 10 to $15 \mathrm{~atm}$. Lower pressures lead to loss of catalyst activity and higher pressures are required as the temperature is elevated. It is useful to include $\mathrm{H}_{2}$ in the process. The addition of $\mathrm{H}_{2}$ accelerates the initial reaction rate and maintains the reaction rate. In the absence of added $\mathrm{H}_{2}$, the initial reaction rate is $\sim 30$ percent slower and becomes increasingly slower as time proceeds. However, in the absence of added $\mathrm{H}_{2}$, the reaction generates significant amounts of $\mathrm{H}_{2}$ spontaneously.

The behavior of the catalyst changes significantly with different nucleophilic components. Figure 10 shows that a typical Mo catalyzed process in which propionic acid is added to generate propionic anhydride (i.e., $\mathrm{R}=\mathrm{EtCO}$ in Equation [11]) yields a nearly linear production of 
Catalyst composition: Etl, $0.7 \mathrm{~mol} ; \mathrm{Mo}(\mathrm{CO})_{6}, 22 \mathrm{mmol} ; \mathrm{Bu}_{4} \mathrm{PI}$, $40 \mathrm{mmol}$. Gas composition and pressure: $5 \% \mathrm{H}_{2}, 50 \% \mathrm{C}_{2} \mathrm{H}_{4}$, 45\% CO; $55 \mathrm{~atm}$, temperature/reactants/solvent: (a) propionic acid (EtCOOH) process: $190{ }^{\circ} \mathrm{C}, 4.5 \mathrm{~mol} \mathrm{H} \mathrm{H}_{2} \mathrm{AcOH}, 7.5 \mathrm{~mol}$ (solvent); (b) propionic anhydride $\left([\mathrm{EtCO})_{2} \mathrm{O}\right.$ ) process, $160{ }^{\circ} \mathrm{C}$, $7.5 \mathrm{~mol} \mathrm{EtCOOH}$ (no solvent).

\section{Figure 10. Comparison of Mo catalyzed processes for} propionic acid and propionic anhydride.

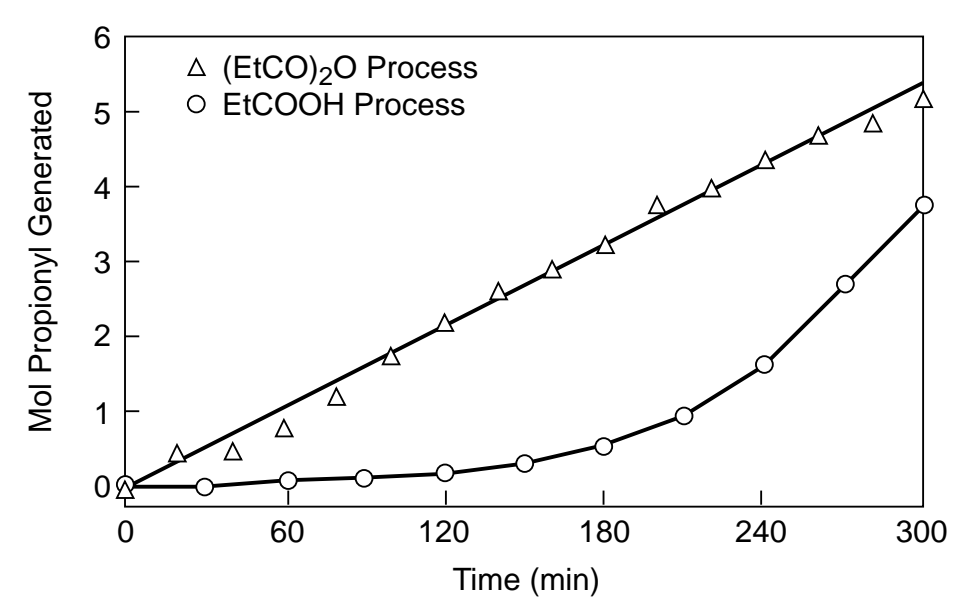

propionic anhydride over a large time span. However, when water is substituted as the primary nucleophile ( $\mathrm{R}=\mathrm{H}$ in Equation [11]), the reaction is initially slow but accelerates as the reaction proceeds. (Similar observations are made if methanol is added to attempt to generate methyl propionate.)

Further, the catalyst does not promote the carbonylation of nonolefinic substrates. For example, attempted carbonylations of methanol, methyl acetate, benzyl alcohol, and benzyl acetate proceed very slowly, if at all. Olefins other than ethylene undergo carbonylation but proceed at slower rates yielding a mixture of carboxylic acid isomers. The unique nature of this catalyst system and the peculiar behavior as the nucleophiles were altered prompted a detailed study of the Mo catalyzed process. This study focused on the propionic anhydride process due to its apparently simpler kinetic behavior.

\subsubsection{Mo Catalyzed Carbonylation of Ethylene to Propionic Anhydride}

When the process is operated with a catalyst composed of $\mathrm{Bu}_{4} \mathrm{PI}, \mathrm{Mo}(\mathrm{CO})_{6}$, and EtI, the Mo catalyzed carbonylation of ethylene to propionic anhydride proceeds smoothly, with a near-linear generation rate, until a 75 to 85 percent conversion of the propionic acid is achieved, at which point the reaction begins to slow. A typical reaction profile for this process appears in Figure 11. The ultimate reaction rates attainable in this process were limited not by catalyst performance but by mass transfer of the gaseous reactants into the reaction medium. The following observations are important in reaching a mechanistic understanding of this unique process. 
Initial composition: Etl, $0.7 \mathrm{~mol}$; EtCOOH, $7.5 \mathrm{~mol}$; $\mathrm{Mo}(\mathrm{CO})_{6}$, $22 \mathrm{mmol} ; \mathrm{Bu}_{4} \mathrm{PI}, 40 \mathrm{mmol}$. Conditions: $160{ }^{\circ} \mathrm{C}, 55 \mathrm{~atm}$. Gas compositions: $5 \% \mathrm{H}_{2}, 50 \% \mathrm{C}_{2} \mathrm{H}_{4}, 45 \% \mathrm{CO}$.

\section{Figure 11. Reaction profile for the carbonylation of ethylene to propionic anhydride.}

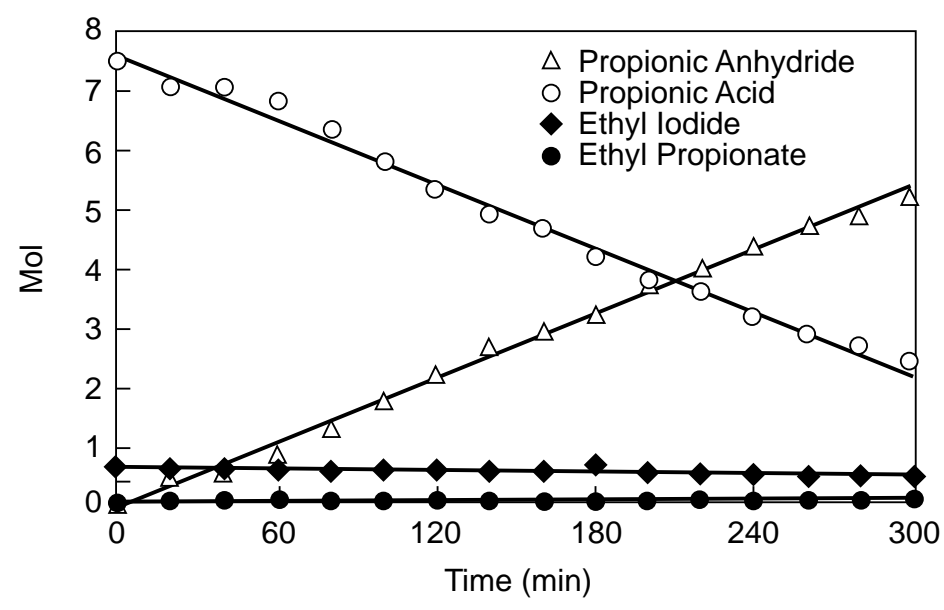

4.1.2.1 Byproducts. The main byproduct in this process is ethyl propionate, likely generated by the acid catalyzed addition of propionic acid to ethylene or nucleophilic displacement of iodide from ethyl iodide. It is generally around 1 percent of the reaction mixture, never exceeds 2 percent of the product mixture, often decreases as the conversion rises, and is a likely substrate for further reaction to propionic anhydride. More informative is the identification of trace byproducts. In the $\mathrm{Bu}_{4} \mathrm{PI}-\mathrm{Mo}(\mathrm{CO})_{6}$-EtI catalyzed system as shown in Figure 12, traces of 3-oxo-4-hexyl propionate (compound 1), 3-oxo-4-hexenyl propionate (compound 2), 5-ethyl-2-oxo-1,5-dihydrofuran (compound 3), and 1,1-propyl dipropionate (compound 4) are observed in the GC-MS. Compounds 1 and 2 were likely derived via known chemistry from 3,4-hexane dione [15], the coupling product of a propionyl radical. This suggested the possibility of a radical pathway. (Compound 3 is likely formed by a second sequential ethylene and $\mathrm{CO}$ insertion into a Mo-C(=O)Et moiety.) One key observation is that neither diethyl ketone or ethane are detected.

4.1.2.2 The Effect of the Nature of Cation and Halide. The nature of the cation incorporated in the salt component is important but not completely understood. A variety of materials was tested and differences are evident in Table 2. (Omitted from Table 1 is an entry for LiI, which gives an initial small quantity of product but was incapable of sustaining the reaction for even an hour. Therefore, rates were not readily attainable with this salt.) It was initially presumed that the phosphines and amines in this study underwent alkylation by reaction with ethyl iodide to form the corresponding quaternary salt. Subsequent ${ }^{1} \mathrm{H},{ }^{13} \mathrm{C}$, and ${ }^{31} \mathrm{P}$ nuclear magnetic resonance (NMR) studies of the product indicated that this was true for all the monophosphines, and the amines were primarily protonated species. However, for the diphosphines (entries 19-22), there is 


\section{Figure 12. Schematic of the $\mathrm{Bu}_{4} \mathrm{PI}-$ $\mathrm{Mo}(\mathrm{CO})_{6}$-Etl catalyzed system.}

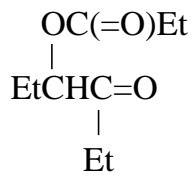

1

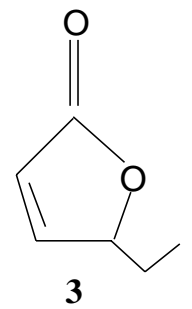

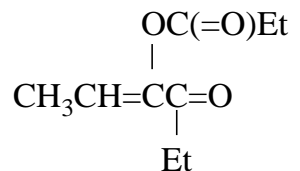

2

$\mathrm{EtCH}(\mathrm{OC}(=\mathrm{O}) \mathrm{Et})_{2}$

4

no evidence of a diagnostic ethyl group bound to phosphorous, except in the case of 1,5-bisdiphenylphosphino-pentane (entry 22).

There is a marked bias toward salts based on $\mathrm{N}$ and $\mathrm{P}$ (added either as the salt or generated in-situ), and the possibility that there was some free phosphine or amine ligand present that altered Mo activity had to be considered. However, in the above-mentioned NMR studies, there is no exchange of alkyl groups (ethyl for butyl) or free phosphine when $\mathrm{Bu}_{4} \mathrm{PI}$ was used (entry 1). Further, there is no direct evidence of a ligated Mo carbonyl species in the in-situ infrared studies (Section 4.1.2.3 below). Therefore, despite the attractiveness of this hypothesis, there is no evidence to support a Mo species with either an N- or P-based ligand, at least when using the mondentate precursors.

Table 3 shows that substitution of bromine for iodine leads to only a small change ( 25 percent decrease) in reaction rate. This relative insensitivity to the nature of the halide suggests an electron transfer process[16].

4.1.2.3 In-situ Infrared Spectroscopic Studies. An in-situ infrared spectroscopic study of $\mathrm{Mo}(\mathrm{CO})_{6}$ with a $\mathrm{Bu}_{4} \mathrm{PI}$ salt was undertaken by observing spectra as

- the catalyst mixture is heated to $160{ }^{\circ} \mathrm{C}$ under 7 to 8 atm of 5 percent $\mathrm{H}_{2}$ in $\mathrm{CO}$ and adjusted the final pressure to 24 atm with 5 percent $\mathrm{H}_{2}$ in $\mathrm{CO}$

- $\quad$ EtI is added

- ethylene is added (only a few spectra are attainable in this portion of the reaction as the $\mathrm{CO}$ is rapidly depleted upon initiating the reaction). 


\section{Table 3. Reaction Rates of Mo Species with Different} Salts

\begin{tabular}{|c|c|c|c|c|}
\hline \multicolumn{5}{|c|}{ 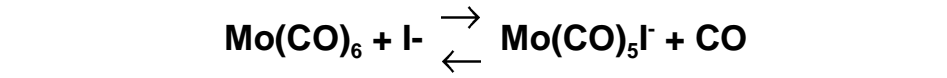 } \\
\hline Salt & Rate & $\mathrm{K}_{\mathrm{eq}}$ & {$\left[\mathrm{MO}(\mathrm{CO})_{6}\right]$} & $\left.\mathrm{Mo}(\mathrm{CO})_{5}\right]^{-1}$ \\
\hline $\mathrm{Nal}$ & 0.79 & ca.0 & 0.033 & 0 \\
\hline$\left[\mathrm{Bu}_{4} \mathrm{P}\right] \mathrm{I}$ & 1.39 & $39 \pm 1$ & 0.030 & 0.003 \\
\hline$[\mathrm{PyH}] \mathrm{I}$ & 2.20 & $21 \pm 3$ & 0.0315 & 0.0015 \\
\hline
\end{tabular}

$@ 0.033 \mathrm{M} \mathrm{Mo}$

for $\mathrm{Bu}_{4} \mathrm{Pl}: \Delta \mathrm{H}=+3.4 \mathrm{kcal} / \mathrm{mol} ; \Delta \mathrm{S}=+4.5 \mathrm{cal} / \mathrm{mol} / \mathrm{K}$

Using concentrations of reagents comparable to those in entry 1 in Table 2, the spectra of a mixture of $\mathrm{Mo}(\mathrm{CO})_{6}$ and $\mathrm{Bu}_{4} \mathrm{PI}$ maintained at $160{ }^{\circ} \mathrm{C}$ and $24 \mathrm{~atm}$ of 5 percent $\mathrm{H}_{2}$ in $\mathrm{CO}$ displayed a clear, strong peak at 1,985 to $1,986 \mathrm{~cm}^{-1}$ diagnostic of $\mathrm{Mo}(\mathrm{CO})_{6}$. Upon addition of EtI, a second, less prominent peak rapidly arose at 2,017 to $2,024 \mathrm{~cm}^{-1}$, which is likely assignable to the strongest peak for $\mathrm{Mo}(\mathrm{CO})_{4} \mathrm{I}_{3}{ }^{-}$(Lit.[Nujol] 2,038 [w], 2,018 [vs], 1,961[s], and 1,942 [s]) $[17,18]$. Under these conditions, the peak at 2,017 to $2,024 \mathrm{~cm}^{-1}$ is in the range of 5 to 20 percent that of the peak at $1,984 \mathrm{~cm}^{-1}$. (In experiments in which there is no hydrogen present, the peak at $2,017 \mathrm{~cm}^{-1}$ gradually becomes the predominant peak.) A third, very weak peak appeared at 1,933 to $1,937 \mathrm{~cm}^{-1}$, which is assignable to $\mathrm{Mo}(\mathrm{CO})_{5} \mathrm{I}[19,20]$.

To enhance the signal-to-noise ratio for the weaker bands, the process was repeated using two and three times the $\mathrm{Mo}(\mathrm{CO})_{6}$ and $\mathrm{Bu}_{4} \mathrm{PI}$ components. Under these conditions, the peak at 1,933 to $1,937 \mathrm{~cm}^{-1}$, assignable to $\mathrm{Mo}(\mathrm{CO})_{5} \mathrm{I}^{-}$, became considerably more prominent, and a peak at $\sim 2,065 \mathrm{~cm}^{-1}$ (corresponding to one of the weaker bands for $\mathrm{Mo}(\mathrm{CO})_{5} \mathrm{I}^{-}$) became observable. At the extreme concentrations, very weak bands at 2,007,2,024, and 2,001 cm $\mathrm{cm}^{-1}$ could also be discerned upon the addition of EtI and ethylene, which might correspond to a fourth unidentified component.

Based on a study of the relative ratios of the key peaks at 1,985 and $1,934 \mathrm{~cm}^{-1}$ as a function of pressure using high levels of $\mathrm{Mo}(\mathrm{CO})_{6}$ and $\mathrm{Bu}_{4} \mathrm{PI}$ and in the absence of EtI, the equilibrium constant for the reaction

$$
\mathrm{Mo}(\mathrm{CO})_{6}+\mathrm{I}^{-} \rightleftharpoons \mathrm{Mo}(\mathrm{CO})_{5} \mathrm{I}^{-}+\mathrm{CO}
$$

was estimated at $\sim 39 \mathrm{~atm}-\mathrm{kg} / \mathrm{mol}$ at $160{ }^{\circ} \mathrm{C}$. The same series of infrared experiments was repeated using first pyridine and then $\mathrm{NaI}$ in place of $\mathrm{Bu}_{4} \mathrm{PI}$. Table 3 shows the results for each of these runs and clearly indicates that the reaction rate is unrelated to the level of $\mathrm{Mo}(\mathrm{CO})_{5} \mathrm{I}^{-}$.

4.1.2.4 Kinetic Effects of Catalyst Components and Reactants. In the propionic anhydride generation, no effect on the reaction rate was assignable to the level of propionic acid present until $>75$ percent of the propionic acid had been converted to propionic anhydride. This 
simplified the kinetic investigation, and the effects of the gas components were measured as the first step in understanding this process.

Three gases were used: hydrogen, ethylene, and carbon monoxide. To measure kinetic effects, a continuously gas-purged autoclave equipped with a liquid sampling loop was employed. Using this apparatus, the partial pressure of each gas could be varied independently, without regard to the 1:1 CO:ethylene stoichiometry of the reaction, which would normally lead to rapid depletion of the limiting gas and still maintain a consistent gas mixture throughout the experiment.

The effect of hydrogen and ethylene (Figures 13 and 14) was insignificant. Whereas hydrogen is necessary, only a small amount is required and there is no kinetic effect beyond that imparted by the initial pressure. The infrared experiments suggests that the role of hydrogen is to maintain the catalyst as $\mathrm{Mo}(\mathrm{CO})_{6}$. In its absence, Mo is gradually oxidized to $\mathrm{Mo}(\mathrm{CO})_{4} \mathrm{I}_{3}^{-}$. Ethylene pressure has virtually no effect on the reaction rate (experimentally measured reaction order $=0.06$ ).

However, the role of carbon monoxide pressure, shown in Figure 15, is much more informative. The measured reaction order using the data in Figure 15 was $-1.17\left(\mathrm{R}^{2}=0.96\right)$. Given the inverse and complex $(>1)$ order dependence upon $\mathrm{CO}$ pressure, the process must involve a step (likely more than one given the complex order) that is inhibited by $\mathrm{CO}$.

It also suggests operating at considerably lower pressures. Consequently, faster reactions at pressures as low as 15 atm of $\mathrm{CO}$ were demonstrated. However, at much lower $\mathrm{CO}$ pressures (using 1:1 CO:ethylene feeds), the reaction rates became erratic and the activity rapidly decreased. The high-pressure infrared spectroscopic experiments indicated that $\mathrm{Mo}(\mathrm{CO})_{6}$ was still stable at these lower pressures, although the amount converted to $\mathrm{Mo}(\mathrm{CO})_{5} \mathrm{I}^{-}$rapidly rises. This conversion of $\mathrm{Mo}(\mathrm{CO})_{6}$ to $\mathrm{Mo}(\mathrm{CO})_{5} \mathrm{I}^{-}$and mass transfer limitations (found to be responsible for the erratic rate behavior) at these low pressures probably combine to establish the lower limit of desirable $\mathrm{CO}$ partial pressures at somewhere between 10 and $15 \mathrm{~atm}$ with existing equipment.

Given the above results, it was necessary to control the $\mathrm{CO}$ partial pressure precisely throughout the remainder of the kinetic study. To do this, each gas mix was analyzed immediately prior to use and the $\mathrm{CO}$ was set at a constant level of 23.8 atm, ignoring any minor fluctuations in ethylene and hydrogen composition as they had little or no effect upon the reaction rate. Using this approach, the kinetic effect of Mo, ethyl iodide, and $\mathrm{Bu}_{4} \mathrm{PI}$ levels was studied.

The effect of $\mathrm{Mo}(\mathrm{CO})_{6}$ and ethyl iodide levels, which are displayed in Figures 16 and 17, respectively, were both complex. The experimentally measured reaction order for $\mathrm{Mo}(\mathrm{CO})_{6}$ using the data displayed in Figure 16 was $0.62\left(\mathrm{R}^{2}=0.99\right)$. Whereas the experimental data for Mo was fairly consistent, the response to ethyl iodide was somewhat more complex. Initially determined experimental orders were 0.52 , but with a mediocre statistical fit $\left(\mathrm{R}^{2}=0.92\right)$. The general form of the reaction was consistent with a catalyst approaching saturation. The dependence upon EtI (with all other variables held constant) was consistent with the general form 
Figure 13. Effect of hydrogen partial pressure.

Initial composition: Etl, $0.7 \mathrm{~mol}$; EtCOOH, $7.5 \mathrm{~mol}$; $\mathrm{Mo}(\mathrm{CO})_{6}$, $22 \mathrm{mmol} ; \mathrm{Bu}_{4} \mathrm{PI}$, $40 \mathrm{mmol}$. Conditions: $160{ }^{\circ} \mathrm{C}$, pressures: ethylene, $27.2 \mathrm{~atm}$; CO, $23.8 \mathrm{~atm}$.

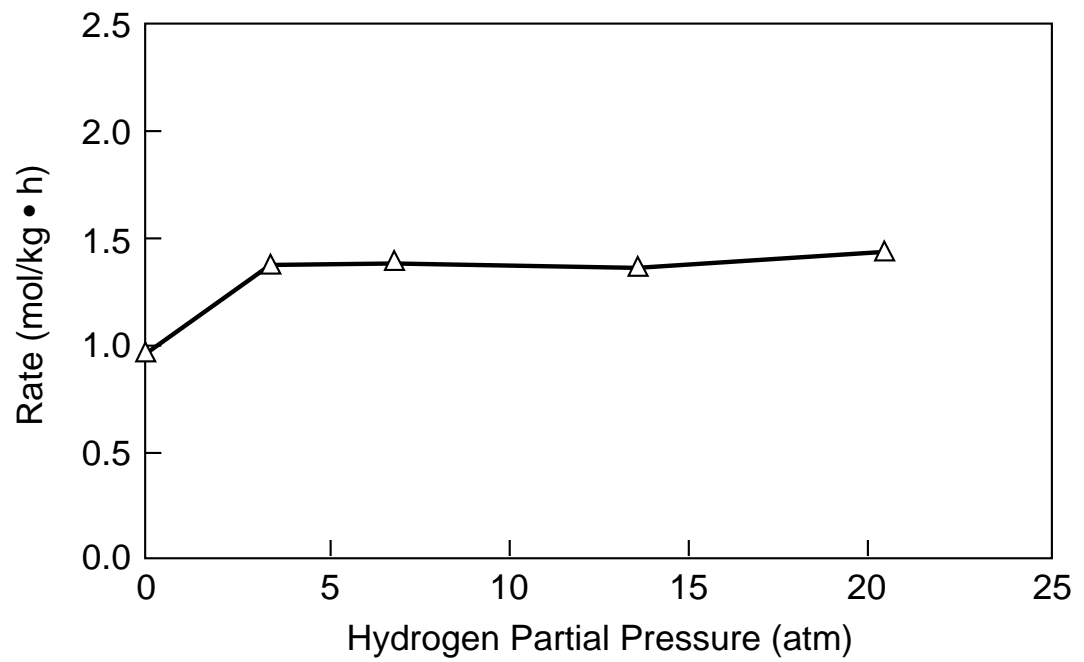

Figure 14. Effect of ethylene partial pressure.

Initial composition: Etl, $0.7 \mathrm{~mol}$; EtCOOH, $7.5 \mathrm{~mol}$; $\mathrm{Mo}(\mathrm{CO})_{6}$, $22 \mathrm{mmol} ; \mathrm{Bu}_{4} \mathrm{Pl}$, 40 mmol. Conditions: $160{ }^{\circ} \mathrm{C}$, pressures: $\mathrm{H}_{2}, 3.4 \mathrm{~atm}$; $\mathrm{CO}, 23.8 \mathrm{~atm}$.

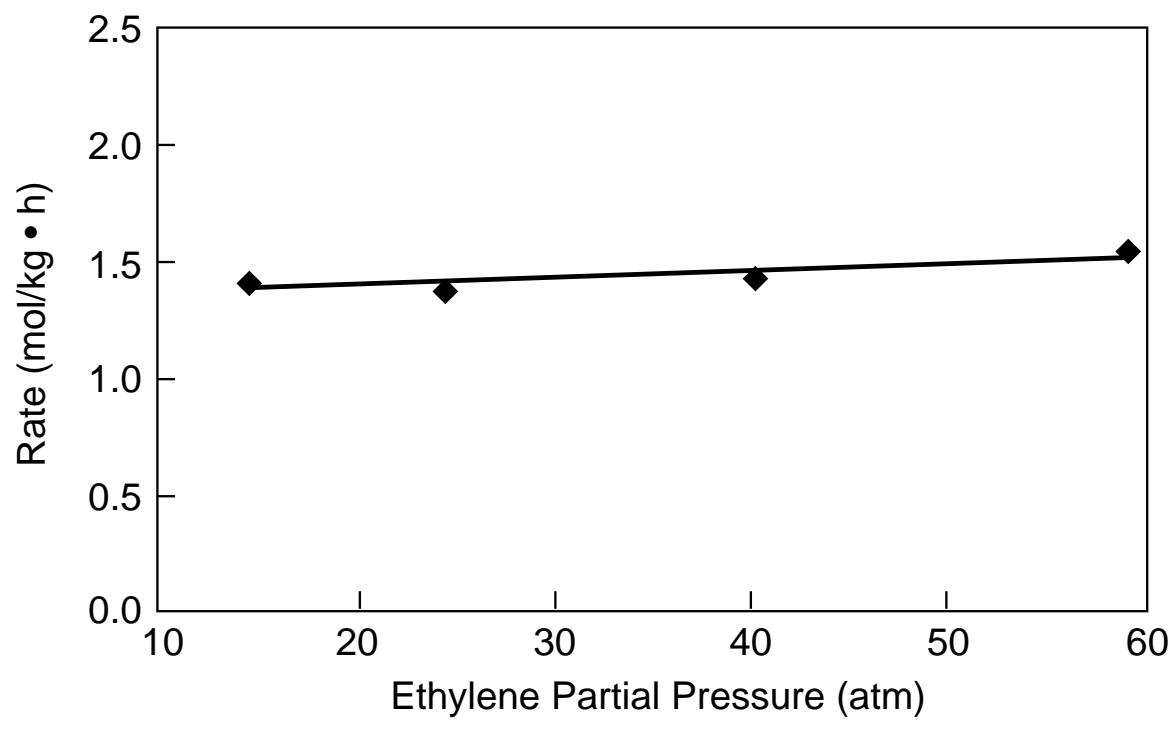


Figure 15. Effect of $\mathrm{CO}$ partial pressure.

Initial composition: Etl, $0.7 \mathrm{~mol}$; $\mathrm{EtCOOH}, 7.5 \mathrm{~mol}$; $\mathrm{Mo}(\mathrm{CO})_{6}, 22 \mathrm{mmol}$; $\mathrm{Bu}_{4} \mathrm{PI}$, $40 \mathrm{mmol}$. Conditions: $160^{\circ} \mathrm{C}$, pressures: ethylene, $27.2 \mathrm{~atm} ; \mathrm{H}_{2}, 3.4 \mathrm{~atm}$.

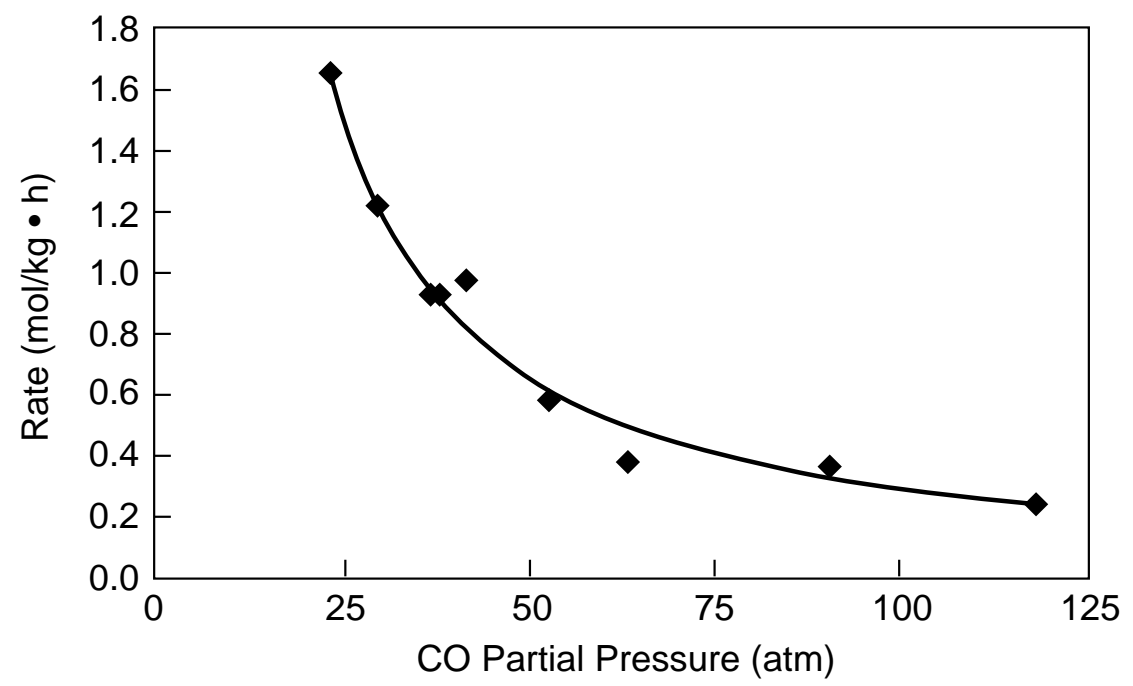

Figure 16. Effect of $\mathrm{Mo}(\mathrm{CO})_{6}$ levels.

Initial composition: Etl, $0.7 \mathrm{~mol}$; EtCOOH, $7.5 \mathrm{~mol}^{\circ} \mathrm{Bu}_{4} \mathrm{Pl}, 40 \mathrm{mmol}$. Conditions: $160{ }^{\circ} \mathrm{C}$, pressures: ethylene, $27.2 \mathrm{~atm} ; \mathrm{CO}, 23.8 \mathrm{~atm} ; \mathrm{H}_{2}, 3.4 \mathrm{~atm}$.

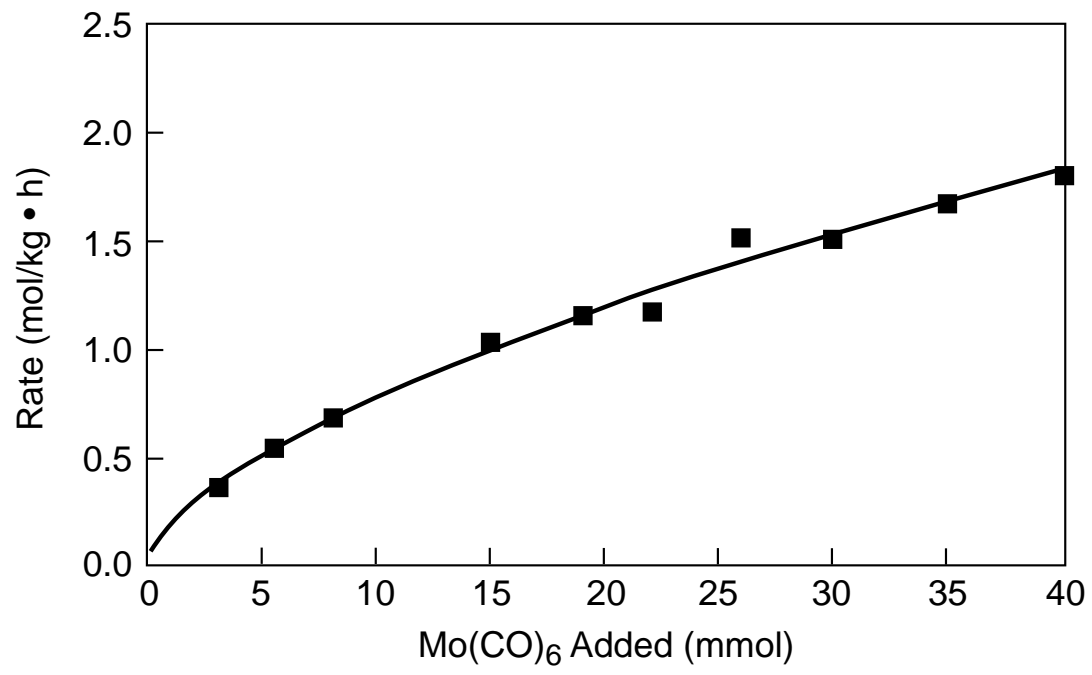


Figure 17. Effect of Etl levels.

Initial composition: $\mathrm{EtCOOH}, 7.5 \mathrm{~mol} ; \mathrm{Mo}(\mathrm{CO})_{6}, 22 \mathrm{mmol} ; \mathrm{Bu}_{4} \mathrm{PI}, 40 \mathrm{mmol}$. Conditions: $160{ }^{\circ} \mathrm{C}$, pressures: ethylene, $27.2 \mathrm{~atm} ; \mathrm{CO}, 23.8 \mathrm{~atm} ; \mathrm{H}_{2}, 3.4 \mathrm{~atm}$.

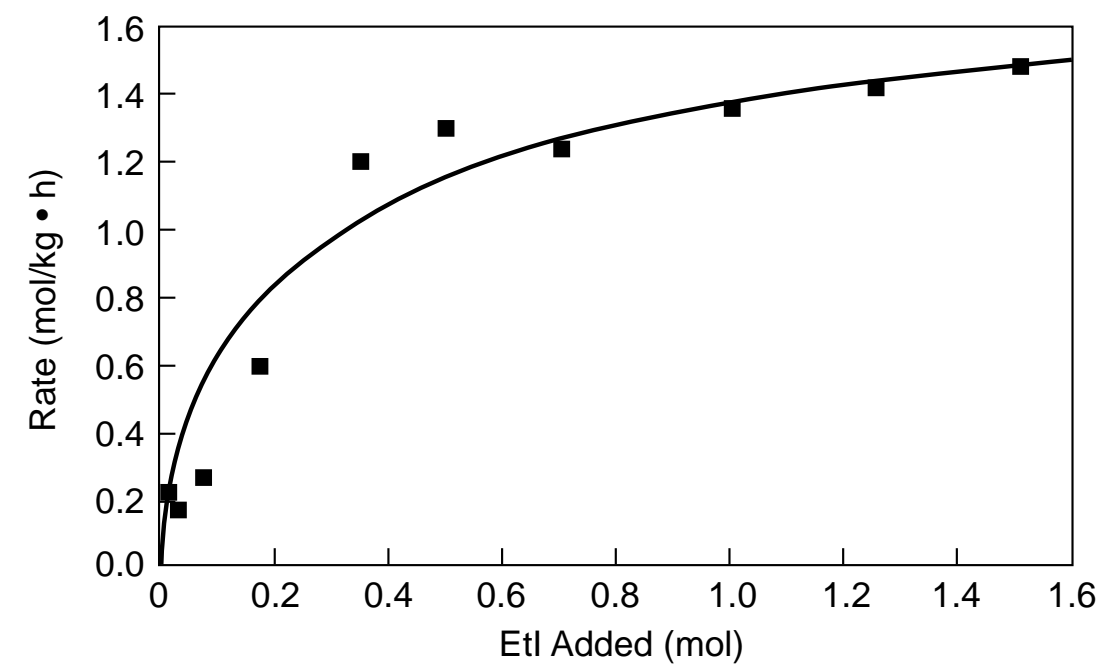

$$
\text { Rate }=\frac{\mathrm{C}_{1}\left[\mathrm{EtI}_{\mathrm{added}}\right]^{1 / 2}}{\left(\mathrm{C}_{2}+\left[\mathrm{EtI}_{\mathrm{added}}\right]\right)^{1 / 2}}
$$

The curve displayed on Figure 17 is fit to this equation where $\mathrm{C}_{1}$ and $\mathrm{C}_{2}$ have been estimated as 1.83 and 0.78 , respectively. The kinetic behavior of the iodide salt levels was much less complex. Figure 18 shows that the reaction is first order $\left(\mathrm{R}^{2}=0.98\right)$ with respect to the level of $\mathrm{Bu}_{4} \mathrm{PI}$ added. The approximately one-half order behaviors of EtI and $\mathrm{Mo}(\mathrm{CO})_{6}$ are indicative of a free radical reaction. In addition, the first order behavior of iodide indicates that it is involved in a key product generation step in the reaction sequence.

\subsubsection{Effects of Temperature, Determination of Activation Parameters. The effect of} temperature was measured between 130 and $170{ }^{\circ} \mathrm{C}$ using identical levels of gas and catalyst components throughout the full range of temperatures. The activation energy $\left(\mathrm{E}_{\mathrm{act}}\right)$ was determined from an Arrhenius plot (Figure 19, $\mathrm{R}^{2}=0.99$ ) and found to be $39.3 \mathrm{kcal} / \mathrm{mol}$. Enthalpy and entropy of activation ( $\Delta \mathrm{H} \neq$ and $\Delta \mathrm{S} \neq$, respectively) could be determined either from the Arrhenius plot or an Eyring plot $(\ln (\mathrm{k} / \mathrm{T})$ vs. $1 / \mathrm{T})$. Although the rate orders were complex with 
Figure 18. Effect of $\mathrm{Bu}_{4} \mathrm{PI}$ levels.

Initial composition: Etl, $0.7 \mathrm{~mol}$; EtCOOH, $7.5 \mathrm{~mol} ; \mathrm{Mo}(\mathrm{CO})_{6}, 22 \mathrm{mmol}$. Conditions: $160{ }^{\circ} \mathrm{C}$, pressures: ethylene, $27.2 \mathrm{~atm} ; \mathrm{CO}, 23.8 \mathrm{~atm} ; \mathrm{H}_{2}, 3.4 \mathrm{~atm}$.

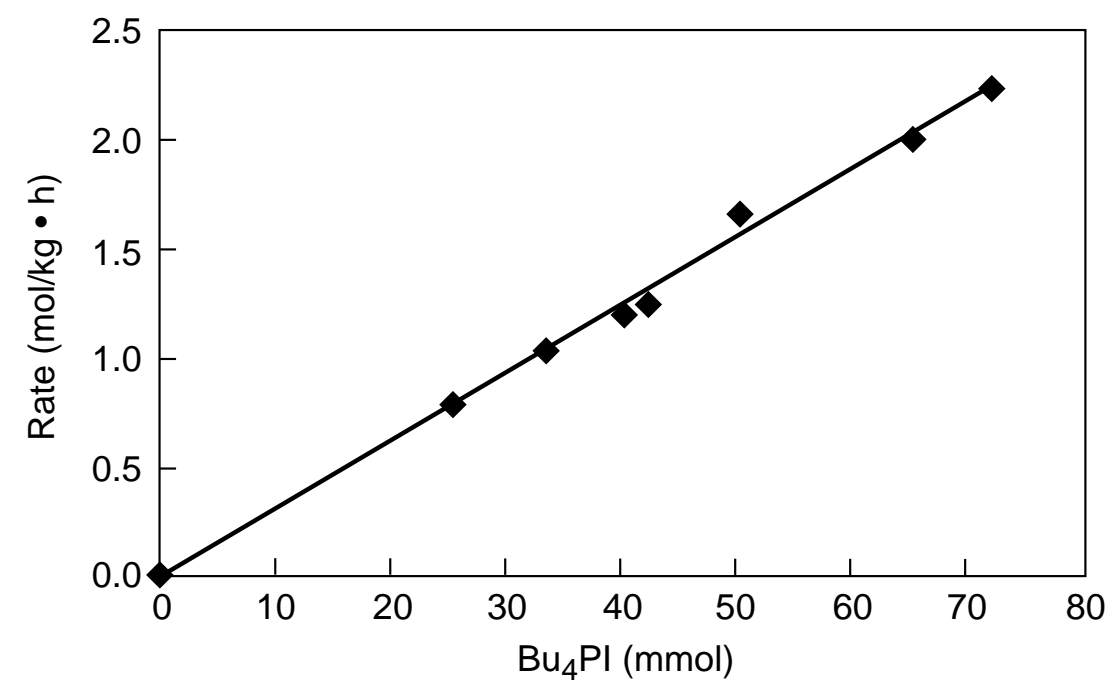

Figure 19. Arrhenius plot.

Initial composition: Etl, $0.7 \mathrm{~mol}$; EtCOOH, $7.5 \mathrm{~mol}$; $\mathrm{Mo}(\mathrm{CO})_{6}, 22 \mathrm{mmol} ; \mathrm{Bu}_{4} \mathrm{PI}$, $40 \mathrm{mmol}$. Pressures: ethylene, $27.2 \mathrm{~atm} ; \mathrm{CO}, 23.8 \mathrm{~atm} ; \mathrm{H}_{2}, 3.4 \mathrm{~atm}$.

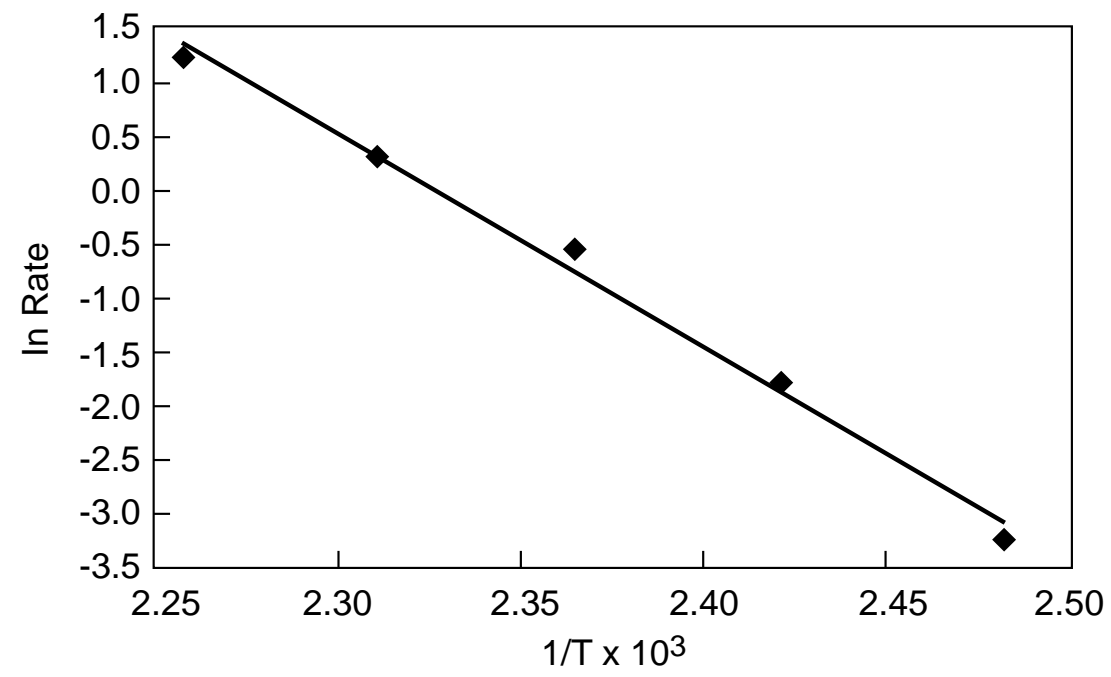


non-integer dependencies upon $\mathrm{Mo}(\mathrm{CO})_{6}, \mathrm{Bu}_{4} \mathrm{PI}$, EtI, and $\mathrm{CO}$, rate constants $(\mathrm{k})$ for use in the Eyring plot were estimated using the following equation:

$$
\mathrm{k}=\frac{\operatorname{Rate} \cdot\left[\mathrm{P}_{\mathrm{co}}\right]^{1.17}}{\left[\mathrm{Mo}(\mathrm{CO})_{6}\right]^{0.62}[\mathrm{EtI}]^{0.52}\left[\mathrm{I}^{-}\right]} .
$$

The experimental terms in Equation (19) represent the experimentally determined rate orders for $\mathrm{Mo}(\mathrm{CO})_{6}, \mathrm{Bu}_{4} \mathrm{PI}$, EtI, and $\mathrm{CO}$ as determined from the best fit of the data obtained in the studies of the gas and catalyst component dependencies discussed in the previous section. The resulting Eyring plot (Figure 20, $\mathrm{R}^{2}=0.99$ ) indicated an enthalpy of activation and entropy of activation of $+38.4 \mathrm{kcal} / \mathrm{mol}$ and $+40 \mathrm{cal} / \mathrm{mol} / \mathrm{K}$, respectively. By keeping the $\mathrm{CO}$ pressure and the catalyst components constant between experiments, inaccuracies in the reaction orders used within Equation (19) have no effect upon the measured $\Delta \mathrm{H} \neq$ and only negligible effect upon the magnitude of $\Delta S \ddagger$. The raw data for his determination appear in Table 4.

These activation parameters are significant in understanding the mechanism. The large, positive $\Delta \mathrm{S} \ddagger$ suggests a dissociative rate-determining step. Further, the most recent (and reliable) estimations establish the dissociation energy of the Mo- $\mathrm{CO}$ bond in $\mathrm{Mo}(\mathrm{CO})_{6}$ (Equation [20]) to be about $40 \mathrm{kcal} / \mathrm{mol}[21,22]$. This is almost identical to $\mathrm{E}_{\text {act }}$ measured here and, along with the positive $\Delta \mathrm{S} \neq$, indicates that the rate-limiting step here is the dissociation of $\mathrm{CO}$ from $\mathrm{Mo}(\mathrm{CO})_{6}$ :

$$
\mathrm{Mo}(\mathrm{CO})_{6} \rightleftharpoons \mathrm{Mo}(\mathrm{CO})_{5}+\mathrm{CO}
$$

The experimentally determined differences in the $\mathrm{E}_{\text {act }}$ and $\Delta \mathrm{H} \ddagger$ are also consistent with this dissociation process. In a process that generates a mole of gas, as in Equation (20), the expected difference between these two values would be $0.84 \mathrm{kcal} / \mathrm{mol}$ at $150{ }^{\circ} \mathrm{C}$, which coincides with the observed difference.

4.1.2.6 Addition of Duroquinone and Other Metals. The addition of duroquinone as a free radical scavenger generally either stops or significantly slows free radical processes. As illustrated in Figure 21, addition of $1.1 \mathrm{~mol}$ duroquinone/mol Mo causes the reaction to proceed at a markedly lower rate. Although duroquinone might slow the reaction by acting as an oxidant for $\mathrm{Mo}(\mathrm{CO})_{6}$, an in-situ infrared spectroscopic experiment in which duroquinone was added to the catalyst mixture showed that the Mo carbonyl spectra were virtually indistinguishable from runs in the absence of duroquinone. The Mo was clearly not oxidized to $\mathrm{Mo}(\mathrm{CO})_{4} \mathrm{I}_{3}{ }^{-}$.

One interesting feature of this experiment is that duroquinone does not completely stop the reaction. This would indicate that the rate of reaction between the initially formed radicals and the components of the catalytic system is competitive with the rate of reaction of the initially formed radicals with duroquinone. The inhibition of Mo-catalyzed ethylene carbonylation by other metals has been observed, likely as they compete to scavenge radicals needed to initiate the process. For example, $\mathrm{Ni}$ and Fe noticeably slow the reaction and $\mathrm{Sn}$ almost completely inhibits the process (see Table 5). 
Initial composition: Etl, $0.7 \mathrm{~mol}$; EtCOOH, $7.5 \mathrm{~mol}$; $\mathrm{Mo}(\mathrm{CO})_{6}, 22 \mathrm{mmol} ; \mathrm{Bu}_{4} \mathrm{Pl}$, $40 \mathrm{mmol}$. Pressures: ethylene, $27.2 \mathrm{~atm}$; $\mathrm{CO}, 23.8 \mathrm{~atm}, \mathrm{H}_{2}, 3.4 \mathrm{~atm}$.

Figure 20. Eyring plot.

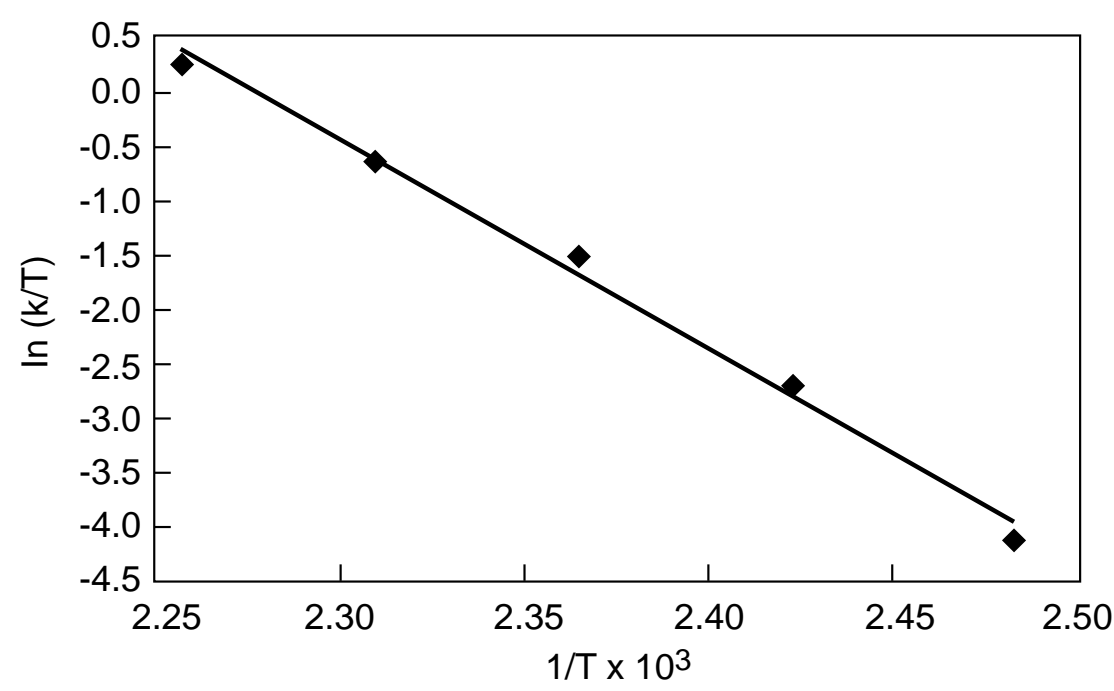

Table 4. Rate as a Function of Temperature

\begin{tabular}{ccc}
\hline $\begin{array}{c}\text { Temperature } \\
\left({ }^{\circ} \mathbf{C}\right)\end{array}$ & $\begin{array}{c}\text { Measured rate } \\
(\mathbf{m o l} / \mathbf{k g} \cdot \mathbf{h})\end{array}$ & $\begin{array}{c}\text { Calculated } \mathbf{k}^{\prime} \\
(\mathbf{J} / \mathbf{m o l} \cdot \mathbf{s e c})\end{array}$ \\
\hline 130 & 0.04 & 6.56 \\
140 & 0.17 & 27.9 \\
150 & 0.58 & 95.1 \\
160 & 1.39 & 228. \\
170 & 3.49 & 572. \\
\hline
\end{tabular}

Initial composition: Etl, $0.7 \mathrm{~mol}$; EtCOOH, $7.5 \mathrm{~mol}$; $\mathrm{Mo}(\mathrm{CO})_{6}$, $22 \mathrm{mmol} ; \mathrm{Bu}_{4} \mathrm{Pl}, 40 \mathrm{mmol}$. Pressures: ethylene, $27.2 \mathrm{~atm} ; \mathrm{CO}$, $23.8 \mathrm{~atm}, \mathrm{H}_{2}, 3.4 \mathrm{~atm}$. 
Initial composition: Etl, $0.7 \mathrm{~mol}$; EtCOOH, $7.5 \mathrm{~mol}$; $\mathrm{Mo}(\mathrm{CO})_{6}, 22 \mathrm{mmol} ; \mathrm{Bu}_{4} \mathrm{Pl}, 40$ mmol. Conditions: $160{ }^{\circ} \mathrm{C}$, pressures: ethylene, $27.2 \mathrm{~atm}$; $\mathrm{CO}, 23.8 \mathrm{~atm}, \mathrm{H}_{2}$, $3.4 \mathrm{~atm}$.

Figure 21. Effect of duroquinone.

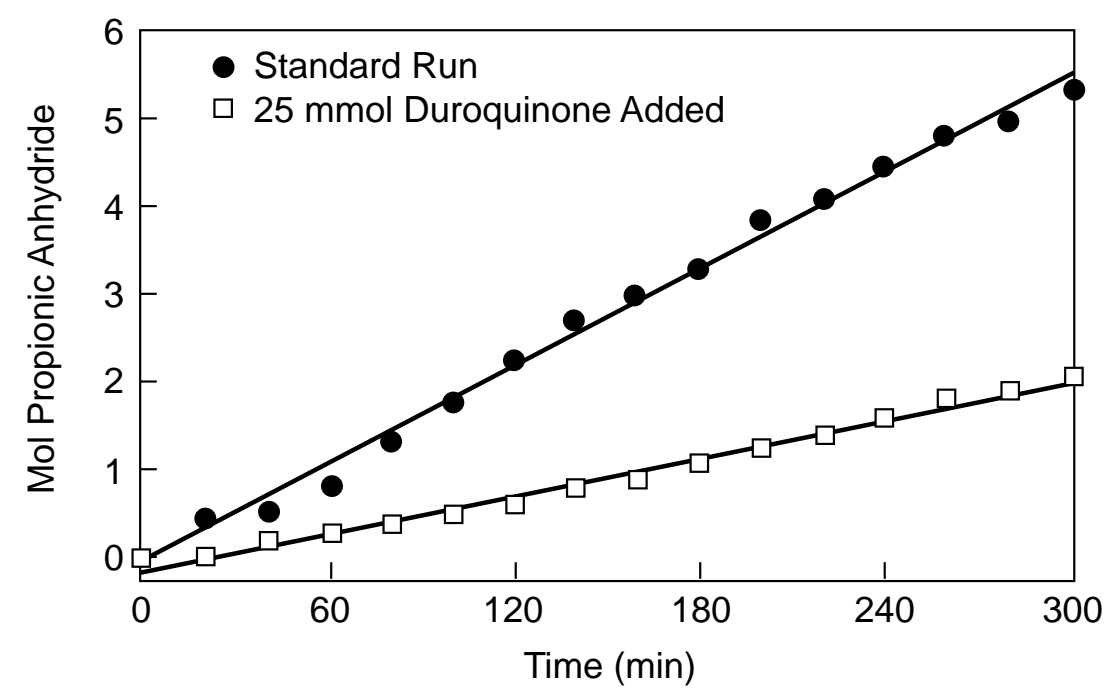

Table 5. Inhibition of Ethylene Carbonylation of Propionic Anhydride by Various Additives

\begin{tabular}{clc}
\hline Entry & \multicolumn{1}{c}{ Inhibitor $(\mathbf{m m o l})$} & $\begin{array}{c}\text { Rate } \\
(\mathbf{m o l} / \mathbf{k g} \cdot \mathbf{h})\end{array}$ \\
\hline 1 & None & 1.39 \\
2 & Duroquinone $(25 \mathrm{mmol})$ & 0.41 \\
3 & $\mathrm{NiI}_{2}(22 \mathrm{mmol})$ & 0.97 \\
4 & $\mathrm{FeI}_{2}(22 \mathrm{mmol})$ & 0.88 \\
5 & $\mathrm{SnI}_{2}(22 \mathrm{mmol})$ & 0.07 \\
\hline
\end{tabular}

Initial composition: EtI, $0.7 \mathrm{~mol}$; EtCOOH, $7.5 \mathrm{~mol} ; \mathrm{Mo}(\mathrm{CO})_{6}, 22 \mathrm{mmol} ; \mathrm{Bu}_{4} \mathrm{PI}$, $40 \mathrm{mmol}$. Conditions: $160{ }^{\circ} \mathrm{C}$, Pressures: ethylene, $27.2 \mathrm{~atm}$; $\mathrm{CO}, 23.8 \mathrm{~atm}, \mathrm{H}_{2}$, $3.4 \mathrm{~atm}$.

4.1.2.7 Attempted Carbonylations of Either Benzyl Alcohol or Methanol Derivatives. The catalyst is not effective in carbonylations involving benzyl halide or MeI intermediates (i.e., carbonylation of benzyl alcohol or methanol derivatives, respectively). This rules out many of the familiar mechanisms involving nucleophilic displacement of the iodide. However, studies on these substrates do provide important further insights. Studies of the stoichiometric reactions between $\mathrm{Mo}(\mathrm{CO})_{6}, \mathrm{Bu}_{4} \mathrm{PBr}$, and benzyl bromide under $\mathrm{CO}$ yielded toluene and bibenzyl among 
several products, clearly indicative of the presence of benzylic radicals, while yielding only small quantities of phenyl acetate derivatives.

4.1.2.8 Other Significant Observations. Radical traps such as the 6-bromo-1-hexene and 5-bromo-1-pentene (to capture an acyl radical intermediate) were also studied. Unfortunately, this catalyst is a very effective olefin isomerization catalyst and the olefins were scrambled more rapidly than the carbonylation reaction proceeded.

Initial results of electron pulse resonance (EPR) examinations indicate that the interaction of $\mathrm{Mo}(\mathrm{CO})_{6}$ with EtI and $\mathrm{Bu}_{4} \mathrm{PI}$ generates a detectable organic radical and a detectable Mo-based radical (defined by it diagnostic 5/2 splitting pattern). However, neither has been completely characterized.

\subsubsection{Mechanistic Interpretation}

The results described in Section 3.1.2 can be summarized as follows:

- Based on the in-situ infrared spectroscopic studies, the largely predominant Mo species in the process is $\mathrm{Mo}(\mathrm{CO})_{6}$, which is slowly oxidized by EtI to $\mathrm{Mo}(\mathrm{CO})_{4} \mathrm{I}_{3}^{-}$. In the presence of even small amounts of hydrogen (generated either in-situ or intentionally introduced), the two species quickly reach a steady state in which $\mathrm{Mo}(\mathrm{CO})_{4} \mathrm{I}_{3}{ }^{-}$is only a minor component. $\mathrm{Mo}(\mathrm{CO})_{5} \mathrm{I}^{-}$is generated in very minor amounts and, although initially believed to be important, now appears to be an inconsequential species in the reaction based on the kinetics.

- The activation parameters indicated that the rate-limiting step was likely the dissociation of $\mathrm{CO}$ from $\mathrm{Mo}(\mathrm{CO})_{6}$.

- The nearly one-half order kinetics, detection of dimeric byproducts, suppression by duroquinone, and detection of (albeit still uncharacterized) EPR signals indicated a free radical process is likely operative.

- The lack of reactivity for substrates other than olefins suggests that the key step in ethylene activation did not involve oxidative addition of EtI because MeI and benzyl halides should be reactive under these circumstances. Most likely, the activation of ethylene involved insertion into a metal hydride species.

A free radical mechanism is consistent with these results and the complex kinetics. Classically, free radical processes are broken down into a sequence of three general portions of the reaction: initiation, chain propagation, and termination. (Subsequent rate expressions can generally be closely approximated using the steady-state approximation.) The kinetics, despite their complexity, provide additional insights into the events that likely occur within each of these portions of the reaction sequence, even before the development of a complete rate expression, specifically the following:

- The one-half order kinetics in EtI and Mo indicate that the initiation step likely involves a bimolecular interaction of Mo and EtI to ultimately form radicals.

- The greater than first inverse dependence upon CO further indicates that the initiation is inhibited by $\mathrm{CO}$ in both the initiation phase and in a subsequent step leading to product 
formation. This is consistent with proposed rate-limiting initiation via a $\mathrm{CO}$ dissociation from $\mathrm{Mo}(\mathrm{CO})_{6}$.

- The predominant termination step should not involve the radicals initially generated by the interaction of Mo and EtI, as this would have led to either 3/2 or first order kinetic behavior. Instead, to be consistent with the half-order behavior in the initiating species, the predominant termination step would have to involve a radical formed later in the process.

- The first order kinetics in iodide and the greater than first inverse order in CO indicate that there must be a competitive reaction between iodide and $\mathrm{CO}$ within the chain propagating sequence. Further, because inhibition in chain-propagating steps is due to chain shortening, the species formed from added $\mathrm{CO}$ is the most likely candidate for the predominant radical species leading to termination.

- Ethylene addition must lie outside the transformation of initially formed radicals and the product formation step, because there was no dependence on ethylene.

These guidelines suggest the mechanism in Figure 22.

Using the steady-state approximation, the anticipated rate expression for the process is

$$
\text { Rate }=\frac{\mathrm{k}_{11} \mathrm{k}_{7}^{1 / 2}[\mathrm{EtI}]^{1 / 2}\left[\mathrm{Mo}(\mathrm{CO})_{6}\right]^{1 / 2}\left[\mathrm{I}^{-}\right]}{\mathrm{k}_{18}^{1 / 2}\left[\mathrm{~K}_{\mathrm{m} 1}\left[\mathrm{P}_{\mathrm{co}}\right]+[\mathrm{EtI}]\right]^{1 / 2}\left[\mathrm{~K}_{\mathrm{m} 2}\left[\mathrm{P}_{\mathrm{co}}\right]+1\right]}
$$

where $\mathrm{K}_{\mathrm{m} 1}=\mathrm{k}_{-1} / \mathrm{k}_{2}$ and $\mathrm{K}_{\mathrm{m} 2}=\mathrm{k}_{-5} / \mathrm{k}_{6}$ and the rate constants $\left(\mathrm{k}_{i}\right)$ correspond to the reaction steps in Figure 22. This rate expression is consistent with experimental observations. The choice of a likely termination process is important. Considering the number of species in Figure 22, there are a considerable number of potential radical coupling processes that can lead to termination. However, only one, the bimolecular interaction depicted in reaction 12 (in Figure 22), leads to the correct kinetic expression. Fortunately, the organic products expected from this coupling agree with the key minor byproducts. Other radical interactions with lower reaction rates are probably operative in chain termination and consequently contribute to deviations in behavior from the above expression.

Based on the kinetics, the radical generation steps can be further described. Because the process proceeds via a rate-limiting $\mathrm{CO}$ dissociation as the initial step, this dissociation would suggest that the initial interaction of EtI with Mo (reaction [2] in Figure 22) proceeds via an inner sphere process. However, this is contrary to earlier investigations of the interaction of benzyl bromide with $(\mathrm{dmpe})_{2} \mathrm{Mo}(\mathrm{CO})_{2}\left(\mathrm{dmpe}=\mathrm{Me}_{2} \mathrm{PCH}_{2} \mathrm{CH}_{2} \mathrm{PMe}_{2}\right)[23,24]$ where an outer sphere electron transfer seemed likely.

Further, the small halide effect would usually indicate that the process represented reaction by (2) in Figure 22 is an electron transfer process as alluded to earlier[16]. However, some caution needs to be exercised in interpreting this halide effect. Further complicating the interpretation of the halide effect are contributions of reactions (5) and (6), both of which enter the rate expression and may influence the magnitude of the halide effect. Of particular concern is the potential effect 
Figure 22. Proposed mechanism for the generation of propionic anhydride from ethylene, $\mathrm{CO}$, and propionic acid.

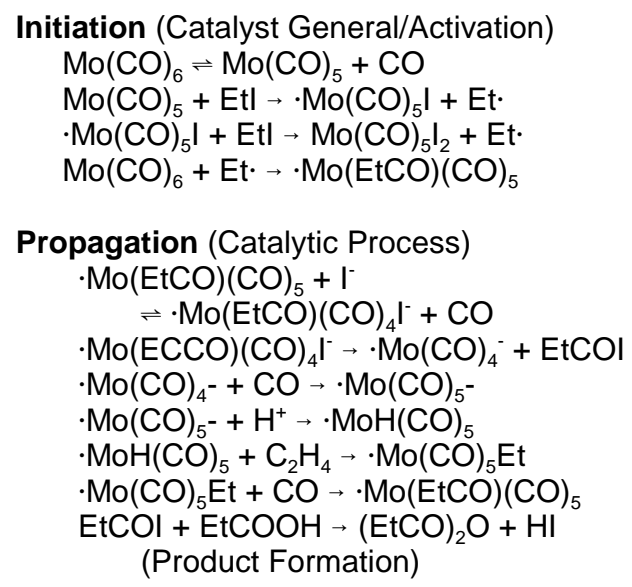

Termination (Catalyst Deactivation)

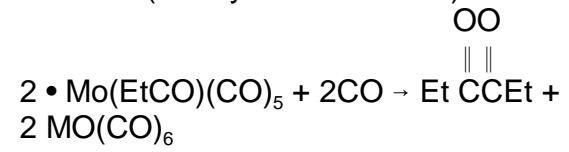

\section{Catalyst Regeneration}

(Reduction of $\mathrm{Mo}(\mathrm{II})$ by hydrogen) $\mathrm{Mo}(\mathrm{CO})_{5} \mathrm{I}_{2}+\mathrm{I}^{-} \rightarrow \mathrm{Mo}(\mathrm{CO})_{4} \mathrm{I}_{3}-$ (observed) $\mathrm{Mo}(\mathrm{CO})_{4} \mathrm{I}_{3}-+\mathrm{H}_{2}+\mathrm{CO} \rightarrow 2 \mathrm{HI}+\mathrm{Mo}(\mathrm{CO})_{5} \mathrm{I}^{-}$

of the halide on the crucial equilibrium expressed by reaction (5) where the halide may be very important. Therefore, although the halide effect should still be interpreted to indicate that this is likely an inner sphere electron transfer process, other potential inner sphere, one-electron processes, such as halogen atom abstraction, cannot be ruled out [25]. The subsequent formation of a second ethyl radical by the interaction of the $17 \mathrm{e}^{-},\left[\cdot \mathrm{Mo}(\mathrm{CO})_{5} \mathrm{I}\right]$, with EtI (reaction [3]) would be expected to be fast.

An inner sphere process would also explain the inhibition of the reaction when either methanol or water are present at high levels. In the presence of large quantities of methanol or water, it is likely that these nucleophiles will inhibit the reaction by competing with EtI for the vacant site on $\mathrm{Mo}(\mathrm{CO})_{5}$.

The species in the initiation process are reasonable. Whereas $\left[\cdot \mathrm{Mo}(\mathrm{CO})_{5} \mathrm{I}\right]$ is unknown, its dimer has been synthesized and the $\mathrm{Cr}$ analog is a well-known stable-free radical metal species [26-28]. The seven coordinate $\mathrm{Mo}(\mathrm{CO})_{5} \mathrm{I}_{2}$ is not observed, but its iodide displacement product, $\mathrm{Mo}(\mathrm{CO})_{4} \mathrm{I}_{3}{ }^{-}$, is both known and observed within the process (vide infra). The species, $\left[\cdot \mathrm{Mo}(\mathrm{EtCO})(\mathrm{CO})_{5}\right]$, generated in the final reaction of our initiation sequence (reaction [4]) is, to our knowledge, unknown in the literature. However, metal species are well-known to be radical traps, and their formation is a rational consequence of the interaction of ethyl radical with the predominant Mo species, $\mathrm{Mo}(\mathrm{CO})_{6}$.

The generation of the $17 \mathrm{e}^{-}$species, $\left[\cdot \mathrm{Mo}(\mathrm{EtCO})(\mathrm{CO})_{5}\right]$, is pivotal, and this species likely represents the predominant radical present in the process at any given time. (As indicated, termination by a bimolecular reaction of this intermediate with itself is the only process consistent with the kinetics.) Although the specific species, $\left[\cdot \mathrm{Mo}(\mathrm{EtCO})(\mathrm{CO})_{5}\right]$, is unknown, the literature regarding $17 \mathrm{e}^{-} \mathrm{Cr}$-group species is extensive, and these complexes are characterized by rapid ligand exchanges, rapid oxidative addition/reductive elimination processes, and rapid 
dimerization $[16,29]$. The ability to undergo rapid ligand exchange is particularly important within this process. Whereas $\mathrm{Mo}(0)$ and $\mathrm{Mo}(+2)$ are generally slow to undergo ligand exchange, a process usually critical to catalysis with olefins, the $17 \mathrm{e}^{-}$Mo species are likely to undergo rapid ligand exchange, allowing ethylene and iodide to rapidly coordinate to the catalyst at critical junctures during chain propagation.

The specific steps within the propagation steps were dictated by kinetics. Only one of the individual species shown in the propagation sequence is known $\left[\cdot \mathrm{Mo}(\mathrm{CO})_{5}{ }^{-}\right]$and has been identified a number of times in the literature [30]. Unless frozen in a matrix, it has a lifetime of only a few seconds. The dimers, $\mathrm{Mo}_{2}(\mathrm{CO})_{10}{ }^{2-}$ and $(\mu-\mathrm{H}) \mathrm{Mo}_{2}(\mathrm{CO})_{10^{-}}$(resulting from coupling combinations of $\left[\cdot \mathrm{Mo}(\mathrm{CO})_{5}{ }^{-}\right]$and $\left.\left[\cdot \mathrm{HMo}(\mathrm{CO})_{5}\right]\right)$ are well-established, but neither species is observed in the process $[31,32]$.

Kinetics suggests that the predominant chain termination process most likely involved is a bimolecular interaction of the pivotal intermediate, $\left[\cdot \mathrm{Mo}(\mathrm{EtCO})(\mathrm{CO})_{5}\right]$. Unfortunately, beyond this insight, any additional indication of the exact mechanism is not given by the data. Based on the propensity of these $17 \mathrm{e}^{-}$Mo species to dimerize, a dimerization to form $\left[\mathrm{Mo}(\mathrm{EtCO})(\mathrm{CO})_{5}\right]_{2}$ with subsequent intramolecular elimination of EtCOOEt might be suggested. However, in the absence of any additional data, the possibility that the reaction might proceed through any of a number of alternative bimolecular processes, including metal to metal electron transfer to generate $\mathrm{Mo}(0)$ and $\mathrm{Mo}(+2)$ species, cannot be excluded.

\subsubsection{Conceptual Design and Economic Analysis of Propionate Synthesis}

Effort was focussed on developing a conceptual plant design and cost estimate for propionic anhydride synthesis via ethylene carbonylation, based on a propionic acid carbonylation synthesis design developed by Eastman. The two designs are almost identical. The only difference is that propionic acid is used as a feed for the propionic anhydride carbonylation synthesis $\left[\mathrm{C}_{2} \mathrm{H}_{4}+\mathrm{CO}+\mathrm{C}_{2} \mathrm{H}_{5} \mathrm{COOH} \rightarrow\left(\mathrm{CH}_{3} \mathrm{CH}_{2} \mathrm{CO}\right)_{2} \mathrm{O}\right]$ whereas water is used for the propionic acid carbonylation $\left[\mathrm{C}_{2} \mathrm{H}_{4}+\mathrm{CO}+\mathrm{H}_{2} \mathrm{O} \rightarrow \mathrm{CH}_{3} \mathrm{CH}_{2} \mathrm{COOH}\right]$. Both reactions take place in the presence of molybdenum hexacarbonyl $\left[\mathrm{Mo}\left(\mathrm{CO}_{6}\right)\right]$ catalyst.

In the earlier stage of the project, it was recognized that using propionic anhydride has several potential advantages over that of propionic acid in a condensation reaction with formaldehyde to form MMA. Propionic anhydride can act as an anhydrous agent, soaking up the water produced as a byproduct from the condensation reaction thus help with increasing the overall conversion. Also, ridding of the byproduct water greatly reduces the MMA product separation cost; it is well known that the MMA condensation effluent contains several organic acid water azeotrope pairs which are difficult to separate.

After a conceptual design was developed and economic analysis performed for propionic anhydride. Subsequent search and experimental testing failed to produce an active condensation catalyst for propionic anhydride. As a result, RTI re-directed its effort and focused on the propionic acid/external formaldehyde condensation catalyst development. It was agreed among the project team members that the process design and economic analysis developed for propionic 
anhydride can be used to estimate the production cost for propionic acid, since the carbonylation synthesis conceptual design and plant cost estimates are identical for both processes.

The propionic anhydride conceptual design and economic analysis was based on Eastman's laboratory result of Mo hexacarbonyl catalyst at conditions of $180^{\circ} \mathrm{C} / 750 \mathrm{psig}$. Conversions are 99 percent with respect to ethylene, 96 percent to $\mathrm{CO}$ and 70 percent to propionic acid.

Unconverted propionic acid is recycled. Ethyl propionate was assumed to be the only significant byproduct and ethyl iodide the only significant organic halide catalyst component. Both are recycled back to the reactor and the ethyl propionate is eventually reacted to form propionic anhydride. Figure 23 shows a simplified flow diagram for the overall process from which a set of detailed heat and material balances was generated, along with a major equipment list which serviced as the basis for plant cost estimate. Final heat and material balance results and the equipment list are presented in the 1996 annual report [34].

Figure 23. Propionic anhydride synthesis unit.

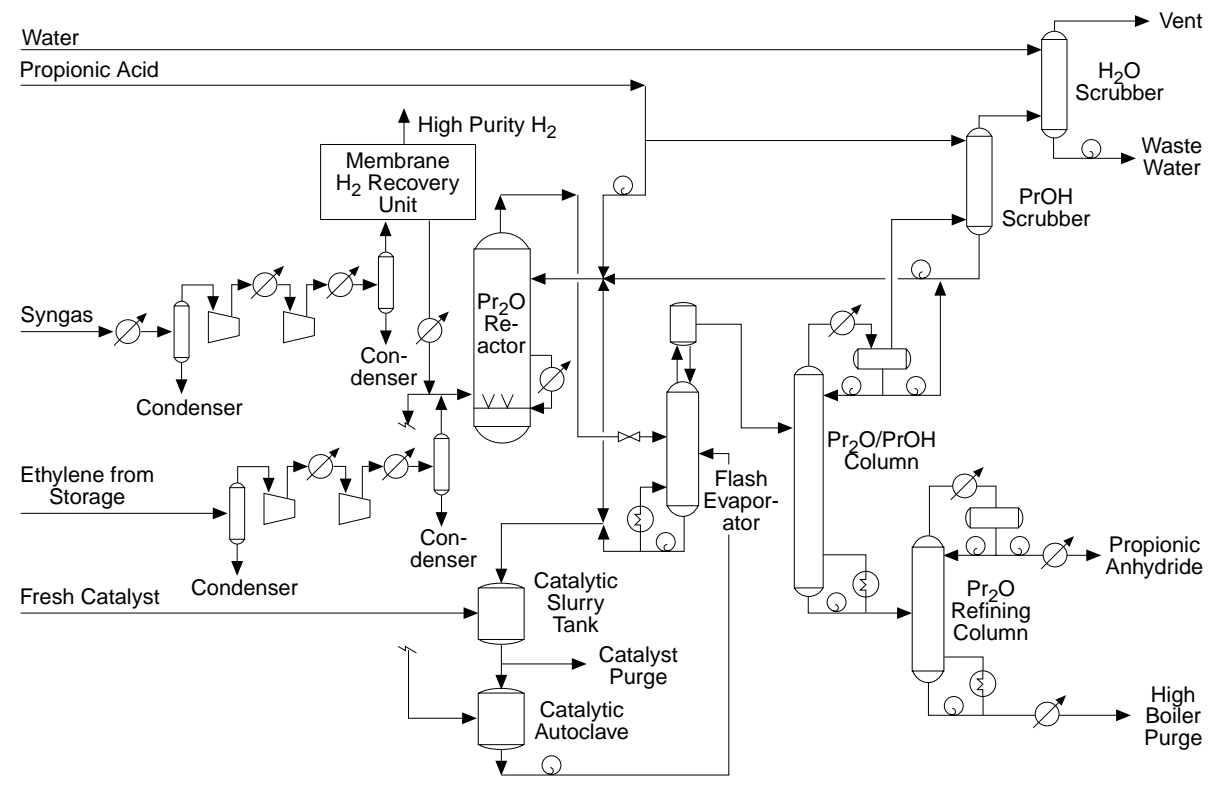

The conceptual design and economic analysis was based on a plant capacity to produce 250 million lb/yr of MMA from propionic anhydride. Estimated total inside battery limits (ISBL) capital cost is about $\$ 21.1$ million. A 35 percent contingency is included in the estimate to account for the first-of-a-kind nature of the plant as recommended by Eastman. This is an adjusted 1992 cost. It is based on U.S. Gulf Cost material and labor productivity rate. Both are consistent with Stanford Research Institute( SRI's) reported cost estimates for the various currently commercial and potentially commercial MMA processes [38] serving as benchmark for the present study. SRI, however, uses only a 25 percent contingency in their cost estimate. Table 6(a) shows the estimated capital cost breakdown for the propionic anhydride carbonylation process. 
Table 6(a). Propionic Anhydride Synthesis-Cost Estimates

1995 cost $\left(\$ 10^{3}\right)$

Adjusted to $1992 \operatorname{cost}\left(\$ 10^{3}\right)$

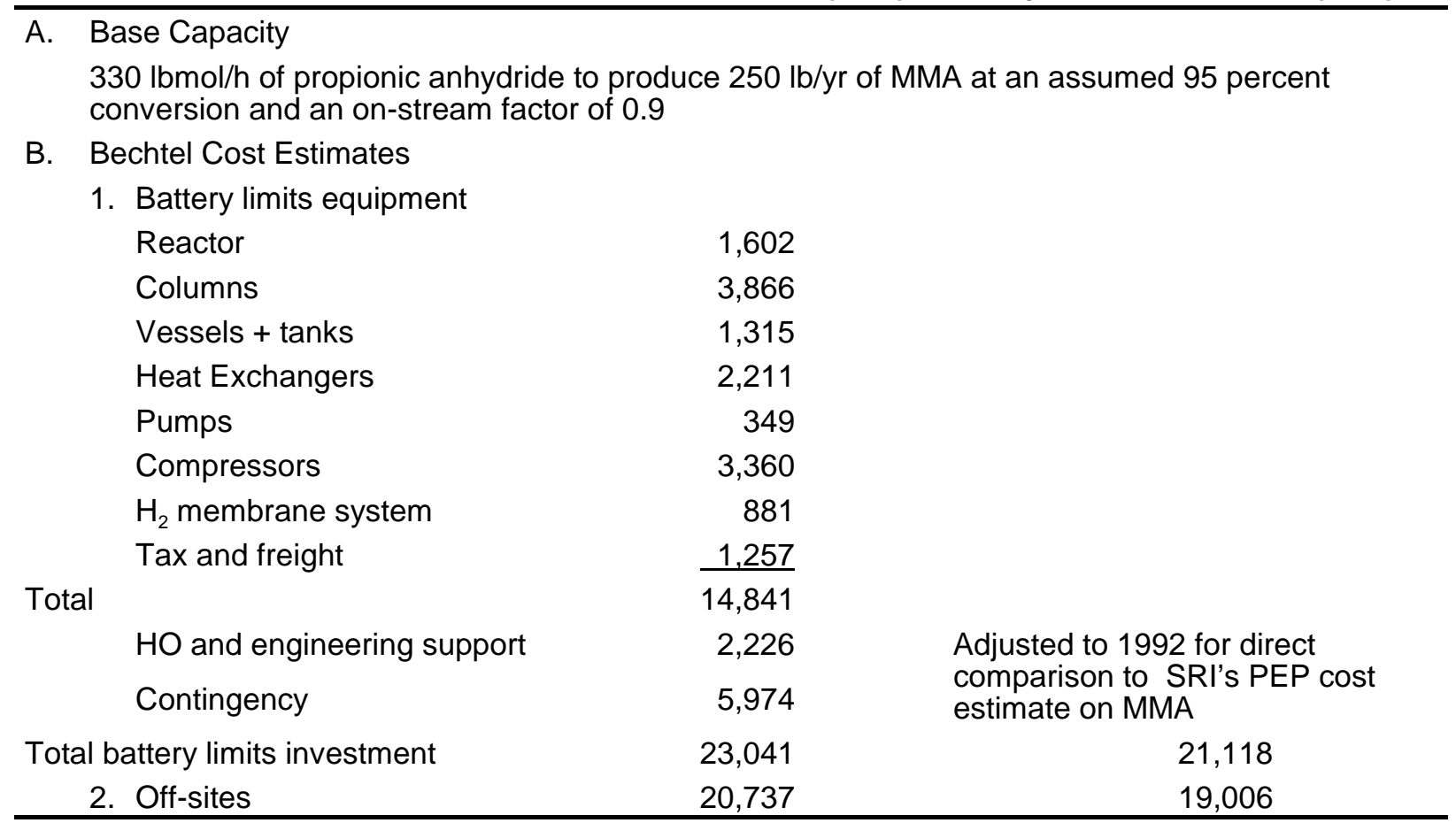

Following SRI's methodology on offsite and utility cost estimations, and financial assumptions, the production cost of propionic anhydride via ethylene carbonylation is estimated at $\$ 0.43$ per lb. Table 6(b) shows the input parameters and assumptions employed.

For ethylene carbonylation route to propionic acid, the plant design is identical to that for propionic anhydride cited above. The only difference is in the use of water instead of propionic acid as a co-feed (in addition to ethylene and CO) for the process. Table 6(c) shows the estimated carbonylation production cost for propionic acid, at slightly over $\$ 0.20$ per $\mathrm{lb}$. This represents a substantial economic benefit over some of the current commercial propionic acid manufacturing processes.

For example, a majority of the currently propionic acid production is manufactured via the oxo process (practiced by Eastman, Union Carbide and Neste) in which ethylene and carbon monoxide are reacted to produce propionaldehyde, which followed by further oxidation is converted to propionic acid - i.e.,

$$
\begin{aligned}
& \mathrm{CH}_{2}=\mathrm{CH}_{2}+\mathrm{CO}+\mathrm{H}_{2} \rightarrow \mathrm{CH}_{3} \mathrm{CH}_{2} \mathrm{CHO} \text { (over Co or Rd catalyst), followed by } \\
& \mathrm{CH}_{3} \mathrm{CH}_{2} \mathrm{CHO}+1 / 2 \mathrm{O}_{2} \rightarrow \mathrm{CH}_{3} \mathrm{CH}_{2} \mathrm{COOH} \text { (Co catalyst). }
\end{aligned}
$$

This two-step process has a propionic acid production cost at about $\$ 0.29$ per lb, according to a recent Chem Systems PERP report [41]. 
Table 6(b). Propionic Anhydride Synthesis Production Cost Estimates

\begin{tabular}{|c|c|c|c|c|}
\hline CAPACITY (MMLb/yr) & 330 & & & \\
\hline \multicolumn{5}{|l|}{ Investments (\$MM) } \\
\hline Battery Limits (BLI) & \multicolumn{4}{|l|}{21.1} \\
\hline Off-Sites & \multicolumn{4}{|l|}{19.0} \\
\hline Total Fixed Capital (TFC) & \multicolumn{4}{|l|}{$\overline{40.1}$} \\
\hline \multicolumn{5}{|l|}{ Production Costs (Cents/Lb) } \\
\hline \multicolumn{2}{|l|}{ Raw Materials } & $\frac{\text { Consumption }}{\text { per Lb of Pr20 }}$ & \multicolumn{2}{|l|}{$\underline{\text { Unit Cost }(\$)}$} \\
\hline Ethylene, Lb & 0.05604 & 0.224176 & $0.25 / \mathrm{Lb}$ & <-- 1995 Chem Market \\
\hline Syngas, MSCF & 0.00729 & 0.004419 & $1.65 / \mathrm{MSCF}$ & $<-1993$ Bechtel cost estimate \\
\hline Propionic acid, lb & 0.24702 & 0.588133 & $0.42 / \mathrm{Lb}$ & <-- 1995 Chem Market \\
\hline Catalyst, Lb & $\underline{0.00000}$ & 4.74E-05 & & \\
\hline (Total) & $\overline{0.31035}$ & & & \\
\hline \multicolumn{5}{|l|}{ Utilities } \\
\hline Process Water, Lb & 0.00000 & $5.13 \mathrm{E}-06$ & 0.89/MGal & <-- SRI Data \\
\hline Cooling Water, GPM & 0.00081 & 0.012714 & $0.064 / \mathrm{MGal}$ & <-- SRI Data \\
\hline 250 \#steam, MLb & 0.00548 & 0.00173 & 3.17/MLb & <-- SRI Data \\
\hline Power, KW & $\underline{0.00092}$ & 0.024969 & $0.037 / \mathrm{KWH}$ & $<--$ SRI Data \\
\hline (Total) & $\overline{0.00723}$ & & & \\
\hline Total Variable Costs & 0.31758 & & & \\
\hline Operating Labor, 3/shift @ \$25.26/hr & 0.00201 & \multirow{4}{*}{\multicolumn{3}{|c|}{$\begin{array}{l}\text { <-- Eastman's estimated labor; SRI PEP rate } \\
\text { <-- SRI PEP financial assumption } \\
\text { <-- SRI PEP financial assumption }\end{array}$}} \\
\hline Maintenance Labor, $3 \% / y r$ of BLI & 0.00192 & & & \\
\hline Control Lab labor, $20 \%$ of Oper. Lab & $\underline{0.00040}$ & & & \\
\hline Total Labor Costs & $\overline{0.00433}$ & & & \\
\hline Maintenance Materials, 3\%/yr of BLI & 0.00192 & \multirow{3}{*}{\multicolumn{3}{|c|}{$\begin{array}{l}\text { <-- SRI PEP financial assumption } \\
\text { <-- SRI PEP financial assumption }\end{array}$}} \\
\hline Operating Supplies, $10 \%$ of oper. Labor & $\underline{0.00020}$ & & & \\
\hline Total Direct Costs & $\overline{0.32402}$ & & & \\
\hline Plant Overhead, $80 \%$ of Labor Costs & 0.00346 & \multirow{4}{*}{\multicolumn{3}{|c|}{$\begin{array}{l}<-- \text { SRI PEP financial assumption } \\
<-- \text { SRI PEP financial assumption } \\
\text { <-- SRI PEP financial assumption }\end{array}$}} \\
\hline Taxes and Insurance, $2 \% / \mathrm{yr}$ of TFC & 0.00243 & & & \\
\hline Depreciation, $10 \% / y r$ of TFC & $\underline{0.01215}$ & & & \\
\hline Plant Gate Cost & $\overline{0.34207}$ & & & \\
\hline G\&A, Sales,Research & $\underline{0.06000}$ & \multirow{2}{*}{\multicolumn{3}{|c|}{ <-- SRI PEP financial assumption }} \\
\hline Production Cost & 0.40207 & & & \\
\hline ROI Before Taxes, $25 \% / y r$ of TFC & 0.03038 & \multicolumn{3}{|c|}{ <-- SRI PEP financial assumption } \\
\hline Product Value, $\$ / 1 b$ & 0.43245 & & & \\
\hline
\end{tabular}


Table 6(c). Propionic Acid Synthesis Production Cost Estimate

\begin{tabular}{|c|c|c|c|c|}
\hline \multicolumn{5}{|l|}{ Investments (\$MM) } \\
\hline $\begin{array}{l}\text { Battery Limits (BLI) } \\
\text { Off-Sites } \\
\text { Total Fixed Capital (TFC) }\end{array}$ & \multicolumn{4}{|l|}{$\begin{array}{l}23.04 \\
\frac{20.7}{43.78}\end{array}$} \\
\hline \multicolumn{5}{|l|}{ Production Costs (Cents/Lb) } \\
\hline Raw Materials & & $\frac{\text { Consumption }}{\text { per Lb of Pr20 }}$ & $\frac{\text { Unit Cost }}{(\$)}$ & \\
\hline $\begin{array}{l}\text { Ethylene, Lb } \\
\text { Syngas, MSCF } \\
\text { Water, Ib } \\
\text { Catalyst, Lb } \\
\text { (Total) }\end{array}$ & $\begin{array}{l}0.05604 \\
0.00729 \\
0.01176 \\
0.00000 \\
0.07510\end{array}$ & $\begin{array}{l}0.22418 \\
0.00442 \\
0.58813 \\
4.74 \mathrm{E}-05\end{array}$ & $\begin{array}{l}0.25 / \mathrm{Lb} \\
1.65 / \mathrm{MSC} \\
\mathrm{F} \\
0.02 / \mathrm{Lb}\end{array}$ & $\begin{array}{l}\text { <-- } 1995 \text { Chem Market } \\
\text { <-- } 1993 \text { Bechtel cost } \\
\text { estimate }\end{array}$ \\
\hline \multicolumn{5}{|l|}{ Utilities } \\
\hline $\begin{array}{l}\text { Process Water, Lb } \\
\text { Cooling Water, GPM } \\
250 \text { \#steam, MLb } \\
\text { Power, KW } \\
\text { (Total) }\end{array}$ & $\begin{array}{l}0.00000 \\
0.00081 \\
0.00548 \\
0.00092 \\
0.00723\end{array}$ & $\begin{array}{l}5.13 \mathrm{E}-06 \\
0.012714 \\
0.00173 \\
0.02497\end{array}$ & $\begin{array}{l}0.89 / \mathrm{MGal} \\
0.064 / \mathrm{MGa} \\
\text { I } \\
3.17 / \mathrm{MLb} \\
0.037 / \mathrm{KW} \\
\mathrm{H}\end{array}$ & $\begin{array}{l}\text { <-- SRI Data } \\
<-- \text { SRI Data } \\
<-- \text { SRI Data } \\
<-- \text { SRI Data }\end{array}$ \\
\hline Total Variable Costs & 0.08232 & & & \\
\hline $\begin{array}{l}\text { Operating Labor, 3/shift @ } \\
\$ 25.26 / h r \\
\text { Maintenance Labor, 3\%/yr of BLI } \\
\text { Control Lab labor, 20\% of Oper. } \\
\text { Lab } \\
\quad \text { Total Labor Costs }\end{array}$ & $\begin{array}{l}0.00201 \\
0.00209 \\
0.00040 \\
0.00450\end{array}$ & \multicolumn{3}{|c|}{$\begin{array}{l}\text { <-- Eastman's estimated labor; SRI PEP rate } \\
\text { <-- SRI PEP financial assumption } \\
\text { <-- SRI PEP financial assumption }\end{array}$} \\
\hline $\begin{array}{l}\text { Maintenance Materials, } 3 \% / y r \text { of } \\
\text { BLI } \\
\text { Operating Supplies, } 10 \% \text { of oper. } \\
\text { Labor } \\
\quad \text { Total Direct Costs }\end{array}$ & $\begin{array}{l}0.00209 \\
0.00020 \\
0.08912\end{array}$ & \multicolumn{3}{|c|}{$\begin{array}{l}<-- \text { SRI PEP financial assumption } \\
<-- \text { SRI PEP financial assumption }\end{array}$} \\
\hline $\begin{array}{l}\text { Plant Overhead, } 80 \% \text { of Labor } \\
\text { Costs } \\
\text { Taxes and Insurance, } 2 \% / y r \text { of } \\
\text { TFC } \\
\text { Depreciation, } 10 \% / y r \text { of TFC } \\
\quad \text { Plant Gate Cost }\end{array}$ & $\begin{array}{l}0.00360 \\
0.00265 \\
0.01327 \\
0.10865\end{array}$ & \multicolumn{3}{|c|}{$\begin{array}{l}\text { <-- SRI PEP financial assumption } \\
\text { <-- SRI PEP financial assumption } \\
\text { <-- SRI PEP financial assumption }\end{array}$} \\
\hline $\begin{array}{l}\text { G\&A, Sales, Research } \\
\text { Production Cost }\end{array}$ & $\frac{0.06000}{0.16865}$ & \multicolumn{3}{|c|}{$<--$ SRI PEP financial assumption } \\
\hline ROI Before Taxes, $25 \% / y r$ of TFC & 0.03317 & \multicolumn{3}{|c|}{$<--$ SRI PEP financial assumption } \\
\hline Product Value, $\$ / \mathrm{lb}$ & 0.20181 & & & \\
\hline
\end{tabular}

\subsubsection{Summary of Propionate Synthesis}

The carbonylation of olefins, particularly ethylene, with a halide-promoted Mo catalyst represents the first efficient carbonylation process using a Cr-group metal as the active catalytic species. Detailed mechanistic examinations indicate that the reaction likely proceeds via a free radical 
pathway, which is initiated by a rate-limiting dissociation of $\mathrm{CO}$ from $\mathrm{Mo}(\mathrm{CO})_{6}$. The precise propionate derivative obtained is determined by the nature of the nucleophilic component.

\subsection{TASK 2-CONDENSATION CATALYSIS}

\subsubsection{Catalyst Characterization of V-Si-P Catalysts}

4.2.1.1 Measurement of Acid-Base Properties. The condensation of formaldehyde with propionic acid (or anhydride) is thought to require a catalyst with both acid and base properties [34]. This suggests that there is a correlation between the acid-base, strength and site distribution, and the condensation yields [32]. This correlation has been explored by measuring the acid-base properties of the catalysts tested for condensation reaction.

The acid-base properties of the V-Si-P series of catalysts was quantified by measuring the $\mathrm{NH}_{3}$ and $\mathrm{CO}_{2}$ temperature programmed desorption properties (Table 7). No apparent trend was observed with total acidity, basicity, and surface area versus V-Si-P ratios. The characteristic $\mathrm{NH}_{3}$ - and $\mathrm{CO}_{2}$-temperature programmed desorption patterns for five of the six catalysts listed in Table 7 have been compared in Figures 24 and 25. Figure 24 gives the $\mathrm{NH}_{3}$-TPD patterns (measuring acidity) and Figure 25 gives the $\mathrm{CO}_{2}$-TPD patterns (measuring basicity). The optimum V-Si-P catalyst with a 1:10:2.8 atomic ratio and the 10 percent Ta-Nalco 1034A catalyst do not exhibit a prominent high temperature $\mathrm{NH}_{3}$ and $\mathrm{CO}_{2}$ desorption peak in the range of 300 to $550{ }^{\circ} \mathrm{C}$, while V-Si-P 1:2.8:2.8 and V-Si-P 1:10:10 show characteristic high temperature adsorption peaks for both $\mathrm{NH}_{3}$ and $\mathrm{CO}_{2}$. The high temperature desorption peaks correspond to high-strength acid and base sites. The presence of a high temperature peak (i.e., strongly acidic and basic sites) does not correspond to high condensation yields. This suggests that the high-strength acid and base sites may react irreversibly with the reactant molecules (propionic anhydride, propionic acid, and formaldehyde). Although the high temperature peak is also present in V-Si-P 2.8:10:2.8, the peak is not as strong as that forV-Si-P 1:2.8:2.8 and 1:10:10. Further, the V-Si-P 2.8:10:2.8 catalyst also has a prominent acid-base peak in the medium temperature region, 150 to $300{ }^{\circ} \mathrm{C}$.

The site distribution of both acid and base sites as a function of temperature (i.e., as a function of strength) can be quantified by deconvoluting the TPD spectrum $\left(\mathrm{NH}_{3}\right.$-TPD pattern for distribution of acid sites as a function of temperature and $\mathrm{CO}_{2}$-TPD pattern for the distribution of base sites as a function of temperature). The distribution of the catalyst sites of a particular type (acid or base), as a function of temperature range, can be quantified by a "q-ratio" defined as [40]

$$
\mathrm{q}=\mathrm{A}(\text { desorbed from } 323<\mathrm{T}<573 \mathrm{~K}) / \mathrm{A}(\text { desorbed from } 323 \mathrm{~K} \text { to } 823 \mathrm{~K})
$$

where A (desorbed at 323 to $573 \mathrm{~K}$ ), that is , the denominator of Equation (18) above, is the total area under the TPD spectrum. The q-ratio is thus the proportion of the activity that is "weak" (i.e., that corresponds to $\mathrm{NH}_{3}$ desorption below $523 \mathrm{~K}$ ). The results of the deconvoluted TPD- $\mathrm{CO}_{2}$ profiles in terms of the q-ratio have been summarized in Table 8. 
Table 7. Effect of Catalyst Acid-Base Properties on Methacrylic Acid Yield ${ }^{a}$

\begin{tabular}{|c|c|c|c|c|c|}
\hline $\begin{array}{l}\text { Catalyst } \\
\text { (atomic } \\
\text { ratio) }\end{array}$ & $\begin{array}{l}\text { Surface area } \\
\left(\mathrm{BET}_{-} \mathrm{N}_{2}, \mathrm{~m}^{2} / \mathrm{g}\right)\end{array}$ & $\begin{array}{c}\text { Total acidity } \\
\left(\mu \mathrm{mol} \mathrm{NH}_{3}\right) / g \\
\text { cat) }\end{array}$ & $\begin{array}{c}\text { Total acidity } \\
\text { ( } \mu \mathrm{mol} \mathrm{NH}_{3} / \mathrm{m}^{2} \\
\text { cat })\end{array}$ & $\begin{array}{c}\text { Total basicity } \\
\left(\mu \mathrm{mol} \mathrm{CO}_{2} / \mathrm{g}\right. \\
\text { cat })\end{array}$ & $\begin{array}{l}\text { Total basicity } \\
\left(\mu \mathrm{mol} \mathrm{CO}_{2} / \mathrm{m}^{2}\right)\end{array}$ \\
\hline $\begin{array}{c}\text { V-Si-P } \\
(1: 12: 2.8)\end{array}$ & 96.5 & 155.7 & 1.62 & 100.2 & 1.04 \\
\hline $\begin{array}{c}\text { V-Si-P } \\
(1: 10: 2.8)\end{array}$ & 94.2 & 150.8 & 1.61 & 96.5 & 1.01 \\
\hline $\begin{array}{c}\text { V-Si-P } \\
(1: 2.8: 2.8)\end{array}$ & 24.5 & 124.5 & 5.11 & 99.8 & 4.07 \\
\hline $\begin{array}{c}\text { V-Si-P } \\
(1: 3.57: 1)\end{array}$ & 114.2 & 174.9 & 1.53 & 59.1 & 0.52 \\
\hline $\begin{array}{c}\text { V-Si-P } \\
(1: 10: 10)\end{array}$ & 3.24 & 81.8 & 25.2 & 74.0 & 22.8 \\
\hline $\begin{array}{c}\text { Ta-1034A } \\
(10 \%)\end{array}$ & 132.1 & 24.52 & 0.186 & 26.0 & 0.197 \\
\hline
\end{tabular}

a Reaction conditions: $\mathrm{T}=300^{\circ} \mathrm{C}, \mathrm{P}=2 \mathrm{~atm}$ (30 psi in-house nitrogen), mole flow rates of propionic anhydride:formaldehyde:nitrogen $=41: 17: 220 \mathrm{mmol} / \mathrm{h}$.

Figure 24. $\mathrm{NH}_{3}$-TPD spectra of V-Si-P and tantalum catalysts.

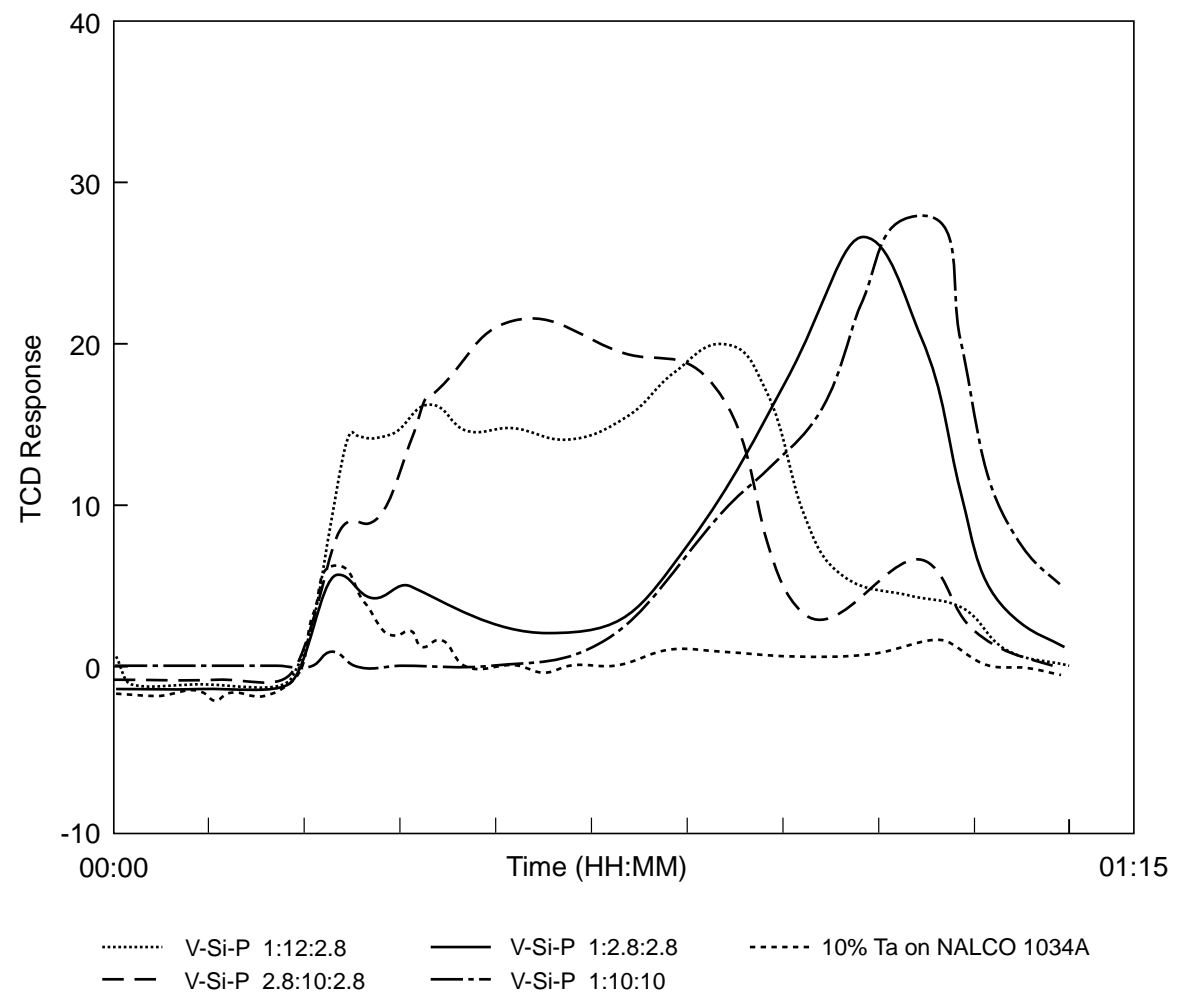




\section{Figure 25. $\mathrm{CO}_{2}$-TPD spectra of V-Si-P and tantalum condensation catalysts.}

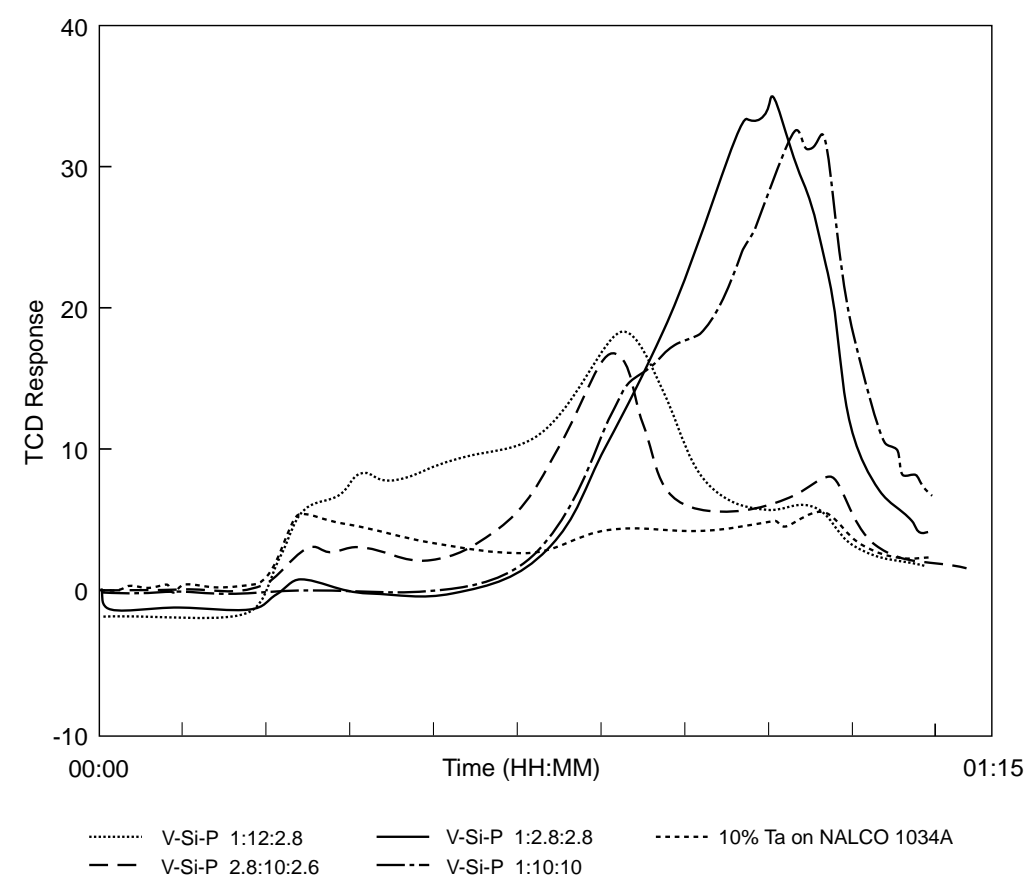

Table 8. Comparison of Formaldehyde Feedstocks ${ }^{a}$

\begin{tabular}{|c|c|c|c|c|c|c|}
\hline & \multicolumn{3}{|c|}{ MAA Yield/HCHO } & \multicolumn{3}{|c|}{ MAA Yield/PA } \\
\hline & Initial & $40 \mathrm{~h}$ & $180 \mathrm{~h}$ & Initial & $40 \mathrm{~h}$ & $180 \mathrm{~h}$ \\
\hline Trioxane ${ }^{\mathrm{b}}$ & 58.6 & 51.2 & 21.1 & 12.5 & 9.9 & 4.6 \\
\hline Formalin ${ }^{c}$ & 22.5 & 10.1 & $\operatorname{tr}^{d}$ & 4.92 & 2.2 & $\operatorname{tr}$ \\
\hline
\end{tabular}

a $\mathrm{T}=300{ }^{\circ} \mathrm{C}, \mathrm{P}=2 \mathrm{~atm}, 10 \% \mathrm{Nb} / \mathrm{SiO}_{2}$ catalyst 8-20 mesh $(0.7-1.1 \mathrm{~mm})$.

b Trioxane feed makeup: 72:16:220 mmol/h; HOPr :HCHO: $\mathrm{N}_{2}$.

c Formalin feed makeup: 72:16:38:4:220 mmol/h; $\mathrm{HOPr}: \mathrm{HCHO}: \mathrm{H}_{2} \mathrm{O}: \mathrm{CH}_{3} \mathrm{OH}: \mathrm{N}_{2}$.

${ }^{d} \operatorname{tr}=$ trace amount.

The q-ratios for the V-Si-P series of catalysts $(1: 12: 2.8,1: 10: 2.8$, and 1:3.57:1) are 0.388, 0.426, and 0.271 . The q-ratio for the 10 percent $\mathrm{Ta} / \mathrm{SiO}_{2}$ catalyst is also high at 0.278 . The lower q-ratios are directly related to lower condensation yields as evidenced by catalyst V-Si-P 1:10:10. The yield of catalyst $\mathrm{V}-\mathrm{Si}-\mathrm{P}$ 1:2.8:2.8 is also high at 38.4 percent, although this catalyst has a characteristically low q-value at 0.086 . The catalyst V-Si-P 1:10:10, which gave the lowest MAA yield, has both a low q-ratio (of 0.063 ) and a very low surface area $\left(3.24 \mathrm{~m}^{2} / \mathrm{g}\right.$ ). Thus, there is a direct correlation between surface area, q-ratio, and MAA yield.

4.2.1.2 Estimation of Activation Energy of the Desorption Peaks. The activation energy of the desorption peaks gives a quantitative measure of the temperature dependence desorption 
processes. The presence of the high temperature peak in both $\mathrm{NH}_{3}$ and $\mathrm{CO}_{2}$ desorption spectrum $(573<\mathrm{T}<823 \mathrm{~K})$ corresponds directly to lower condensation yield. These high-strength acid and base sites may react irreversibly with the reactant modules. The higher the desorption activation energy, the higher the energy barrier a reactant molecule must overcome to make it reactive.

The determination of activation energy of desorption processes has been described elsewhere $[35,36]$. For first-order desorption with a linear heating rate, and in the absence of any intra- and interparticle diffusional effects, the material balance for a preadsorbed molecule on the solid adsorbent that is subjected to thermal desorption into a carrier gas is given by

and

$$
-\mathrm{v}_{\mathrm{m}}(\delta \theta / \delta \mathrm{t})=\mathrm{v}_{\mathrm{m}} \mathrm{k}_{\mathrm{d}} \theta-\mathrm{k}_{\mathrm{a}} \mathrm{C}(1-\theta)
$$

$$
\mathrm{FC}=\mathrm{V}_{\mathrm{s}} \mathrm{v}_{\mathrm{m}} \mathrm{k}_{\mathrm{d}} \theta-\mathrm{V}_{\mathrm{s}} \mathrm{k}_{\mathrm{a}} \mathrm{C}(1-\theta) .
$$

In these expressions, $\mathrm{v}_{\mathrm{m}}$ represents the amount of sample adsorbed per unit volume of the solid phase when the surface coverage $\theta$ is unity, $\mathrm{k}_{\mathrm{d}}$ and $\mathrm{k}_{\mathrm{a}}$ are the rate constants of desorption and adsorption, respectively, $\mathrm{C}$ is the concentration of the sample in carrier gas, $\mathrm{F}$ is the carrier gas flow rate, and $\mathrm{V}_{\mathrm{s}}$ is the volume of the solid phase. For a linear heating rate defined by

$$
\mathrm{T}=\mathrm{T}_{\mathrm{o}}+\beta \mathrm{t}
$$

and assuming that the readsorption of the desorbed molecule during the course of TPD is negligible, the rate of desorption $\mathrm{k}_{\mathrm{d}}$ can be related to the activation energy of desorption by

$$
\left(\mathrm{k}_{\mathrm{d}}\right)_{\mathrm{M}}=\mathrm{A} \exp \left(-\mathrm{E}_{\mathrm{d}} / \mathrm{RT}_{\mathrm{M}}\right)=\beta \mathrm{E}_{\mathrm{d}} / \mathrm{RT}_{\mathrm{M}}{ }^{2} .
$$

At any known rate of catalyst heating $\beta$, Equation (26) defines the activation energy of desorption $\mathrm{E}_{\mathrm{d}}$ for an observed temperature of peak maximum $\mathrm{T}_{\mathrm{M}}$. Given that $\mathrm{A}$ is known, or if a reasonable value can be assumed for it, the value of $\mathrm{E}_{\mathrm{d}}$ can be determined from Equation (20).

Frequently, when "A" values are not known or cannot be assumed within a reasonable range, Equation (26) can be rewritten in the form:

$$
2 \ln \mathrm{T}_{\mathrm{M}}-\ln \beta=\mathrm{E}_{\mathrm{d}} / \mathrm{RT}_{\mathrm{M}}+\ln \left(\mathrm{E}_{\mathrm{d}} / \mathrm{AR}\right) .
$$

Thus, a plot of $\left(2 \ln T_{M}-\ln \beta\right)$ vs. $1 / T_{M}$ will be, in principle, useful for determining $E_{d}$ and $A$.

The V-Si-P series of catalysts were subjected to different desorption heating rates. Following isothermal adsorption from a 10 percent $\mathrm{NH}_{3} / \mathrm{N}_{2}$ adsorbing gas at $323 \mathrm{~K}$ for $30 \mathrm{~min}$, the TPD$\mathrm{NH}_{3}$ was carried out at five different heating rates: $1,5,10,20$, and $30{ }^{\circ} \mathrm{C} / \mathrm{min}$. The characteristic $\mathrm{NH}_{3}$-TPD curves for these five heating rates are shown in Figures 26 through 30 . The temperature of the peak maximum (for the high-strength acid peak) as a function of the heating rate is summarized in Table 7. 
Figure 26. $\mathrm{NH}_{3}$-TPD pattern for V-Si-P 1:12:2.8 catalyst, TPD heating rate $1^{\circ} \mathrm{C} / \mathrm{min}$.

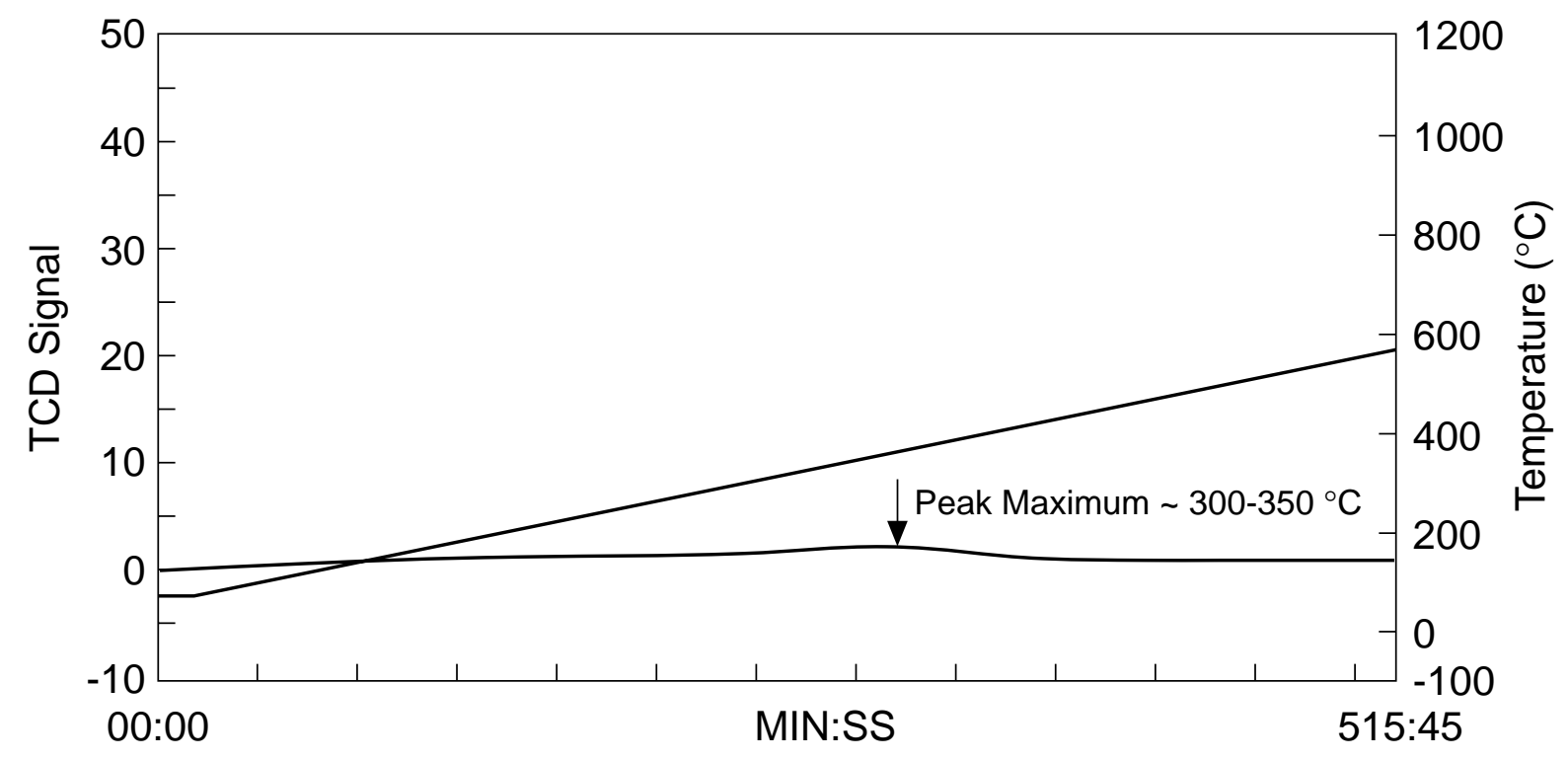

Figure 27. $\mathrm{NH}_{3}$-TPD pattern for V-Si-P 1:12:2.8 catalyst, TPD heating rate $5{ }^{\circ} \mathrm{C} / \mathrm{min}$.

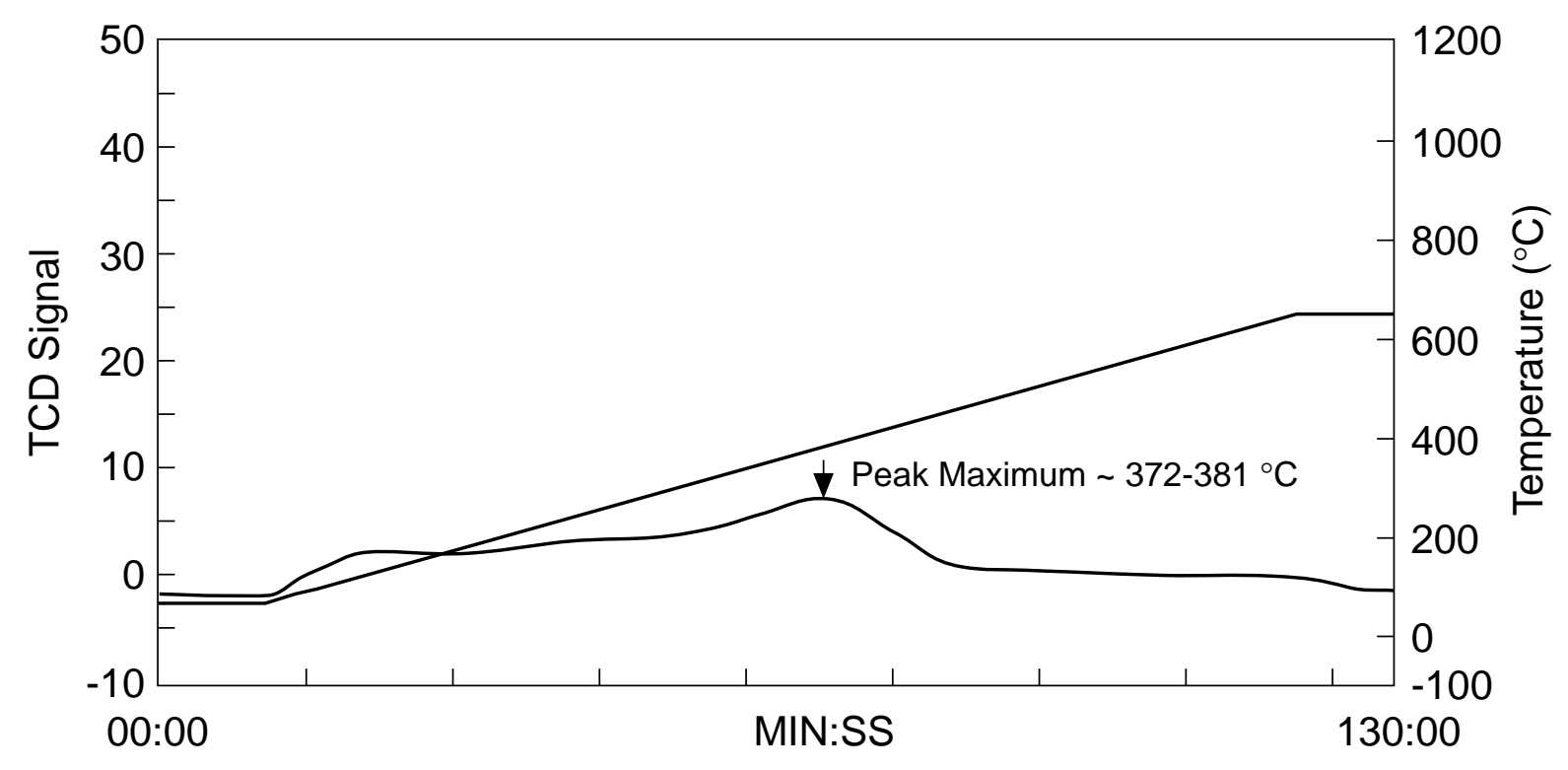


Figure 28. $\mathrm{NH}_{3}$-TPD pattern for V-Si-P 1:12:2.8 catalyst, TPD heating rate $10{ }^{\circ} \mathrm{C} / \mathrm{min}$.

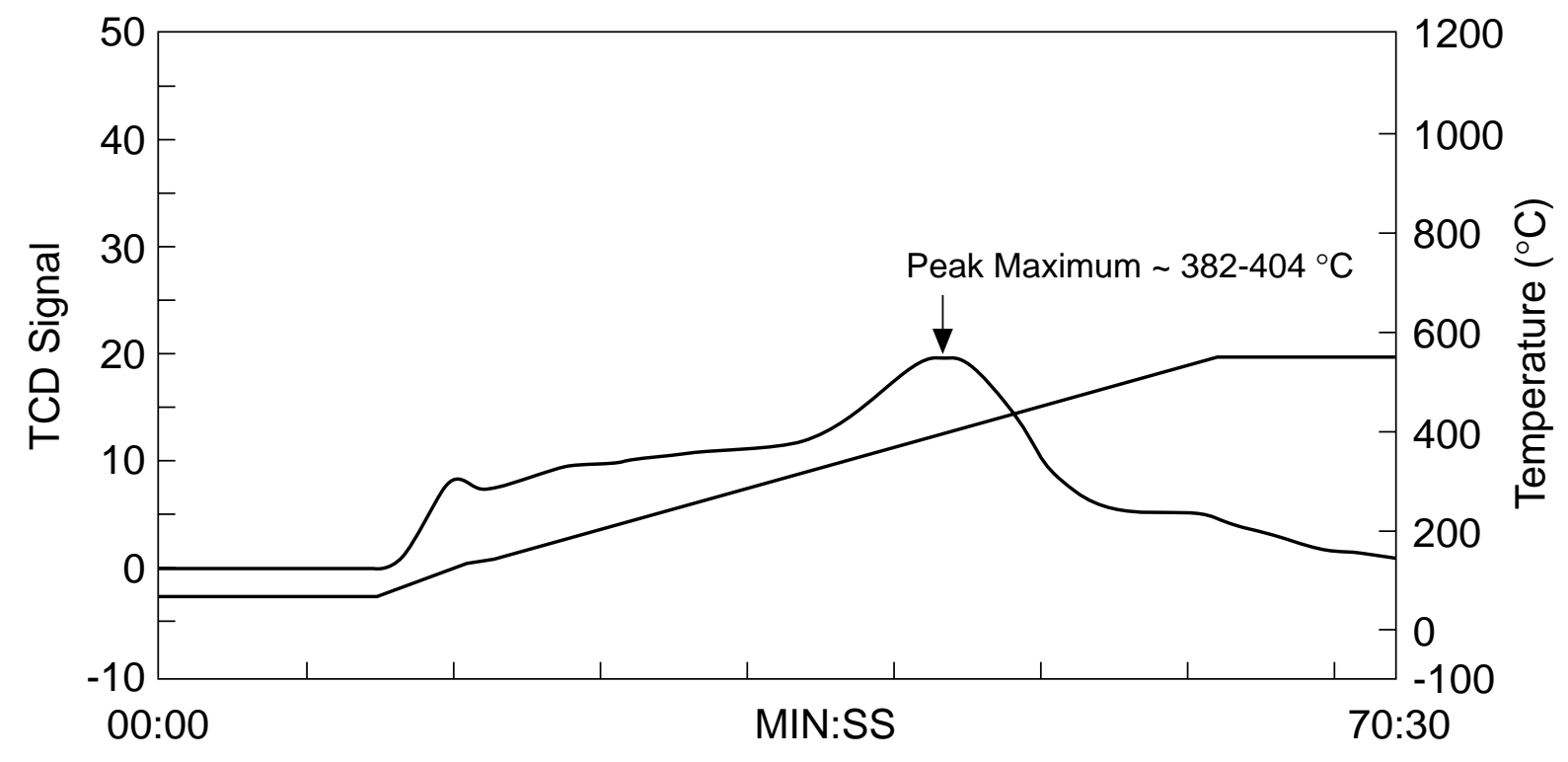

Figure 29. $\mathrm{NH}_{3}$-TPD pattern for V-Si-P 1:12:2.8 catalyst, TPD heating rate $20^{\circ} \mathrm{C} / \mathrm{min}$.

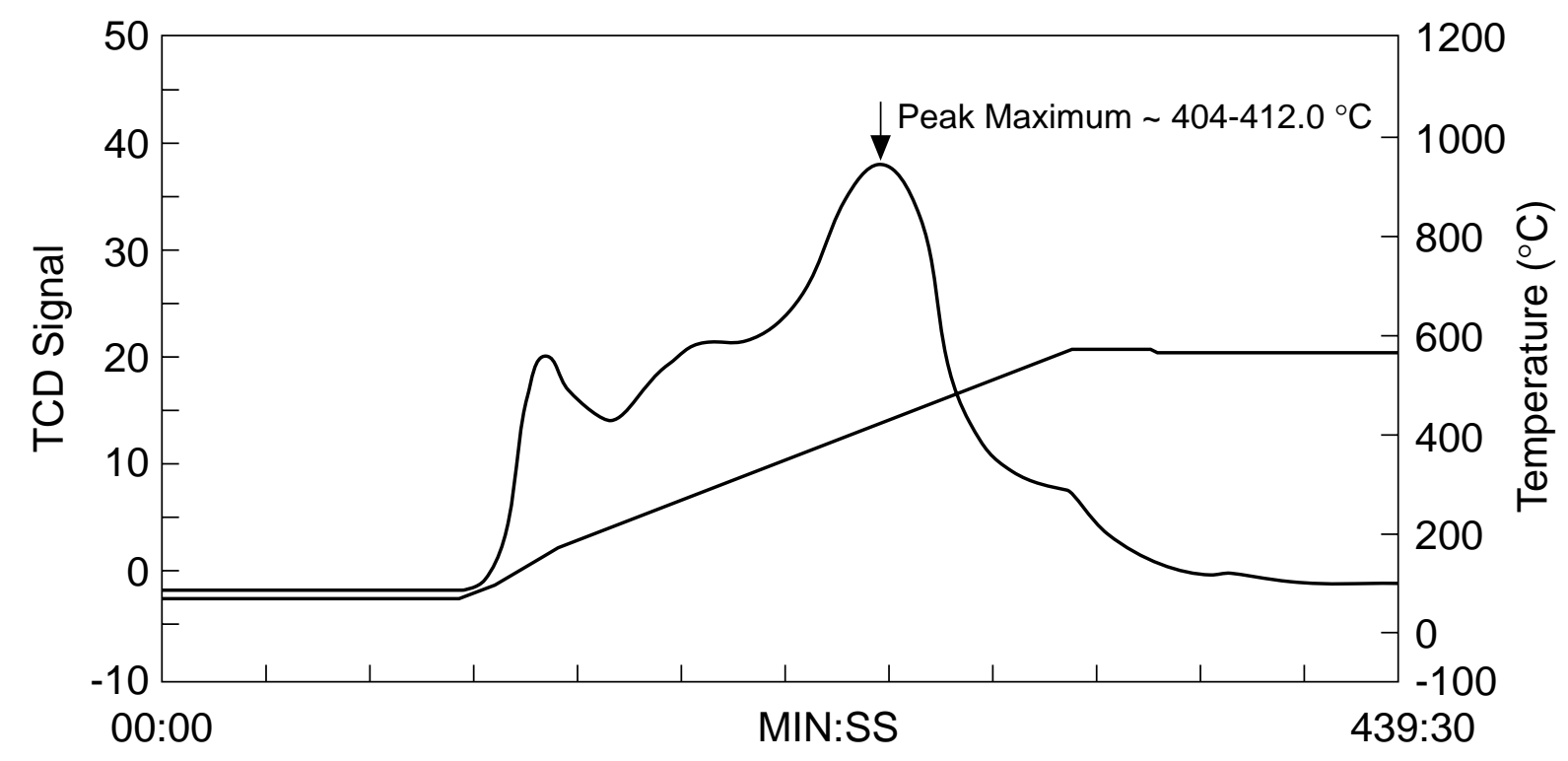


Figure 30. $\mathrm{NH}_{3}$-TPD pattern for V-Si-P 1:12:2.8 catalyst, TPD heating rate $30^{\circ} \mathrm{C} / \mathrm{min}$.

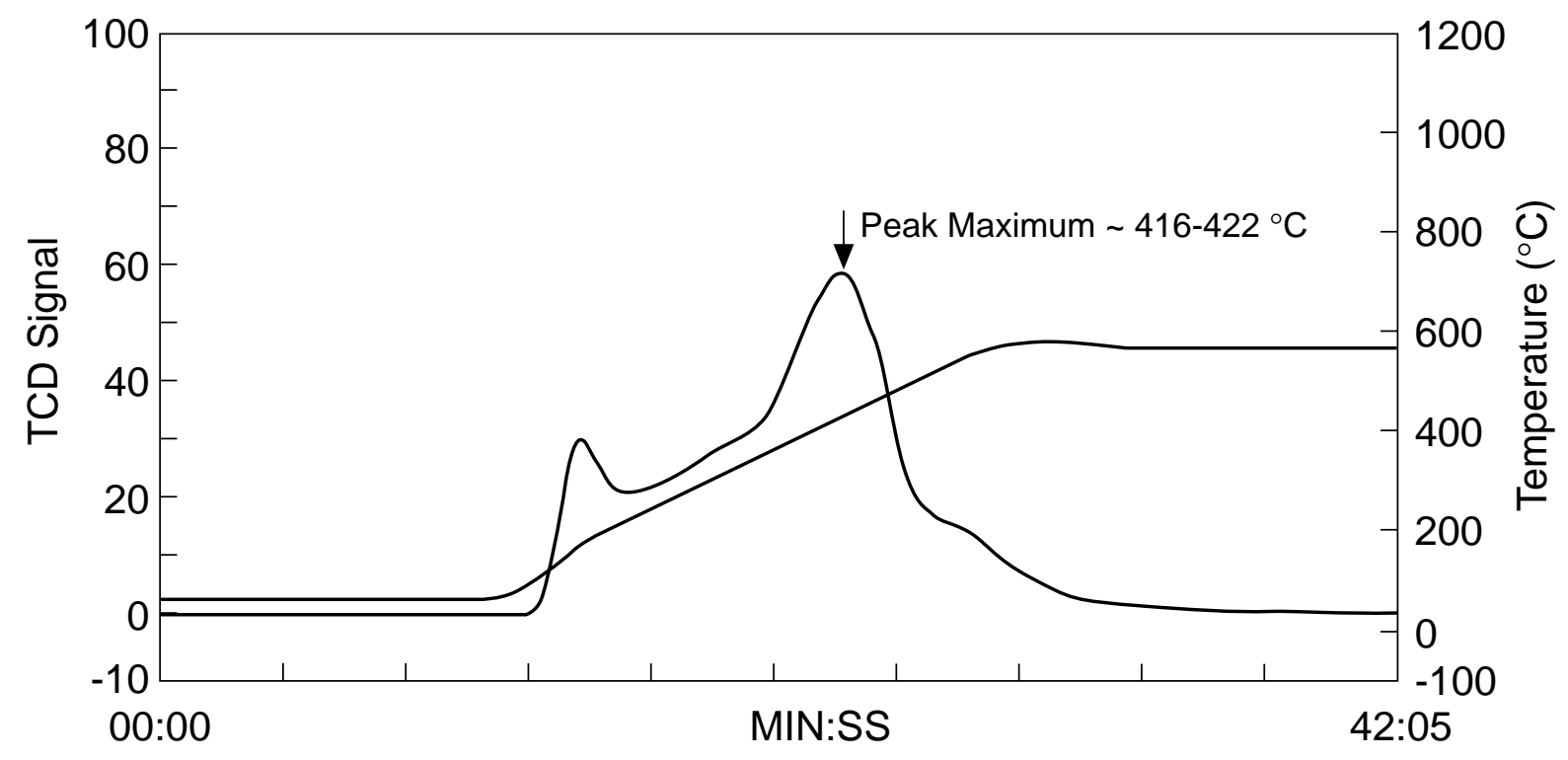

The slope of the plot of $\left(2 \ln T_{M}-\ln \beta\right)$ vs. $1 / T_{M}$ is $1.28 \times 10^{4}$. The slope is the value of $E_{d} / R$, so the activation energy of the high temperature desorption peak is estimated to be $25.4 \mathrm{kcal} / \mathrm{mol}$. It is clear from the MMA yield that high-temperature peak (corresponding to high-strength acid sites) contributes directly to lower yields, suggesting that a catalyst with an activation energy equal to or higher than $25.4 \mathrm{kcal} / \mathrm{mol}$ will be less active than the optimum V-Si-P catalyst.

\subsubsection{Formalin as an Alternative Feedstock}

Formalin was evaluated as an alternative feedstock to trioxane, because it is an inexpensive source of formaldehyde. It is readily available and consists of a solution of $37 \mathrm{wt} \%$ formaldehyde in water, with about 8 to 10 percent methanol as a stabilizer.

The comparison between trioxane and formalin as the feedstock is shown in Table 7. The results clearly show that both the initial yield of MAA and the long-term MAA yield using trioxane is higher than with formalin. While the initial MAA yield was 58.6 percent using trioxane, the yield was only 22.5 percent using formalin. Over a 180 -h reaction test, the MAA yield decreased from 58.6 percent to 21.1 percent for trioxane, while the 10 percent $\mathrm{Nb} / \mathrm{SiO}_{2}$ catalyst deactivated to almost trace MAA yields under the same test conditions using formalin. The MAA yield for this long-term activity test is shown in Figure 31. The material balance for each of the data points was carefully checked and is also included in Figure 31. The average carbon balance for this experimental set is approximately 92 percent. One unexpected trend was the increased CO formation rates with formalin as the feed, shown in Figure 32. While the initial rate of CO is only at $0.15 \mathrm{mmol} / \mathrm{g}$ cat $\mathrm{h}$, the $\mathrm{CO}$ and MAA formation rates nearly become equal after about $50 \mathrm{~h}$ of reaction time. While the mechanism for increased $\mathrm{CO}$ formation with formalin is not yet completely understood, it can be speculated that $\mathrm{CO}$ formation occurs via $\mathrm{HCHO}$ decomposition 
Figure 31. Results of long-term activity test with $10 \% \mathrm{Nb} / \mathrm{SiO}_{2}$ catalyst-

MAA yields.

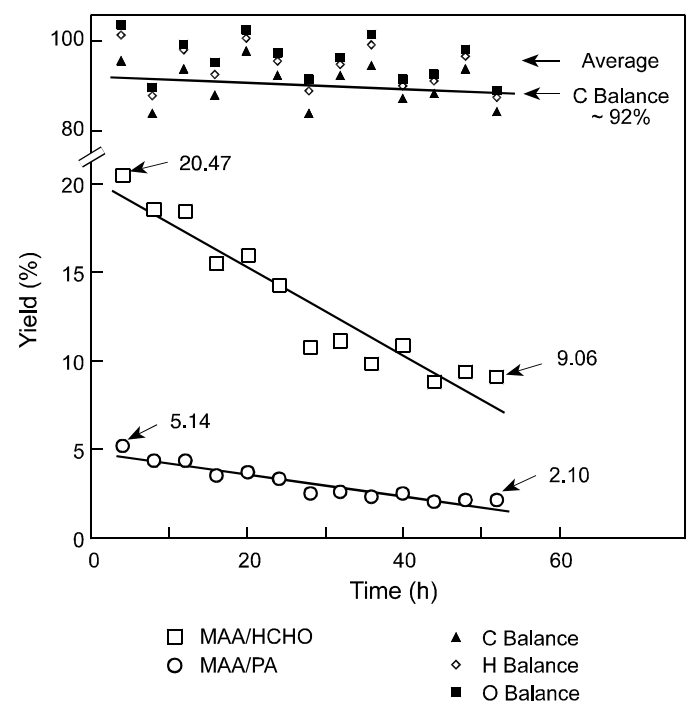

Experimental Conditions: $\mathrm{T}=300{ }^{\circ} \mathrm{C}, \mathrm{P}=2 \mathrm{~atm}, 5 \mathrm{~g} \mathrm{8-20}$ mesh $(0.7-1.1 \mathrm{~mm})$ $\mathrm{Nb} / \mathrm{SiO}_{2}$ catalyst, feed makeup $=72: 16: 38: 4: 220 \mathrm{mmol}$ propionic acid: formaldehyde:water:methanol:nitrogen

Figure 32. Results of long-term activity test with $10 \% \mathrm{Nb} / \mathrm{SiO}_{2}$ catalyst-MAA and $\mathrm{CO}$ rates.

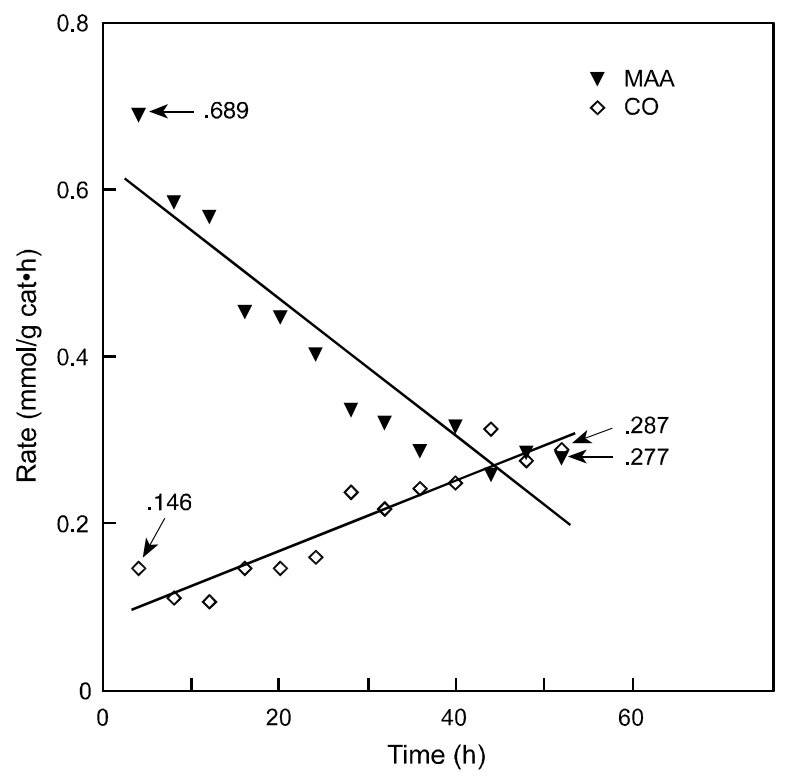

Experimental Conditions: $\mathrm{T}=300^{\circ} \mathrm{C}, \mathrm{P}=2 \mathrm{~atm}, 5 \mathrm{~g}$ 8-20 mesh $(0.7-1.1 \mathrm{~mm})$ $\mathrm{Nb} / \mathrm{SiO}_{2}$ catalyst, feed makeup $=72: 16: 38: 4: 220 \mathrm{mmol}$ propionic acid: formaldehyde:water:methanol:nitrogen. 
$\left(\mathrm{HCHO} \rightarrow \mathrm{CO}+\mathrm{H}_{2}\right)$. The presence of methanol and water in the feed may alter the oxidation state of niobium. The oxidation state of $\mathrm{Nb}$ in $\mathrm{Nb}_{2} \mathrm{O}_{5}$ is +5 , and this oxidation state may be reduced to a lower value in the presence of reductants. The presence of water vapor from the formalin also decreases the reaction rate compared to earlier studies [13].

\subsubsection{Characterization with TGA, XRD, and XPS}

An earlier long-term deactivation run showed that the 10 percent $\mathrm{Nb} / \mathrm{SiO}_{2}$ is the most active and stable catalyst on a normalized MAA-yield basis [37]. Coke burnoff at $300{ }^{\circ} \mathrm{C}$ under a mildly oxidizing environment did not restore the catalytic activity of 10 percent $\mathrm{Nb} / \mathrm{SiO}_{2}$, unlike the $\mathrm{V}-\mathrm{Si}-\mathrm{P}$ and Ta catalysts. It was suspected that the nature of coke and content may be different in the $\mathrm{Nb}$ case compared with the $\mathrm{V}-\mathrm{Si}-\mathrm{P}$ and Ta catalysts. Thermogravimetric analysis (TGA) test (Figure 33) on the deactivated $\mathrm{Nb}$ catalyst showed that coke burnoff occurs at $370{ }^{\circ} \mathrm{C}$; therefore, the $300{ }^{\circ} \mathrm{C}$ regeneration temperature was not sufficient for coke oxidation and burnoff. The TGA test also showed that the coke loading also is higher for the $\mathrm{Nb}$ (ca. 12 to 13 percent) compared to the V-Si-P catalyst (ca. 6 percent), which explains the more rapid deactivation and difficulty in regeneration.

As reported in Section 4.2.2, $\mathrm{Nb} / \mathrm{SiO}_{2}$ catalyst deactivated to almost trace MAA yields after the same test in the presence of formalin. In order to further examine the reasons for this rapid catalyst deactivation in the presence of formalin, RTI and Eastman carried out a detailed XRD analysis and XPS on the used 20 percent $\mathrm{Nb} / \mathrm{SiO}_{2}$. The XRD pattern for the fresh 20 percent $\mathrm{Nb} / \mathrm{SiO}_{2}$ catalyst is shown in Figure 34. The corresponding peak identification has been summarized in Table 9. The XRD pattern for the deactivated 20 percent $\mathrm{Nb} / \mathrm{SiO}_{2}$ and comparative XRD patterns of fresh and deactivated 20 percent $\mathrm{Nb} / \mathrm{SiO}_{2}$ catalysts are shown in Figures 35 and 36. The peak identification corresponding to the XRD pattern for the deactivated catalyst is shown in Table 10.

From the XRD patterns, there are at least nine well-defined crystalline peaks for the fresh 20 percent $\mathrm{Nb} / \mathrm{SiO}_{2}$ catalyst. The peak at d-spacing of $3.92 \AA$ corresponding to $2 \theta=22.6^{\circ}$ results from $\mathrm{Nb}_{2} \mathrm{O}_{5}(\mathrm{Nb}(\mathrm{V})$ oxide); the intensity match for this peak with the standard library component for pure $\mathrm{Nb}_{2} \mathrm{O}_{5}$ is 100 percent. Other peaks corresponding to d-spacing of 3.12, 2.74, 2.44, and 1.96 also match pure $\mathrm{Nb}_{2} \mathrm{O}_{5}$, although the match is significantly less than 100 percent. For both the fresh and deactivated catalyst, the XRD results suggest that the bulk oxide phase is pentavalent niobium oxide $\left(\mathrm{Nb}_{2} \mathrm{O}_{5}\right)$. This suggests that there is no change of oxidation state for the deactivated catalyst: no divalent niobium $(\mathrm{NbO})$ or tetravalent niobium $\left(\mathrm{NbO}_{2}\right)$ peaks were observed.

Comparing the fresh catalyst to the deactivated catalyst, peaks corresponding to d-spacing of 2.44 $\AA$, $1.81 \AA$, and $1.66 \AA$ (equivalent $2 \theta$ s are $36.7,50.4$, and 55.2) are absent, indicating that there is a significant loss in crystallinity. The peak broadening (d-spacing, $3.92 \AA, 2 \theta=32.60)$ for the deactivated catalyst suggests that the crystallite size for the deactivated catalyst is reduced compared with that for a fresh catalyst. For example, the peaks for the deactivated catalyst all appear to be broader and less intense. A higher peak width at half peak-intensity suggests again that crystallites for the deactivated catalysts are finer and smaller, compared to those for the fresh 
Figure 33. TGA test on deactivated $10 \% \mathrm{Nb} / \mathrm{SiO}_{2}$ catalyst.

Coke burnoff occurs $\sim 370{ }^{\circ} \mathrm{C}$

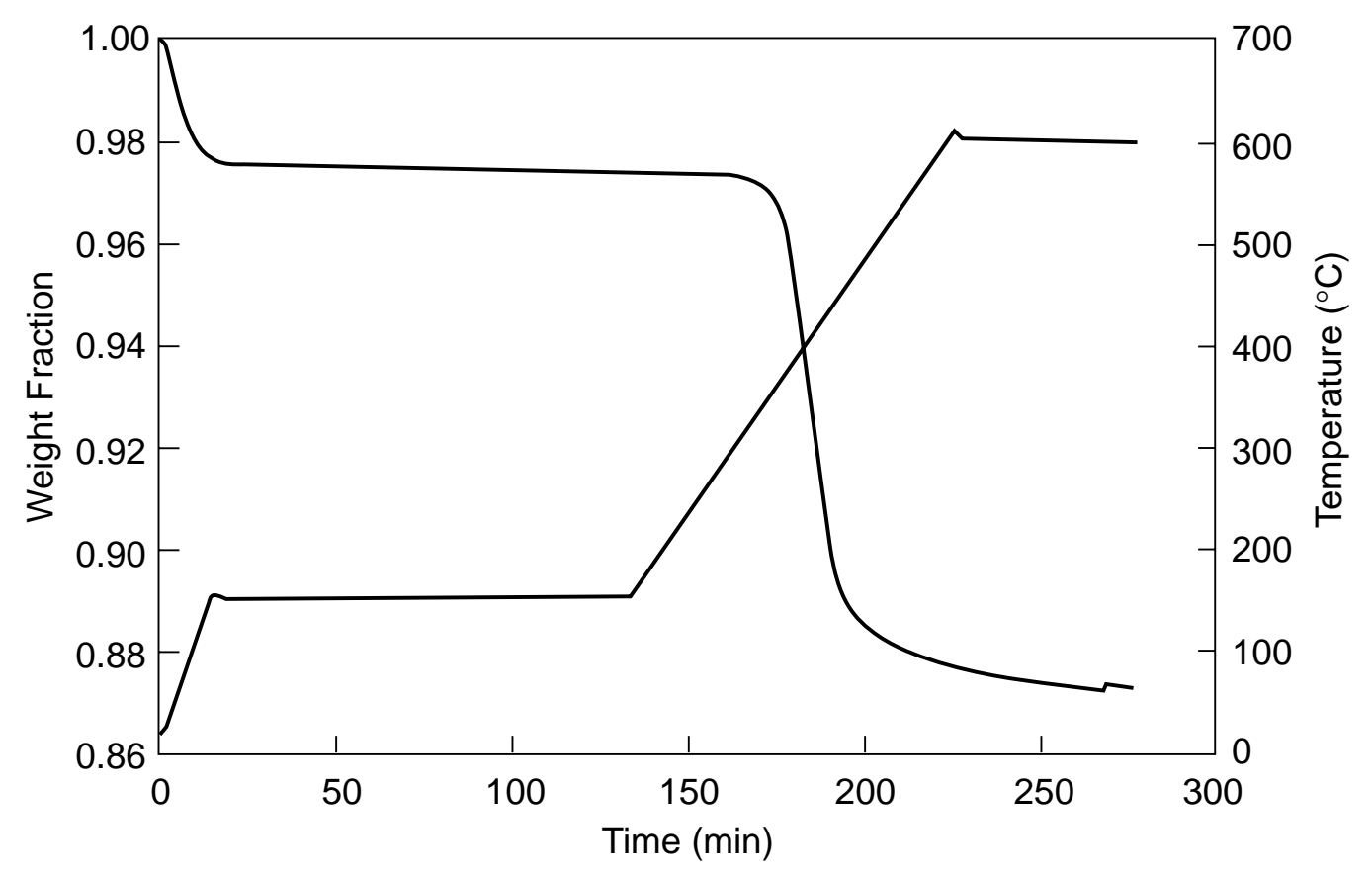

Figure 34. XRD pattern for a fresh $20 \% \mathrm{Nb} / \mathrm{SiO}_{2}$ catalyst.

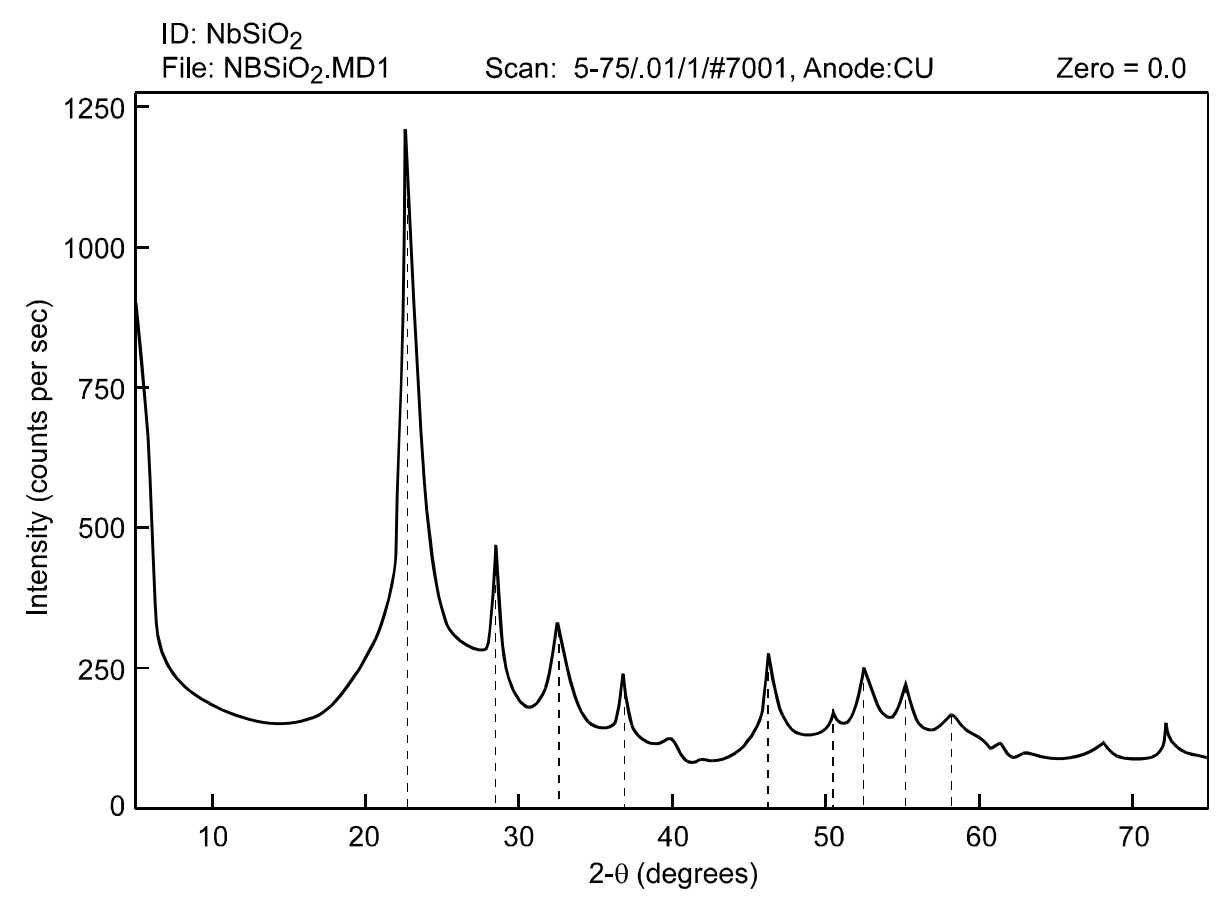


Table 9. Peak Listing for a XRD of a Fresh $20 \% \mathrm{Nb} / \mathrm{SiO}_{2}$ Catalyst

\begin{tabular}{ccccccc}
\hline Peak No. & $\mathbf{2 \theta}$ & $\mathbf{d}(\mathbf{\AA})$ & Background & Peak & $\begin{array}{c}\text { Intensity } \\
(\%)\end{array}$ & Area \\
\hline 1 & 22.6 & 3.92 & 337 & 875 & 100 & 67,489 \\
2 & 28.5 & 3.12 & 230 & 241 & 27.5 & 9,056 \\
3 & 32.5 & 2.74 & 160 & 165 & 18.9 & 7,025 \\
4 & 36.7 & 2.44 & 115 & 129 & 14.7 & 1,127 \\
5 & 46.2 & 1.96 & 109 & 173 & 19.8 & 8,794 \\
6 & 50.4 & 1.81 & 120 & 65 & 7.4 & 383 \\
7 & 52.5 & 1.74 & 139 & 124 & 14.2 & 2,284 \\
8 & 55.2 & 1.66 & 133 & 88 & 10.1 & 461 \\
9 & 58.1 & 1.58 & 100 & 96 & 11.0 & 791 \\
\hline
\end{tabular}

Figure 35. XRD pattern for deactivated $20 \% \mathrm{Nb} / \mathrm{SiO}_{2}$ catalyst.

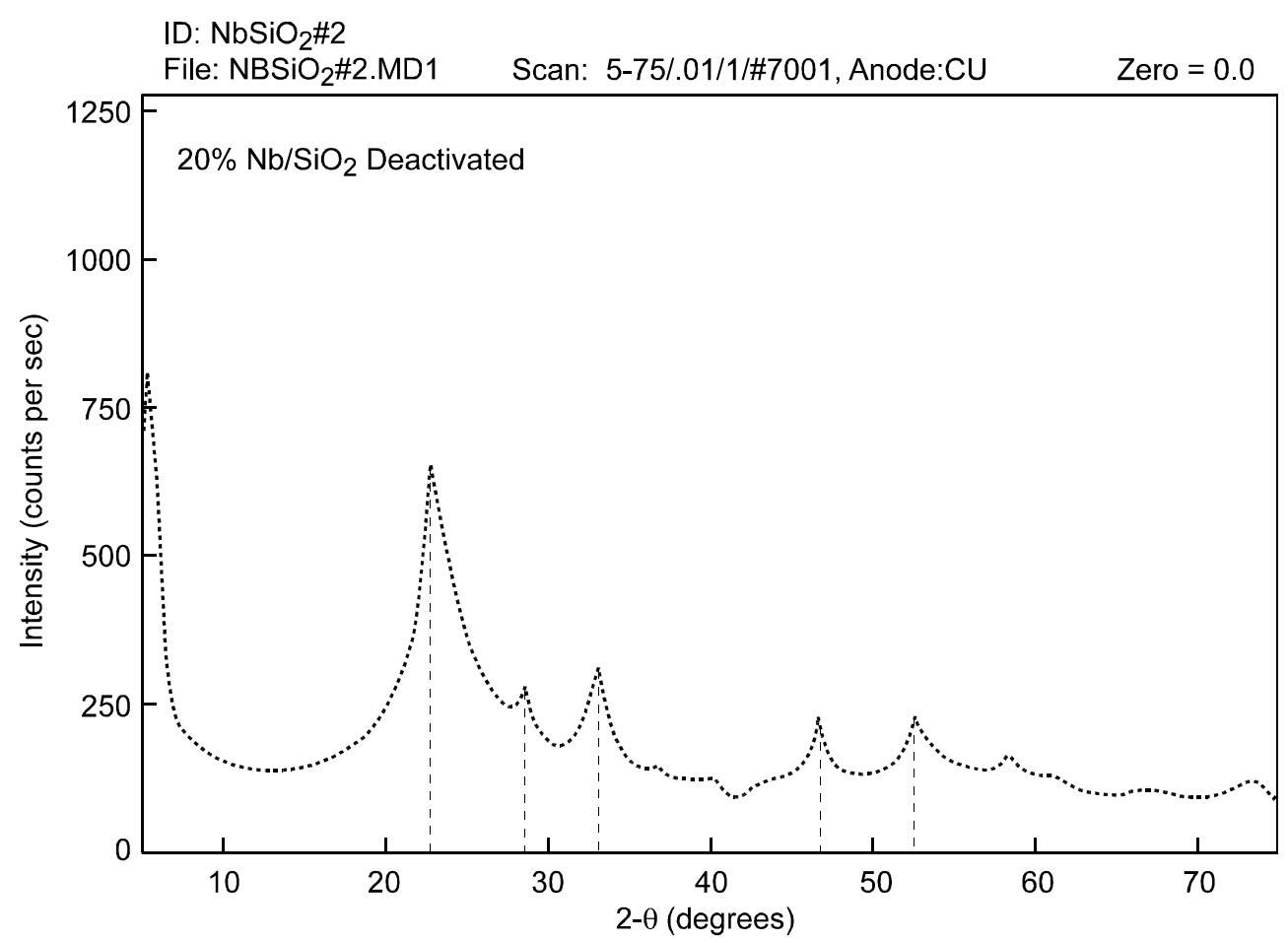


Figure 36. Comparative XRD patterns for fresh and deactivated $20 \%$ $\mathrm{Nb} / \mathrm{SiO}_{2}$ catalyst.

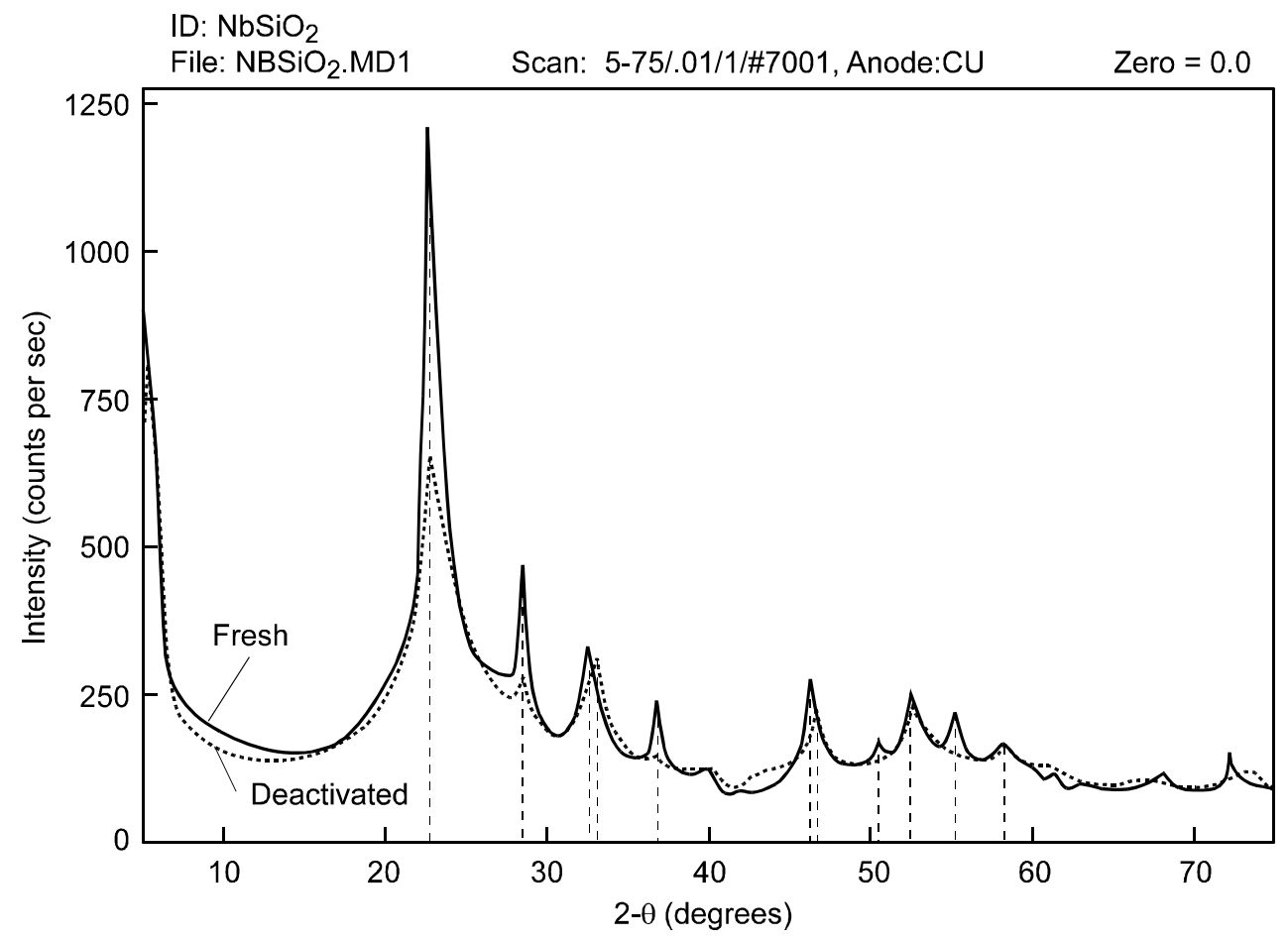

Table 10. Peak Listing for XRD of a Deactivated $20 \% \mathrm{Nb} / \mathrm{SiO}_{2}$ Catalyst

\begin{tabular}{ccccccr}
\hline Peak No. & $\mathbf{2 \theta}$ & $\mathbf{d}(\AA)$ & Background & Peak & Intensity (\%) & Area \\
\hline 1 & 23.0 & 3.86 & 333 & 319 & 100 & 24,329 \\
2 & 28.6 & 3.11 & 200 & 77 & 24.1 & 283 \\
3 & 33.2 & 2.69 & 170 & 141 & 44.2 & 361 \\
4 & 46.8 & 1.94 & 111 & 79 & 24.8 & 2,255 \\
5 & 52.8 & 1.73 & 139 & 89 & 27.9 & 595 \\
6 & 58.2 & 1.58 & 117 & 52 & 16.3 & 360 \\
\hline
\end{tabular}

catalyst. While the interference due to the presence of coke on the catalyst surface and/or smaller particle size can result in generally broader peaks for the deactivated catalyst, the XRD analysis indicates that the redispersion of metal crystallites may reduce the crystallite size, with time onstream, under formalin conditions.

Eastman Chemical also carried out the XPS studies on fresh and deactivated niobium catalysts. The results are shown in Figures 37 through 39. Figure 37 shows the XPS pattern for a fresh 20 percent $\mathrm{Nb}_{2} \mathrm{O}_{5} / \mathrm{SiO}_{2}$ catalyst, along with the concentrations of surface atoms for carbon, oxygen, silicon, niobium, and fluorine. (Fluorine results from $\mathrm{NbF}_{5}$, a starting material in catalyst 
Figure 37. XPS pattern for a deactivated $20 \%$ $\mathrm{Nb}_{2} \mathrm{O}_{5} / \mathrm{SiO}_{2}$ catalyst.

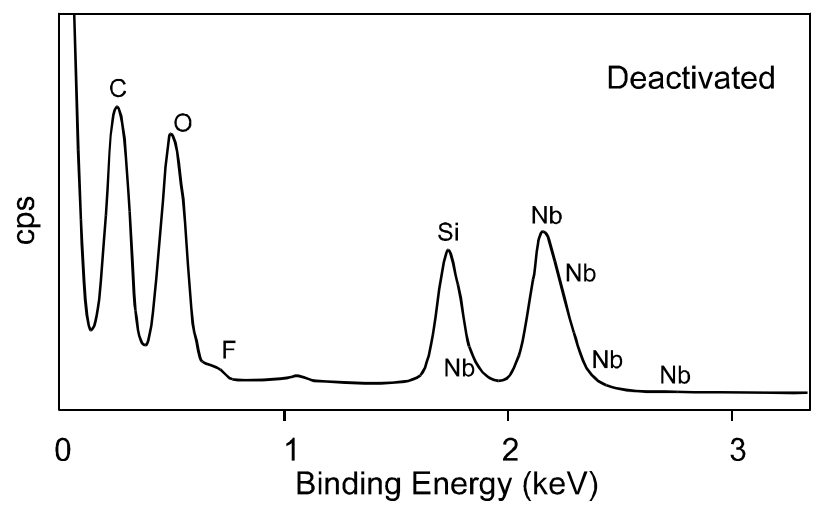

\begin{tabular}{|l|c|c|c|}
\hline Element & $\begin{array}{c}\text { Height } \\
\text { (cps) }\end{array}$ & $\begin{array}{c}\text { Sensitivity } \\
\text { Factor }\end{array}$ & $\begin{array}{c}\text { Concentration } \\
\text { (\%) }\end{array}$ \\
\hline C1s & 1630 & 0.296 & 17.38 \\
O1s & 11521 & 0.711 & 51.14 \\
Si2p & 2161 & 0.262 & 26.03 \\
Nb3d & 1535 & 1.647 & 2.94 \\
F1s & 796 & 1.000 & 2.51 \\
\hline
\end{tabular}

Figure 38. XPS pattern for a fresh $20 \% \mathrm{Nb}_{2} \mathrm{O}_{5} / \mathrm{SiO}_{2}$ catalyst.

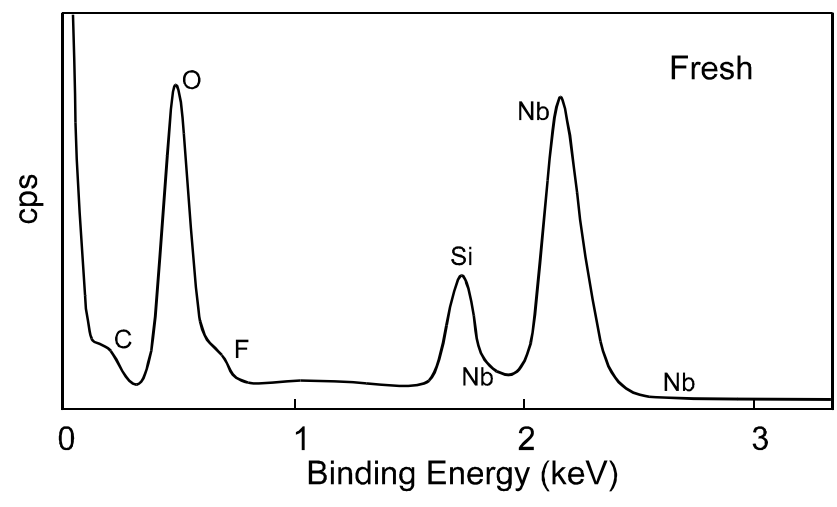

\begin{tabular}{|l|c|c|c|}
\hline Element & $\begin{array}{c}\text { Height } \\
\text { (cps) }\end{array}$ & $\begin{array}{c}\text { Sensitivity } \\
\text { Factor }\end{array}$ & $\begin{array}{c}\text { Concentration } \\
\text { (\%) }\end{array}$ \\
\hline C1s & 908 & 0.296 & 6.83 \\
O1s & 17530 & 0.711 & 54.86 \\
Si2p & 3522 & 0.262 & 29.91 \\
Nb3d & 2760 & 1.647 & 3.73 \\
F1s & 2098 & 1.000 & 4.67 \\
\hline
\end{tabular}




\section{Figure 39. Comparative XPS patterns for fresh and deactivated $20 \% \mathrm{Nb}_{2} \mathrm{O}_{5} / \mathrm{SiO}_{2}$ catalysts.}

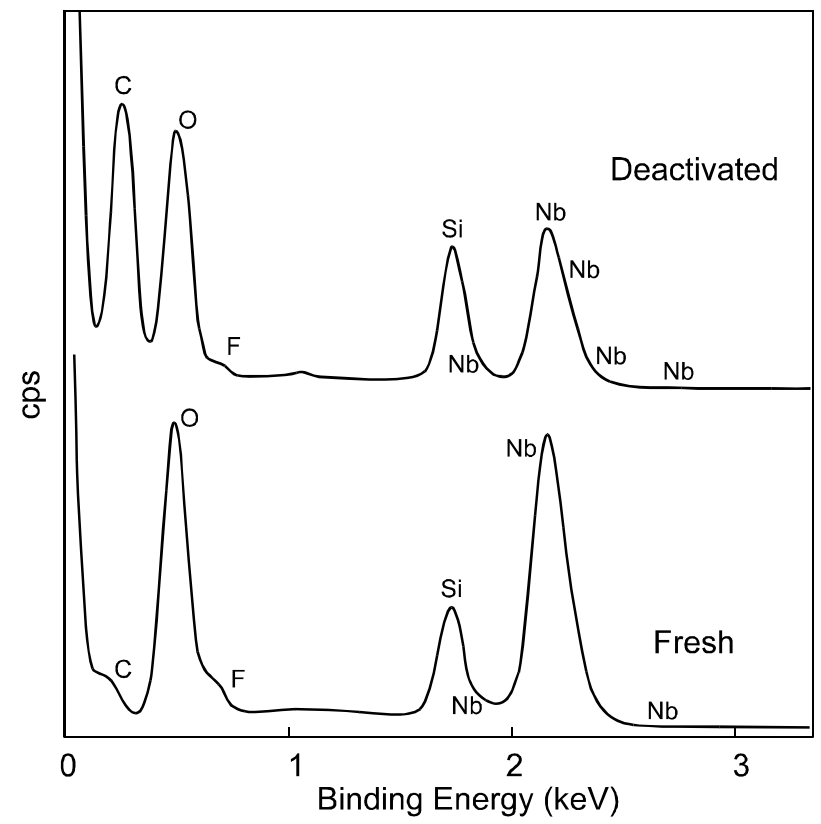

preparation. Silicon is from the $\mathrm{SiO}_{2}$ catalyst support.) The XPS pattern for the deactivated catalyst is shown in Figure 38, and the XPS spectra of the two catalysts are shown togther in Figure 39. Several observations are apparent as the catalyst deactivates:

- Carbon on the catalyst surface increases from 6.83 to 17.38 percent.

- Surface niobium concentration decreases from 3.73 to 2.94 percent.

- Silicon, oxygen, and fluorine concentrations are relatively invariant.

The XPS analysis shows that an increase in carbon surface concentration and a concomitant decrease in surface niobium, which might be covered preferentially by the coke, leads to catalyst deactivation.

To obtain another series of fresh, deactivated, and reactivated catalysts for XPS analysis, a longterm activity test on a 10 percent $\mathrm{Nb}_{2} \mathrm{O}_{5} / \mathrm{SiO}_{2}$ catalyst was carried out at $300{ }^{\circ} \mathrm{C}$ over a 70 -h period. To examine the causes of catalyst deactivation, surface area, pore volume, and TGA, characterization tests were carried out on the fresh, deactivated, and reactivated catalysts. (Reactivation was carried out with a 2 percent $\mathrm{O}_{2} / \mathrm{N}_{2}$ gas mixture for $24 \mathrm{~h}$, at $400{ }^{\circ} \mathrm{C}$, with a nominal flow rate of $120 \mathrm{~mL}(\mathrm{STP}) / \mathrm{min}$.) The comparative TGA plot among the four catalysts is shown in Figure 40. For the deactivated catalyst (DEACT.6/18/97), TGA weight loss indicates that there is about 7.14 percent carbon on the catalyst surface. The TGA patterns of the fresh, reactivated ( (REACT. 6/20/97)) and reactivated ( (REACT. 7/1/97))are virtually identical, suggesting a near complete coke burn-off in these two successive reactivations. Comparative plots of the fresh, deactivated (DEACT. 6/18/97), and reactivated (REACT. 7/1/97) also suggest 
Figure 40. Comparative TGA plots of fresh, deactivated, and reactivated $10 \% \mathrm{Nb}_{2} \mathrm{O}_{5} / \mathrm{SiO}_{2}$ catalysts.

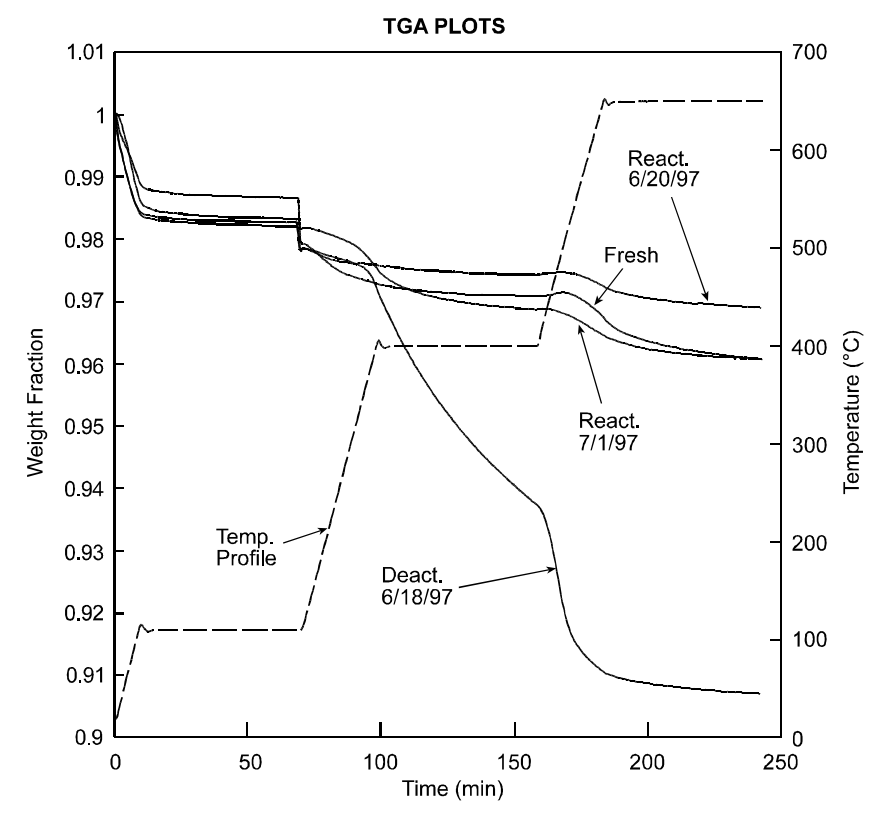

that coke deposition is a slow, gradual process. The cumulative pore areas as a function of pore size for the four catalysts are shown in Figures 41 (fresh catalyst), 42 (deactivated catalyst), 43 (reactivated catalyst), and 44 (reactivated catalyst subjected to $5 \mathrm{~h}$ on stream, under formalin conditions). The results show that the pore size distribution of the four catalysts is virtually identical, indicating that there is no loss/change in internal pore structure of the catalyst. The results in Table 11, which lists the BET- $\mathrm{N}_{2}$ surface area, total mercury intrusion volume, total pore area, average pore diameter, and porosity of each of these catalysts, also suggest that the deactivation occurs by carbon deposition and is completely reversible under mildly oxidizing conditions.

Because unsupported niobia $\left(\mathrm{Nb}_{2} \mathrm{O}_{5}\right)$ is much less expensive than the supported niobia, a pure $\mathrm{Nb}_{2} \mathrm{O}_{5}$ catalyst (Alfa Aesar) was tested. The as-received catalyst was calcined at $350{ }^{\circ} \mathrm{C}$ for $4 \mathrm{~h}$ and at $450{ }^{\circ} \mathrm{C}$ for $6 \mathrm{~h}$ in a forced-air convection oven. The catalyst was sieved into a 0.7 - to 1.1-mm size fraction for condensation tests. The catalyst (5-g portion) was tested at the following conditions:

- $\mathrm{T}=300{ }^{\circ} \mathrm{C}$

- $\mathrm{P}=4 \mathrm{~atm}$

- $\mathrm{W}=5 \mathrm{~g}$

- $\mathrm{F}=72: 38: 16: 4: 220 \mathrm{mmol} / \mathrm{h}, \mathrm{HOPr}: \mathrm{H}_{2} \mathrm{O}: \mathrm{HCHO}: \mathrm{CH}_{3} \mathrm{OH}: \mathrm{N}_{2} \mathrm{O}$.

The results, summarized in Table 12, show that pure $\mathrm{Nb}_{2} \mathrm{O}_{5}$ had a much lower initial MAA yield (8.8 percent vs. 22.5 percent) than a 10 percent $\mathrm{Nb}_{2} \mathrm{O}_{5} / \mathrm{SiO}_{2}$ when formalin was used. 
Figure 41. Pore size distribution for a fresh $10 \% \mathrm{Nb}_{2} \mathrm{O}_{5} / \mathrm{SiO}_{2}$ catalyst.

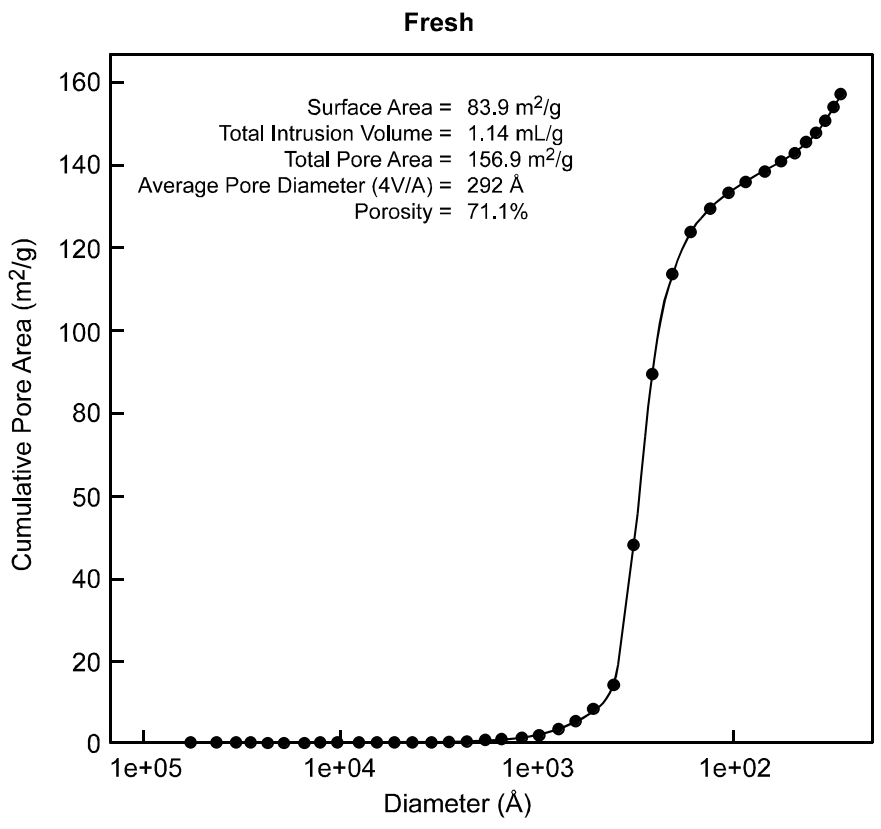

Figure 42. Pore size distribution for a reactivated $10 \% \mathrm{Nb}_{2} \mathrm{O}_{5} / \mathrm{SiO}_{2}$ catalyst (regenerated using a $2 \% \mathrm{O}_{2} / \mathrm{N}_{2}$ mixture at $120 \mathrm{~mL} / \mathrm{min}$ at $400{ }^{\circ} \mathrm{C}$ for $24 \mathrm{~h}$ ).

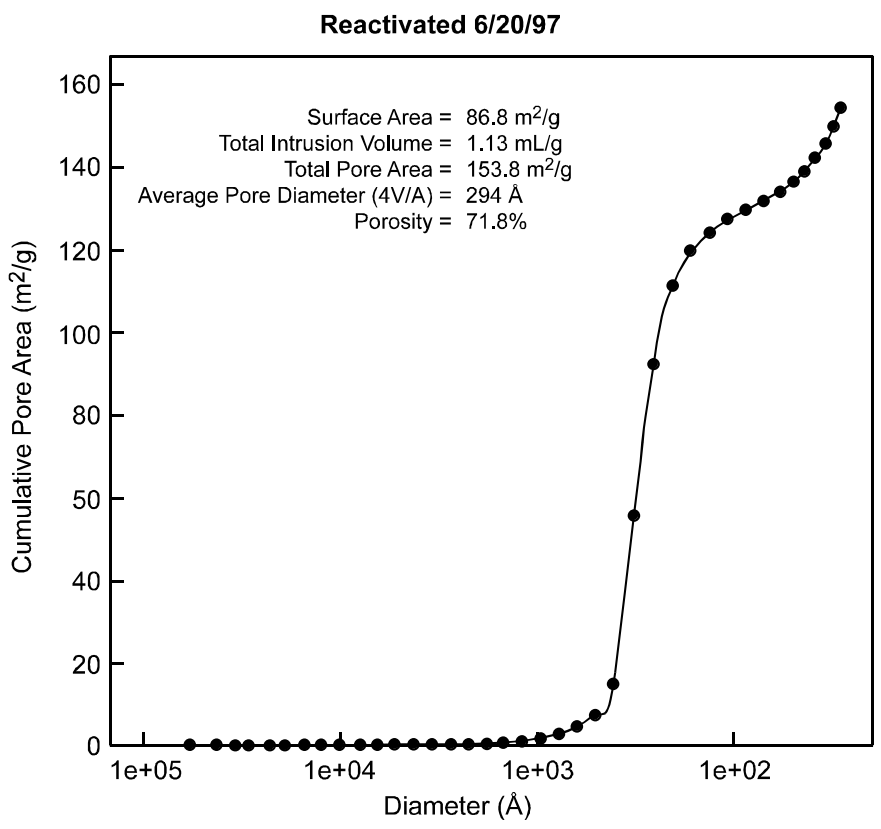


Figure 43. Pore size distribution for a reactivated $10 \% \mathrm{Nb}_{2} \mathrm{O}_{5} / \mathrm{SiO}_{2}$ catalyst

(reactivated catalyst in Figure 33 subjected to two experimental runs under formalin conditions).

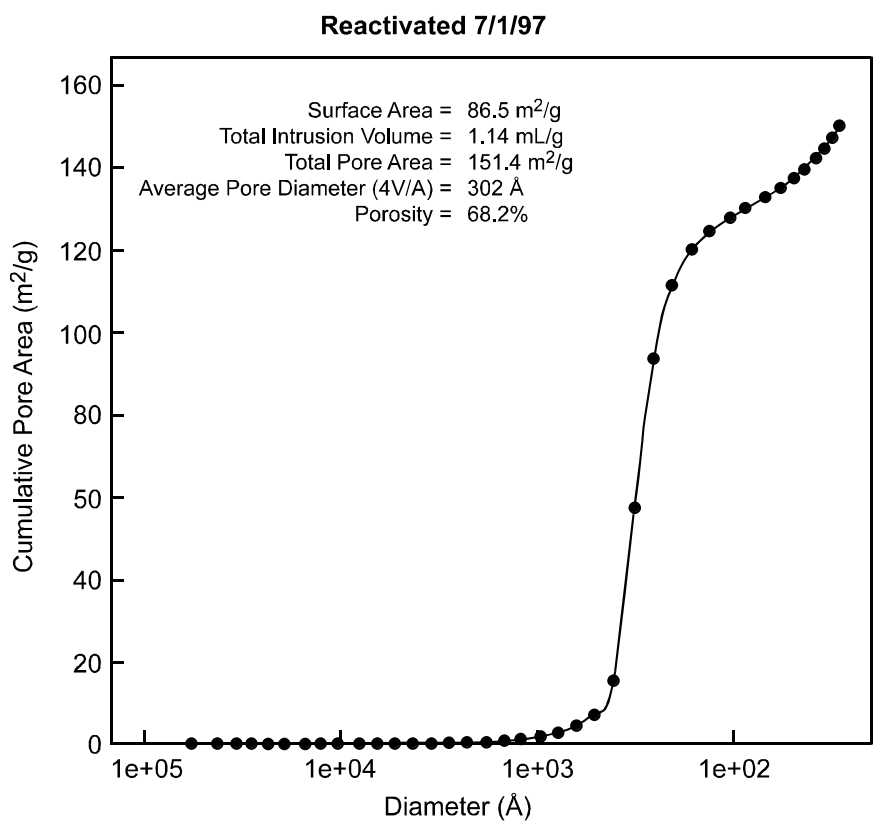

Figure 44. Pore size distribution for a deactivated $10 \% \mathrm{Nb}_{2} \mathrm{O}_{5} / \mathrm{SiO}_{2}$ catalyst (subjected to long-term run for $70 \mathrm{~h}$ under formalin conditions).

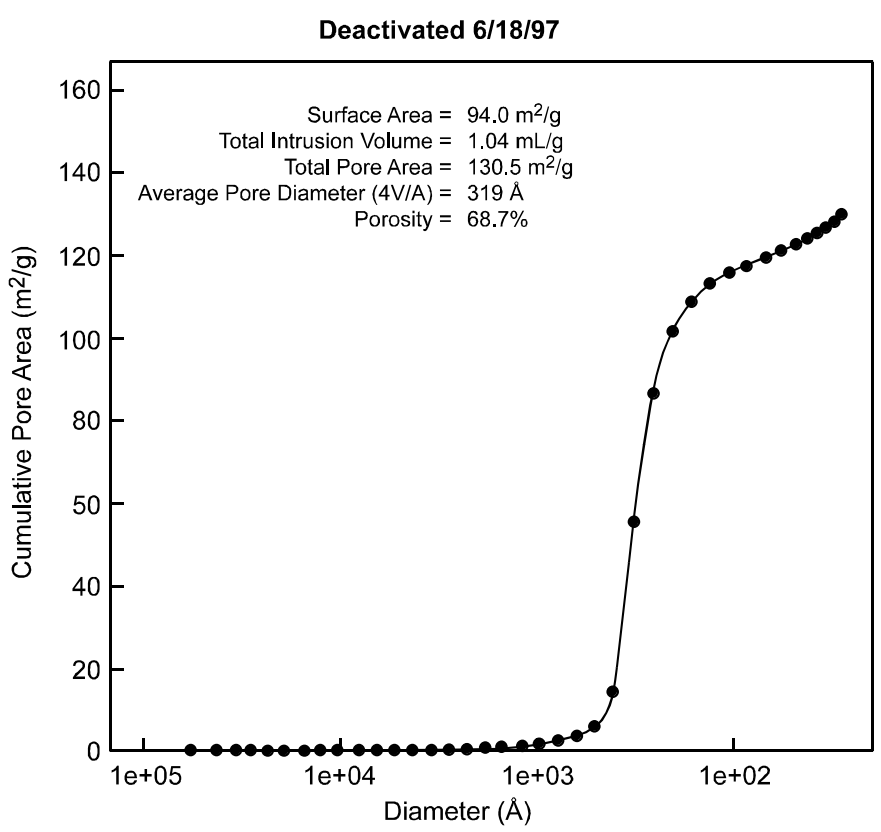


Table 11. Surface Area and Pore Structure Properties of $10 \% \mathrm{Nb}_{2} / \mathrm{O}_{5} / \mathrm{SiO}_{2}$

\begin{tabular}{cccccc}
\hline Catalyst & $\begin{array}{c}\text { BET- } \mathbf{N}_{\mathbf{2}} \text { surface } \\
\text { area }\left(\mathbf{m}^{2} / \mathbf{g}\right)\end{array}$ & $\begin{array}{c}\text { Total } \mathbf{H g} \\
\text { intrusion } \\
\text { volume }(\mathbf{m L} / \mathbf{g})\end{array}$ & $\begin{array}{c}\text { Total pore } \\
\text { area }\left(\mathbf{m}^{2} / \mathbf{g}\right)\end{array}$ & $\begin{array}{c}\text { Average } \\
\text { pore diameter } \\
(\AA \mathbf{A})\end{array}$ & $\begin{array}{c}\text { Porosity } \\
(\%)\end{array}$ \\
\hline A & 83.9 & 1.15 & 156.9 & 292 & 71.2 \\
B & 94.0 & 1.04 & 130.5 & 319 & 68.7 \\
C & 86.8 & 1.13 & 153.8 & 294 & 71.9 \\
D & 86.6 & 1.14 & 151.4 & 302 & 68.2 \\
\hline
\end{tabular}

Catalyst A: Fresh; B: Deactivated; C: Reactivated; D: Reactivated (subjected to $5 \mathrm{~h}$ on-stream under formalin conditions).

Table 12. Comparison of Pure $\mathrm{Nb}_{2} \mathrm{O}_{5}$ and $10 \%$ $\mathrm{Nb}_{2} \mathrm{O}_{5} / \mathrm{SiO}_{2}$ for Condensation Reactions ${ }^{\mathrm{a}}$

\begin{tabular}{lcc}
\hline & $\begin{array}{c}\text { MAA yield/ } \\
\text { HCHO (\%) }\end{array}$ & $\begin{array}{c}\text { MAA yield/ } \\
\text { PA (\%) }\end{array}$ \\
\hline Pure $\mathrm{Nb}_{2} \mathrm{O}_{5}$ & 8.8 & 1.56 \\
$10 \% \mathrm{Nb}_{2} \mathrm{O}_{5} / \mathrm{SiO}_{2}$ & 22.5 & 4.92 \\
\hline a $\mathrm{T}=300^{\circ} \mathrm{C}, \mathrm{P}=4 \mathrm{~atm}$, feed makeup: \\
$72: 38: 16: 4: 220 \mathrm{mmol} / \mathrm{h}, \mathrm{HOPr}: \mathrm{H}_{2} \mathrm{O}: \mathrm{HCHO}: \mathrm{CH}_{3} \mathrm{OH}: \mathrm{N}_{2}$.
\end{tabular}

The comparative XRD patterns of pure fresh $\mathrm{Nb}_{2} \mathrm{O}_{5}$ and a 20 percent $\mathrm{Nb}_{2} \mathrm{O}_{5} / \mathrm{SiO}_{2}$ are shown in Figure 45 . The pure $\mathrm{Nb}_{2} \mathrm{O}_{5}$ shows sharp, well-defined peaks, indicating a highly ordered crystal structure with large crystallites of $\mathrm{Nb}_{2} \mathrm{O}_{5}$, and the 20 percent $\mathrm{Nb}_{2} \mathrm{O}_{5} / \mathrm{SiO}_{2}$ shows a more broad, amorphous pattern, likely due to the amorphous nature of the silica support. The finer crystallites of $\mathrm{Nb}_{2} \mathrm{O}_{5}$ may also contribute to an increased activity of the 20 percent (and 10 percent) $\mathrm{Nb}_{2} \mathrm{O}_{5} / \mathrm{SiO}_{2}$ catalysts compared with pure $\mathrm{Nb}_{2} \mathrm{O}_{5}$.

\subsubsection{Long-Term Tests on V-Si-P (1:10:2.8) and $\mathrm{Ta} / \mathrm{SiO}_{2}$ Catalysts}

To investigate the long-term activity of the V-Si-P (1:10:2.8) and Ta/SiO ${ }_{2}$ catalysts, an extended activity experiment was carried out with both catalysts. The initial MAA yield (based on charged $\mathrm{HCHO}$ ) is higher for the V-Si-P catalyst (56 percent compared to 46.4 percent for the 10 percent $\left.\mathrm{Ta} / \mathrm{SiO}_{2}\right)$. However, after a 180 -h period, the catalyst activity drops significantly for both catalysts. For the V-Si-P catalyst, the MMA yield at $4 \mathrm{~h}$ was 55.8 percent (based on charged formaldehyde) but dropped to 2.74 percent after $180 \mathrm{~h}$. The drop in catalytic activity for the 10 percent $\mathrm{Ta} / \mathrm{SiO}_{2}$ is not as sharp; however, the activity drops from an initial value of 46.4 percent to 28 percent, and activity is stable at 28 percent for nearly $54 \mathrm{~h}$ (Figure 46 ). The causes of catalyst deactivation could be 
Figure 45. Comparative XRD patterns for pure $\mathrm{Nb}_{2} \mathrm{O}_{5}$ (labeled as calcined $\mathrm{Nb}$ ) and $20 \% \mathrm{Nb} / \mathrm{SiO}_{2}$ (labeled as $\mathrm{NbSiO}_{2}$ ).

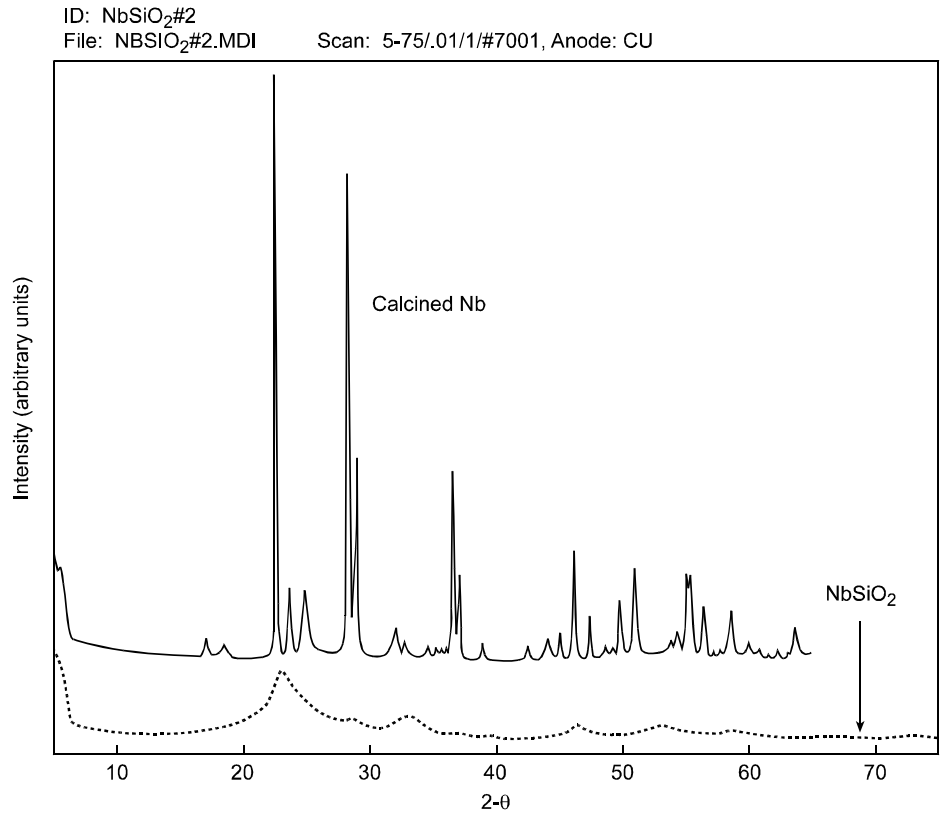

Figure 46. Long-term activity check on V-Si-P 1:10:2.8, 10\% Ta-Si, and 10\% Nb-Si catalysts.

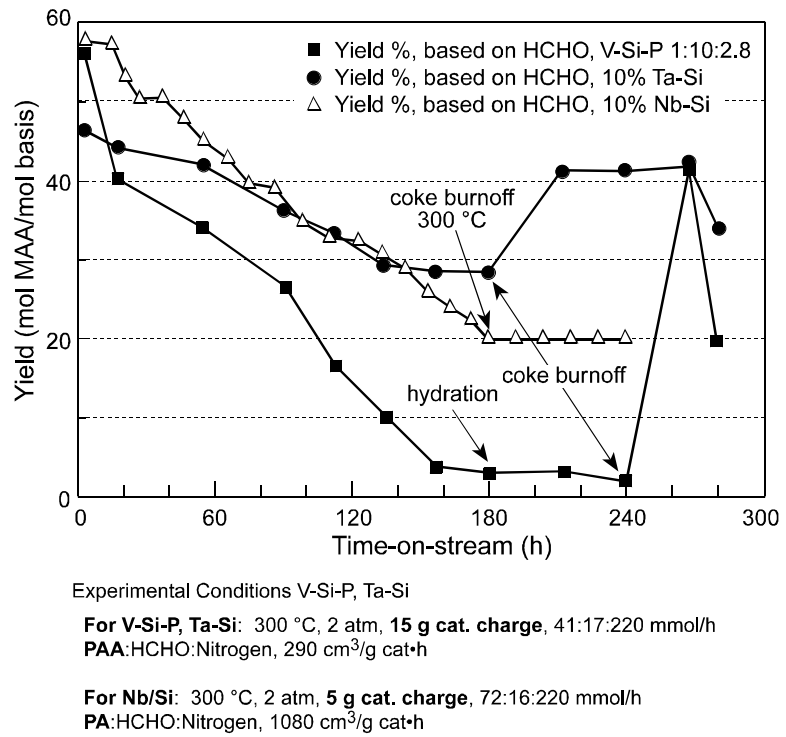


- loss of acidity by hydroxyl groups,

- loss of surface area and/or porosity, or

- carbon deposition due to coking.

Two possible causes have been investigated as follows:

4.2.4.1 Catalyst Hydration. If the loss in catalyst activity was due to the loss in surface acidity, hydration of the catalyst might restore the surface hydroxyl groups. The deactivated catalyst was steam-treated under an inert nitrogen atmosphere for $24 \mathrm{~h}$. Water was injected through a syringe pump at a nominal flow rate of $\sim 300 \mathrm{mmol} / \mathrm{h}$. Nitrogen was used as an inert diluent at $600 \mathrm{mmol} / / \mathrm{h}$. The concentration of steam was thus at 33.3 percent by volume. The catalyst activity was checked after a 24-h treatment at those conditions. Figure 46 shows that catalyst hydration is ineffective in restoring the $\mathrm{V}$-Si-P catalyst activity. This also suggests that the loss in catalyst activity is not due to loss of surface hydroxyl groups.

4.2.4.2 Regeneration by Flowing Air Oxidation at $300{ }^{\circ} \mathrm{C}$. Because the catalyst activity could not be restored by hydration, an alternative cause could be coke formation. To test this hypothesis, the deactivated catalyst was treated at $300{ }^{\circ} \mathrm{C}$ under a flowing $220 \mathrm{mmol} / \mathrm{h}$ for $24 \mathrm{~h}$. The results of this regeneration for both the $\mathrm{Nb}$ and $\mathrm{Ta}$ catalysts are shown in Table 13. The MAA yield (based on charged HCHO) was restored to 40.8 percent, compared to 55.8 percent for the fresh catalyst. For the 10 percent $\mathrm{Ta} / \mathrm{SiO}_{2}$ catalyst, the regeneration restored the catalyst activity to about 41.1 percent, compared to original catalyst activity of 46.4 percent. However, the deactivation pattern continues after the oxidation regeneration for both $\mathrm{V}-\mathrm{Si}-\mathrm{P}$ and Tacatalyst (Figure 46). The tantalum catalyst is more stable and has a higher on-stream life, based on these catalyst long-term activity studies.

\subsubsection{Acid-Base Properties of V-Si-P Catalysts}

The effects of pretreatment time, temperature, and the acid-base properties of fresh and deactivated catalysts were studied with the goal of improving the overall catalyst on-stream life. The results have been summarized in Figures 47 through 50. Figure 47 shows the effect of pretreatment temperature on the surface acidity, and Figures 48 and 49 show the effects of pretreatment time and the deactivation on the surface acidity. Figure 50 shows a comparative $\mathrm{NH}_{3}$-TPD pattern for a fresh catalyst pretreated at $600{ }^{\circ} \mathrm{C}$ for $6 \mathrm{~h}$ and a deactivated catalyst (on stream for $180 \mathrm{~h}$ at $300{ }^{\circ} \mathrm{C}$ and $2 \mathrm{~atm}$, with molar flow rates of propionic anhydride:formaldehyde:nitrogen $=41: 17: 220 \mathrm{mmol} / \mathrm{h}$ ).

The results of TPD at pretreatment temperature of 300 and $600{ }^{\circ} \mathrm{C}$ for an hour are shown together in Figure 47. There is no apparent difference between TPD patterns at 300 and $600{ }^{\circ} \mathrm{C}$. This implies that the surface acidity is relatively insensitive to the pretreatment temperature between 300 and $600{ }^{\circ} \mathrm{C}$. This can further mean that the catalyst pretreatment temperature within this range may not affect the surface acidity, albeit the effect of pretreatment temperature on bulk surface area has not been studied. However, Figure 48 shows that the length of pretreatment at $600{ }^{\circ} \mathrm{C}$ decreases the total acidity and acid site distribution by about 80 percent (from $\sim 150 \mu \mathrm{mol} / \mathrm{g}$ catalyst to $\sim 30 \mu \mathrm{mol} \mathrm{NH}_{3} / \mathrm{g}$ catalyst). This decrease is mainly attributable to the high temperature peak $\left(\mathrm{T}>300{ }^{\circ} \mathrm{C}\right)$, that is, strong acidic sites. It is clear that a longer heat 
Table 13. Regeneration of Vanadia and Tantalum Catalysts

\begin{tabular}{lcc}
\hline Catalysts & $\begin{array}{c}\text { MMA yield } \\
\text { Initial }\end{array}$ & $\begin{array}{c}\text { MAA yield (based } \\
\text { on HCHO) after } \\
\text { regeneration }\end{array}$ \\
\hline V-Si-P 1:10:2.8 & 55.8 & 40.8 \\
$10 \% \mathrm{Ta} / \mathrm{SiO}_{2}$ & 0.17 & 41.1 \\
\hline
\end{tabular}

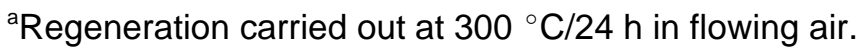

Figure 47. $\mathrm{NH}_{3}$-TPD pattern (surface acidity) of a V-Si-P 1:10:2.8 catalyst as a function of pretreatment temperature.

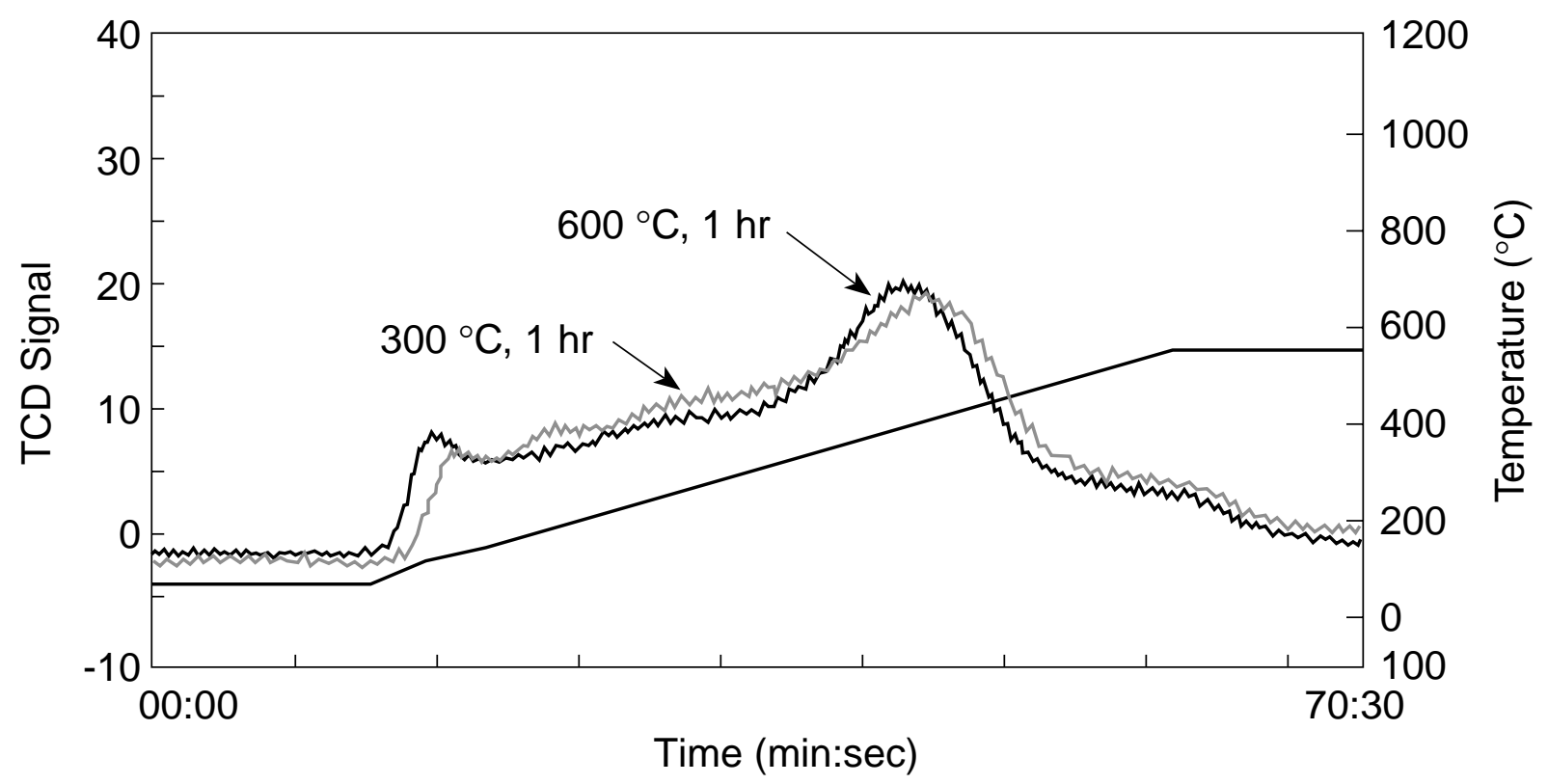


Figure 48. $\mathrm{NH}_{3}$-TPD pattern (surface acidity) of a V-Si-P 1:10:2.8 catalyst as a function of pretreatment time.

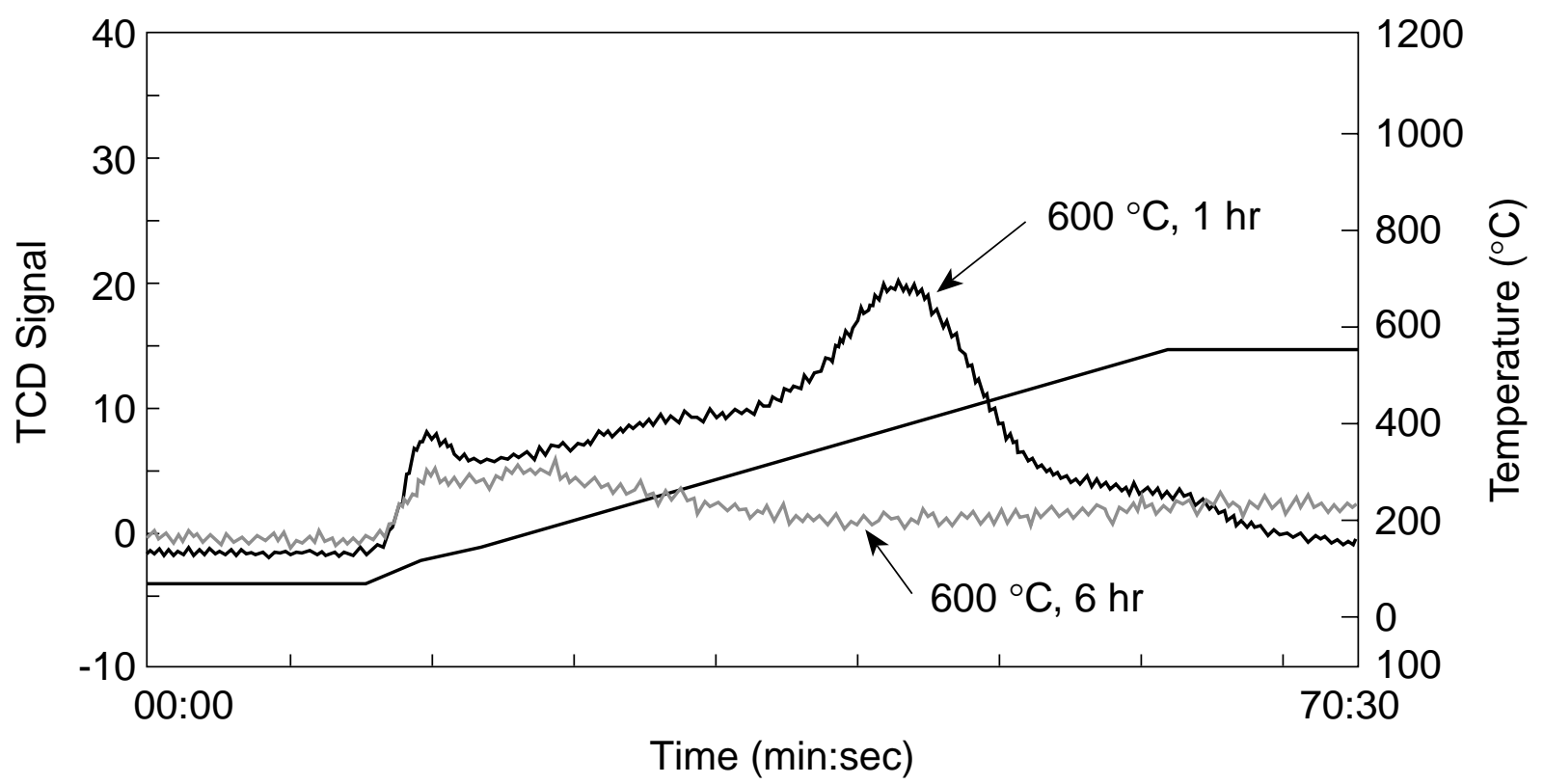

Figure 49. $\mathrm{NH}_{3}$-TPD pattern (surface acidity) of fresh and deactivated V-Si-P 1:10:2.8 catalysts.

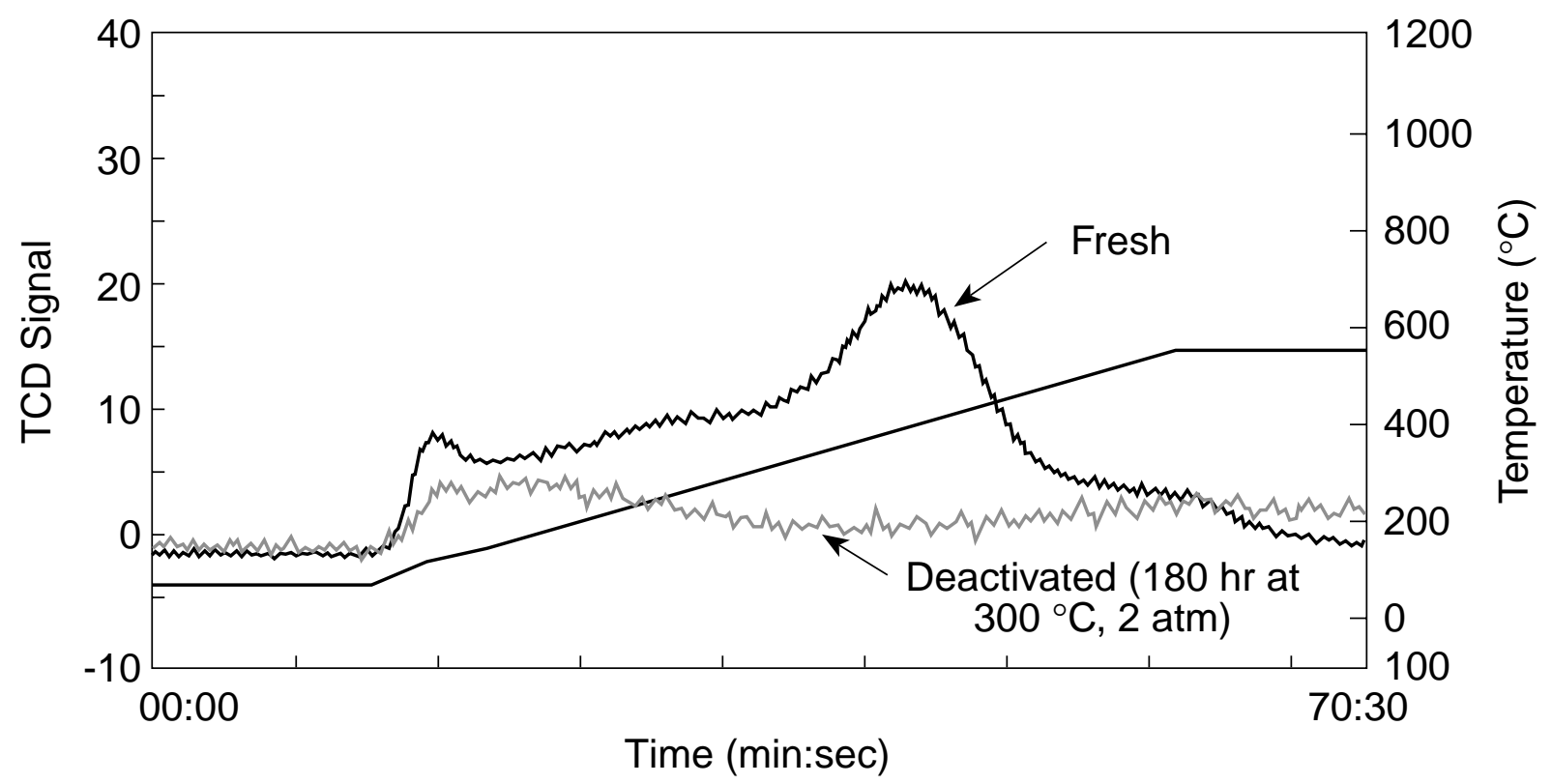


Figure 50. Comparative $\mathrm{NH}_{3}$-TPD patterns (surface acidity) of fresh and deactivated V-Si-P 1:10:2.8 catalysts.

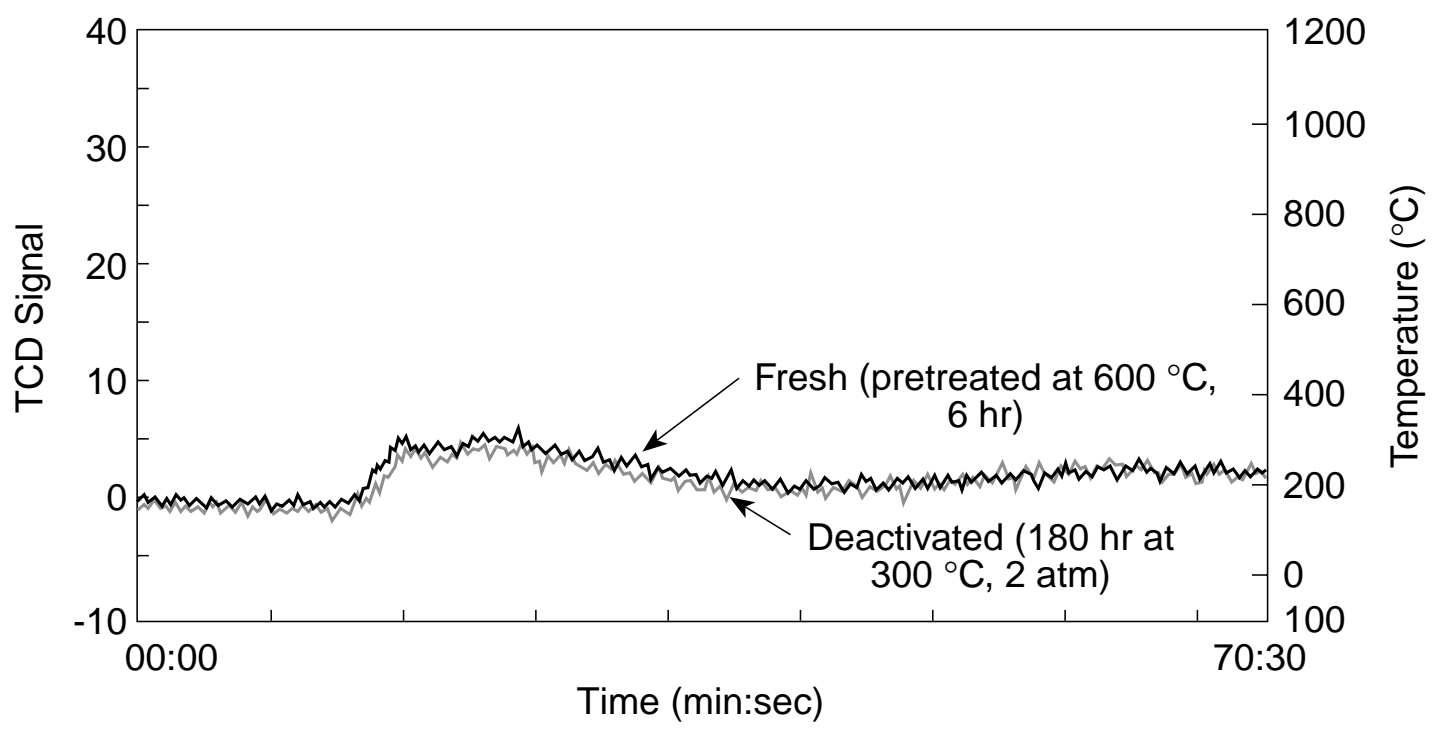

treatment destroys these stronger acid sites preferentially; the mechanism of this preferential destruction is an open question, however.

Figure 49 compares the TPD results of the fresh and deactivated catalysts. The fresh catalyst was pretreated at $600{ }^{\circ} \mathrm{C}$ for $1 \mathrm{~h}$. (Figure 50 shows that pretreatment temperature does not affect the surface acidity.) The results demonstrate that after $180 \mathrm{~h}$ on stream at $300{ }^{\circ} \mathrm{C}$ and $2 \mathrm{~atm}$, with the inlet mole ratios of propionic anhydride:formaldehyde:nitrogen $=41: 17: 200 \mathrm{mmol} / \mathrm{h}$, the total acidity decreases and the acid site distribution changes dramatically. The major acidity decrease is from the loss of strongly acidic sites. Catalyst deactivation is apparently caused by coking (as supported by the regeneration of activity by air oxidation [Figure 46]). However, the effect of temperature on catalytic deactivation cannot be ruled out because the condensation reaction is highly exothermic and the TPD results show similar increase of desorption at the end of TPD by both used and heat-treated (pretreatment at $600{ }^{\circ} \mathrm{C}$ for $6 \mathrm{~h}$ ) catalysts.

Figure 50 further supports the assertion that extended exposure to higher temperature $\left(600{ }^{\circ} \mathrm{C}\right.$ for $6 \mathrm{~h}$ rather than $1 \mathrm{~h}$ ) has a very similar effect on total acidity and acid site distribution as the 180-h run at $300{ }^{\circ} \mathrm{C}$ and $2 \mathrm{~atm}$. This suggests that the strongly acidic sites are lost due to high surface temperatures during the reaction.

Based on this acid-base property study, a low surface acidity with a high q-ratio (i.e., a high proportion of weak acidic sites), coupled with an effective reactor design to control temperature, would be needed for a commercial condensation process. 


\subsubsection{Extended Activity and Stability Tests of Niobium Catalysts}

4.2.6.1 Tests on $10 \% \mathrm{Nb}_{2} \mathrm{O}_{5} / \mathrm{SiO}_{2}$. Another series of long-term condensation tests using formaldehyde and propionic acid was carried out over 10 percent $\mathrm{Nb}_{2} \mathrm{O}_{5} / \mathrm{SiO}_{2}$ at $300{ }^{\circ} \mathrm{C}$ (Figure 51). This test consisted of two deactivation/regeneration cycles. During the first activity test period, the activity slowly decreased to 22.6 percent after $33 \mathrm{~h}$ on stream. The first regeneration was started after $55 \mathrm{~h}$ on stream with about $100 \mathrm{~cm}^{3} / \mathrm{min}$ of 2 percent $\mathrm{O}_{2}$ in nitrogen at $400{ }^{\circ} \mathrm{C} . \mathrm{O}_{2}, \mathrm{CO}_{2}$, and $\mathrm{CO}$ emissions during this regeneration were monitored every $10 \mathrm{~min}$ during the first $2 \mathrm{~h}$. During the first $2 \mathrm{~h}$ of the regeneration, the $\mathrm{CO}_{2}$ concentrations were close to 2 percent, and $\mathrm{O}_{2}$ and $\mathrm{CO}$ concentrations were negligible, which indicated that $\mathrm{O}_{2}$ is completely consumed for combustion to $\mathrm{CO}_{2}$ and that the regeneration was incomplete after only $2 \mathrm{~h}$. After $18 \mathrm{~h}$ of regeneration, the emission of $\mathrm{O}_{2}, \mathrm{CO}_{2}$, and $\mathrm{CO}$ was taken again. Negligible levels of $\mathrm{CO}_{2}$ and $\mathrm{CO}$ indicated that regeneration was complete. The condensation reaction was then begun for the second cycle. The activity then slowly decreased to 25.6 percent after $68.5 \mathrm{~h}$ on stream.

Figure 51. Reaction-regeneration cycle study on a $10 \% \mathrm{Nb}_{2} \mathrm{O}_{5} / \mathrm{SiO}_{2}$ catalyst.

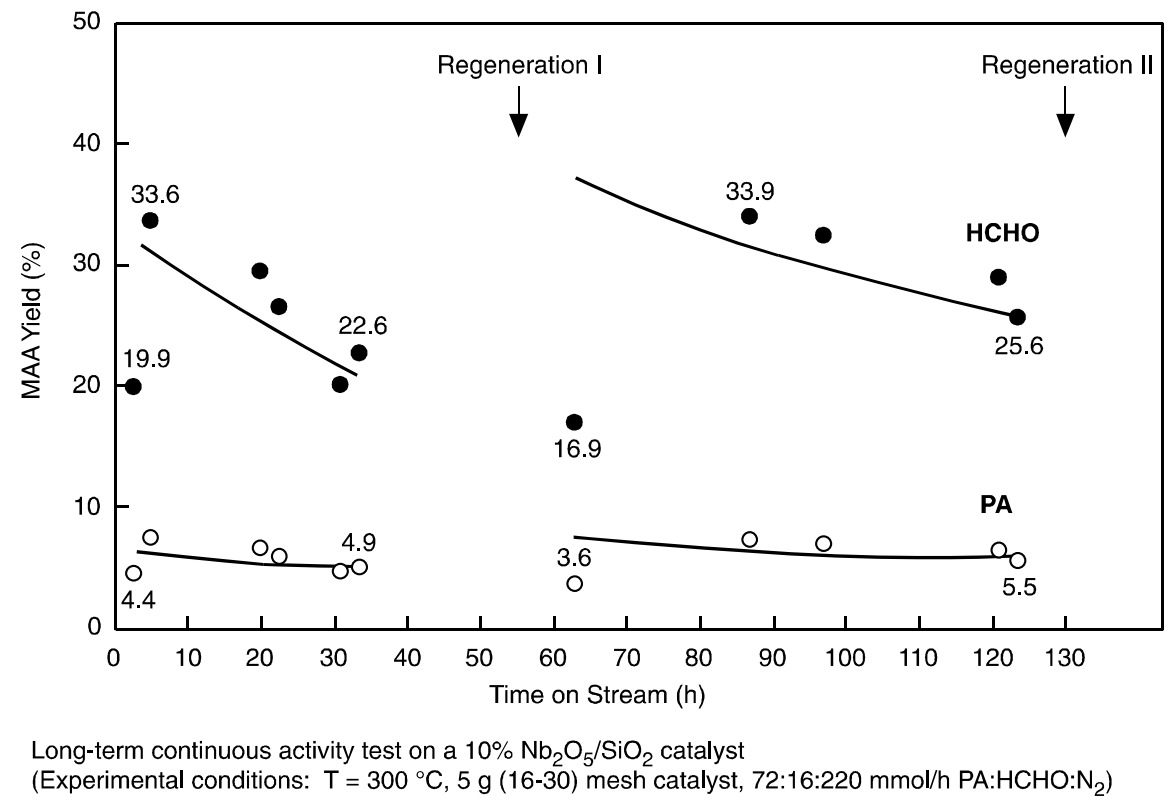

The results indicate that 10 percent $\mathrm{Nb}_{2} \mathrm{O}_{5} / \mathrm{SiO}_{2}$ deactivates slowly with time but can be regenerated to its original activity with similar stability using 2 percent $\mathrm{O}_{2}$ in nitrogen at $400{ }^{\circ} \mathrm{C}$.

Effect of Regeneration. To study the deactivation over a longer period of time, a long-term continuous condensation of formaldehyde with propionic acid, with regeneration, over 10 percent $\mathrm{Nb}_{2} \mathrm{O}_{5} / \mathrm{SiO}_{2}$ at $300{ }^{\circ} \mathrm{C}$, was completed. Figure 52 shows the six activity and five regeneration cycles, with the MAA yield calculated based on both $\mathrm{HCHO}$ and $\mathrm{HOPr}$. The total time on stream, not including the time for regenerations, is $400 \mathrm{~h}$. The 10 percent $\mathrm{Nb}_{2} \mathrm{O}_{5} / \mathrm{SiO}_{2}$ deactivates 


\section{Figure 52. Long-term reaction-regeneration cycle study on a $10 \% \mathrm{Nb}_{2} \mathrm{O}_{5} / \mathrm{SiO}_{2}$ catalyst.}

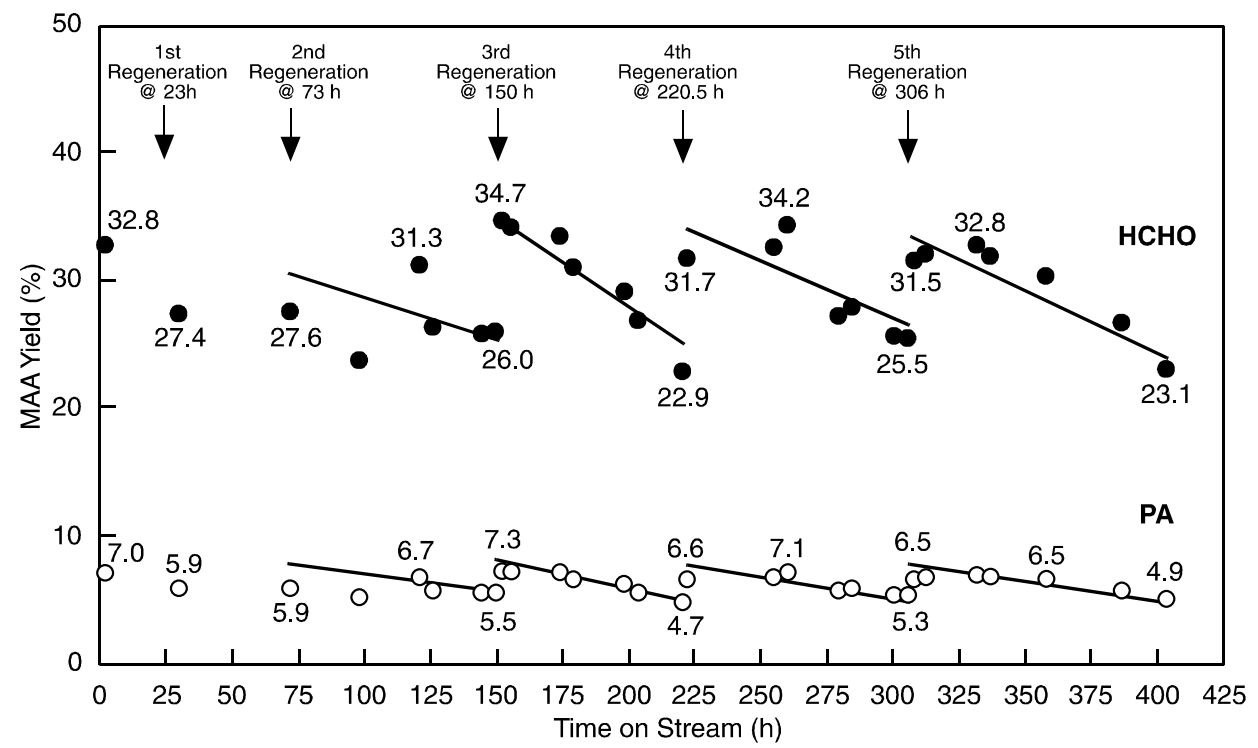

slowly with time but can be regenerated to its original activity with 2 percent $\mathrm{O}_{2}$ in nitrogen over night at $400{ }^{\circ} \mathrm{C}$. For example, the fourth activity cycle decreases from the initial activity of 34.7 percent yield down to 22.9 percent yield of MAA over $70 \mathrm{~h}$. After the fourth regeneration, the activity was brought back to 31.7 percent, followed by slow deactivation, which resulted in 25.5 percent yield after about $80 \mathrm{~h}$. The fifth regeneration resulted in similar regeneration and deactivation trends. The carbon balance over these activity/regeneration cycles was typically 90 percent. The results suggest that $\mathrm{Nb}_{2} \mathrm{O}_{5} / \mathrm{SiO}_{2}$ catalyst can be regenerated, at least over the period of time tested here.

Effect on Selectivity. However, there is a change in the selectivity to undesirable byproducts that is apparent only in these longer term tests. Figure 53 shows the selectivity to DEK and $\mathrm{CO}_{2}$ trends during this long-term test. Although the rate of DEK formation is low compared to the rate of MAA formation and remains fairly constant during each of the activity cycles, the rate increases with regeneration. For example, the rate of DEK formation is negligible during the first activity cycle, but it increases to about $0.057 \mathrm{mmol} / \mathrm{g}$ cat $\cdot h$ after the fifth regeneration.

Regeneration does not affect the rate of MAA formation, but it does increase the rate of DEK formation, resulting in a decrease in the overall selectivity to MAA. The $\mathrm{CO}_{2}$ formation rate (measured by collecting the gaseous products in a Tedlar bag) was measured at the end of the fifth activity cycle and during the sixth activity cycle. Over this period of time, the rate of $\mathrm{CO}_{2}$ formation is relatively constant, suggesting that the decomposition of $\mathrm{HOPr}$ to $\mathrm{CO}_{2}$ $\left(2 \mathrm{CH}_{3} \mathrm{CH}_{2} \mathrm{COOH} \rightarrow \mathrm{CO}_{2}+\left(\mathrm{C}_{2} \mathrm{H}_{5}\right)_{2} \mathrm{CO}\right)$ is not affected by the regeneration and catalytic deactivation. 
Figure 53. Rate formation of MAA, DEK, and $\mathrm{CO}_{2}$ during the long-term run over $10 \%$ $\mathrm{Nb}_{2} \mathrm{O}_{5} / \mathrm{SiO}_{2}$ at $300{ }^{\circ} \mathrm{C}$.

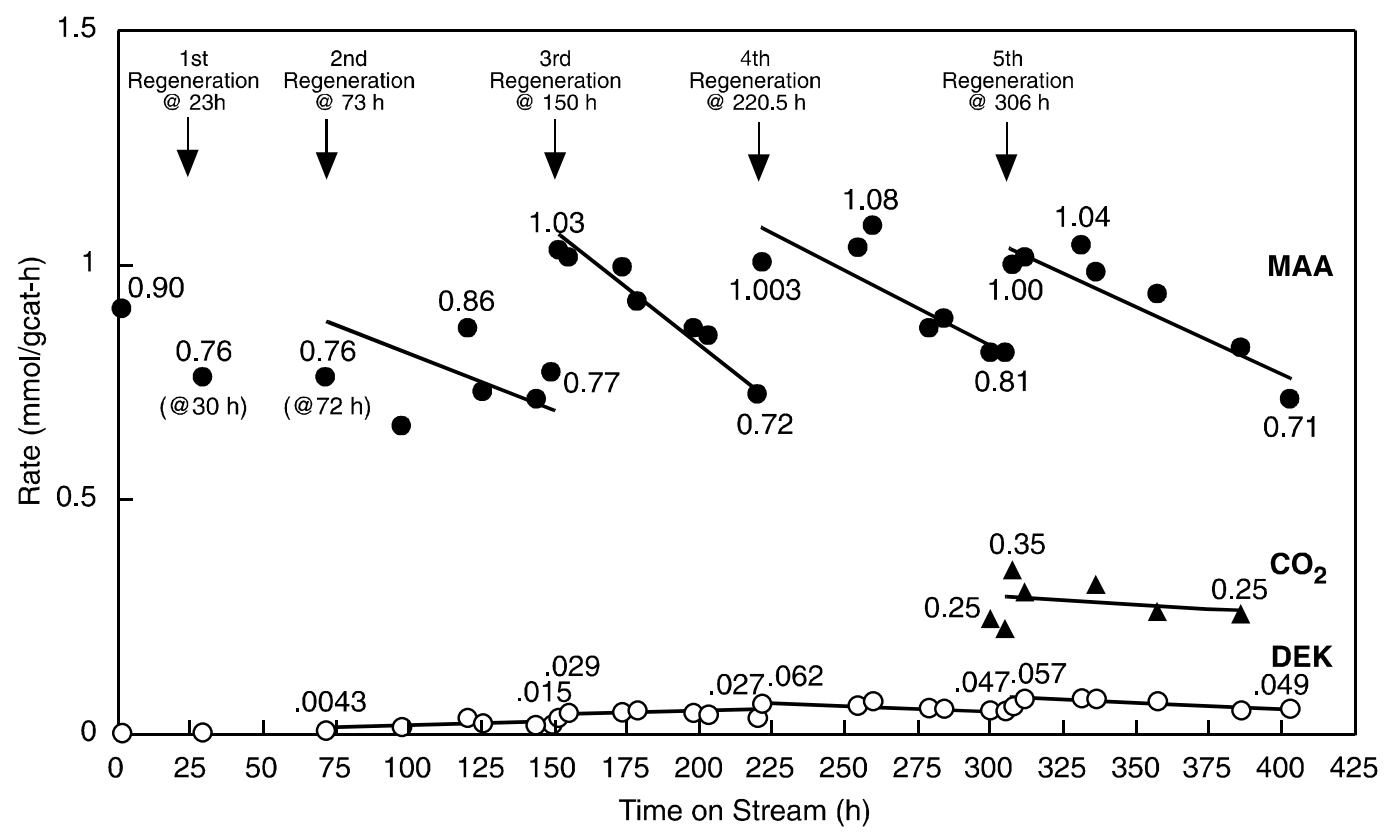

4.2.6.2 Tests on $10 \% \mathrm{Nb}_{2} \mathrm{O}_{5} / \mathrm{SiO}_{2}$. Eastman and Bechtel tests were carried out at various propionic acid:formaldehyde ratios (PA: $\mathrm{HCHO}=4.5: 1$ to $1.5: 1$ ) and reaction temperatures (280 to $300{ }^{\circ} \mathrm{C}$ ) over 20 percent $\mathrm{Nb}_{2} \mathrm{O}_{5} / \mathrm{SiO}_{2}$ catalysts.

Effect of Regeneration. Table 14 shows that the effect of regeneration on 20 percent $\mathrm{Nb}_{2} \mathrm{O}_{5} / \mathrm{SiO}_{2}$ is similar to the effect on 10 percent $\mathrm{Nb}_{2} \mathrm{O}_{5} / \mathrm{SiO}_{2}$. The regeneration restores the deactivated catalyst to its original activity. MAA yields are fairly constant after each regenerations (39.9 percent, 36.8 percent, and 38.1 percent over the fresh catalysts, catalysts after the first regeneration, and catalysts after the second regeneration, respectively). However, the selectivity to MAA decreases after each regeneration (from 84.0 percent to 79.6 percent, then to 74.0 percent). The selectivity to DEK, on the other hand, increases from 0.6 percent to 1.1 percent, then 3.2 percent, and $\mathrm{CO}_{2}$ selectivity increases from 14.5 percent to 19.3 percent, then to 22.8 percent with successive regeneration.

Table 14. Regeneration Effect on MAA Yield and Product Selectivity over $20 \% \mathrm{Nb}_{2} \mathrm{O}_{5} / \mathrm{SiO}_{2}$ at $300{ }^{\circ} \mathrm{C}$

\begin{tabular}{lcccc}
\hline \multicolumn{1}{c}{ Catalysts } & $\begin{array}{c}\text { MAA } \\
\text { Yield (\%) }\end{array}$ & $\begin{array}{c}\text { MAA Sel. } \\
(\%)\end{array}$ & $\begin{array}{c}\text { DEK Sel. } \\
(\%)\end{array}$ & CO $_{2}$ Sel. $(\%)$ \\
\hline Fresh & 39.9 & 84.9 & 0.6 & 14.5 \\
$1^{\text {st }}$ regeneration & 36.8 & 79.6 & 1.1 & 19.3 \\
$2^{\text {nd }}$ regeneration & 38.1 & 74.0 & 3.2 & 22.8 \\
\hline
\end{tabular}


Effect of HOPr:HCHO Ratio. Three HOPr:HCHO ratios were investigated: 4.5:1, 2.25:1, and 1.5:1. When the HOPr:HCHO ratio is decreased from $4.5: 1$ to $2.25: 1$, then to $1.5 / 1$ at $300{ }^{\circ} \mathrm{C}$, the MAA yield decreases from 39.5 percent to 31.8 percent, then to 21.8 percent, as shown in Table 15. Because the total flow rate of reactants was held constant at each different feed ratio, the total molar flow rate of HCHO increased in experiments with lower HOPr:HCHO feed ratios. The rate of MAA formation (MAA per unit time and per unit amount of catalyst) actually increases with decreasing HOPr:HCHO ratio (i.e., increasing HCHO feeding rate). This result suggests that the rate of MAA formation is first order in HCHO. The MAA selectivity actually increases from 73.7 percent to 85.4 percent, then decreases to 83.5 percent with decreasing HOPr:HCHO ratio. On the other hand, DEK byproduct formation consistently decreases, but $\mathrm{CO}_{2}$ selectivity first decreases, then increases with decreasing HOPr:HCHO ratio.

Table 15. Effect of HOPr:HCHO Ratio on MAA Yield and Product Selectivity over $20 \% \mathrm{Nb}_{2} \mathrm{O}_{5} / \mathrm{SiO}_{2}$

\begin{tabular}{cccccc}
\hline $\begin{array}{c}\text { Temp. } \\
\left({ }^{\circ} \mathbf{C}\right)\end{array}$ & HOPr:HCHO & $\begin{array}{c}\text { MAA } \\
\text { Yield (\%) }\end{array}$ & $\begin{array}{c}\text { MAA } \\
\text { Sel. }(\%)\end{array}$ & $\begin{array}{c}\text { DEK } \\
\text { Sel. }(\%)\end{array}$ & $\begin{array}{c}\mathrm{CO}_{2} \\
\text { Sel. }(\%)\end{array}$ \\
\hline 300 & $4.5 / 1$ & 39.5 & 73.7 & 4.1 & 22.2 \\
300 & $2.25 / 1$ & 31.8 & 85.4 & 1.0 & 13.6 \\
300 & $1.5 / 1$ & 21.8 & 83.5 & 0.0 & 16.5 \\
280 & $4.5 / 1$ & 30.7 & 82.2 & 2.3 & 15.5 \\
280 & $2.25 / 1$ & 11.2 & 78.7 & 0.0 & 21.3 \\
\hline
\end{tabular}

Effect of Temperature. Table 15 also shows that decreasing the reaction temperature from 300 to $280{ }^{\circ} \mathrm{C}$ decreases the MAA yield from 39.5 percent to 30.7 percent but increases the MAA selectivity from 73.7 percent to 82.2 percent (at $\mathrm{HOPr}: \mathrm{HCHO}=4.5: 1$ ). The selectivities to DEK (4.1 percent to 2.3 percent) and $\mathrm{CO}_{2}$ (22.2 percent to 15.5 percent) decrease when the temperature is decreased from 300 to $280{ }^{\circ} \mathrm{C}$, suggesting a lower activation energy for the reactions leading to these decomposition products.

At a HOPr:HCHO ratio of $1.5: 1$ at $300{ }^{\circ} \mathrm{C}$ and $2.25: 1$ at $280{ }^{\circ} \mathrm{C}$, solid materials appeared in the impinger located at the reactor exit. This suggests that additional reactions are taking place at those conditions. The materials were analyzed and the carbon and hydrogen contents of unknown solid material are listed in Table 16, along with the theoretical compositions of formaldehyde and MAA polymers. The carbon and hydrogen contents of the unknown solid material are 39.07 percent and 7.11 percent, respectively, which closely match those of formaldehyde (C: 40.0 percent, $\mathrm{H}: 6.72$ percent), but not MAA (C: 55.8 percent, $\mathrm{H}: 7.02$ percent). The unknown solid material appears to be a formaldehyde polymer, formed due to the incomplete reaction of formaldehyde.

4.2.6.3 Tests on High Nb-conent Catalysts. To determine the deactivation behavior of catalyst with higher loadings of $\mathrm{Nb}_{2} \mathrm{O}_{5}$, a long-term test was carried out on a 30 percent $\mathrm{Nb}_{2} \mathrm{O}_{5} / \mathrm{SiO}_{2}$ catalyst using formaldehyde with propionic acid at $300{ }^{\circ} \mathrm{C}$. Three activity and two regeneration cycles were completed. The total time on stream, not including the time for 
Table 16. Carbon and Hydrogen Content of Unknown Solid and HCHO Polymer and Polymethacrylate

\begin{tabular}{lcc}
\hline & C (wt\%) & H (wt\%) \\
\hline Unknown & 39.07 & 7.11 \\
HCHO polymer & 40.00 & 6.72 \\
Polymethacrylate & 55.8 & 7.02 \\
\hline
\end{tabular}

regenerations, was $200 \mathrm{~h}$. The results are summarized in Figure 54. The results show that 30 percent $\mathrm{Nb}_{2} \mathrm{O}_{5} / \mathrm{SiO}_{2}$ deactivates slowly with time but can be regenerated to its original activity with 2 percent $\mathrm{O}_{2}$ in nitrogen, as was the case for the 10 percent $\mathrm{Nb}_{2} \mathrm{O}_{5} / \mathrm{SiO}_{2}$ at $400{ }^{\circ} \mathrm{C}$. The MAA yield in the second activity cycle decreases from 32.5 percent yield to 27.1 percent over $73 \mathrm{~h}$. After the second regeneration, the activity was brought back to 32.4 percent yield of MAA followed by slow deactivation to 28.9 percent yield after about $72 \mathrm{~h}$. The yield of MAA over 30 percent $\mathrm{Nb}_{2} \mathrm{O}_{5} / \mathrm{SiO}_{2}$ is similar to the yield over 10 percent $\mathrm{Nb}_{2} \mathrm{O}_{5} / \mathrm{SiO}_{2}$, but the deactivation over 30 percent $\mathrm{Nb}_{2} \mathrm{O}_{5} / \mathrm{SiO}_{2}$ appears to be slower than the deactivation over 10 percent $\mathrm{Nb}_{2} \mathrm{O}_{5} / \mathrm{SiO}_{2}$.

Figure 54. Long-term reaction-regeneration cycle study of HOPr: $\mathrm{HCHO}$ condensation on a $30 \% \mathrm{Nb}_{2} \mathrm{O}_{5} / \mathrm{SiO}_{2}$ catalyst.

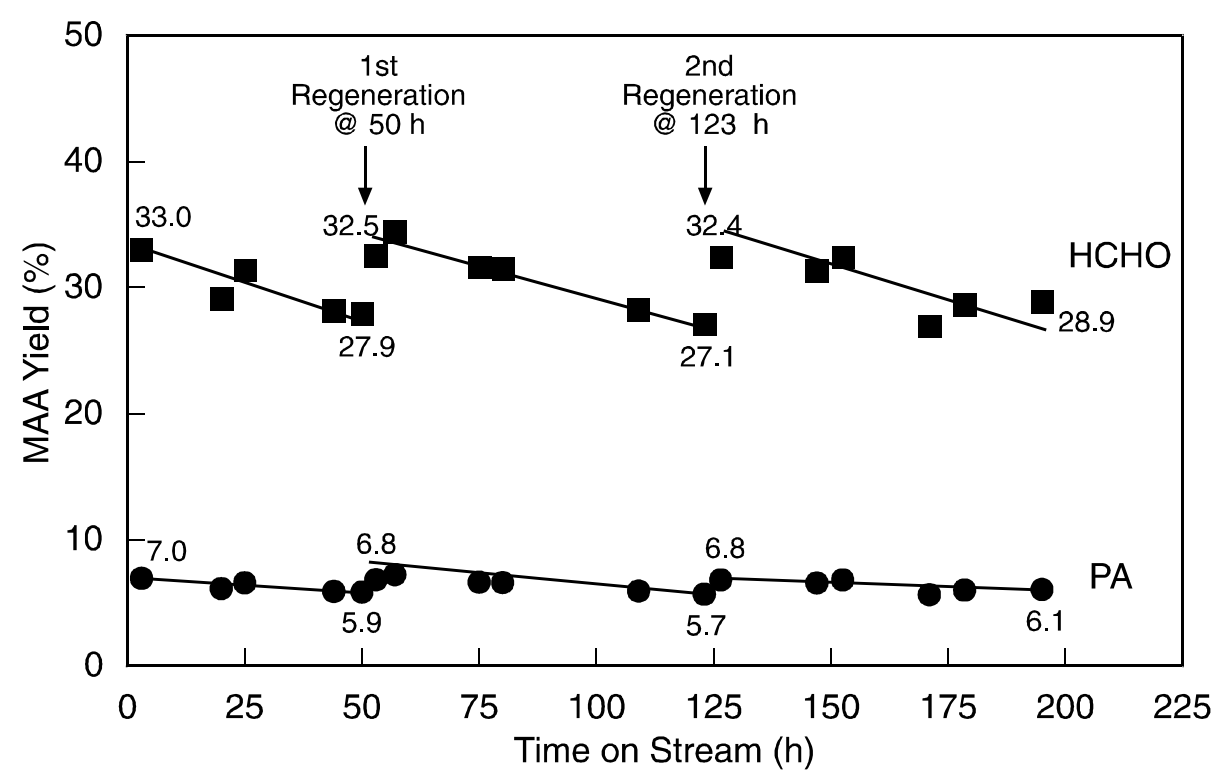

\subsubsection{Summary}

$\mathrm{Nb}$-silica, $\mathrm{V}$-Si-P, and Ta-silica catalysts are active and selective for the condensation of propionic anhydride with formaldehyde. Catalysts that exhibit higher condensation yields have a relatively weak acidity and basicity (i.e., characteristic low-temperature acid and base desorption peaks in the temperature range of 50 to $300{ }^{\circ} \mathrm{C}$ and absence of a high temperature peak in the 
range of 300 to $550{ }^{\circ} \mathrm{C}$ ). A parameter called the q-ratio is also defined, which is a measure of the distribution of sites of a particular function, acid or base, as a function of temperature, or the strength. A higher q-ratio and higher surface area are directly related to high MAA yield.

A long-term ( $\sim 400 \mathrm{~h})$ continuous condensation of formaldehyde with propionic acid has been demonstrated over 10 percent $\mathrm{Nb}_{2} \mathrm{O}_{5} / \mathrm{SiO}_{2}$ at $300{ }^{\circ} \mathrm{C}$. Six activity and five regeneration cycles were completed in this time period. The deactivation appears to be accelerated when formalin is used as a source of formaldehyde, compared to trioxane at otherwise identical operating conditions. These results suggest that water, either in the feed or as a product, accelerates the deactivation. The analysis of the fresh and deactivated catalysts indicates that surface area, pore volume, pore diameter, and internal pore structure of these $\mathrm{Nb}_{2} \mathrm{O}_{5}-\mathrm{SiO}_{2}$ catalysts are essentially unchanged due to deactivation, suggesting that coke deposits are primarily external to the catalyst surface and do not block the pores of the catalyst, limiting access to the reactants to active sites, which was further supported by XRD and XPS analysis.

The studies of effects of regeneration, HOPr:HCHO ratio (4.5:1 to 1.5:1), and reaction temperature $\left(280\right.$ to $300{ }^{\circ} \mathrm{C}$ ) on reaction activity and product selectivity suggest that the selectivity to MAA overall niobium catalysts decreases with regeneration while the selectivity to DEK and $\mathrm{CO}_{2}$ increases. When the HOPr:HCHO ratio is decreased from 4.5:1 to 2.25:1, then to 1.5:1 at $300{ }^{\circ} \mathrm{C}$, the MAA yield decreases, but the MAA selectivity increases first and then decreases. Lowering the reaction temperature from 300 to $280{ }^{\circ} \mathrm{C}$ decreases the MAA yield and increases MAA selectivity. A 200-h long-term test of HOPr-HCHO condensation over 30 percent $\mathrm{Nb}_{2} \mathrm{O}_{5} / \mathrm{SiO}_{2}$ showed that the deactivation appears to be slower with 30 percent $\mathrm{Nb}_{2} \mathrm{O}_{5} / \mathrm{SiO}_{2}$ compared with 10 percent $\mathrm{Nb}_{2} \mathrm{O}_{5} / \mathrm{SiO}_{2}$.

\subsection{TASK 3-SLURRY REACTOR STUDIES}

The use of a slurry reactor minimizes temperature gradients and has the potential to lower the process costs if the formaldehyde needed for the condensation can be generated by the partial oxidation of methanol and consumed in-situ. The slurry reactor studies consisted of two sets of tests. First, tests were carried out to select a slurry fluid that would be stable in the presence of oxygen. Initial tests for the slurry reactor focused on decalin as the slurry fluid. Next, tests were carried out to test the concept of in-situ generation/condensation of formaldehyde with propionic acid. The results show that the both MMA and MAA can be coproduced in one single slurry reactor, although an analysis of the product indicates that there are at least 40 other species present (Figure 55). Some of these products may have been formed by the thermal or chemical degradation of the slurry fluid (decalin). Because of the poor selectivity to MAA and MMA, and because initial economic analysis by Eastman showed that a propionic acid/formaldehyde route may be economically attractive, no further slurry reactor tests werre undertaken, and further efforts were focused on the study of condensation catalysts. 
Figure 55. GC-FID product analysis from slurry reactor.

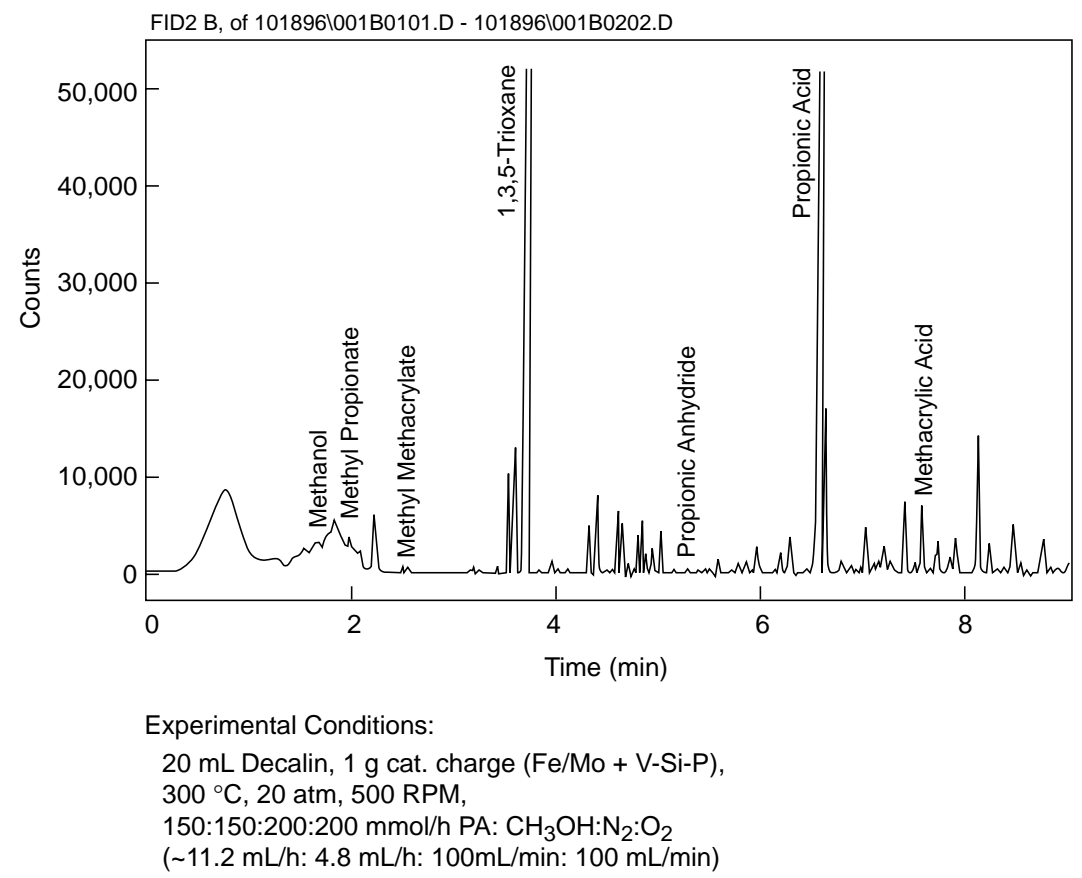

\subsection{TASK 4-CONCEPTUAL DESIGN AND ECONOMIC ANALYSIS: "EXTERNAL" FORMALDEHYDE - PROPIONIC ACID CONDENSATION ROUTE (BECHTEL)}

Condensation of propionic acid with externally supplied formaldehyde is an integrated process to synthesize MMA from coal-derived syngas. Figure 56 shows the block flow diagram for the overall process. The complex consists of four processing sections: ethylene carbonylation to synthesize propionic acid (HOPr), formalin dehydration to produce an anhydrous formaldehyde (HCHO) feed, formaldehyde/propionic acid condensation to make MAA, and esterification of MAA with methanol to form MMA.

An overall conceptual design, based on RTI's experimental data of $\mathrm{HCHO}$ and $\mathrm{HOPr}$ condensation reaction using niobium oxide catalysts, was developed for a plant to produce 250 million lb/yr of MMA. U.S. Gulf Coast basis for capital equipment, raw material and utilities, and operating labor cost were assumed. Results are compared to the MMA synthesis process economic analyses reported by SRI [38].

\subsubsection{Process Description/Design Basis}

4.4.1.1 Ethylene Carbonylation with $\mathrm{CO}$ and Water for HOPr Synthesis. This section is based on Eastman's synthesis of propionic anhydride via carbonylation of ethylene, $\mathrm{CO}$ with HOPr (the process economic analysis is reported in Section 4.1.4). The overall carbonylation design for HOPr synthesis is essentially identical to that of propionic anhydride, except for the use of water instead of HOPr as one of the feeds. 
Figure 56. External formaldehyde/propionic acid condensation route to MMA.

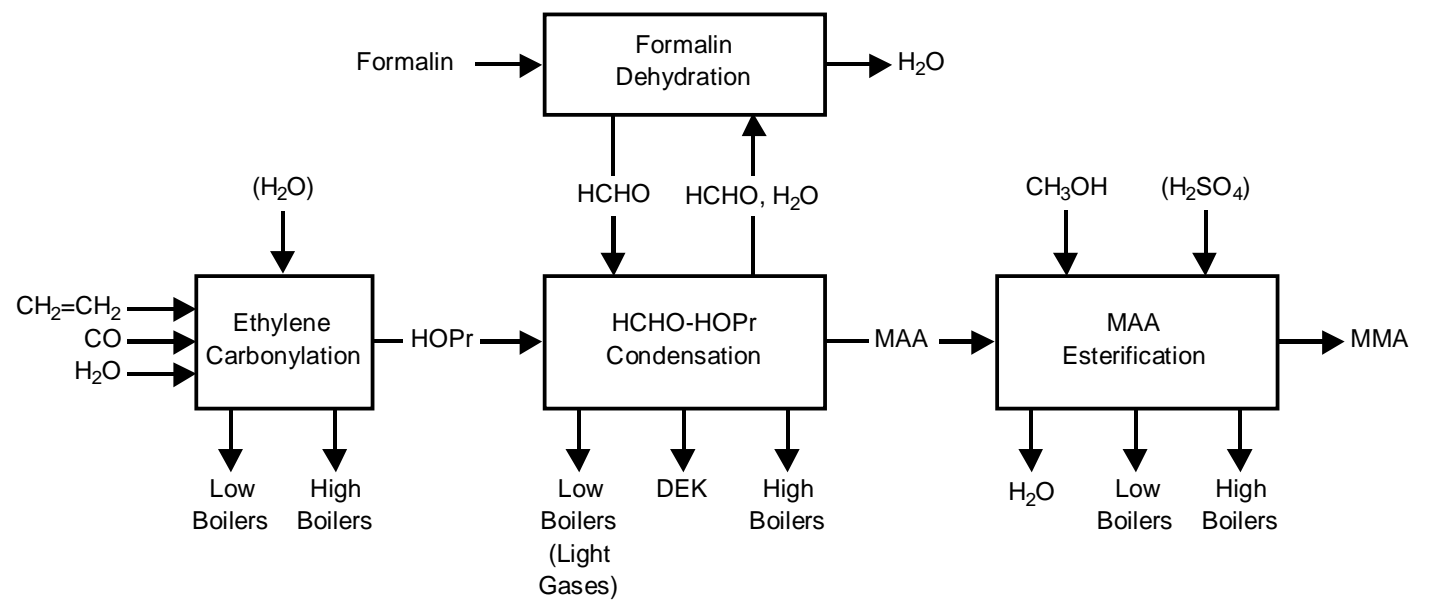

In the ethylene carbonylation part of the process (Figure 56), ethylene $\left(\mathrm{C}_{2} \mathrm{H}_{4}\right)$ is carbonylated with $\mathrm{CO}$ and water to produce propionic acid according to the reaction

$$
\mathrm{C}_{2} \mathrm{H}_{4}+\mathrm{CO}+\mathrm{H}_{2} \mathrm{O} \longrightarrow \mathrm{C}_{2} \mathrm{H}_{5} \mathrm{COOH}
$$

Similar to the carbonylation reaction for propionic anhydride synthesis, this reaction takes place in the presence of a molybdenum hexacarbonyl $\left[\mathrm{Mo}\left(\mathrm{CO}_{6}\right)\right]$ catalyst (see Section 4.1.2). This produces a liquid HOPr stream, which has to be heat exchanged before feeding it to the $\mathrm{HCHO} /$ HOPr condensation reactor.

The "ethylene carbonylation to propionic acid" design is assumed to be identical to that of propionic anhydride, the cost estimate of which is given in Section 4.1.4, and is not replicated here. Propionic acid is treated as a feedstock for the cost estimate here, and sensitivity analysis is carried out to assess its effect on the overall MMA production cost.

4.4.1.2 Formalin Dehydration. This part of the process produces an anhydrous formaldehyde stream from industrially available formalin solution ( $\sim 37 \mathrm{wt} \%$ formaldehyde in water/methanol) for the subsequent vapor phase condensation reaction with HOPr. Figure 57 shows a simplified process flow diagram for this section. The design is adopted from an earlier study [38] and adjusted based on capacity for study here. All equipment has been resized and cost estimates adjusted to current dollars.

The design involves reacting the purchased formalin with 2-ethylhexanol to form a hemiacetal intermediate. The hemiacetal is then dehydrated via fractionation; the water is distilled overhead, along with any light byproducts in the recycled formaldehyde solution from the condensation reaction, and discarded. The hemiacetal is then thermally decomposed into anhydrous formaldehyde vapor and 2-ethylhexanol for recycle. The anhydrous formaldehyde is then used as a reactant in the propionic acid condensation reactor. 
Figure 57. Simplified process flow diagram (formalin dehydration section).

\begin{tabular}{|c|c|c|c|c|}
\hline $\begin{array}{l}\text { Formaldehyde } \\
\text { Formage Tank }\end{array}$ & 2-EH Storage Tank & $\frac{\mathrm{R}-101}{\text { HemiacetalReactor }}$ & HemiacetalColumn & $\begin{array}{c}\text { F-102 } \\
\text { Formaldehyde } \\
\text { Separator }\end{array}$ \\
\hline
\end{tabular}

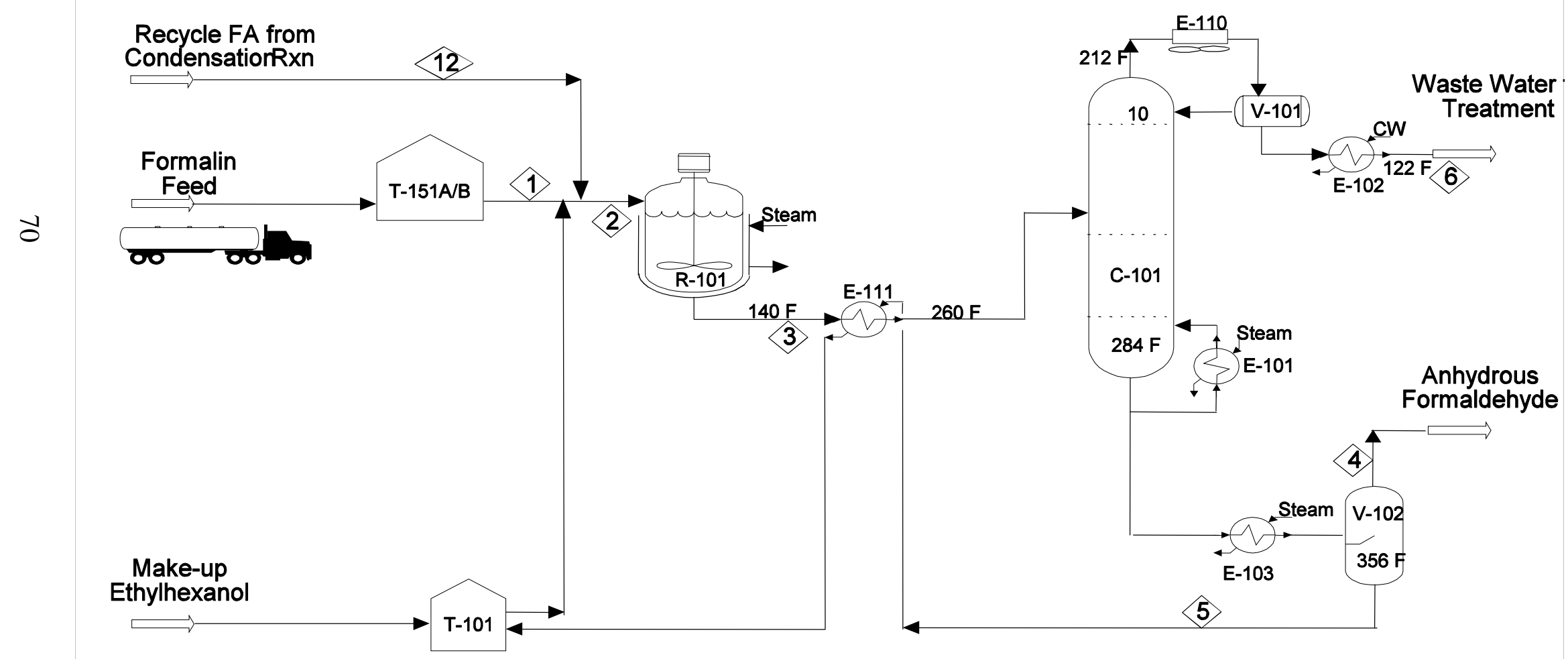


4.4.1.3 Formaldehyde and Propionic Acid Condensation. This section represents the bulk of the process design/economic analysis efforts, based on RTI's experimental development of niobium condensation catalysts. In this section, the formaldehyde and propionic acid vapor is reacted as follows to form MAA:

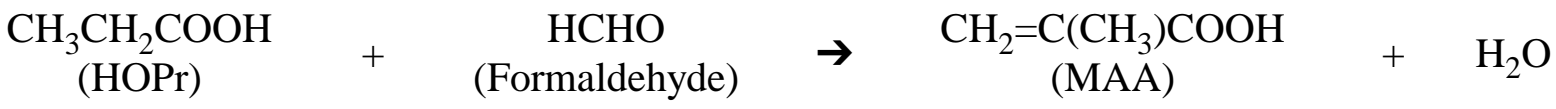

The reaction is carried out via a fixed-bed reactor filled with a $\mathrm{Nb}_{2} \mathrm{O}_{5} / \mathrm{SiO}_{2}$ catalyst. Two reactors operate in parallel: one on stream while the other is on standby after regeneration. Based on the catalyst deactivation study, it is assumed that the $\mathrm{Nb}_{2} \mathrm{O}_{5} / \mathrm{SiO}_{2}$ catalyst can be regenerated by 2 percent $\mathrm{O}_{2}$ in $\mathrm{N}_{2}$ at $400{ }^{\circ} \mathrm{C}$ [33] with negligible decrease in reaction rate, conversion, and selectivity over time. The overall plant design is based on RTI data of the 20 percent $\mathrm{Nb}_{2} \mathrm{O}_{5} / \mathrm{SiO}_{2}$ formulation. Design conditions, data, and assumptions are as follows:

A. Vapor-phase reactor operating conditions

- $300{ }^{\circ} \mathrm{C}$

- 15 to 30 psig

B. Feed ratio

- 2:1 molar ratio of HOPr:HCHO with no nitrogen dilution

C. Conversion and production rate

- 45 percent based HCHO (22.5 percent based on HOPr)

- 2 gmol MAA/(liter catalyst-h) [33]

D. Selectivity

HCHO Selectivity

- to MAA [33]

- to DEK (diethyl ketone)

- to coke and light ends

- to heavy boilers
$70 \%$

None

$25 \%$

$5 \%$
HOPr Selectivity

- to MAA [33] $75 \%$

- to DEK $5 \%$

- to coke and light ends $\quad 15 \%$

- to heavy boilers

$15 \%$

The above data suggests the following reaction loss:

- DEK Formation

$\underset{\text { 2 }}{2} \mathrm{CH}_{3} \mathrm{CH}_{2} \mathrm{COOH}$
Unidentified Losses
HOPr $\rightarrow$ HOPr losses due to coke and light gases
HCHO $\rightarrow$ HCHO losses due to coke and light gases
HOPr $\rightarrow$ HOPr losses due to heavy boilers
HCH
HCHO $\rightarrow$ HCHO losses due to heavy boilers
E. Catalyst life
$\quad$ - 1 year


Figure 58 shows a simplified process flow diagram for this section. MAA product separation is a key design challenge for the process. The reactor effluent contains the main product, MAA; byproducts $\mathrm{H}_{2} \mathrm{O}$, DEK, and $\mathrm{CO}_{2}$; unconverted $\mathrm{HCHO}$ and $\mathrm{HOPr}$ reactants; and both the light end and heavy boiler byproducts, which can be treated as inerts. Both MAA and HOPr form azeotropes with water, and both azeotropes have a boiling point of $\sim 100{ }^{\circ} \mathrm{C}$. Furthermore, $\mathrm{HCHO}$, in the presence of water, reacts with water to form a hydrate of methylene glycol, which itself tends to polymerize to poly(oxmethylene glycol) $\left[\mathrm{HO}-\left(\mathrm{CH}_{2} \mathrm{O}\right)_{n}-\mathrm{H}\right]$. Its vapor liquid equilibrium also exhibits a binary $\mathrm{HCHO} / \mathrm{H}_{2} \mathrm{O}$ azeotropic behavior having a boiling point of $100{ }^{\circ} \mathrm{C}$. In addition, the byproduct DEK also forms a heterogenous azeotrope with water. All of the above contribute to the cost of MAA product separation.

This effluent separation portion of the overall process is to produce a water-free stream of MAA with minimum residual HOPr for subsequent esterification. MAA product separation requires distillation of multiple binary water-based azeotropes, which is challenging and will be discussed in detail in Section 4.4.2.

4.4.1.4 MAA Esterification. Figure 59 shows the simplified process flow diagram for this section. It is a "standard" MAA esterification process design adopted from a recent report [38] without modification. Stream flows are adjusted for capacity for the current study and all equipment are resized and cost estimates adjusted to current dollars.

\subsubsection{Formaldehyde and Propionic Acid Condensation-Design and ASPEN Simulation}

This section represents the bulk of the overall process design and economic analysis effort, with special emphasis placed on the condensation reaction effluent separation.

4.4.2.1 Formaldehyde/Propionic Acid Condensation Reaction. For design heat and material balance purposes, the condensation reaction is modeled via a stoichiometric reactor (RSTOIC with ASPEN Plus) at $570{ }^{\circ} \mathrm{F}\left(300{ }^{\circ} \mathrm{C}\right)$ and 30 psia per RTI's design data (20 percent Nb:Si, 2:1 HOPr:HCHO molar feed ratio) given in Section 4.4.1.3. Reaction equations were provided for the MAA formation from $\mathrm{HOPr}$ and $\mathrm{HCHO}$, and DEK formation from HOPr. Stoichiometric reaction schemes are assumed to account for coke, light ends, and heavy boiler formation from both $\mathrm{HOPr}$ and HCHO. Six reaction schemes are modeled:

HCHO Reactions: 45 percent conversion

HOPr Reaction: 22.5 percent conversion

$$
\begin{aligned}
& 2 \mathrm{HOPr} \longrightarrow \mathrm{DEK}+\mathrm{CO}_{2}+\mathrm{H}_{2} \mathrm{O} \\
& \mathrm{HOPr} \longrightarrow 2 \mathrm{C}+\mathrm{CO}_{2}+3 \mathrm{H}_{2} \\
& 2 \mathrm{HOPr}+\mathrm{H}_{2} \longrightarrow \mathrm{C}_{6} \mathrm{H}_{14} \mathrm{O}_{4}
\end{aligned}
$$


Figure 58. Simplified process flow diagram (formaldehyde/propionic acid condensation section).

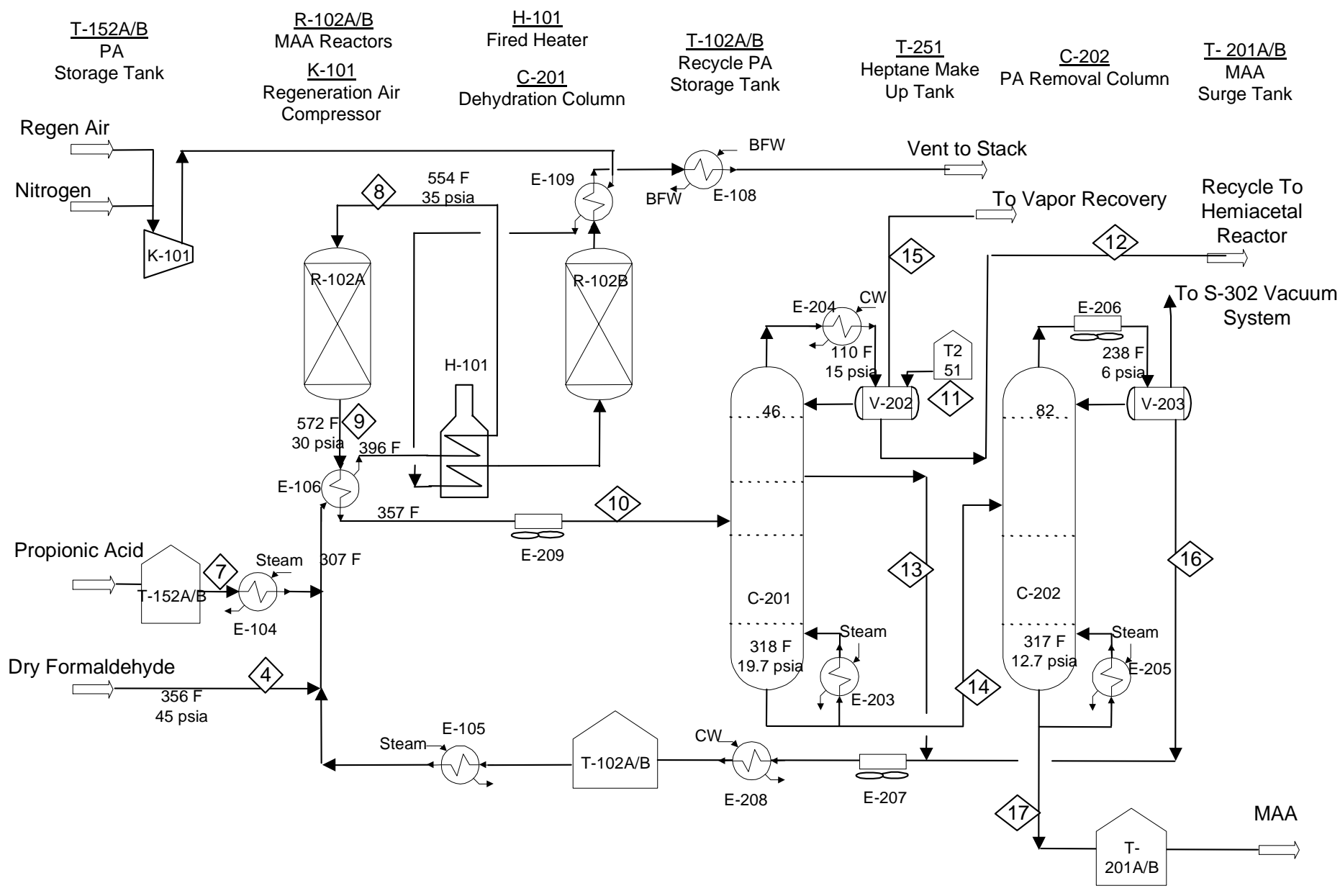


Figure 59. Simplified process flow diagram (MAA esterification section).

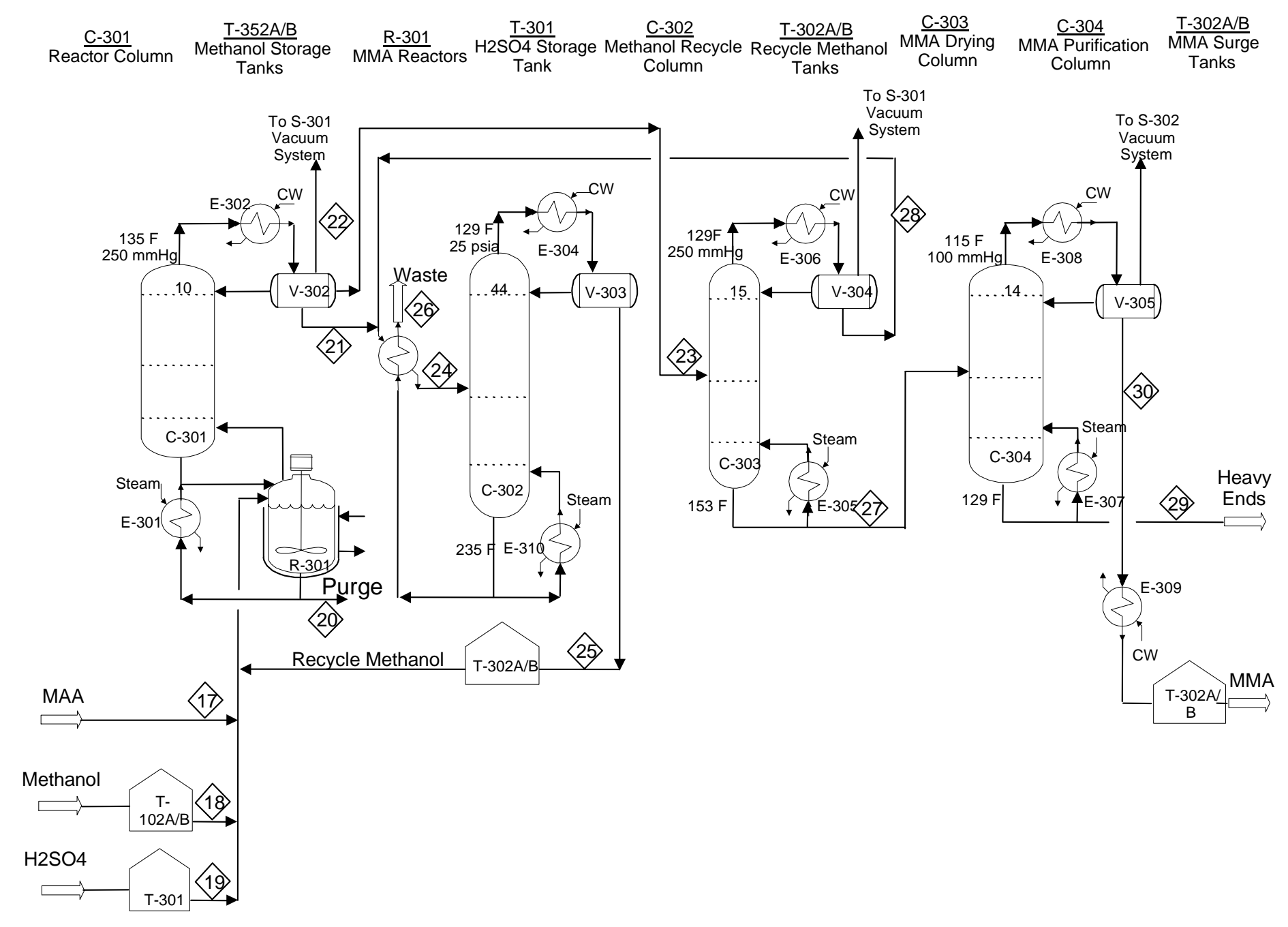


$\mathrm{C}_{6} \mathrm{H}_{14} \mathrm{O}_{4}$ (triethylene glycol), which is a known component in the ASPEN data bank, was used to represent the high boiling compound formed from HOPr.

Due to the material balance and stoichiometry constraints, the HOPr selectivity had to be adjusted from RTI data. Final selectivities for the design are as follows:

\begin{tabular}{lccc} 
& HCHO Selectivity & HOPr Selectivity \\
\cline { 2 - 3 } MAA & $70 \%$ & $70 \%$ \\
DEK & None & $6 \%$ \\
Coke and light gases & $25 \%$ & $18 \%$ \\
Heavy boilers & $5 \%$ & $6 \%$
\end{tabular}

The overall process is based on two separate fixed-bed condensation reactors in parallel: one online with the process whereas the other is kept on standby after regeneration with 2 percent $\mathrm{O}_{2}$ at $400{ }^{\circ} \mathrm{C}$. A one year catalyst life is assumed.

\subsubsection{Condensation Reaction Effluent Separation - Azeotropic Distillation Simulation.} Azeotropic distillation was selected to purify the MAA product. Earlier work based on a similar type of system (i.e., reaction effluent from a vapor phase condensation reaction between $\mathrm{HCHO}$ and HOPr) has shown that with a proper organic hydrocarbon entrainer, azeotropic distillation can be effective in producing a MAA product free of water from the reaction mixture [39]. This process, by Amoco, shows that when using an organic solvent $\left(n-C_{7}\right)$ as an entrainer to form a heterogeneous azeotrope with water (which has a boiling point lower than that of the $\mathrm{MAA} / \mathrm{H}_{2} \mathrm{O}$, $\mathrm{HOPr} / \mathrm{H}_{2} \mathrm{O}$ binary homogeneous azeotrope pairs), water can be removed from the mixture as an overhead $n-\mathrm{C}_{7} / \mathrm{H}_{2} \mathrm{O} / \mathrm{HCHO}$ stream, and that a nearly anhydrous MAA and HOPr stream can be produced from the bottom of the column. A sidedraw stream containing mostly HOPr and HCHO can be recovered and recycled as feed. The $n-\mathrm{C}_{7} / \mathrm{H}_{2} \mathrm{O}$ overhead is condensed and phase separated. The upper organic $\left(n-C_{7}\right)$ layer is returned to the column as reflux. The aqueous lower layer is recycled for recovery of $\mathrm{HCHO}$ (see Figure 58).

The Amoco azeotropic distillation process was simulated using ASPEN; a water-free MAA and HOPr bottom stream was produced, and a sidedraw stream containing mostly $\mathrm{HCHO}$ and $\mathrm{HOPr}$ was recovered. Column was operated/simulated at reasonable temperature, $156{ }^{\circ} \mathrm{C}\left(310{ }^{\circ} \mathrm{F}\right)$, and pressure conditions ( atmospheric) to avoid MAA polymerization. (Amoco cited in their patent that this is required and a suitable inhibitor needs to be added to the mixture to prevent MAA polymerization.) The azeotropic distillation was simulated using ASPEN Plus as a three-phase Radfrac model, using an UNIQUAC activity coefficient model, a FMEH20 package to predict the VLE behavior of formaldehyde and water mixture, and customized Newton/Azeotrope convergence algorithm. 
The success with simulating Amoco's data led to the following:

(1) Identification of an activity coefficient model (e.g., UNIQUAC but not Wilson) and convergence algorithm (Newton/Azeotropic) for three-phase Radfrac azeotropic distillation modeling.

(2) The use of a FMEH2O property package for predicting formaldehyde and water mixture VLE (vapor liquid equilibrium). The package takes into consideration formaldehyde/water oligomerization and vapor phase (Hayden O'Connell) association.

(3) An understanding of the column pressure constraint. In order to avoid using vacuum distillation, the operating bottom pressure is limited by the maximum allowable column bottom operating temperature of $158{ }^{\circ} \mathrm{C}\left(315^{\circ} \mathrm{F}\right)$ (to avoid MAA polymerization) where the MAA vapor pressure is only about 17 to 18 psia. At this pressure and temperature, binary VLE of MAA and HOPr (the two components leaving the bottom of the column other than the high boiler) shows that the bottom stream will contain a high proportion ( 70 percent) of HOPr. We selected to operate the column at a pressure slightly higher ( 3 psi) than Amoco's specified upper bound of $158{ }^{\circ} \mathrm{C}\left(315^{\circ} \mathrm{F}\right)$ to avoid the use of vacuum distillation in the dehydration column.

(4) Identification of a set of initial column specifications for simulating the RTI data.

An azeotropic distillation train was built into the formaldehyde/propionic acid condensation section simulation model, as shown in Figure 58. The purpose of the main effluent column (dehydration column) is to remove the water from the reaction azeotropic mixture and send the MAA product onto the esterification section after further purification to remove HOPr. The objective is to operate the column at a reasonable temperature (to avoid MAA polymerization) and pressure (to avoid using vacuum if possible) and separate the reaction effluent into three separate streams: the bottom stream containing the anhydrous MAA and HOPr (plus the high boiler) product, a side-draw stream containing mostly HOPr for recycling without further purification, and a distillate that can be separated into a $n-\mathrm{C}_{7}$ organic stream for reflux and an aqueous stream containing mostly $\mathrm{HCHO}$ and water with little HOPr, which then can be recycled to the formaldehyde/hemiacetal section to recover the formaldehyde.

Final simulation material balance result for the formaldehyde/propionic acid condensation reaction and product separation is shown in Table 17. The final dehydration (azeotropic distillation) column contains 46 theoretical stages producing a bottom MAA/HOPr stream essentially free of water, a side draw containing essentially pure HOPr (94 mol\%) with 2 percent MAA, which can be recycled back to the condensation reactor after being heat exchanged, a distillate organic phase consisting of 94 percent $n-C_{7}$ (with 4.5 percent DEK) as reflux, and a distillate aqueous phase containing $\mathrm{HCHO}$ and $\mathrm{H}_{2} \mathrm{O}$ (total of $97 \mathrm{~mol} \%$ ), which is sent to the formaldehyde/hemiacetal section for $\mathrm{HCHO}$ recovery and recycling. The bottom MAA product stream contains $70 \mathrm{~mol} \%$ of HOPr. An additional downstream column is needed to purify the MAA before sending it on to the esterification section. This column is operated under vacuum to achieve a high MAA purity. 
Table 17. Process Material Balance-Stream Flow

\begin{tabular}{|c|c|c|c|c|c|c|c|c|c|c|c|c|}
\hline \multicolumn{2}{|l|}{ Stream No. } & \multicolumn{2}{|c|}{1} & \multirow{2}{*}{$\begin{array}{c}2 \\
\text { Hemiacetal } \\
\mathrm{Rx} \mathrm{Fd} \\
\end{array}$} & \multirow{2}{*}{$\begin{array}{c}3 \\
\text { Hemiacetal } \\
\text { Rx Effl } \\
\end{array}$} & \multirow{2}{*}{$\begin{array}{c}4 \\
\text { Anhydrous } \\
\mathrm{H}_{2} \mathrm{CO} \\
\end{array}$} & \multirow{2}{*}{$\begin{array}{c}6 \\
\text { Water to } \\
\text { Treatment }\end{array}$} & \multirow{2}{*}{$\begin{array}{c}5 \\
\text { 2-EH Recy }\end{array}$} & \multirow{2}{*}{$\begin{array}{c}7 \\
\mathrm{PrOH} \\
\end{array}$} & \multirow{2}{*}{$\begin{array}{c}8 \\
\text { MAA } \\
\text { Rx Fd } \\
\end{array}$} & \multirow{2}{*}{$\begin{array}{c}9 \\
\text { MAA } \\
\text { Rx Efflu }\end{array}$} & \multirow[b]{2}{*}{$\begin{array}{c}\text { Coke } \\
\text { Deposits }\end{array}$} \\
\hline Components & mol wt & Formalin & $\begin{array}{l}\text { 2-Ehex-ol } \\
\text { MakeUp }\end{array}$ & & & & & & & & & \\
\hline $\mathrm{CO}_{2}$ & 44.01 & - & - & 9 & 9 & & 9 & & - & 16 & 7,428 & - \\
\hline $\mathrm{CO}$ & 28.01 & - & - & - & - & & - & & - & - & & - \\
\hline $\mathrm{H}_{2}$ & 2.02 & - & - & 0 & 0 & & 0 & & - & 0 & 749 & - \\
\hline Water & 18.02 & 19,052 & - & 24,641 & 24,641 & & 24,641 & & - & 372 & 6,687 & - \\
\hline Formaldehyde & 30.03 & 14,969 & - & 31,738 & 31,738 & 31,738 & - & & - & 32,017 & 17,609 & - \\
\hline $\mathrm{PrOH}$ & 74.08 & - & - & 991 & 991 & & 991 & & 37,040 & 160,601 & 124,878 & - \\
\hline MAA & 86.09 & - & - & 0 & 0 & & 0 & & - & 1,794 & 30,711 & - \\
\hline n-Heptane & 100.2 & - & - & 281 & 281 & & 281 & & - & 0 & 0 & - \\
\hline DEthKetone & 86.13 & - & - & 799 & 799 & & 799 & & - & 262 & 1,522 & - \\
\hline 2-E-Hexanol & 130.23 & - & - & 137,636 & 137,636 & & - & 137,636 & - & - & & - \\
\hline Hiboiler & 150.17 & - & - & - & - & & - & & - & - & 2,648 & - \\
\hline $\mathrm{H}_{2} \mathrm{SO}_{4}$ & 98.08 & - & - & - & - & & - & & - & - & & - \\
\hline Methanol & 32.04 & - & - & - & - & & - & & - & - & & - \\
\hline Coke & 12 & - & - & - & - & & - & & - & - & 2,830 & 2,830 \\
\hline MMA & 100.11 & - & - & - & - & & - & & - & - & & - \\
\hline DME & 46.07 & - & - & - & - & & - & & - & - & & - \\
\hline Total & $\mathrm{lb} / \mathrm{hr}$ & 34,021 & - & 196,096 & 196,096 & 31,738 & 26,722 & 137,636 & 37,040 & 195,062 & 195,062 & 2,830 \\
\hline
\end{tabular}


Table 17. (continued)

\begin{tabular}{|c|c|c|c|c|c|c|c|c|c|c|c|c|}
\hline \multicolumn{2}{|l|}{ Stream No. } & \multirow{2}{*}{$\begin{array}{c}10 \\
\\
\text { Dehy Col } \\
\text { Feed }\end{array}$} & \multirow{2}{*}{$\begin{array}{c}12 \\
\text { Dehy Col } \\
\text { Ovhd Liq }\end{array}$} & \multirow{2}{*}{$\begin{array}{c}13 \\
\\
\text { PrOH } \\
\text { Side Draw } \\
\end{array}$} & \multirow{2}{*}{$\begin{array}{c}15 \\
\text { Vent to } \\
\text { Vac Sys }\end{array}$} & \multirow{2}{*}{$\begin{array}{c}14 \\
\text { Dehy Col } \\
\text { Btms }\end{array}$} & \multirow{2}{*}{$\begin{array}{c}16 \\
\text { Recy } \\
\text { PrOH } \\
\text { fr PrOH } \\
\text { Col } \\
\end{array}$} & \multirow{2}{*}{$\begin{array}{c}17 \\
\text { MAA } \\
\end{array}$} & \multirow{2}{*}{$\begin{array}{c}11 \\
\text { n-Heptane } \\
\text { Make Up }\end{array}$} & \multirow{2}{*}{$\begin{array}{c}18 \\
\text { Methanol }\end{array}$} & \multirow{2}{*}{$\begin{array}{c}19 \\
\mathrm{H}_{2} \mathrm{SO}_{4} \\
\end{array}$} & \multirow{2}{*}{$\begin{array}{c}25 \\
\text { Recy Meth } \\
\text { fr } \mathrm{C}_{3} \mathrm{O}_{2} \\
\end{array}$} \\
\hline Components & mol wt & & & & & & & & & & & \\
\hline $\mathrm{CO}_{2}$ & 44.01 & 7,428 & 9 & 16 & 7,402 & - & & - & & - & - & \\
\hline $\mathrm{CO}$ & 28.01 & - & - & & - & - & & - & & - & - & \\
\hline Formaldehyde & 30.03 & 17,609 & 16,768 & 279 & 562 & - & & - & & - & - & \\
\hline $\mathrm{PrOH}$ & 74.08 & 124,878 & 991 & 62,458 & 7 & 61422 & 61,103 & 319 & & - & - & \\
\hline MAA & 86.09 & 30,711 & 0 & 1,177 & 0 & 29,534 & 617 & 28,917 & & - & - & \\
\hline n-Heptane & 100.2 & 0 & 281 & 0 & 9,906 & - & & - & 10,187 & - & - & \\
\hline $\mathrm{H}_{2} \mathrm{SO}_{4}$ & 98.08 & - & - & & - & - & & - & & - & 159 & \\
\hline Methanol & 32.04 & - & - & & - & - & & - & & 10,394 & - & 1,821 \\
\hline Coke & 12 & - & - & & - & - & & - & & - & - & \\
\hline MMA & 100.11 & - & - & & - & - & & - & & - & - & 1,205 \\
\hline DME & 46.07 & - & - & & - & - & & - & & - & - & 523 \\
\hline Total & $\mathrm{lb} / \mathrm{hr}$ & 192,233 & 24,438 & 64,550 & 19,813 & 93,619 & 61,735 & 31,883 & 10,187 & 10,394 & 159 & 4,698 \\
\hline
\end{tabular}


Table 17. (continued)

\begin{tabular}{|c|c|c|c|c|c|c|c|c|c|c|c|}
\hline \multicolumn{2}{|l|}{ Stream No. } & \multirow{2}{*}{$\begin{array}{c}23 \\
\text { Raw MMA } \\
\text { to Dry Col }\end{array}$} & \multirow{2}{*}{$\begin{array}{c}20 \\
\text { Dry Col } \\
\text { Btms } \\
\text { Purge }\end{array}$} & \multirow{2}{*}{$\begin{array}{l}21 \\
\text { Methanol } \\
\text { to C-302 }\end{array}$} & \multirow{2}{*}{$\begin{array}{c}22 \\
\text { Vent from } \\
\text { C-301 } \\
\end{array}$} & \multirow{2}{*}{$\begin{array}{c}24 \\
\text { Meth Recy } \\
\text { Col Fd } \\
\end{array}$} & \multirow{2}{*}{$\begin{array}{c}26 \\
\text { Waste } \\
\text { Water } \\
\end{array}$} & \multirow{2}{*}{$\begin{array}{c}28 \\
\text { Recy Meth } \\
\text { fr C303 } \\
\end{array}$} & \multirow{2}{*}{$\begin{array}{c}27 \\
\text { MAA Fd } \\
\text { to Purif Col }\end{array}$} & \multirow{2}{*}{$\begin{array}{c}29 \\
\begin{array}{c}\text { Purif Col } \\
\text { Btms }\end{array} \\
\end{array}$} & \multirow{2}{*}{$\begin{array}{c}30 \\
\text { MMA to } \\
\text { Storage }\end{array}$} \\
\hline Components & mol wt & & & & & & & & & & \\
\hline $\mathrm{CO}_{2}$ & 44.01 & & - & - & - & - & - & - & - & - & - \\
\hline $\mathrm{CO}$ & 28.01 & & - & - & - & - & - & - & - & - & - \\
\hline $\mathrm{H}_{2}$ & 2.02 & & - & - & - & - & - & - & - & - & - \\
\hline Water & 18.02 & 619 & 7 & 6,357 & - & 6,966 & 5,817 & 609 & 10 & - & 10 \\
\hline Formaldehyde & 30.03 & & - & - & - & - & - & - & - & - & - \\
\hline $\mathrm{PrOH}$ & 74.08 & & - & - & - & - & - & - & - & - & - \\
\hline MAA & 86.09 & & 1,430 & - & - & - & - & - & - & - & - \\
\hline n-Heptane & 100.2 & & - & - & - & - & - & - & - & - & - \\
\hline DEthKetone & 86.13 & & - & - & - & - & - & - & - & - & - \\
\hline 2-E-Hexanol & 130.23 & & - & - & - & - & - & - & - & - & - \\
\hline Hiboiler & 150.17 & 113 & 2,837 & - & - & - & - & - & 113 & 59 & 54 \\
\hline $\mathrm{H}_{2} \mathrm{SO}_{4}$ & 98.08 & & 159 & - & - & - & - & - & - & - & - \\
\hline Methanol & 32.04 & 895 & - & 935 & 2 & 1,830 & 9 & 895 & - & - & - \\
\hline Coke & 12 & & - & - & - & - & - & - & - & - & - \\
\hline MMA & 100.11 & 32,903 & - & 332 & - & 1,224 & 19 & 892 & 32,011 & 45 & 31,966 \\
\hline DME & 46.07 & 46 & - & 477 & 22 & 523 & - & 46 & - & - & - \\
\hline Total & $\mathrm{lb} / \mathrm{hr}$ & 34,576 & 4,433 & 8,101 & 24 & 10,543 & 5,845 & 2,442 & 32,134 & 104 & 32,030 \\
\hline
\end{tabular}




\subsubsection{Simplified Overall Process Flow Diagram and Material Balance}

A simplified process flow diagram is presented in Figures 57 to 59 for the formalin dehydration, formaldehyde/propionic acid condensation, and the MAA esterification section. Major equipment listing with a brief description of each equipment were also shown, along with the stream number identifying all major stream flows in the plant. Material balance for the plant is given in Table 17. Individual stream flow is identified with a stream number identical to that on the process flow diagrams. Based on the overall plant material balance, an equipment list for the overall inside battery limits (ISBL) plant was generated, which then serves as the basis for the overall plant capital cost estimates. As stated earlier, U.S. Gulf Coast basis for capital equipment, raw material and utilities, and operating labor cost are assumed.

\subsubsection{Cost Estimates}

Estimates are based on the process design and the major equipment associated with the plant as described above, along with the following assumptions:

- 250 million $1 \mathrm{~b} / \mathrm{yr}$ MMA production

- $\quad$ On-stream plant factor of 0.9

- License fee and royalty not included.

Because $\mathrm{HOPr}$ and MMA are present throughout the condensation processing section and $\mathrm{H}_{2} \mathrm{SO}_{4}$ in the esterification section, stainless steel (either 304 or 316) construction was specified where appropriate, stainless steel cladding was assumed to save cost.

The estimated capital investment for the 250 million lb/yr MMA plant is about $\$ 55.1$ million, (in 1999 dollars). Table 18 shows the estimated cost breakdown, categorized by the type of ISBL equipment used. Total ISBL installed cost is estimated at $\$ 27.2$ million, including major equipment, bulk materials, freight and tax, both direct and indirect installation labor, and indirect support. A 35 percent contingency was assumed. Offsite costs were not estimated in detail, but are assumed to be a fixed percentage of the total ISBL cost [38]. Offsite includes both feed and product storage tankage and a waste water treatment facility. Estimated capital cost breakdown for three processing sections are 20,56, and 24 percent for formaldehyde dehydration, $\mathrm{HCHO} / \mathrm{HOPr}$ condendation, and MAA esterification, respectively.

\subsubsection{Process Economics}

The current RTI-Eastman-Bechtel MMA process economics have been compared to the various commercial (or potentially commercial) technologies for MMA production as reported in the 1993 SRI PEP report [37,38]. The 1993 SRI report [38] describes the economics of an MMA process based on MAA production via a formaldehyde/propionic acid condensation reaction using an Amoco patented Cs catalyst against which the current process can be directly compared. To facilitate this comparison, the production cost estimation methodology used by SRI is employed for the present analysis. Production cost is based on a 25 percent rate of return of 


\section{Table 18. "External” Formaldehyde/ Propionic Acid Condensation Route to MMA}

Total Capital Investment

\begin{tabular}{lc}
\hline Battery Limits Equipment FOB & Cost (\$million) \\
\hline Columns \& Vessels & 3.82 \\
Tanks & 0.70 \\
Heat Exchangers & 1.60 \\
Pumps & 1.15 \\
Compressor & 0.22 \\
Others & 0.40 \\
Bulk Materials & 4.00 \\
Freight \& Tax & 1.10 \\
$\quad$ Subtotal: & 12.98 \\
Direct/Indirect Installation Costs & 4.51 \\
Home Office \& Engineering & 2.62 \\
Supports & \\
Contingency (35\%) & 7.04 \\
Total ISBL Investment & 27.16 \\
Estimated OSBL & 27.98 \\
\hline Total Investment & 55.14 \\
\hline
\end{tabular}

capital investment. Amoco's process/economic analysis assumes purchased propionic acid as a feed at a price of $\$ 0.25 / \mathrm{lb}$.

Table 19 shows the input parameters and the assumptions employed to estimate the MMA production cost. The economic data represents the production cost of MMA based on purchased propionic acid, at a current selling price of $\$ 0.41 / \mathrm{lb}$. Under this scenario, RTI-Eastman-Bechtel's niobium-catalyst-based "External Formaldehyde/Propionic Acid Condensation" route for manufacturing MMA is not economical. Estimated MMA production cost of $\$ 0.89 / \mathrm{lb}$ is higher than the current market price for MMA at $\$ 0.65$ to $\$ 0.70 / \mathrm{lb}$ [40]. However, raw material costs dominate the overall economics: propionic acid cost alone accounts for about 54 percent of the total MMA production cost.

For the current MMA process to be economical, the carbonylation step for HOPr synthesis has to be included as an integral part of the overall MMA process. Assuming that the ethylene carbonylation process design for HOPr synthesis is identical to that of the propionic anhydride design that is reported in Section 3.1.4 and that the cost estimates for the two designs are in the same order of magnitude (the only difference is the use of water instead of HOPr as the feed), 
Table 19. "External" Formaldehyde/Propionic Acid Condensation MMA Synthesis

Product Costs-Purchased HOPr Feed

\begin{tabular}{|c|c|c|c|c|c|}
\hline \multirow{2}{*}{$\frac{\text { CAPACITY (Mlb/yr) }}{\text { Investments (\$MM) }}$} & \multirow[t]{2}{*}{250} & \multicolumn{4}{|c|}{$31710 \mathrm{lb} / \mathrm{hr}$} \\
\hline & & & & & \\
\hline Battery Limits (BLI) & 27.16 & & & & \\
\hline Off-Sites & 27.98 & & & & \\
\hline Total Fixed Capital (TFC) & 55.14 & & & & \\
\hline \multicolumn{2}{|l|}{ Production Costs (Cents/lb) } & \multicolumn{4}{|c|}{ Consumption (lb) } \\
\hline \multirow{2}{*}{\multicolumn{2}{|c|}{ Raw Materials }} & \multirow[b]{2}{*}{ per lb of MMA } & \multirow{2}{*}{$\begin{array}{c}\text { Total } \\
\text { Consumption }\end{array}$} & \multicolumn{2}{|c|}{ Unit } \\
\hline & & & & $\operatorname{Cost}(\$)$ & Unit \\
\hline Formalin, lb & 0.12875 & 1.072886 & 34021 & 0.12 & lb \\
\hline Propionic acid, lb & 0.47892 & 1.168093 & 37040 & 0.41 & $\mathrm{lb}$ \\
\hline $\mathrm{nC7}, \mathrm{lb}$ & 0.03823 & 0.321257 & 10187 & 0.119 & $\mathrm{lb}$ \\
\hline $\mathrm{MeOH}, \mathrm{lb}$ & 0.01770 & 0.327785 & 10394 & 0.054 & $\mathrm{lb}$ \\
\hline $\mathrm{H}_{2} \mathrm{SO}_{4}, \mathrm{lb}$ & 0.00019 & 0.005014 & 159 & 0.0385 & $\mathrm{lb}$ \\
\hline Catalyst, lb & 0.00000 & & & 0 & lb \\
\hline (Total) & 0.66379 & & & & \\
\hline \multicolumn{6}{|l|}{ Utilities } \\
\hline Cooling Water, GPM & 0.00164 & 0.025656 & 13559 & 0.064 & Mgal \\
\hline 250 \#steam, Mlb & 0.02633 & 0.008305 & 263.34 & 3.17 & Mlb \\
\hline Fuel, MMBtu & 0.00127 & 0.000637 & 20.2 & 2.00 & MMBtu \\
\hline Power, KW & 0.02649 & 0.715993 & 946 & 0.037 & Kwh \\
\hline (Total) & 0.05573 & & & & \\
\hline Total Variable Costs & 0.71952 & & & & \\
\hline Operating Labor, 9/shift @ \$25.26/hr & 0.00795 & \multicolumn{4}{|c|}{$<--$ SRI's estimated labor and rate } \\
\hline Maintenance Labor, $3 \% / y r$ of BLI & 0.00326 & \multicolumn{4}{|c|}{$<--$ SRI PEP financial assumption } \\
\hline Control Lab Labor, $20 \%$ of Oper. Lab & 0.00159 & \multicolumn{4}{|c|}{ _<-- SRI PEP financial assumption } \\
\hline Total Labor Costs & 0.01280 & & & & \\
\hline Maintenance Materials, $3 \% / y r$ of BLI & 0.00326 & \multicolumn{4}{|c|}{$<--$ SRI PEP financial assumption } \\
\hline Operating Supplies, $10 \%$ of oper. Labor & 0.00080 & \multicolumn{4}{|c|}{ _-- SRI PEP financial assumption } \\
\hline Total Direct Costs & 0.73638 & & & & \\
\hline Plant Overhead, $80 \%$ of Labor Costs & 0.01024 & \multicolumn{4}{|c|}{ <-- SRI PEP financial assumption } \\
\hline Taxes and Insurance, $2 \% / y r$ of TFC & 0.00441 & \multicolumn{4}{|c|}{$<--$ SRI PEP financial assumption } \\
\hline Depreciation, $10 \% / \mathrm{yr}$ of TFC & 0.02206 & \multicolumn{4}{|c|}{ _-- SRI PEP financial assumption } \\
\hline Plant Gate Cost & 0.77309 & & & & \\
\hline G\&A, Sales, Research & 0.06000 & \multicolumn{4}{|c|}{ _-- SRI PEP financial assumption } \\
\hline Production Cost & 0.83309 & \multirow{2}{*}{\multicolumn{4}{|c|}{ <-- SRI PEP financial assumption }} \\
\hline ROI Before Taxes, $25 \% / y r$ of TFC & 0.05514 & & & & \\
\hline Product Value, $\$ / \mathrm{lb}$ & 0.88823 & & & & \\
\hline
\end{tabular}


HOPr production cost via ethylene and $\mathrm{CO}$ carbonylation can be estimated. It was found that HOPr can be produced under $\$ 0.20 / \mathrm{lb}$.

Table 20 shows the revised economics for an integrated MMA plant (assumed HOPr cost of $\$ 0.20 / \mathrm{lb}$ ). Under this scenario, MMA production cost of $\$ 0.64 / \mathrm{lb}$ is competitive with the current market price for a 25 percent rate of return on investment (ROI). Raw material costs still contribute to a significant portion of the overall MMA production economics, however.

In comparison with the reported MMA production cost for the Amoco process based on Cs catalyzed $\mathrm{HCHO} / \mathrm{HOPr}$ condensation [38], the integrated RTI-Eastman-Bechtel MMA process still has a 20 percent higher production cost. The primary reasons for this are due to the following:

(1) A higher reported $\mathrm{HOPr}$ and $\mathrm{HCHO}$ condensation reaction conversion and selectivity for the Amoco process: 39 percent HOPr conversion and 90 percent selectivity to MAA (vs. 22.5 percent and 70 percent respectively for the RTI-Eastman-Bechtel process).

(2) The Amoco process produces much less light ends and uses a lower HOPr:HCHO feed ratio for the condensation reaction (1.5:1 vs. $2: 1)$, and the loss of unconverted reactants ( $\mathrm{HCHO}$ and $\mathrm{HOPr})$ are less. The entrainer $\left(\mathrm{n}-\mathrm{C}_{7}\right)$ loss from the product dehydration column was also minimized; the produced light ends have the tendency to strip off a significant amount of the $n-C_{7}$ to the column overhead.

This effect is demonstrated in Figure 60, which shows the sensitivity of the MMA production cost for the RTI-Eastman-Bechtel process as a function of HOPr conversion and selectivity.

As shown, the overall integrated MMA process economics is very much driven by the selectivity of the HOPr and $\mathrm{HCHO}$ consumptions. To gain significant economic advantage over other competitive technologies, the current RTI-Eastman-Bechtel niobium-based HCHO/HOPr condensation reaction selectivity needs to be higher to minimize feedstock (particularly HOPr) loss. There are significant advantages in doing so. Increasing the selectivity to 95 percent lowers the MMA cost to about $\$ 0.48 / \mathrm{lb}$, significantly lower than the current market price even at a 25 percent ROI. Raw material costs still have a significant impact on the final MMA process economics. An additional 4-cent savings, as shown in Figure 60, can be achieved if the process recovers $\mathrm{HOPr}, \mathrm{HCHO}$, and $n-\mathrm{C}_{7}$ from both the vapor and the waste water streams leaving the condensation section.

\subsection{TASK 5-DME CONDENSATION STUDY (RTI AND EASTMAN)}

As an alternative to the condensation of externally-supplied formaldehyde with propionic acid, the use of DME (as a source of formaldehyde and an esterfying agent), has the potential to lower the overall costs even further and can be integrated directly with DOE's liquid phase methanol plant in Kingsport, TN. Figure 61 shows the possible process scheme. The key to this process, the "MMA Synthesis" is to study DME in-situ condensation with methyl propionate to MMA. The direct condensation between formaldehyde and methyl propionate was first studied. Since formaldehyde from partial oxidation of DME can form MMA directly with methyl propionate. 
Table 20. "External" Formaldehyde/Propionic Acid Condensation MMA Synthesis

Product Costs-Integrated Carbonylation Process

\begin{tabular}{|c|c|c|c|c|c|}
\hline \multirow{2}{*}{$\frac{\text { CAPACITY (MMlb/yr) }}{\text { Investments (\$MM) }}$} & \multirow[t]{2}{*}{250} & \multicolumn{4}{|c|}{$31710 \mathrm{lb} / \mathrm{hr}$} \\
\hline & & & & & \\
\hline Battery Limits (BLI) & 27.16 & & & & \\
\hline Off-Sites & 27.98 & & & & \\
\hline Total Fixed Capital (TFC) & 55.14 & & & & \\
\hline \multicolumn{2}{|l|}{ Production Costs (Cents/lb) } & \multicolumn{4}{|c|}{ Consumption (lb) } \\
\hline \multirow{2}{*}{\multicolumn{2}{|c|}{ Raw Materials }} & \multirow{2}{*}{$\begin{array}{c}\text { per lb } \\
\text { of MMA }\end{array}$} & \multirow{2}{*}{$\begin{array}{c}\text { Total } \\
\text { Consumption }\end{array}$} & \multicolumn{2}{|c|}{ Unit } \\
\hline & & & & $\operatorname{Cost}(\$)$ & Unit \\
\hline Formalin, lb & 0.12875 & 1.072889 & 34021 & 0.12 & lb \\
\hline Propionic acid, lb & 0.23362 & 1.16809 & 37040 & 0.2 & $\mathrm{lb}$ \\
\hline $\mathrm{nC7}, \mathrm{lb}$ & 0.03823 & 0.32126 & 10187 & 0.119 & $\mathrm{lb}$ \\
\hline $\mathrm{MeOH}, \mathrm{lb}$ & 0.01770 & 0.32779 & 10394 & 0.054 & $\mathrm{lb}$ \\
\hline $\mathrm{H}_{2} \mathrm{SO}_{4}, \mathrm{lb}$ & 0.00019 & 0.00501 & 159 & 0.0385 & $\mathrm{lb}$ \\
\hline Catalyst, lb & 0.00000 & & & 0 & lb \\
\hline (Total) & 0.41849 & & & & \\
\hline \multicolumn{6}{|l|}{ Utilities } \\
\hline Cooling Water, GPM & 0.00164 & 0.02566 & 13559 & 0.064 & Mgal \\
\hline 250 \#steam, Mlb & 0.02633 & 0.0083 & 263.34 & 3.17 & Mlb \\
\hline Fuel, MMBtu & 0.00127 & 0.00064 & 20.2 & 2.00 & MMBtu \\
\hline Power, KW & 0.02649 & 0.71599 & 946 & 0.037 & Kwh \\
\hline (Total) & 0.05573 & & & & \\
\hline Total Variable Costs & 0.47422 & & & & \\
\hline Operating Labor, 9/shift @ \$25.26/hr & 0.00795 & \multicolumn{4}{|c|}{$<--$ SRI's estimated labor and rate } \\
\hline Maintenance Labor, $3 \% / y r$ of BLI & 0.00326 & \multicolumn{4}{|c|}{$<--$ SRI PEP financial assumption } \\
\hline Control Lab Labor, $20 \%$ of Oper. Lab & 0.00159 & \multicolumn{4}{|c|}{ _<-- SRI PEP financial assumption } \\
\hline Total Labor Costs & 0.01280 & & & & \\
\hline Maintenance Materials, $3 \% / y r$ of BLI & 0.00326 & \multicolumn{4}{|c|}{$<--$ SRI PEP financial assumption } \\
\hline Operating Supplies, $10 \%$ of oper. Labor & 0.00080 & \multicolumn{4}{|c|}{ _-- SRI PEP financial assumption } \\
\hline Total Direct Costs & 0.49108 & & & & \\
\hline Plant Overhead, $80 \%$ of Labor Costs & 0.01024 & \multicolumn{4}{|c|}{ <-- SRI PEP financial assumption } \\
\hline Taxes and Insurance, $2 \% / y r$ of TFC & 0.00441 & \multicolumn{4}{|c|}{$<--$ SRI PEP financial assumption } \\
\hline Depreciation, $10 \% / \mathrm{yr}$ of TFC & 0.02206 & \multicolumn{4}{|c|}{ _-- SRI PEP financial assumption } \\
\hline Plant Gate Cost & 0.52779 & & & & \\
\hline G\&A, Sales, Research & 0.06000 & \multicolumn{4}{|c|}{ _-- SRI PEP financial assumption } \\
\hline Production Cost & 0.58799 & \multirow{2}{*}{\multicolumn{4}{|c|}{ <-- SRI PEP financial assumption }} \\
\hline ROI Before Taxes, $25 \% / y r$ of TFC & 0.05514 & & & & \\
\hline Product Value, $\$ / \mathrm{lb}$ & 0.64293 & & & & \\
\hline
\end{tabular}


Figure 60. RTI-Eastman-Bechtel MMA process in sensitivity analysis.

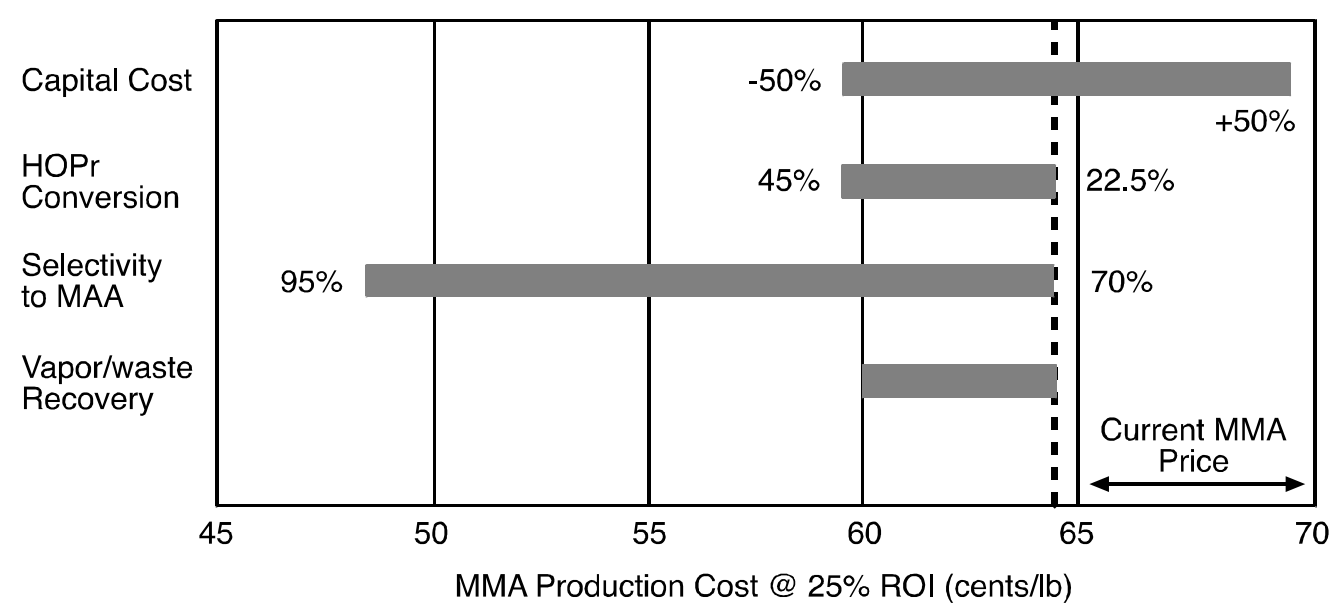

Figure 61. DME-based MMA process.

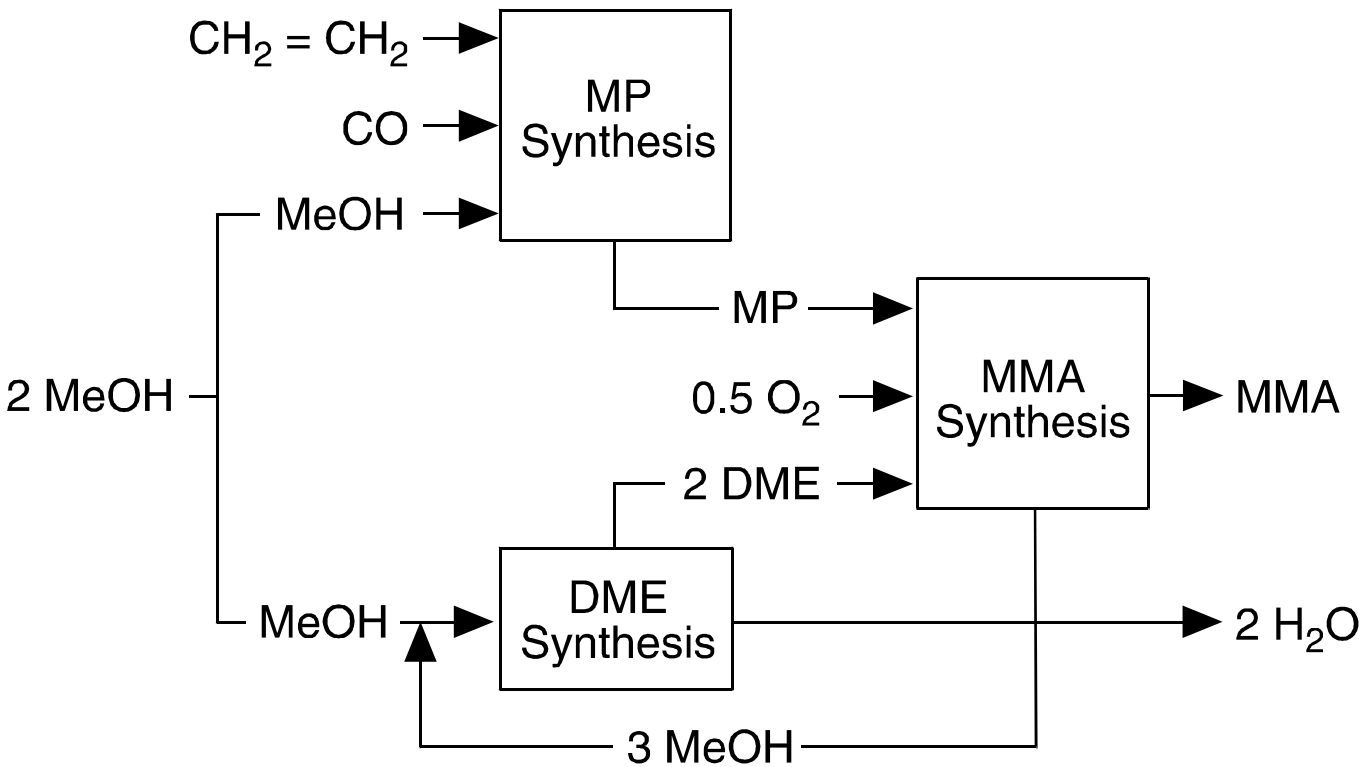




\subsubsection{HCHO-MP Condensation}

The condensation of methyl propionate and formaldehyde (MP:HCHO=4.5:1) was carried out at temperatures from 280 to $360{ }^{\circ} \mathrm{C}$ over 5 percent, 10 percent, and 20 percent $\mathrm{Nb}_{2} \mathrm{O}_{5} / \mathrm{SiO}_{2}$ catalysts. The results are summarized in Table 21 . The carbon balance of those tests ranges from 80 to 98 percent. The conversion of $\mathrm{HCHO}$ increases with reaction temperature and niobium loading over all three catalysts.

Table 21. Summary of methyl propionate condensation with formaldehyde (trioxane) over $5 \%, 10 \%$, and $20 \% \mathrm{Nb}_{2} \mathrm{O}_{5} / \mathrm{SiO}_{2}$. Feed makeup: MP:HCHO: $\mathrm{N}_{2}=72: 16: 220 \mathrm{mmol} / \mathrm{h}$

\begin{tabular}{lccccc}
\hline Catalyst & $\begin{array}{c}\mathrm{Temp} \\
\left({ }^{\circ} \mathrm{C}\right)\end{array}$ & $\begin{array}{c}\mathrm{HCHO} \\
\text { Conv. } \\
(\%)\end{array}$ & $\begin{array}{c}\text { MMA } \\
\text { Sel. }(\%)\end{array}$ & $\begin{array}{c}\text { MAA } \\
\text { Sel.(\%) }\end{array}$ & $\begin{array}{c}\text { MMA+MAA } \\
\text { Sel.(\%) }\end{array}$ \\
\hline $5 \% \mathrm{Nb}_{2} \mathrm{O}_{5} / \mathrm{SiO}_{2}$ & 300 & 38.8 & 47.7 & 13.4 & 61.1 \\
& 320 & 51.8 & 54.7 & 12.5 & 67.2 \\
$10 \% \mathrm{Nb}_{2} \mathrm{O}_{5} / \mathrm{SiO}_{2}$ & 300 & 49.0 & 41.2 & 9.6 & 50.8 \\
& 320 & 58.5 & 60.4 & 11.9 & 72.3 \\
& 340 & 84.6 & 44.4 & 7.1 & 51.5 \\
& 360 & 94.9 & 35.4 & 7.5 & 42.9 \\
& 280 & 36.7 & 34.2 & 2.9 & 37.1 \\
& 300 & 55.9 & 42.8 & 7.6 & 50.4 \\
& 320 & 71.2 & 50.7 & 7.4 & 58.1 \\
& 340 & 86.0 & 35.5 & 5.4 & 40.9 \\
\hline
\end{tabular}

Table 21 also shows that MMA and MAA selectivities do not vary monotonically with niobium loading or temperature. MMA selectivity increases from 47.7 percent to 54.7 percent from 300 to $320{ }^{\circ} \mathrm{C}$ over 5 percent $\mathrm{Nb}_{2} \mathrm{O}_{5} / \mathrm{SiO}_{2}$, but for 10 percent $\mathrm{Nb}_{2} \mathrm{O}_{5} / \mathrm{SiO}_{2}$, the MMA selectivity first increases from 41.2 to 60.4 percent when temperature was increased from 300 to $320{ }^{\circ} \mathrm{C}$. A further temperature increase from 320 to 340 and $360{ }^{\circ} \mathrm{C}$ decreases the selectivity (to 44.4 percent and 35.4 percent, respectively). The MMA selectivity trend for the 10 percent $\mathrm{Nb}_{2} \mathrm{O}_{5} / \mathrm{SiO}_{2}$ is similar to that of MMA increasing from 9.6 percent at $300{ }^{\circ} \mathrm{C}$ to 11.9 percent at $320{ }^{\circ} \mathrm{C}$, then decreasing to 7.1 percent and 7.5 percent at 340 and $360{ }^{\circ} \mathrm{C}$. The total selectivity to MMA+MAA goes through a maximum with the temperature- 72.3 percent at $320{ }^{\circ} \mathrm{C}$ based on $\mathrm{HCHO}$ consumed. For the 20 percent $\mathrm{Nb}_{2} \mathrm{O}_{5} / \mathrm{SiO}_{2}$ catalyst, the maximum MMA+MAA selectivity is 58.1 percent at $320{ }^{\circ} \mathrm{C}$. The results indicate fresh 10 percent $\mathrm{Nb}_{2} \mathrm{O}_{5} / \mathrm{SiO}_{2}$ is more selective than either 5 percent or 20 percent $\mathrm{Nb}_{2} \mathrm{O}_{5} / \mathrm{SiO}_{2}$ for condensation of methyl propionate with $\mathrm{HCHO}$ to MMA and MAA. However, the activity and selectivity decrease with time on stream.

The deactivation of the 10 percent $\mathrm{Nb}_{2} \mathrm{O}_{5} / \mathrm{SiO}_{2}$ is summarized in Table 22 . The activity decreases quickly with reaction time on stream. For example, at $320^{\circ} \mathrm{C}$, the $\mathrm{HCHO}$ conversion decreases from 58.5 percent after $2.5 \mathrm{~h}$ on stream to 50.0 percent after $5.5 \mathrm{~h}$. The MMA+MAA selectivity decreases from 72.3 to 46.2 percent. The deactivation is much faster than the 


\begin{tabular}{|c|c|c|c|c|}
\hline $\begin{array}{l}\text { Temp } \\
\left({ }^{\circ} \mathrm{C}\right)\end{array}$ & $\begin{array}{l}\text { Time on } \\
\text { Stream } \\
\text { (h) }\end{array}$ & $\begin{array}{c}\mathrm{HCHO} \\
\text { Conv. } \\
(\%)\end{array}$ & $\begin{array}{c}\text { MP } \\
\text { Conv. } \\
(\%)\end{array}$ & $\begin{array}{c}\text { MMA+MAA } \\
\text { Sel. (\%) }\end{array}$ \\
\hline \multirow[t]{2}{*}{300} & 2.5 & 49.5 & 24.9 & 50.8 \\
\hline & 4.5 & 34.5 & 22.6 & 50.4 \\
\hline \multirow[t]{2}{*}{320} & 2.5 & 58.5 & NA & 72.3 \\
\hline & 5.5 & 50.0 & 26.1 & 46.2 \\
\hline \multirow[t]{2}{*}{340} & 2.5 & 84.6 & 34.8 & 51.5 \\
\hline & 5.0 & 69.4 & 31.8 & 44.5 \\
\hline \multirow[t]{2}{*}{360} & 3.0 & 94.9 & 39.6 & 42.9 \\
\hline & 5.5 & 88.5 & 37.8 & 39.1 \\
\hline
\end{tabular}

deactivation of the same catalyst for $\mathrm{HOPr}-\mathrm{HCHO}$ condensation, suggesting that the deactivation is not simply caused by the polymerization of $\mathrm{HCHO}$. Although fresh $\mathrm{Nb}_{2} \mathrm{O}_{5} / \mathrm{SiO}_{2}$ catalysts are active and selective for direct condensation of methyl propionate with $\mathrm{HCHO}$, the results suggest that the deactivation needs to be minimized for commercial application. In an attempt to minimize deactivation, 2 percent $\mathrm{O}_{2}$ was added to the inlet feed to the reactor. The results showed that this does not decrease the rate of deactivation. Higher temperatures are likely needed to oxidize coke precursors.

\subsubsection{DME Partial Oxidation}

Partial oxidation of DME to formaldehyde is the first importnat step in the in-situ DME condensation with methyl propionate to $\mathrm{MMA}, \mathrm{CH}_{3} \mathrm{OCH}_{3}+\mathrm{O}_{2} \rightarrow 2 \mathrm{HCHO}+\mathrm{H}_{2} \mathrm{O}$. The formation of formaldehyde from partial oxidation of DME was studied to determine the conversion and selectivity of specific catalysts.

Table 23 shows that the conversion of DME first increases with temperature reaching a maximum of 90.7 percent at $400{ }^{\circ} \mathrm{C}$, then decreases. The selectivity to $\mathrm{HCHO}$ also increases with reaction temperature (the highest $\mathrm{HCHO}$ selectivity is 34.4 percent at $350{ }^{\circ} \mathrm{C}$ ) and then decreases at temperatures above $350{ }^{\circ} \mathrm{C}$, accompanied by the increasing selectivity to $\mathrm{CO}_{2}$.

Table 23. Partial Oxidation of Dimethyl Ether to Formaldehyde

\begin{tabular}{cccccccc}
\hline & $200^{\circ} \mathrm{C}$ & $250^{\circ} \mathrm{C}$ & $300^{\circ} \mathrm{C}$ & $350^{\circ} \mathrm{C}$ & $400^{\circ} \mathrm{C}$ & $450^{\circ} \mathrm{C}$ & $500^{\circ} \mathrm{C}$ \\
\hline DME Conv.(\%) & 18.4 & 13.8 & 27.6 & 72.9 & 90.7 & 84.7 & 77.8 \\
HCHO Sel.(\%) & 2.0 & 9.9 & 26.7 & 34.4 & 11.9 & 6.5 & 2.3 \\
\hline
\end{tabular}

$0.1 \%$ DME, $0.1 \% \mathrm{O}_{2}$, balance $\mathrm{N}_{2}$, $100 \mathrm{cc} / \mathrm{min}, 5 \mathrm{~g} 5 \% \mathrm{Nb}_{2} \mathrm{O}_{5} / \mathrm{SiO}_{2}$. 
The maximum in conversion and selectivity with temperature is due to the competitive reactions between partial oxidation of DME by reaction (28) and the total oxidation to $\mathrm{CO}_{2}$ (reaction [29]):

$$
\begin{aligned}
& \mathrm{CH}_{3} \mathrm{OCH}_{3}+\mathrm{O}_{2} \rightarrow 2 \mathrm{HCHO}+\mathrm{H}_{2} \mathrm{O} \\
& \mathrm{CH}_{3} \mathrm{OCH}_{3}+3 \mathrm{O}_{2} \rightarrow 2 \mathrm{CO}_{2}+3 \mathrm{H}_{2} \mathrm{O}
\end{aligned}
$$

The stoichiometric ratios of DME to oxygen are 1:1 for partial oxidation and 1:3 for complete oxidation. The tests in Table 22 were all carried out at a 1:1 ratio of DME to oxygen. If only $\mathrm{HCHO}$ is formed during the reaction, the conversion of DME can be complete. If only $\mathrm{CO}_{2}$ is formed from the oxidation of DME, the maximum conversion of DME can reach only 33.3 percent. At lower temperatures, the partial oxidation is more favored than at higher temperatures. With increasing temperature, the conversion of DME increases and more oxygen is consumed, decreasing the $\mathrm{HCHO}$ selectivity. The results suggest that silica-supported niobium catalysts are active for partial oxidation of DME to $\mathrm{HCHO}$ and that the optimum temperatures for partial oxidation are between 300 and $400{ }^{\circ} \mathrm{C}$.

Because this study was carried out at very dilute inlet concentrations (safety reasons), the amount of products collected is close to the analytical detection limit of the system. The carbon balance is poor, ranging from 50 to 80 percent.

\subsubsection{In-situ DME Oxidation and Condensation with MP}

The in-situ DME condensation with MP has the advantages of lower costs by combining formaldehyde generation, condensation, and esterification into one step. Formaldehyde generation from DME also minimizes the formation of $\mathrm{H}_{2} \mathrm{O}$ byproduct, which may cause deactivation or kinetically inhibit the reaction.

The overall reaction scheme is as follows:

$$
\begin{gathered}
\mathrm{CH}_{3} \mathrm{OCH}_{3}+\mathrm{O}_{2} \rightarrow 2 \mathrm{HCHO}+\mathrm{H}_{2} \mathrm{O} \\
\frac{\left.2 \mathrm{HCHO}+2 \mathrm{CH}_{3} \mathrm{CH}_{2} \mathrm{COOCH}_{3} \rightarrow \mathrm{CH}_{2}=\mathrm{C}_{2} \mathrm{CH}_{3}\right) \mathrm{COOCH}_{3}+2 \mathrm{H}_{2} \mathrm{O}}{\mathrm{CH}_{3} \mathrm{OCH}_{3}+\mathrm{O}_{2}+2 \mathrm{CH}_{3} \mathrm{CH}_{2} \mathrm{COOCH}_{3} \rightarrow 2 \mathrm{CH}_{2}=\mathrm{C}\left(\mathrm{CH}_{3}\right) \mathrm{COOCH}_{3}+3 \mathrm{H}_{2} \mathrm{O}}
\end{gathered}
$$

In-situ formaldehyde generation and condensation with methyl propionate were tested over 10 percent $\mathrm{Nb} / \mathrm{SiO}_{2}$ and 10 percent $\mathrm{W} / \mathrm{SiO}_{2}$ catalysts at 320 and $340{ }^{\circ} \mathrm{C}$. A review of the literature suggests that this is the first demonstration of MMA synthesis directly from DME, oxygen, and methyl propionate in one single reactor. The results are summarized in Table 24. The 10 percent $\mathrm{Nb} / \mathrm{SiO}_{2}$ is active for the partial oxidation of DME to $\mathrm{HCHO}$, but the selectivity to formaldehyde is not high. The conversion of DME at $320{ }^{\circ} \mathrm{C}$ is 32.0 percent with only 5.1 percent selectivity to formaldehyde. The conversion increases to 39.5 percent when temperature is increased to $340{ }^{\circ} \mathrm{C}$, and the selectivity decreases to 2.5 percent, suggesting increased selectivity to total oxidation. When the partial oxidation of DME is combined with in-situ condensation with methyl propionate (reaction [30]) the results are quite different. The conversion of DME decreases in the presence of methyl propionate from 32.0 to 16.1 percent at 
Table 24. DME Partial Oxidation and In-Situ Condensation with Methyl Propionate

\begin{tabular}{lcc|cc|ccc}
\hline & & & \multicolumn{3}{|c|}{ Conversion (\%) } & \multicolumn{3}{c}{ Selectivity (\%) } \\
\cline { 4 - 7 } \multicolumn{1}{c}{ Reaction } & Catalyst & $\mathrm{T}\left({ }^{\circ} \mathrm{C}\right)$ & $\mathrm{DME}$ & $\mathrm{MP}$ & $\mathrm{MMA}$ & $\mathrm{MAA}$ & $\mathrm{HCHO}$ \\
\hline DME partial oxidation & $10 \% \mathrm{Nb} / \mathrm{SiO}_{2}$ & 320 & 32.0 & $\mathrm{NA}$ & $\mathrm{NA}$ & $\mathrm{NA}$ & 5.1 \\
DME partial oxidation & $10 \% \mathrm{Nb} / \mathrm{SiO}_{2}$ & 340 & 39.5 & $\mathrm{NA}$ & $\mathrm{NA}$ & $\mathrm{NA}$ & 2.5 \\
In-situ condensation & $10 \% \mathrm{Nb} / \mathrm{SiO}_{2}$ & 320 & 16.1 & 17.6 & 36.3 & 3.6 & 19.2 \\
In-situ condensation & $10 \% \mathrm{Nb} / \mathrm{SiO}_{2}$ & 340 & 9.9 & 27.4 & 99.6 & 8.4 & 22.6 \\
DME partial oxidation & $10 \% \mathrm{~W} / \mathrm{SiO}_{2}$ & 340 & 30.7 & $\mathrm{NA}$ & $\mathrm{NA}$ & $\mathrm{NA}$ & 20.0 \\
In-situ condensation & $10 \% \mathrm{~W} / \mathrm{SiO}_{2}$ & 340 & 9.5 & 13.6 & 14.1 & 5.5 & 148.5 \\
\hline
\end{tabular}

DME:MP: $\mathrm{O}_{2}: \mathrm{N}_{2}=5: 63: 5: 210 \mathrm{mmol} / \mathrm{h}$.

Selectivity calculation is based on DME consumption.

$320{ }^{\circ} \mathrm{C}$ (MP conversion is 17.6 percent), indicating that DME and methyl propionate both react with oxygen to form unwanted products. When the reaction temperature increases from 320 to $340{ }^{\circ} \mathrm{C}$, the conversion of DME decreases further to 9.9 percent and the conversion of methyl propionate increases to 27.4 percent.

DME reacts with oxygen in at least two ways (reactions [28] and [29]), and methyl propionate can also react in several ways: the direct oxidation to $\mathrm{CO}_{\mathrm{x}}$, reverse esterification, and condensation with formaldehyde. To improve the selectivities to MMA or MAA, direct oxidation of methyl propionate and DME to $\mathrm{CO}_{\mathrm{x}}$ needs to be minimized.

The selectivities to MMA, MAA, and formaldehyde as a function of reaction temperature are also reported in Table 24 (calculated based on the consumption of DME). The MMA selectivity increases from 36.3 to 99.6 percent and the MAA selectivity increases from 3.6 to 8.4 percent when temperature increases from 320 to $340{ }^{\circ} \mathrm{C}$. These results can be understood by recognizing that formaldehyde can be generated by two reactions: partial oxidation of DME (reaction [28]) and partial oxidation of methanol (produced by the hydrolysis of methyl propionate):

$$
\begin{gathered}
\mathrm{MP}+\mathrm{H}_{2} \mathrm{O} \rightarrow \mathrm{MeOH}+\mathrm{HOPr} \\
\mathrm{MeOH}+1 / 2 \mathrm{O}_{2} \rightarrow \mathrm{HCHO}+\mathrm{H}_{2} \mathrm{O}
\end{gathered}
$$

The selectivities to formaldehyde, possibly generated both from DME and methanol (from the hydrolysis of methyl propionate), are 19.2 percent and 22.6 percent at 320 and $340{ }^{\circ} \mathrm{C}$. (Note that the sum of selectivities to MMA, MAA, and formaldehyde exceeds 100 percent, because methanol, as well as DME, can form formaldehyde. The selectivities can thus exceed 100 percent when they are normalized by DME reacted). The portion of formaldehyde generated from DME or methanol (from methyl propionate hydrolysis) cannot be determined.

A 10 percent $\mathrm{W} / \mathrm{SiO}_{2}$ catalyst was also tested for partial oxidation and in-situ condensation with methyl propionate. The reactions were carried out at $340{ }^{\circ} \mathrm{C}$, and the results are shown in Table 24. The conversion of DME over 10 percent $\mathrm{W} / \mathrm{SiO}_{2}$ is lower than the conversion over 
10 percent $\mathrm{Nb} / \mathrm{SiO}_{2}$, but the selectivity is higher. Conversion and selectivity are 30.7 percent and 20.0 percent over 10 percent $\mathrm{W} / \mathrm{SiO}_{2}$, respectively. The conversion of DME drops significantly to 9.5 percent in the presence of methyl propionate at $340{ }^{\circ} \mathrm{C}$, with relatively lower MMA (14.1 percent) and MAA (5.5 percent) selectivity, but with extremely high selectivity to formaldehyde (148.5 percent; recall that selectivities above 100 percent are possible-see previous paragraph). Again, the formaldehyde formation may come from both DME and methanol partial oxidation. Although the supported tungsten catalyst shows less activity for MMA and MAA formation than the supported niobium catalyst, it results in higher formaldehyde selectivity in the presence or absence of methyl propionate. The results suggest a need to further improve the activity and selectivity of the reaction. For example, using supported tungsten catalyst for partial oxidation of DME to formaldehyde, followed by condensation over supported niobium catalyst, may be an effective approach to improve the process. 


\section{CONCLUSIONS}

\subsection{Propionate Synthesis}

The novel RTI-Eastman-Bechtel process for synthesis of methyl methacrylate (MMA) from coalderived syngas has served as the basis for the technical and economic assessment of the production of this high-volume oxygenate from coal-derived synthesis gas. Task 1 focuses on propionate generation from ethylene, carbon monoxide, and steam, which is the first step in the process to generate MMA from coal-derived syngas. Novel Cr-group catalysts were developed and patented for this reaction. They operate best at pressures from 30 to $70 \mathrm{~atm}$ and temperatures from 150 to $200{ }^{\circ} \mathrm{C}$, much less severe conditions than other catalysts for this reaction.

Mechanistic investigations of the Mo-based process imply that the reaction is initiated by a ratelimiting $\mathrm{CO}$ dissociation from $\mathrm{Mo}(\mathrm{CO})_{6}$. This dissociation appears to be followed by a process that ultimately transfers an iodine atom from EtI to the coordinately unsaturated $\mathrm{Mo}(\mathrm{CO})_{5}$, likely via an inner sphere electron transfer process. Subsequent reaction of the resultant ethyl radical with $\mathrm{Mo}(\mathrm{CO})_{6}$ likely generates very reactive odd electron Mo species, which are capable of rapid catalysis via classical olefin carbonylation mechanisms. This discovery represents the first case of an efficient carbonylation process based on the Cr-group metals and a unique method for initiating carbonylation catalysis.

\subsection{Condensation Catalysis}

In Task 2, Group $\mathrm{V}$ catalysts ( $\mathrm{V}, \mathrm{Nb}$, and $\mathrm{Ta}$ ) have been discovered to be active and selective, and a 20 percent $\mathrm{Nb}_{2} \mathrm{O}_{5} / \mathrm{SiO}_{2}$ gives the optimum performance. The condensation catalysts typically possess high surface areas, a low overall surface acidity, and high proportion of weak acidic sites. Although $\mathrm{Nb}_{2} \mathrm{O}_{5}$-based catalysts are active, they deactivate steadily due to carbon deposition with time on stream. The catalysts can, however, be completely regenerated under a mild oxidative regeneration, using a 2 percent oxygen/nitrogen gas stream, at $400{ }^{\circ} \mathrm{C}$. A longterm $(\sim 400 \mathrm{~h})$ study of formaldehyde condensation with propionic acid (PA) is carried out over 10 percent $\mathrm{Nb}_{2} \mathrm{O}_{5} / \mathrm{SiO}_{2}$ at $300{ }^{\circ} \mathrm{C}$. Surface area, pore volume, pore diameter, and internal pore structure of these $\mathrm{Nb}_{2} \mathrm{O}_{5}-\mathrm{SiO}_{2}$ catalysts were found to be essentially unchanged due to deactivation, suggesting that coke deposits are primarily external to the catalyst surface and do not block the pores of the catalyst; XRD and XPS analysis support this hypothesis.

The effects of catalyst regeneration, $\mathrm{HOPr}: \mathrm{HCHO}$ feed ratio (HOPr:HCHO=4.5:1 to 1.5:1) and reaction temperature $\left(280\right.$ to $\left.300{ }^{\circ} \mathrm{C}\right)$ on reaction activity and product selectivity over 20 percent $\mathrm{Nb}_{2} \mathrm{O}_{5} / \mathrm{SiO}_{2}$ catalysts show that the selectivity to MAA decreases with regeneration, and the selectivity to diethyl ketone (DEK) and $\mathrm{CO}_{2}$ increases. When the HOPr:HCHO ratio is decreased, the MAA yield decreases, but the MAA selectivity increases first and then decreases. Lowering the reaction temperature from 300 to $280{ }^{\circ} \mathrm{C}$ decreases the MAA yield from 39.5 to 30.7 percent but increases the MAA selectivity. The results indicate that both temperature and the HOPr:HCHO ratio are important parameters to optimize the economics of the condensation between propionic acid and $\mathrm{HCHO}$. A 30 percent catalysts deactivates more slowly than other $\mathrm{Nb}_{2} \mathrm{O}_{5} / \mathrm{SiO}_{2}$ catalysts. 


\subsection{Slurry Reactor Studies}

In-situ condensation catalysis in a slurry reactor, where methanol, oxygen, and propionic acid are fed under high pressures and temperatures, over a physical mixture of two catalysts suspended in an inert fluid, produces MMA in one single step. However, the slurry fluid, decalin, is not stable in the presence of oxygen and the product mixture contains more than 40 different compounds.

\subsection{Economics}

A detailed conceptual design of the RTI-Eastman-Bechtel HOPr-HCHO condensation process for a 250 million lb/yr MMA plant has been developed and economic analysis compared. The result shows that the MMA production cost of $\$ 0.64 / \mathrm{lb}$ is in line with the current market price (at a 25 percent rate of return of investment and a 35 percent contingency). It is expected that the cost will be further decreased by improving the conversion of $\mathrm{HOPr}$, the selectivity to MAA, and the recovery of some reactants in the vapor and wastewater streams.

\subsection{DME Condensation}

In Task 5, direct condensation between methyl propionate and formaldehyde to MMA was studied (MP: $\mathrm{HCHO}=4.5: 1,280$ to $360{ }^{\circ} \mathrm{C}$ ). The conversion of $\mathrm{HCHO}$ increases with reaction temperature and niobium loading. MMA+MAA selectivity goes through a maximum with temperature. However, the catalysts deactivated rapidly with time on stream.

In the study of partial oxidation of DME, the conversion of DME first increases with temperature reaching a maximum at $400{ }^{\circ} \mathrm{C}$, then decreases. The selectivity to $\mathrm{HCHO}$ also increases with reaction temperature, up to $350{ }^{\circ} \mathrm{C}$, accompanied by the increasing selectivity to $\mathrm{CO}_{2}$. Best temperatures for partial oxidation are between 300 and $400{ }^{\circ} \mathrm{C}$.

The first in-situ formaldehyde generation from DME and subsequent condensation with methyl propionate to make MMA in one reactor was successfully demonstrated. The reaction shows high selectivities to MMA, MAA, and formaldehyde (based on the consumption of DME), suggesting that the in-situ DME condensation route may be an effective way to manufacture MMA directly. This route eliminates the problem of formaldehyde handlingand combines formaldehyde generation, condensation and esterification into one step. However, costs have not been estimated for this process. 


\section{RECOMMENDATIONS}

Although detailed economic analysis of the RTI-Eastman-Bechtel three-step process shows the MMA production cost is in line with the current market price with a 25 percent rate of return of investment and a 35 percent contingency, further improvement in $\mathrm{HOPr}: \mathrm{HCHO}$ condensation selectivity will greatly increase the competitiveness of the process, because propionate raw material represents the major portion of the cost for the manufacturing of methacrylates. To further improve the selectivity of propionate condensation with formaldehyde to methacrylates, the following recommendations are made to improve the process economics:

- Synthesize high surface niobium catalysts to increase the reaction rate while minimizing the side reactions, including decarboxylation and coking, that increase overall costs.

- Investigate the condensation reaction mechanism to understand the effects of acidity/basicity, niobium precursors, niobium oxide distribution, and support on deactivation and side reactions.

The first in-situ DME partial oxidation and condensation with methyl propionate has been demonstrated and the reaction appears to selectively produce methyl methacrylate and methyl acrylic acid over niobium/silica catalysts. To further investigate this reaction, parameters such as feed concentration, space velocity, catalyst, and reactor design to reduce side reactions including deep oxidation of both DME and MP should be studied to achieve high yield of MMA. 


\section{REFERENCES}

1. U.R. Samel, W. Kohler, A.O. Gamer, and U. Keuser, "Propionic Acid and Derivatives," in Ullmann's Encyclopedia of Industrial Chemistry, 5th edit., Vol. A22, VCH Publishers, New York, NY, p. 223 (1993).

2. J.J. Spivey, M.R. Gogate, B.W.L. Jang, E.D. Middlemas, J.R. Zoeller, S.S. Tam, and G.N. Choi, in Proceedings of the Contractors' Review Meeting on Coal Liquefaction and Gas Conversion, pp. 385-395, USDOE/PETC, Pittsburgh, HOPr (1995).

3. J.J. Spivey, M.R. Gogate, E.D. Middlemas, J.R. Zoeller, S.S.Tam, and G.N. Choi, Invited Paper Presented at the Second World Environmental Congress, London, Ontario (September 11-16, 1995).

4. W. Bertleff, "Carbonylation," in Ullman's Encyclopedia of Industrial Chemistry, 5th edit., Vol. A5, VCH Publishers, New York, NY, p. 223 (1986).

5. P. Pino, F. Piacenti, and M. Bianchi, in Organic Syntheses via Metal Carbonyls, eds. I. Wender and P. Pino, Vol. 2, John Wiley \& Sons, Inc., New York, NY, pp. 223-296 (1977).

6. A. Mullen, in New Syntheses With Carbon Monoxide, ed. J. Falbe, Springer-Verlag, Berlin, Germany, pp. 275-286 (1980).

7. H.M. Colquhoun, D.J. Thompson, and M.V. Twigg, Carbonylation-Direct Synthesis of Carbonyl Compounds, Plenum Press, New York, NY, pp. 102-106; 119-130 (1991).

8. D. Forster, A. Hershman, and D.E. Morris, Catalysis Rev.—Sci. Eng., 23:89 (1981).

9. M. Imbeaux, H. Mestdagh, K. Moughamir, and C. Rolando, J. Chem. Soc., Chem. Comm., 1678-1679 (1992).

10. B.M. Lichstein, U.S. Patent 3,790,607 (1974).

11. M.. Ai, J. Catal., 107:201 (1987).

12. M. Ai, J. Catal., 124:293 (1990).

13. M. Ai, Appl. Catal., 63:29 (1990).

14. J.D. Holmes, U.S. Patent 4,085,143 (1978).

15. J.R. Zoeller and C.J. Ackerman, J. Org. Chem., 55:1354 (1990).

16. T.A. Huber, D.H. Macartney, and M.C. Baird, Organomet., 14:592 (1995) and references cited therein.

17. R.B. King, Inorg. Chem., 3:1039 (1964).

18. M..C. Ganorkar and M.H.B. Stiddard, J. Chem. Soc., 3494 (1965).

19. W.E. Abel, I.S. Butler, and J.G. Reid, J. Chem. Soc., 2068 (1963).

20. E.W. Abel, M.A. Bennett, and G. Wilkinson, Chem. and Ind., 442 (1960).

21. A.W. Ehlers and G. Frenking, J. Chem. Soc., Chem. Comm., 1709 (1993) and references cited therein. 
22. A.W. Ehlers and G. Frenking, J. Amer. Chem. Soc., 116:1514 (1994) and references cited therein.

23. J.A. Conner and P.I. Riley, J. Chem. Soc., Dalton Trans., 1318 (1979).

24. J.A. Conner and P.I. Riley, J. Chem. Soc., Chem. Comm., 634 (1976).

25. J.P. Collman, L.S. Hegedus, J.R. Norton, and R.G. Finke, Principles and Applications of Organotransition Metal Chemistry, University Science Books, Mill Valley, CA (1987), Chap. 5.

26. C. Schmid, R. Boese, and E. Welz, Chem. Ber., 108:260 (1975).

27. H. Behrens, R. Schwab, and D. Hermann, Z. Naturforsch., Teil B, 21:590 (1966).

28. H. Behrens and R. Schwab, Z. Naturforsch., Teil B, 19:768 (1964).

29. S.L. Scott, J.H. Espenson, and A. Bakac, Organomet., 12:1044 (1993).

30. C.J. Pickett and D. Pletcher, J. Chem. Soc., Dalton Trans., 749 (1976).

31. C.J. Picket and D. Pletcher, J. Chem. Soc., Dalton Trans., 749 (1976).

32. R.G. Hayter, J. Amer. Chem. Soc., 88:4376 (1966).

33. Based on data for $20 \% \mathrm{Nb}_{2} \mathrm{O}_{5}: \mathrm{SiO}_{2}, 2.25: 1 \mathrm{HOPr}: \mathrm{HCHO}$ at $300{ }^{\circ} \mathrm{C}$ (RTI Presentation at Eastman [12/16/98]).

34. Gogate et al., "Synthesis of Methacrylates from Coal Derived Syngas," Annual Report, December 1996.

35. R.J. Cvetanovic and Y. Amenomiya, Catal. Rev., 6:21 (1972).

36. Y. Amenomiya, CHEMTECH, 2:128 (1976).

37. Gogate et al., "Synthesis of Methacrylates from Coal Derived Syngas," Annual Report, December 1997.

38. SRI, Methacrylic Acid and Esters, PEP Report 11D, Chapter 8 (1993).

39. Process for Recovery of Methacrylic Acid; U.S. Patent 4,599,144 (1986).

40. Chemical Marketing Report (August 1999).

41. Chem Systems, Propionic Acid, PERP Report 98/99S10 (1999). 